UNIVERSIDADE DE SÃO PAULO

FFCLRP - DEPARTAMENTO DE BIOLOGIA

PROGRAMA DE PÓS-GRADUAÇÃO EM BIOLOGIA COMPARADA

"Revisão sistemática, tafonomia, distribuição geográfica e estratigráfica da classe Tentaculitoidea no Devoniano brasileiro".

\author{
Jeanninny Carla Comniskey
}

Tese apresentada à Faculdade de Filosofia, Ciências e Letras de Ribeirão Preto da USP, como parte das exigências para a obtenção do título de Doutor em Ciências, Área: Biologia Comparada

RIBEIRÃO PRETO - SP

2016 
UNIVERSIDADE DE SÃO PAULO

FFCLRP - DEPARTAMENTO DE BIOLOGIA

PROGRAMA DE PÓS-GRADUAÇÃO EM BIOLOGIA COMPARADA

"Revisão sistemática, tafonomia, distribuição geográfica e estratigráfica da classe Tentaculitoidea no Devoniano brasileiro".

\author{
Jeanninny Carla Comniskey \\ Orientador: Max Cardoso Langer \\ Co-orientador: Renato Pirani Ghilardi
}

VERSÃO CORRIGIDA

Tese apresentada à Faculdade de Filosofia, Ciências e Letras de Ribeirão Preto da USP, como parte das exigências para a obtenção do título de Doutor em Ciências, Área: Biologia Comparada

RIBEIRÃO PRETO - SP

2016 
Autorizo a reprodução e divulgação total ou parcial deste trabalho, por qualquer meio convencional ou eletrônico, para fins de estudo e pesquisa, desde que citada à fonte.

Comniskey, Jeanninny Carla

Revisão sistemática, tafonomia, distribuição geográfica e estratigráfica da classe Tentaculitoidea no Devoniano brasileiro, 2016. $152 \mathrm{p}$.

Tese de Doutorado, apresentada à Faculdade de Filosofia, Ciências e Letras de Ribeirão Preto/USP. Área de concentração: Biologia Comparada.

Orientador: Langer, Max Cardoso

1. Classe Tentaculitoidea. 2. Bacia do Paraná. 3. Bacia do Amazonas. 4. Bacia do Parnaíba. 5. Tentaculites. 6. Homoctenus. 7. Styliolina 8. Uniconus. 
Dedico esta tese a minha família pelo suporte, compreensão, paciência e amor a mim conferidos 


\section{AGRADECIMENTOS}

Agradeço ao meu orientador Prof. Dr. Max Cardoso Langer pela oportunidade auxílio em realizar o doutorado sob sua tutela pela Faculdade de Filosofia, Ciências e Letras de Ribeirão Preto (FFCLRP).

Ao meu Co-orientador Prof. Dr. Renato Pirani Ghilardi minha gratidão por ter acreditado em mim, pelas orientações, dedicação, paciência e críticas que foram necessárias para o meu crescimento como pesquisadora, bem como o crescimento pessoal.

Á Coordenação de Aperfeiçoamento de Pessoal de Nível Superior (CAPES) pelos meses de bolsa concedidos no início do doutorado.

Agradeço ao suporte financeiro concedido pela Fundação de Amparo à Pesquisa do Estado de São Paulo (FAPESP), por ter financiado este projeto (2013/04884-0).

Agradeço aos pesquisadores e curadores responsáveis pelas instituições de pesquisa visitadas, listadas a baixo, por permitirem o acesso à coleção científica, bem como a atenção e as informações concedidas:

- Laboratório de Paleontologia da Universidade de São Paulo - Ribeirão Preto (USP), aos cuidados do Prof. Dr. Max Cardoso Langer.

- Núcleo de estudos Paleontológicos e Estratigráficos da Universidade Federal do Rio de Janeiro (UFRJ), aos cuidados de Prof. Dr. Ismar de Souza Carvalho, as curadoras Flavia Alessandra Figueiredo e Monica de Medina Coeli.

- Ao Departamento de Paleoinvertebrados, Setor de Geologia e Paleontologia, Museu Nacional/UFRJ, aos cuidados do Prof. Dr. Antonio Carlos Sequeira Fernandes e Dr. Sandro Marcelo Scheffler.

- Laboratório de Paleontologia da Universidade Federal do Paraná (UFPR), aos cuidados da Prof $^{\mathrm{a}}$ Dr. Cristina Vega.

- Laboratório de Paleontologia e Sistemática do Instituto de Geociências da Universidade de São Paulo (IGc - USP), aos cuidados da Prof ${ }^{\mathrm{a}}$. Dr. Juliana de Moraes Leme e a curadora Ivone Cardoso Gonzales.

- Departamento Nacional de Produção Mineral (DNPM), aos cuidados de Rodrigo da Rocha Machado.

- Ao Laboratório de Estratigrafia e Paleontologia da Universidade Estadual de Ponta Grossa (UEPG), aos cuidados do Prof. Dr. Elvio Pinto Bosetti. 
-Ao Laboratório de Estudos de Comunidades Paleozóicas da Universidade Federal do Estado do Rio de Janeiro (UNIRIO), aos cuidados da Profa. Dra. Deusana Maria Machado.

- Laboratório de Paleontologia de Macroinvertebrados (LAPALMA) da Universidade Estadual Paulista "Júlio de Mesquita Filho" (UNESP-Bauru), aos cuidados do Prof. Dr. Renato Pirani Ghilardi.

Ao Prof. Dr. Elvio Pinto Bosetti pela iniciação aos estudos na paleontologia, ainda em meados de 2005, sua orientação, amizade, paciência e sua dedicação foram essenciais na minha formação como pesquisadora e crescimento pessoal.

Agradeço a Prof ${ }^{\mathrm{a}}$. Mirian Liza Forancelli Pacheco, da Universidade Federal de São Carlos (UFSCar) pelas análises de Espectroscopia de Energia Dispersiva (MEVEDS) e Energia Dispersiva de Fluorescência de Raios-X (EDXRF) e pelas informações concedidas.

Agradeço ao Prof. Luiz Eduardo Anelli por ter me recebido no Instituto de Geociências da Universidade de São Paulo (IGc - USP) e ensinado a utilização de novas técnicas fotográficas.

Agradeço aos pesquisadores Dr. Eberhard Schindler (Museu de Historia Natural de Senckenberg - Alemanha), Jacalyn Wittmer (Universidade de Illinois - Estados Unidos), Christian Klug (Universidade de Zurique - Suíça), Björn Kröger (Universidade de Helsinki - Finlândia), Jeffrey Thompson (Universidade de Ohio - Estados Unidos), Michał Zatoń (Universidade da Silésia - Polônia), John Malinky (Califórnia - Estados Unidos) e Olev Vinn (University of Tartu - Estonia), pelas informações e trabalhos fornecidos.

Ao Dr. Rodrigo Scalise Horodyski (Universidade do Vale do Rio dos Sinos UNISINOS), pelas orientações, informações e paciência sobre estratigrafia de sequências.

Agradeço a Dr. Hilda Leonor Cuevas de Azevedo-Soares pelo material e informações concedidas.

Aos colegas do Grupo Palaios - Paleontologia Estratigráfica (UEPG/CNPq), em especial ao Msc. Lucinei J. Myszynski Jr. Pelo auxílio nas atividades de campo e pelos conselhos fornecidos. As biólogas Carla Maria Heirich e Beatriz de Almeida nos auxílios durante as atividades de campo e laboratoriais.

Agradeço aos colegas do Laboratório de Paleontologia de Macroinvertebrados (Lapalma), por terem me recebido de braços abertos e por sempre estarem dispostos a 
me ajudar. Agradecimento em especial ao colega Msc. Fabio Augusto Carbonaro pela amizade, conselhos e informações fornecidas.

Aos meus amigos por estarem sempre presentes em momentos difíceis, onde o apoio de vocês foi essencial, bem como estarem junto de mim durante as minhas batalhas vencidas.

Ao meu companheiro por acreditar em mim, ter paciência, me incentivar e estar presente em momentos difíceis.

Ao meu grande irmão por sempre acreditar que eu seria capaz, por seus conselhos, seu carinho e dedicação a mim conferidos. Aos meus pais um agradecimento especial por terem me fornecido todo o apoio necessário, compreensão, carinho e me incentivando todos os dias. 
"The function of education is to teach one to think intensively and to think critically. intelligence plus character - that is the goal of true education." 


\section{RESUMO}

COMNISKEY, J. C. Revisão sistemática, tafonomia, distribuição geográfica e estratigráfica da classe Tentaculitoidea no Devoniano brasileiro. 2016. 152p. Tese (Doutorado) - Faculdade de Ciências e Letras de Ribeirão Preto, Universidade de São Paulo, Ribeirão Preto, 2016.

Os tentaculitoideos são invertebrados marinhos extintos comumente encontrados nos estratos devonianos brasileiros. São reconhecidos pelo formato da concha coniforme carbonática com pequenas dimensões. Na América do Sul, o registro dos primeiros tentaculitoideos ocorreu durante o início do Siluriano, com o gênero Tentaculites. Representantes das ordens Dacryoconarida e Homoctenida foram encontrados a partir do Devoniano Inferior. No Brasil o grupo possui registro nas bacias do Paraná (Formações Ponta Grossa e São Domingos), Amazonas (Formações Maecuru e Ererê) e Parnaíba (Formação Cabeças). As análises sistemáticas demonstraram a presença dos gêneros Tentaculites e Styliolina (foram constatados nas Bacias do Amazonas, Paraná e Parnaíba) e Uniconus e Homoctenus (registro apenas para a Bacia do Paraná). Foram reconhecidos 8 representantes da ordem Tentaculitida, 2 da ordem Homoctenida e 2 dacryoconarídeos. As espécies Tentaculites crotalinus, Tentaculites jaculus, Tentaculites kozlowskius, Tentaculites paranaensis, Uniconus ciguelius, Homoctenus katzerius e Styliolina cf. Styliolina fissurella foram encontradas na Bacia do Paraná. Já as espécies Tentaculites eldredgianus, Tentaculites trombetensis e Styliolina clavulus encontradas nas Bacias do Amazonas e do Parnaíba. Enquanto que a espécie Tentaculites stubeli somente registrada para a Bacia do Amazonas e Tentaculites oseryi apenas para a Bacia do Parnaíba. Nas bacias do Amazonas e do Parnaíba só existe registro das ordens Tentaculitida e Dacryoconarida. Verificaram-se dois padrões de preservação: espécimes isolados e agrupados, desses padrões foram estabelecidas 6 classes tafonômicas, as quais foram distribuídas de acordo com a paleobatimetria, foram registradas em ambientes de shoreface, offshore transicional e offshore. Foi observado que os tentaculitoideos do Devoniano da Bacia do Paraná possuem uma preferência por ambientes mais calmos, localizados entre o Nível de Base de Tempo Bom (NBOTB) e o Nível de Base de Tempestade (NBOT). As classes analisadas encontram-se distribuídas entre as sequências B e E do Devoniano da Bacia do Paraná. Não foram encontradas feições bioestratinômicas como incrustação e predação. As análises com Espectroscopia de Energia Dispersiva (MEV-EDS) e Energia Dispersiva de Fluorescência de Raios-X 
(EDXRF) evidenciaram a presença de crômio e pirita nas amostras, características de ambientes anóxicos, corroborando com a hipótese que a extinção da classe esteja relacionada a uma grande extinção global.

Palavras chave: Classe Tentaculitoidea. Bacia do Paraná. Bacia do Amazonas. Bacia do Parnaíba. Devoniano. Tentaculites. Homoctenus. Styliolina. Uniconus. 


\begin{abstract}
COMNISKEY, J. C. Systematic review, taphonomy, geographic and stratigraphic distribution of Tentaculitoidea class in Brazilian Devonian. 2016. 152p. Tese (Doutorado) - Faculdade de Ciências e Letras de Ribeirão Preto, Universidade de São Paulo, Ribeirão Preto, 2016.
\end{abstract}

The Tentaculitoidea are extinct invertebrates, exclusively marine, commonly found in Brazilian Devonian strata. They are recognized by the conic shell shape, this being, carbonate with small dimensions. In South America, the record of the first tentaculitoideos occurred during the early Silurian, with Tentaculites genus. Representatives of Dacryoconarida and Homoctenida orders were found from the Lower Devonian. In Brazil, the group is registered in the Paraná basins (Ponta Grossa and São Domingo Formations), Amazonas (Maecuru and Ererê Formations) and Parnaíba (Cabeças Formation). Systematic analysis showed the presence of Tentaculites and Styliolina genus (were found in the Amazon, Paraná and Parnaíba Basin) Uniconus and Homoctenus (registration only for the Paraná Basin). Were registered 8 representatives of Tentaculitida order, 2 Homoctenida order and 2 dacryoconarídeos. The species Tentaculites crotalinus, Tentaculites jaculus, Tentaculites kozlowskius, Tentaculites paranaensis, Uniconus ciguelius, Homoctenus katzerius e Styliolina cf. Styliolina fissurella were found in the Paraná Basin. Already species Tentaculites eldredgianus, Tentaculites trombetensis and Styliolina clavulus found in the Amazonas and Parnaíba Basin. While Tentaculites stubeli only recorded for the Amazonas Basin and Tentaculites oseryi only for the Parnaíba Basin. In the Amazonas and Parnaíba basins exists only record of Tentaculitida and Dacryoconarida orders. Two preservation patterns were observed: isolated and grouped specimens. Were established 6 Taphonomic classes, which were distributed according to paleobathymetry were recorded in shoreface environments, offshore transitional and offshore. It was observed that the Tentaculitoidea of the Paraná Basin have a preference for quieter environments, located between the Fair Weather Wave-Base (FWWB) and Storm Wave-Base (SWB). The analyzed classes are distributed among the sequences B and E in the Devonian of the Paraná Basin. There were no biostratinomy features as incrustation and predation. The analysis with energy dispersive spectroscopy (SEM-EDS) and Energy Dispersive Fluorescence X-rays (EDXRF) revealed the presence of chromium and pyrite in the 
samples, characteristic of anoxic environments, supporting the hypothesis that the extinction of the class is related a major global extinction.

Keywords: Class Tentaculitoidea. Paraná Basin. Amazonas Basin. Parnaíba Basin. Devonian. Tentaculites. Homoctenus. Styliolina. Uniconus. 


\section{LISTA DE FIGURAS}

Figura 1. Classificação dos tentaculitoideos adotada nesse trabalho (Modificado de LARDEUX, 1969)...... .21

Figura 2. Figura mostra as diferentes partes morfológicas nas três ordens de tentaculitoideos Tentaculitida (A), Homoctenida (B) e Dacryoconarida (C e D). (Modificado de WITTMER; MILLER, 2011). .23

Figura 3. Regiões da concha de um tentaculitoideo (Modificado de LARSSON, 1979)...........24

Figura 4. Distribuição mundial das formas larvais fósseis encontradas. (Modificado de FARSAN, 2005). . .30

Figura 5. Reconstrução da concha com as partes do desenvolvimento da concha de tentaculitoideos (Modificado de FARSAN, 2005)

Figura 6. Na imagem acima, estão demonstrados os hábitos de vida dos tentaculitoideos já citados na literatura. Porém, hoje em dia sabe-se que os Tentaculitida são bentônicos e Homoctenida e Dacryoconarida são planctônicos (Modificado de WITTMER; MILLER, 2011).

Figura 7. Registro da distribuição geográfica com as ocorrências da classe Tentaculitoidea. (modificado de <http://www.guiageo-mapas.com>. Acesso em: 01/05/2016).

Figura 8. Distribuição paleogeográfica dos tentaculitoideos durante o Ordoviciano, Siluriano e Devoniano (Modificado de WITTMER; MILLER, 2011) .38

Figura 9. Mapa com a localização do ponto de coleta na Bacia do Paraná, Sub - bacia Apucarana (Modificado de MILANI et al., 2007). .47

Figura 10. Posição estratigráfica das Sub-bacias Apucarana (Formação Furnas, Ponta Grossa e São Domingos) e Alto Garças (Unidades 1, 2, 3 e 4), de onde foram analisados os fósseis encontrados (Modificado de GRAHN et al., 2013).

Figura 11. Localização dos afloramentos do Devoniano nas Sub - bacia Apucarana e Sub bacia Alto Garças. (Modificado de GRAHN et al., 2010a). . .53

Figura 12. Carta estratigráfica da sucessão devoniana - carbonífera da Bacia do Parnaíba (Segundo SCHEFFLER, 2010).

Figura 13. Mapa com a localização das Formações Cabeças e Pimenteiras na Bacia do Parnaíba. Informações cedidas pela prof. Dr. Deusana Machado (Modificado de SCHEFFLER,

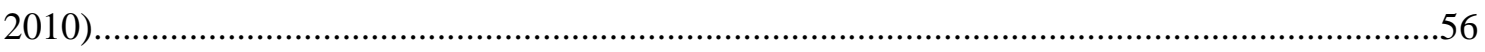

Figura 14. Carta estratigráfica da Bacia do Amazonas (Segundo SCHEFFLER, 2010)............57

Figura 15. Localização dos afloramentos na Bacia do Amazonas onde foram encontrados amostras com tentaculitoideos. Informações cedidas pela prof. Dr. Deusana Machado (Modificado de SCHEFFLER, 2010). . .58

Figura 16. Espécimes de Tentaculites crotalinus observados em coleções científicas. A) Igc 1/E 
1308. B) CCLP 11. C) NR 7420. D) NR 6057. E) NR 8634. F) CCLP 23. H) CCLP 21. I) MPI 9842. Na figura $\mathrm{C}$, a flecha demonstra os macroanéis dispostos irregularmente e de tamanhos irregulares, característica encontrada nesta espécie. (Escala $0,5 \mathrm{~cm}$ ). 61

Figura 17. Tentaculites jaculus observados nas coleções científicas. A) UNIRIO 104 te. B) MPI 9836. C) MN 6453. D) MN 7042. E) UNIRIO 1 te. (Escala 1,0 cm).

Figura 18. Espécimes de Tentaculites kozlowskius. A) Igc 1/E 1285. B) MPI 2077. C) MPI 9837. D) MPI 9832. E) CCLP 29. F) CCLP 52. G) MN 7030. H) MN 7034. I) UFRJ 05 te. (Escala $0,5 \mathrm{~cm}$ ). .66

Figura 19. Espécimes representantes da espécie Tentaculites eldredgianus. A) UNIRIO 41. B) UNIRIO 41. C) UNIRIO 55. D) UNIRIO 35. (Escala de 0,5 cm). 68

Figura 20. Exemplares de Tentaculites Stubeli. A) UNIRIO 05. B) DGM 2912. C) UNIRIO 05. (Escala $0,5 \mathrm{~cm}$ ). 69

Figura 21. Espécimes da espécie Tentaculites oseryi. A) UNIRIO 58. B) UNIRIO 59. Na figura $\mathrm{A}$, a flecha indicando como os anéis e interespaços encontram-se dispostos praticamente com a mesma espessura (Escala $0,5 \mathrm{~cm}$ ).

Figura 22. Alguns exemplares de Tentaculites trombetensis. A) UNIRIO 38. B) MN 2697. C) UNIRIO 37. (Escala de $0,5 \mathrm{~cm}$ ) .73

Figura 23. Alguns dos espécimes de Tentaculites paranaensis. A) Igc 1/E 3242. B) Igc 1/E 1287. C) NR 7137. D) NR 7458. E) NR 4784. F) UNIRIO 97. G) NR 5466. H) UNIRIO 90. I) Igc 1/E 3247. J) Igc 1/E 1296. K) NR 6115. L) Igc 1/E 3414. (Escala 1,0 cm).. .75

Figura 24. Espécimes de Uniconus ciguelius observadas nas análises. A) CCLP 39. B) CCLP 40. C) UFRJ 22te. D) CCLP 22. E) MPI 10152. F) DGM 1923. G) CCLP 39. (Escala 0,5 $\mathrm{cm})$.

Figura 25. Homoctenus katzerius. A) Igc 1/E 1294. B) CCLP 25. C) Igc 1/E 3411. D) CCLP 10. E) CCLP 21. F) Igc 1/E 3633. G) UFRJ 07 te. H) Igc 1/E 3428. (Escala 0,5 cm). . .80

Figura 26. Espécimes de Styliolina cf. Styliolina fissurella. A) UNIRIO 16. B) MN 7430. C)

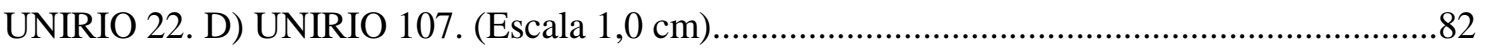

Figura 27. Styliolina clavulus. A) UNIRIO 36. B) UNIRIO 43. C) UNIRIO 44. D) UNIRIO 42. (Escala 1,0 cm). .83

Figura 28. Estampa ilustrativa de prováveis tentaculitoideos encontrados em afloramentos do Devoniano médio, Bacia do Paraná. A e B (UEPG, sem numeração). C) MPI 8628. D) MPI 9298 (Escala de 1mm).

Figura 29. Amostra com prováveis tubos vestimentíferos. (UEPG, amostra sem numeração. Escala 1mm). .86

Figura 30. Demonstração das classes tafonômicas descritas, em níveis paleobatimétrica. Classe $\mathrm{C} 1$ ocorrentes no shoreface. Classes $\mathrm{C} 2$ encontrada no offshore transicional, logo abaixo do 
NBOTB. As classes C3, C4, e C5 encontram-se acima do Nível de Base de Tempo Bom (NBOT), no offshore transicional. Enquanto que a classe C6 localiza-se abaixo do Nível de Base de Tempestade (NBOT), no offshore. .88

Figura 31. Distribuição bioestratigráfica das espécies de tentaculitoideos encontrados nas Bacias do Paraná, Amazonas e Parnaíba. As espécies da Bacia do Paraná possuem um registro desde o final do Praguiano, enquanto que as espécies da Bacia do Amazonas e Parnaíba iniciam sua distribuição apenas durante o Eifeliano. .94

Figura 32. A figura acima mostra uma forma larval de tentaculitoideo encontrado no município de Jaguariaíva, Devoniano da Bacia do Paraná. As setas em branco demonstram a parte larval da concha. (Amostra CCLP 15, UNESP-Bauru. Escala 4mm). .96

Figura 33. A figura demonstra a distribuição paleogeográfica das espécies brasileiras encontradas durante o Devoniano Inferior. Em vermelho as espécies encontradas durante o Devoniano Inferior (Modificado de TORSVIK; COCKS, 2004) 101

Figura 34. A figura demonstra a distribuição paleogeográfica das espécies brasileiras encontradas durante o Devoniano Médio. Em vermelho as espécies encontradas durante o Devoniano Médio (modificado de TORSVIK; COCKS, 2004). 102

FIGURA 35. Análise de duas amostras de tentaculitoideos verifica se os altos índices de cromo .106 


\section{SUMÁRIO}

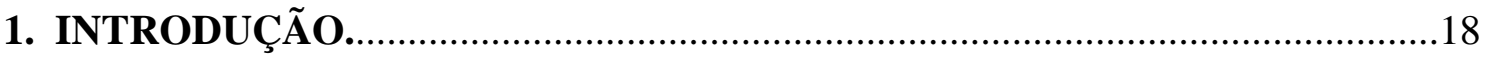

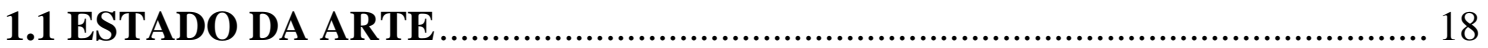

1.1. CLASSE TENTACULITOIDE: RESENHA HISTÓRICA, AFINIDADES BIOLÓGICAS E SISTEMATIZAÇÃO DA CLASSE ......................................... 18

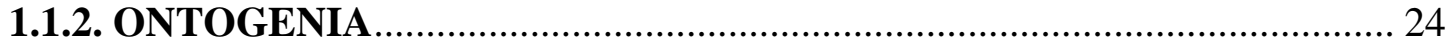

1.1.3. ECOLOGIA E MODO DE VIDA …………………………………….... 32

1.2. DISTRIBUIÇÃO GEOGRÁFICA E ESTRATIGRÁFICA.............................35

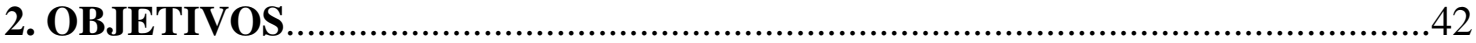

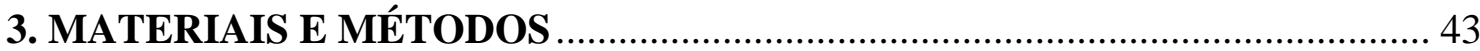

4. GEOLOGIA DAS ÁREAS ESTUDADAS …………………………………….... 46

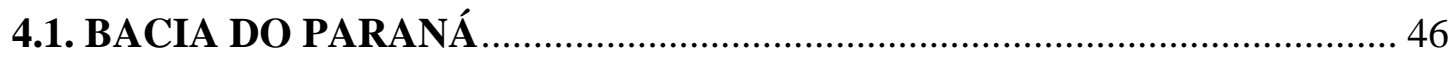

4.1.1. Sub-bacia Apucarana............................................................................... 50

4.1.1.1. Formação Furnas ............................................................................... 50

4.1.1.2. Formação Ponta Grossa ............................................................................ 50

4.1.1.3 Membro Tibagi da Formação São Domingos............................................ 50

4.1.1.4. Formação São Domingos ……………………………………………... 51

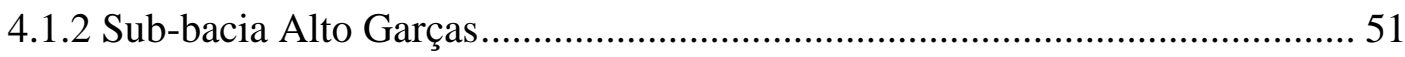

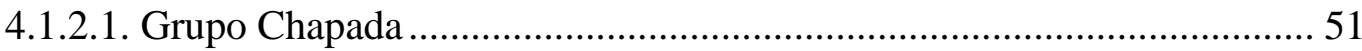

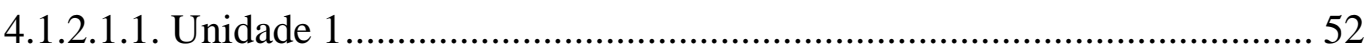

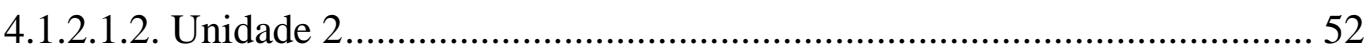

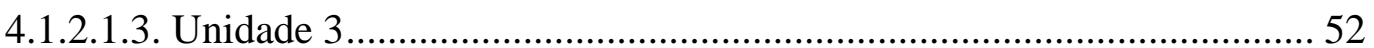

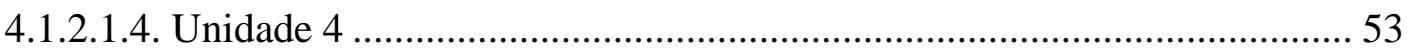

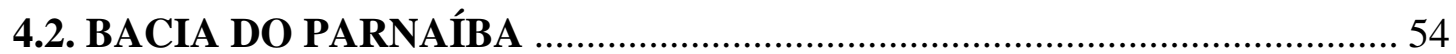

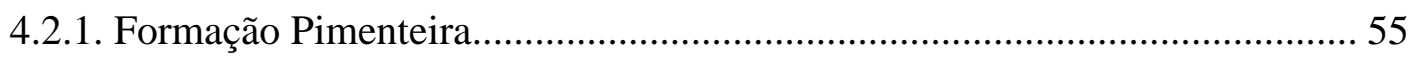

4.2.2. Formação Cabeças......................................................................................... 55

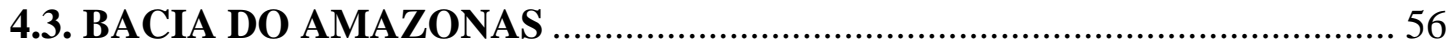

4.2.1. Formação Maecuru ................................................................................... 57

4.2.2 Formação Ererê ……………………………………………………….... 57

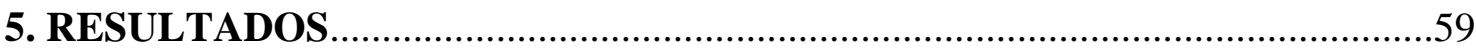

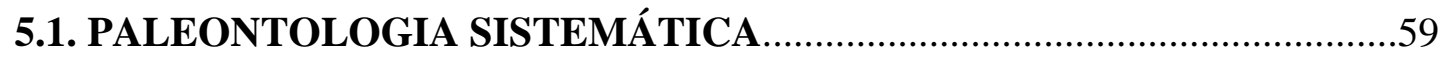

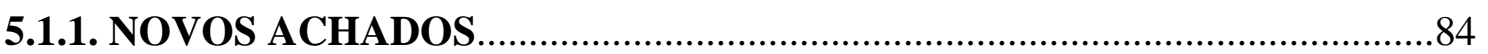




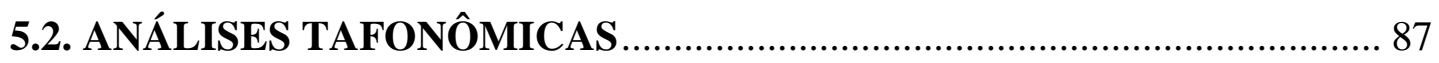

5.3. DISTRIBUIÇÃo GEOGRÁFICA E PALEOBIOGEOGRÁFICA.............. 94

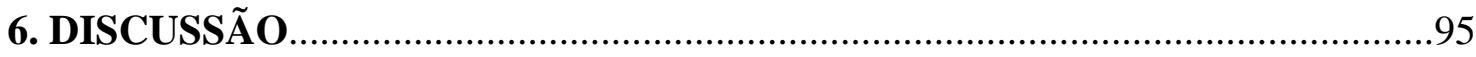

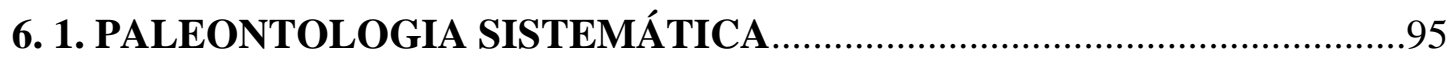

6.2. ANÁLISES TAFONÔMICAS.....................................................................97

6.3. BIOESTRATIGRAFIA E EXTINÇÃO DA CLASSE ................................. 100

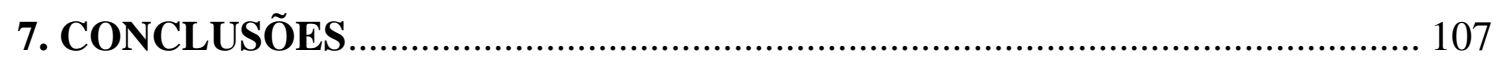

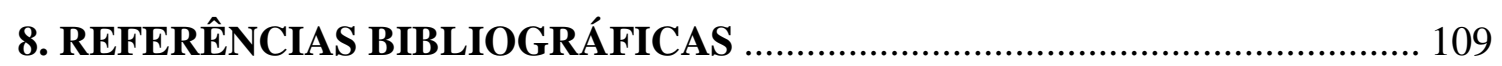

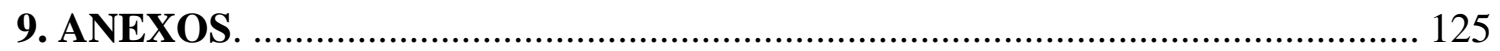

9.1.“COMNISKEY, J. C.; GHILARDI, R. P. Levantamento histórico da Classe Tentaculitoidea no Devoniano brasileiro: principais características e padrões de preservação. Terr@ Plural, v. 7,p. 115-126, 2013.”

9. 2. COMNISKEY, J. C.; GHILARDI, R. P.; BOSETTI, E. P. Conhecimento atual sobre os tentaculitoideos devonianos das bacias do Amazonas e Parnaíba, Brasil, depositados em instituições brasileiras. Boletim do Museu Paraense Emilio Goeldi, v. 10 , n. 1 , p. $49-61,2015$. 138 


\section{INTRODUÇÃO}

\subsection{ESTADO DA ARTE}

\subsubsection{CLASSE TENTACULITOIDEA: RESENHA HISTÓRICA, AFINIDADES BIOLÓGICAS E SISTEMATIZAÇÃO DA CLASSE}

Walch (1775) realiza a primeira menção aos organismos, embora apenas com o trabalho de Schlotheim (1820) o gênero Tentaculites tenha sido introduzido. Apesar dos organismos terem sido nomeados como "Tentaculites" fazendo alusão a animais que possuem "tentáculos", essa característica não foi encontrada em pesquisas posteriores (FISHER, 1962; SCHINDLER, 2012).

O estudo da classe Tentaculitoidea obteve um grande avanço desde o início dos anos 50, com os trabalhos de Lyashenko (1955, 1957, 1959 e 1969) que descreveu grande parte dos gêneros e espécies de tentaculitoideos conhecidos hoje. Seus trabalhos estabeleceram a base dos estudos dos tentaculitoideos.

Os tentaculitoideos são tratados como um grupo "problemático" ou "enigmático" visto a taxonomia diversificada e pela falta de consenso sobre a sua origem após o Ordoviciano ou o Siluriano (FISHER; YOUNG, 1955; FISHER, 1962; FARSAN, 2005; WITTMER, 2009; WITTMER \& MILLER, 2011; SCHINDLER, 2012). Segundo Wittmer (2009), nunca houve um estudo sobre a diversidade definitiva e as análises paleoecológicas voltadas especificamente para este grupo são quase que escassas na literatura, sendo esse fato surpreendente dada à abundância de tentaculitoideos em alguns ambientes marinhos durante a sua breve existência.

A sistemática dos Tentaculitoideos ainda é alvo de intensas discussões (WITTMER; MILLER, 2011; SCHINDLER, 2012; WEI et al., 2012). Segundo Ciguel (1989) e Azevedo-Soares (1999), a classificação dos tentaculitoideos é baseada, exclusivamente, em aspectos morfológicos da concha, a partir da ornamentação externa. Lyashenko (1955) e Fisher (1962) elaboraram modelos para classificação taxonômica utilizando a parede interna da concha, embora sejam trabalhos relevantes no que se diz respeito à taxonomia do grupo, esta metodologia não foi aceita (BOUČEK, 1964; AZEVEDO-SOARES, 1999; SCHINDLER, 2012), visto que na maior parte dos casos a preservação ocorre apenas como moldes internos e externos. Registros sobre a preservação de material orgânico de tentaculitoideos em resíduos, obtidos através de 
análises palinológicas, foram registrados por Filipiak e Jazynka (2009). Nesse trabalho os autores descrevem treze restos orgânicos de prováveis tentaculitoideos, similares às partes embrionárias e juvenis, provenientes do Devoniano Superior (Frasniano) da Polônia. Apesar de relatarem a pobre preservação, classificam o material como sendo prováveis representantes da ordem Dacryoconarida. Mais recentemente, Marshall e Telnova (2012) relatam uma nova ocorrência de restos orgânicos, sem detalhamento taxonômico, porém para o Devoniano da Rússia.

Os tentaculitoideos são classificados como invertebrados extintos providos de concha carbonática, coniforme, tamanho milimétrico a centimétrico. A maioria apresenta a concha reta, sendo que poucos apresentam concha encurvada e até mesmo enrolada Podem possuir concha lisa ou com ornamentação e, neste último caso, apresentam anéis, microanéis, macroanéis, estrias e espaços interanulares (FISHER; YOUNG, 1955; LYASHENKO, 1955, 1957, 1959, 1969; BLIND, 1969; FISHER, 1962; LARDEUX, 1969; ALBERTI，1970，1987，1988，1993，1997，1999，2000; HAJŁASZ, 1974, 1993; YODER; ERDTMANN, 1975; LARSSON, 1979; LUKES, 1982, 1984, 1985, 1989, 1991; YOCHELSON, 1986; FARSAN, 1981, 1984, 1993, 1994, 2005; MELO, 1985; CIGUEL, 1989; AZEVEDO-SOARES, 1999; LI, 2000; NIKO, 2000; BERKYOVÁ, 2004; WITTMER, 2007, 2009; WITTMER; MILLER, 2011; SCHINDLER, 2012; THASSANAPAK ET AL., 2012; WEI et al., 2012; COMNISKEY; GHILARDI, 2013).

O grupo já foi classificado como crinoides (Barrande, 1852), anelídeos (SHARPE; SALTER, 1856), pterópodes (CLARKE, 1899), espinhos de braquiópodes (TOWE, 1978) e possíveis lofoforados (VINN; MUTVEI, 2009), bem como foraminíferos (para maiores informações veja: BLIND, 1969). Bouček (1964) e Farsan (1994) defendem, através de estudos baseados na composição e estrutura da concha que os tentaculitoideos apresentam afinidades biológicas mais próximas como moluscos. Desde então, é a afinidade biológica mais aceita dentre grande parte dos pesquisadores.

Entretanto, Wei et al. (2012) sugerem a existência de duas principais linhas quanto à posição taxonômica do grupo. A primeira seria uma afinidade com os moluscos devido à semelhança com a morfologia da concha e a estrutura da parede da concha (BLIND, 1969; LARDEUX, 1969; FARSAN, 1994; SCHINDLER, 2012), sendo a mais aceita e já discutida anteriormente. Por outro lado, a segunda linha de pesquisas reconhece os tentaculitoideos como um grupo irmão dos microconchídeos (WEEDON, 1991; VINN; TAYLOR, 2007; VINN; MOTUS, 2008; ZATOŃ; 
TAYLOR, 2009; VINN, 2010; VINN; ZATOŃ, 2012; VINN, 2013). Para essa segunda linha sobre afinidade taxonômica, os tentaculitoideos possuem maiores afinidades biológicas com os "vermes" do que com os moluscos. Segundo Wittmer e Miller (2011) e Schindler (2012) ainda existe uma falta de consenso sobre as questões biológicas do grupo, o que acarreta uma incerteza quanto as suas afinidades biológicas. Embora estas duas hipóteses ainda sejam muito discutidas, nesse trabalho adota-se a interpretação da afinidade com os moluscos, devido à semelhança com a concha e as paredes da mesma em análises com MEV e EDS realizadas, bem como em análises realizadas também por Ciguel et al. (1987), as quais suportam a hipótese de que os tentaculitoideos possuem afinidades biológicas mais próximas dos moluscos.

Ao passar dos anos, a sistemática do grupo foi modificada por diferentes autores (LYASHENKO, 1955, 1957, 1969; FISHER, 1962; BOUČEK, 1964; BLIND, 1969; LARDEUX, 1969; HAJ屯ASZ, 1974; LARSSON, 1979; FARSAN, 1994). Para Farsan (1994), a falta de informação sobre a construção da concha, ontogenia e estrutura da concha, dificultou as pesquisas sistemáticas do grupo. Schindler (2012) complementa que atualmente é questionável se a investigação da composição da concha e sua estrutura pode fornecer uma ferramenta para a atribuição sistemática, seja nível de classe ou quanto ao grupo que o organismo localiza, necessitando-se maiores estudos a respeito.

As primeiras publicações sobre os tentaculitoideos foram realizadas com os fósseis provenientes da plataforma Russa, República Tcheca e África do Norte. Destacam se aqui os trabalhos de Lyashenko (1955, 1957), Bouček (1964), Lardeux (1969), Alberti (1970, 1987, 1988, 1993, 1999, 2000).

Dentre as classificações propostas ao longo dos anos, destacam-se as de Lyashenko (1955), os quais também levaram em consideração a morfologia e a ornamentação da parede interna da concha. Lyashenko (1955) propõe a classe Coniconchia contendo as quatro ordens Tentaculitida, Nowakiida, Styliolinida e Hyolithida. Lyashenko (1957) cria a classe Tentaculitoidea e descreve uma série de famílias e grande quantidade de gêneros foi introduzida nesta época.

Fisher (1962) realiza o reagrupamento dos grupos propostos por Lyashenko (1955, 1957) e, em função da espessura da concha, substitui o nome da classe Coniconchia pelo novo nome Cricoconarida. Adicionalmente, agrupam as duas ordens Nowakiida e Styliolinida em uma nova ordem com o novo nome Dacryoconarida e mantém a ordem Tentaculitida proposta por Lyashenko (1955). Bouček (1964) não 
concorda com Fisher (1962) na maneira como reorganizou o grupo e introduz três novas ordens à classificação Homoctenida, Coleolida e Cornulitida.

Lardeux (1969) reorganiza a classificação proposta pelos autores anteriores (LYASHENKO, 1955; FISHER, 1962; BOUČEK, 1964), sendo a utilizada atualmente. Segundo Lardeux (1969), portanto, a classe Tentaculitoidea, proposta por Lyashenko, 1957 (= Cricoconarida FISHER, 1962), é constituída por três ordens: Tentaculitida Lyashenko, 1955, Homoctenida Bouček, 1964 e Dacryoconarida Fisher, 1962 (Figura $1)$.

Classe Tentaculitoidea Lyashenko, 1955

Ordem Tentaculitida Lyashenko, 1955

Familia Tentaculitidae Walcott, 1886

Gênero Tentaculites Schlotheim, 1820

Gênero Seretites Lyashenko, 1969

Família Uniconidae Lyashenko, 1955

Gênero Uniconus, 1955

Ordem Homoctenida Bouček, 1964

Família Homoctenidae Lyashenko, 1955

Gênero Homoctenus Lyashenko, 1955

\section{Ordem Dacryoconarida Fisher, 1962}

Família Styliolinidae Grabau \& Shimer, 1910

Gênero Styliolina Karpinsky, 1884

Figura 1. Classificação dos tentaculitoideos adotada nesse trabalho (Modificado de LARDEUX, 1969).

A ordem Tentaculitida (Figura 2) é composta por animais de conchas com paredes espessas, tamanho médio, com tamanho aproximado de $1 \mathrm{~mm}$ a $80 \mathrm{~mm}$ de comprimento e aproximadamente $6 \mathrm{~mm}$ de diâmetro (FISHER, 1962; LARDEUX, 1969). Os espécimes analisados neste trabalho possuíam de 0,7 a $3,7 \mathrm{~cm}$. Possuem anéis arredondados de diferentes formas e tamanhos. São providos de macroanéis e 
microanéis (em alguns casos). Os diferentes tamanhos e formatos dos anéis são características cruciais para separar gêneros e espécies. Por exemplo, representantes do gênero Tentaculites apresentam macroanéis espessos, os quais aumentam de tamanho irregularmente ao longo da concha, apresentam interespaços entre os anéis dispostos irregularmente ao longo da concha, associados à microanéis esporádicos. No caso de Uniconus os macroanéis são voltados para a região da abertura.

Geralmente apresentam a região apical lisa (sem ornamentações) e pontiaguda. Possuem concha reta ou levemente encurvada (LYASHENKO, 1955). Abertura perpendicular ao eixo da concha ou ligeiramente oblíquo. A porção juvenil da concha forma septos os quais dividem o interior da concha em várias câmaras (BOUČEK, 1964). Estrias longitudinais na superfície da concha não são encontradas. Apresentam modo de vida bentônico (LARSSON, 1979; FARSAN, 1994; SCHINDLER, 2012).

Segundo Wittmer e Miller (2011) os representantes da ordem Tentaculitida apresentam o maior intervalo de registro estratigráfico dos tentaculitoideos e o primeiro a aparecer no início do Ordoviciano (FISHER; YOUNG, 1955), extinguindo-se no final do Devoniano. Essa ordem inclui o gênero de tentaculitoideo mais comum, Tentaculites (WITTMER; MILLER, 2011).

A ordem Homoctenida (Figura 2) apresenta concha de pequeno tamanho $(0,8$ a $1,5 \mathrm{~cm})$ e paredes finas, em formato de cone estreito, ligeiramente encurvado ou raramente reto, às vezes assemelham-se a uma série de cones (SCHINDLER, 2012). A ornamentação consiste em anéis, frequentemente numerosos, de perfil anguloso, todos semelhantes entre si ou apresentando uma ligeira diferença no diâmetro, com interespaços côncavos. As microornamentações são frequentes, porém pouco expressivas, principalmente na região da abertura da concha (LYASHENKO, 1955). Apresenta câmara embrionária cônica além de apêndice tubular filiforme na extremidade apical (LYASHENKO, 1955).

Um dos gêneros mais conhecidos desta ordem e encontrados no Brasil é o Homoctenus o qual possui macroanéis angulosos dispostos regularmente e com interespaços aumentando de tamanho de maneira regular ao longo da concha. Em alguns casos ocorre a presença de micro anéis (encontrados na região adulta e da abertura).

Comumente encontrados em folhelhos e siltitos. Diferente dos outros tentaculitoideos, os homoctenídeos são restritos ao Devoniano (BOND, 2006; 
WITTMER; MILLER, 2011). Apresentam modo de vida planctônico (WITTMER; MILLER, 2011; SCHINDLER, 2012).

Os representantes da ordem Dacryoconarida (Figura 2) são animais pequenos (0,8 a 2,0 cm), conchas finas (apresenta apenas a camada primária) e mais cônica se comparada aos representantes das outras ordens. O ápice goticular representa o estágio embrionário do organismo, que se expande para dentro da câmara larval (WITTMER; MILLER, 2011). O ângulo de crescimento é maior dos tentaculitoideos. Na porção juvenil lisa ou com anéis fracamente desenvolvidos. Os Dacryoconarida são inferidos como de hábito de vida planctônico (WITTMER \& MILLER, 2011; SCHINDLER, 2012). Não há registro de septos nesta ordem. Os dacryoconarídeos surgem no final do Ordoviciano e extinguem-se no final do Devoniano (WITTMER; MILLER, 2011).

Os representantes dessa ordem podem apresentar anéis do tipo arredondado (e.g. Viriatella e Paranowakia), anéis proeminentes e angulosos (e.g. Nowakia) ou não apresentar (e.g. Styliolina). Em alguns casos apresentam estrias de crescimento irregularmente desenvolvidas. Até o presente momento foi registrado a ocorrência apenas do gênero Styliolina para a América do Sul (FISHER, 1962; LARDEUX, 1969).

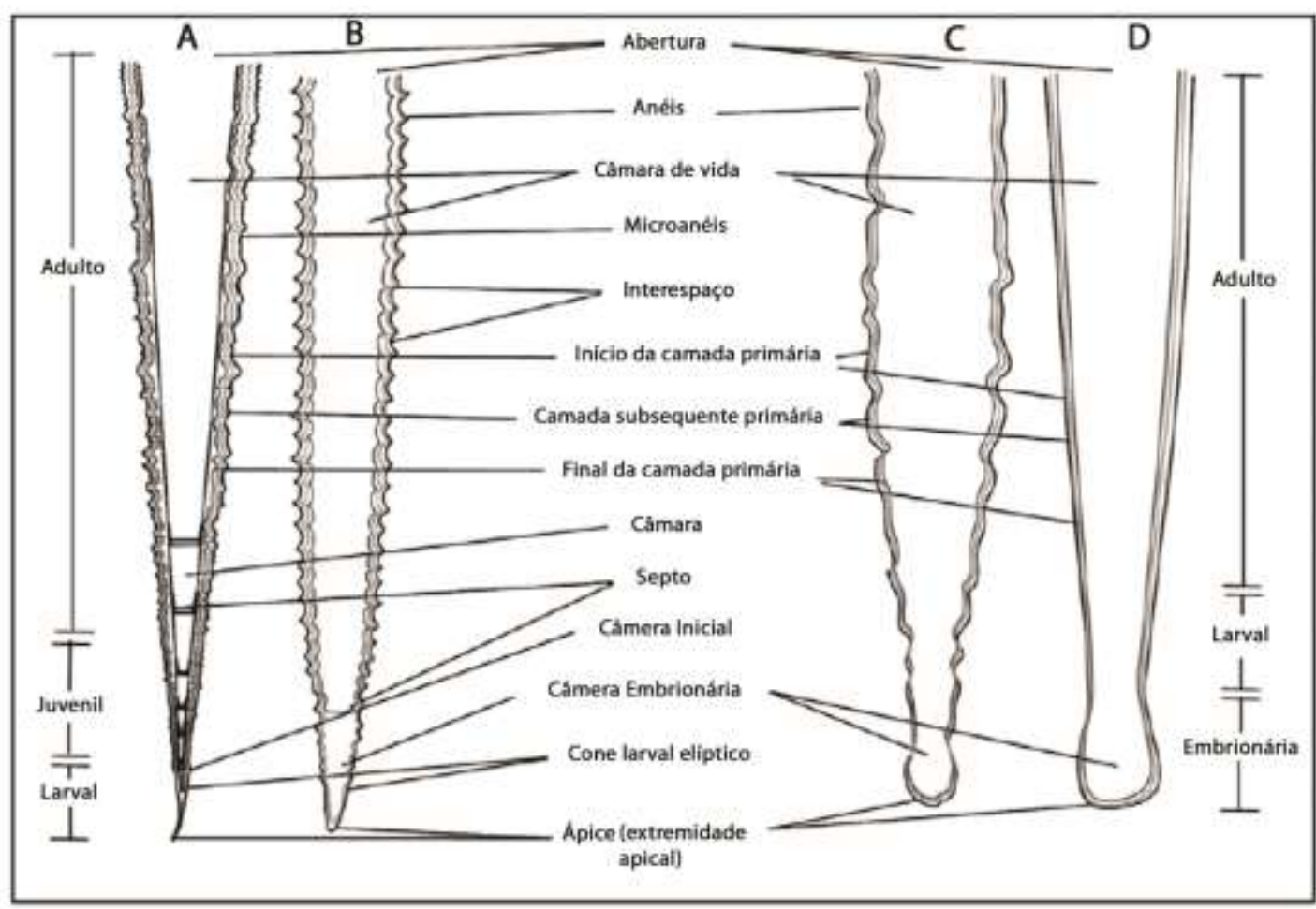

Figura 2. Figura mostra as diferentes partes morfológicas nas três ordens de tentaculitoideos Tentaculitida (A), Homoctenida (B) e Dacryoconarida (C e D). (Modificado de WITTMER; MILLER, 2011). 


\subsubsection{ONTOGENIA}

A ontogenia dos tentaculitoideos já foi relatada por alguns autores (LYASHENKO, 1958，1959; FISHER，1962; BOUČEK，1964; BLIND, 1969; LARDEUX, 1969; LARSSON, 1979; FARSAN, 1994, 2005).

Lyashenko (1959) foi pioneira sobre detalhamentos das características da concha. Descrevendo a câmara embrionária e as ornamentações da concha, como sendo as características mais importantes na sistemática do grupo. Para a autora a concha divide-se em quatro partes: embrionária, juvenil, adulta e abertura (Figura 3).

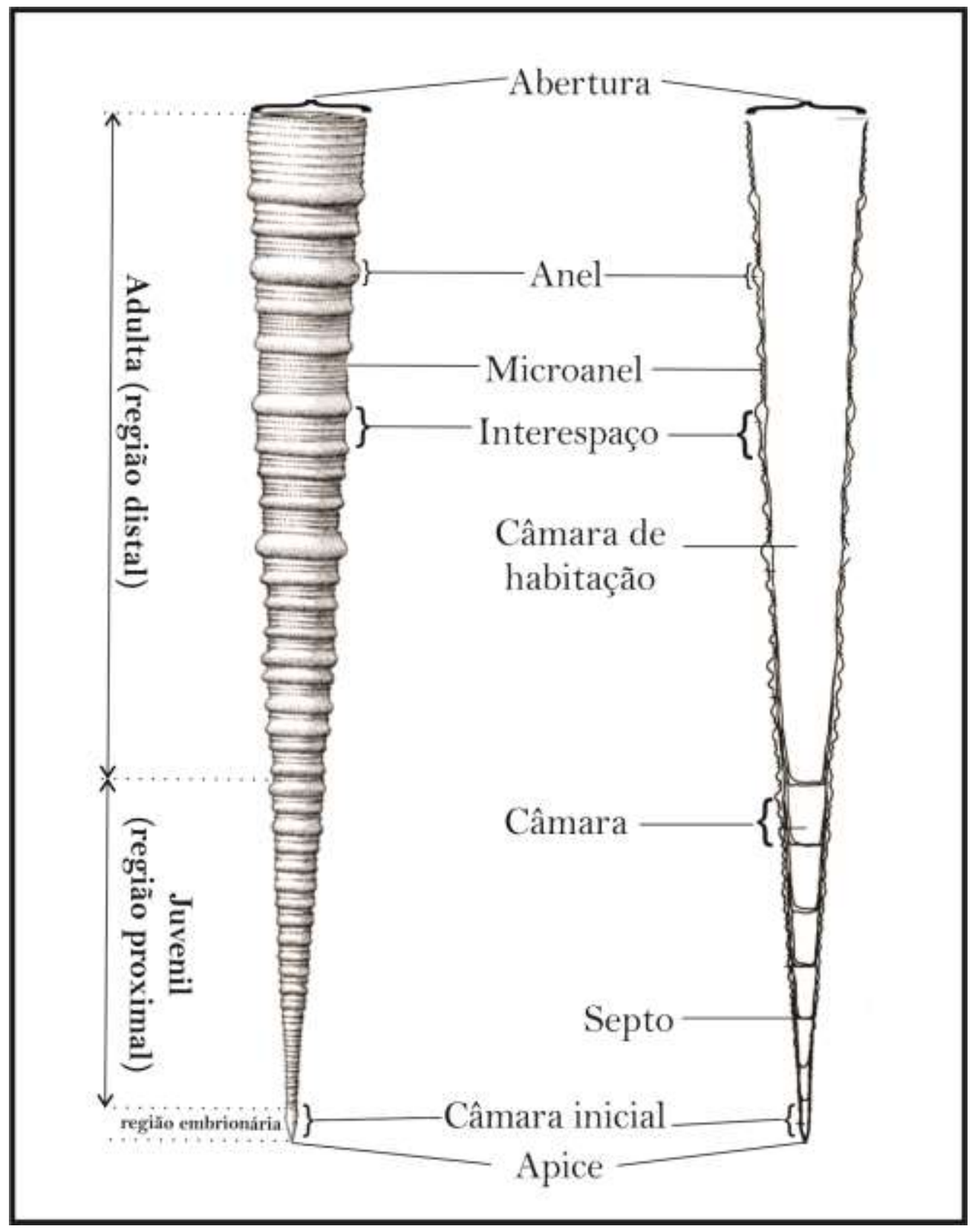

Figura 3. Regiões da concha de um tentaculitoideo (Modificado de LARSSON, 1979). 
Fisher (1962) apoia a interpretação feita Lyashenko (1959), sobre a câmara embrionária, que segundo o autor é um recurso taxonômico importante como o registro da primeira câmara embrionária para o gênero Tentaculites. Fisher (1962) ainda utiliza esta mesma característica para todos os representantes da ordem Tentaculitida. De acordo com o autor a concha consiste em carbonato de cálcio, exceto quando é substituída secundariamente por sílica.

Para Bouček (1964) na ordem Tentaculitida o tubo é simplesmente alongado a um espaço estreito. Possui ápice cônico e fechado. A maior parte da parte apical é muitas vezes cheia com substâncias minerais, secundariamente, a partir da qual são formadas as paredes dos tubos. Ainda nesse trabalho, Bouček (1964) cria a ordem Homoctenida e afirma que o ápice em Homoctenus é fechado como nos Tentaculitida. Para o autor, a câmara inicial em Dacryoconarida é de formato oval. Segundo o autor a concha é formada por calcita, sendo formada por vários números de camadas, as quais são divididas em camada interna e externa.

Blind (1969) reconheceu três estágios de desenvolvimento (embrionária, juvenil e fase adulta), os quais são características externas da metamorfose das partes moles, da concha dos Tentaculitida. O autor utilizou o método de transeção para a visualização dessa característica. Durante a fase larval ocorre início das primeiras ornamentações na concha, com o aparecimento dos primeiros anéis larvais. À medida que os anéis crescem, paralelos à parede da concha, as ondulações vão formando as três camadas da concha, à medida que o crescimento aumentava. Como consequência deste crescimento, seriam formados dois tipos de anéis: finos e espessos. Diferenciando assim, os organismos de paredes finas e grossas (AZEVEDO-SOARES, 1999). Na fase larval, a câmara embrionária e os septos são pouco desenvolvidos, sendo assim, diferenciando-os da terceira fase que é a de crescimento. Em seu trabalho Blind (1969) afirma que a região da abertura era fechada por um opérculo, estrutura encontrada em Hyolites (moluscos bentônicos, com distribuição estratigráfica do Cambriano ao Permiano). Entretanto, esta característica morfológica foi descartada por autores posteriores (LARSSON, 1979; FARSAN, 1994), por falta de indícios que comprovem o mesmo.

Blind (1969) também reconheceu que a concha dos tentaculitoideos é claramente lamelar, sendo que a concha primária é composta por três camadas: camada mais externa orgânica, uma camada micro lamelar composta de calcita que constitui grande parte da concha e uma camada orgânica interna. 
Lardeux (1969) após exaustivo trabalho mostrou que a câmara inicial mesmo nos Tentaculites apresenta diferenças em tamanho, forma e preenchimento calcário. $\mathrm{O}$ autor divide a concha dos Tentaculitida em regiões: apical, mediana e da abertura.

A investigação de Blind (1969) e Lardeux (1969) não só lidou com a morfologia externa da parte ontogenético dos Tentaculitida, mas ambos os autores também tentaram pela primeira vez reconstruir uma ontogenia completa dos tentaculitoideos em termos de estrutura da concha e características internas. Ambos os autores reconheceram que a concha dos tentaculitoideos é constituída de uma estrutura lamelar.

Hajłasz (1974) em seu estudo na reconstrução da ontogenia dos Tentaculitida não apresenta novas informações relevantes. A autora utiliza à sistemática e a ontogenia proposta por Lyashenko (1979) e considerou que a câmara inicial cônica era representativa de Tentaculitida.

Larsson (1979) analisa as diferentes partes ontogenéticas dos Tentaculitida, baseados em seus estudos com o grupo do Siluriano de Gotlândia (Suécia), reclassificando como: parte juvenil ou proximal e parte adulta ou distal. Para o autor a parte juvenil compreende em aproximadamente 20 a $30 \%$ do comprimento total da concha, enquanto que a parte adulta compreende entre 70 e $80 \%$ do total. Larsson (1979) concorda com Blind (1969) no que diz respeito ao crescimento da concha dos tentaculitoideos sejam caracterizados por três fases de desenvolvimento (embrionária, juvenil e adulta), isto é refletido na tríplice divisão da concha.

Larsson (1979) diferencia a parte embrionária ou câmara inicial possuindo formato cônico. Também realizou a divisão interna da concha em câmara inicial, câmara intermediária e câmara de habitação, sendo esta última localizada na parte adulta da concha (Figura 3). A parte embrionária, raramente, é encontrada isolada do resto da concha (LARSSON, 1979). Para Larsson (1979), a parte juvenil compreende a porção da concha da câmara inicial para o último septo. Neste último nível, o ângulo de crescimento e as microornamentações são alterados. Em muitos tentaculitoideos a parte juvenil mais próxima, após a câmara inicial, se expande a um baixo ângulo e por isso tem uma forma subcilíndrica. Segundo o autor, o interior da parte juvenil é dividido por partições transversais denominados septos. A quantidade de septos varia de acordo com a espécie (Figura 3). Complementa ainda que o espaço dos septos livres é bastante variável. Em algumas espécies é regular, mas em outros há uma alta variabilidade. Os septos podem ou não ser simétricos (LARSSON, 1979). 
Segundo Larsson (1979) a região adulta compreende a parte distal da concha dos tentaculitoideos. $\mathrm{O}$ autor afirma que em espécimes adultos o último septo é formado na região onde o ângulo de crescimento muda. Constitui, assim, outra característica para distinguir a parte juvenil e formas adultas. $\mathrm{O}$ interior da parte adulta compreende a câmara de habitação, isto é, a cavidade na qual os tecidos moles dos tentaculitoideos habitavam. Larsson (1979) descarta a ideia de que os tentaculitoideos possuíam um opérculo, proposto por Blind (1969). Segundo o autor, Blind (1969) apresentou "fragmentos de conchas estranhos espalhados nas aberturas de algumas conchas". Para Larsson (1979) a concha se torna mais fina à medida que se aproxima da região da abertura, influenciando alguns autores a diferenciar esta região, porém, o autor afirma ser "supérflua" esta divisão visto que a abertura é um caráter morfológico presente em todos os estágios ontogenéticos.

Larsson (1979) concorda com Blind (1969) sobre a composição da concha e a divisão em três camadas para a concha primária.

Alberti (1993) em seu trabalho com os homoctenídeos e dacryoconarídeos, apresenta novos parâmetros necessários para a classificação taxonômica do grupo. As características como ângulo apical ou ângulo de crescimento (ângulo entre as paredes opostas na extremidade apical) e adoral (ângulo entre as paredes opostas na região da abertura) seriam imprescindíveis para a classificação.

Farsan (1994) foi o primeiro a registrar estágios ontogenéticos dos tentaculitoideos. Ainda, o desenvolvimento e a aparência dessas fases ontogênicas nos Tentaculitida e Homoctenida sempre seguem o mesmo parâmetro durante um longo intervalo de tempo (FARSAN, 1994). Complementa ainda que a duração das fases individuais de desenvolvimento ou o comprimento das partes correspondentes da concha podem ser diferentes em todas as categorias sistemáticas.

Sobre a composição da concha, Farsan (1994) afirma que a concha calcária primária consiste em três camadas de diferentes espessuras, que também diferem na sua microestrutura, a quantidade de matéria orgânica e, por conseguinte, também na sua função. A concha é constituída por três camadas (inicial, posterior e final) na concha primária na fase larval. A camada inicial é constituída por camadas de calcário, sendo considerada uma camada muito fina e de grande importância para a estrutura da concha visto que possui uma elevada flexibilidade da borda do manto e, portanto é responsável pela construção dos elementos morfológicos e esculturas específicas, durante todo o desenvolvimento ontogênico. São encontrados cristais de calcita não paralelamente a 
superfície da concha larval, enquanto que nas partes juvenis e adultas tais cristais encontram-se dispostos paralelamente à superfície. A camada primária posterior encontra-se diretamente no interior da superfície interior da camada primária inicial, servindo como um reforço para a camada primária inicial. A camada final é muito fina e se situa sobre a superfície interna da camada primária posterior que cobre a superfície interna da concha. A camada primária final é muito semelhante à camada primária inicial em termos de microestrutura, espessura e da quantidade de material orgânico.

Segundo o autor, esta última camada desempenha grande importância, visto que em dacryoconarídeos e homoctenídeos a concha secundária está ausente, sendo que assim, a ligação à camada primária final e partes moles permanece durante toda a vida do animal. Enquanto que nos Tentaculitida a ligação entre a camada de primária final e as partes moles existe apenas por um curto período de tempo e termina logo após a construção das camadas da concha subsequentes.

Para Farsan (1994) a concha possui quatro partes distintas: embrionária, larval, juvenil e adulta. $\mathrm{O}$ autor constata que todas as partes da concha que foram desenvolvidos na fase larval provavelmente não possuem a câmara embrionária, visto que, elas encontram-se sempre abertas. Complementa ainda, que a concha larval é um tubo aberto construído pela camada primária inicial. Os anéis larvais são os únicos elementos da superfície da concha larval. Eles apresentam diferentes formas que se desenvolvem como dobras onduladas da camada primária inicial (FARSAN, 1994). A parte terminal da concha larval, o cone larval, exerce a maior influência sobre a metamorfose ontogenética da concha, o que só pode ser entendida como resultante de uma grande mudança na anatomia das partes moles. Farsan (1994) afirma ainda que as mudanças ontogenéticas da concha demonstram que a transição de parte larval para a juvenil era contínua. $\mathrm{O}$ autor verificou que no final da parte larval, quando os anéis larvais começam a se reorientar, o espessamento da concha intensifica. Farsan (1994) verificou que a orientação dos anéis larvais marca a posição da orla da abertura. Adicionalmente, observou-se que na fase larval o tamanho dos anéis aumenta enquanto que a quantidade diminui, por exemplo: na parte proximal encontram-se 34-35 anéis em um espaço de $0,1 \mathrm{~mm}$, enquanto que na parte distal, no mesmo intervalo de $0,1 \mathrm{~mm}$, apenas 25-30 anéis larvais aparecerem (FARSAN, 1994).

Farsan (1994) descreve que com a construção do último anel larval a fase larval é terminada. Enquanto, que o início da fase juvenil é marcado pela presença da 
obliquidade do primeiro anel juvenil, bem como o diâmetro da concha neste momento aumenta em relação à fase larval.

No seu conjunto os primeiros três anéis juvenis são construídos obliquamente ao eixo longitudinal da concha, enquanto que o ângulo do terceiro anel diminui significativamente. Os primeiros anéis juvenis frequentemente não só diferem na sua forma e altura dos seguintes anéis, mas também são separadas por áreas interespaços maiores (FARSAN, 1994).

Farsan (1994) afirma que a parte juvenil inclui a porção da concha entre o último anel larval e os primeiros ciclos do anel que aparecem nas Tentaculitida com anéis ciclicamente construídos. A concha juvenil inicia-se com os primeiros três anéis de juvenis que são morfologicamente isoladas a partir de anéis subsequentes por uma maior distância entre si e a posição oblíqua em relação ao eixo da concha.

A presença do septo foi relatada por Blind (1969), Lardeux (1969) e Larsson (1979), os quais afirmaram que o primeiro septo é construído relativamente tarde na ontogenia, ou seja, na transição para a fase adulta, e isso só pode ser constatado em alguns espécimes preservados de Tentaculitida. Para Farsan (1994) os estudos apontaram que o primeiro septo é construído exatamente entre o último anel larval e o primeiro anel oblíquo juvenil. O primeiro septo, provavelmente, aparece durante a metamorfose (FARSAN, 1994). A parte adulta da concha corresponde à região posterior da concha e distingue-se da parte juvenil por sua morfologia e estrutura (FARSAN, 1994). Na parte adulta a geometria da concha e as ornamentações são completamente diferentes do que nas outras partes.

Como já citado por Larsson (1979), a disposição dos anéis ocorre de maneira cíclica. O mesmo fato foi observado por Farsan (1994), que complementa as informações indicando que quando os anéis ocorrem comprimidos em ciclos há uma grande variedade de ordens de anéis. A ciclicidade também é de longe o elemento escultórico mais amplamente distribuído nos Tentaculitida e caracteriza os grupos com o maior número de formas. Geralmente, os ciclos podem ser divididos de acordo com o número de anéis. Formas com um anel (monoanular) que ocorrem dentro de uma determinada distância na concha dos adultos são raros ou formas com dois ciclos de anéis (bianular).

Farsan (2005) realiza um novo estudo sobre a ontogenia dos estágios iniciais de tentaculitoideos, relatando o local de origem do material analisado (Figura 4). 


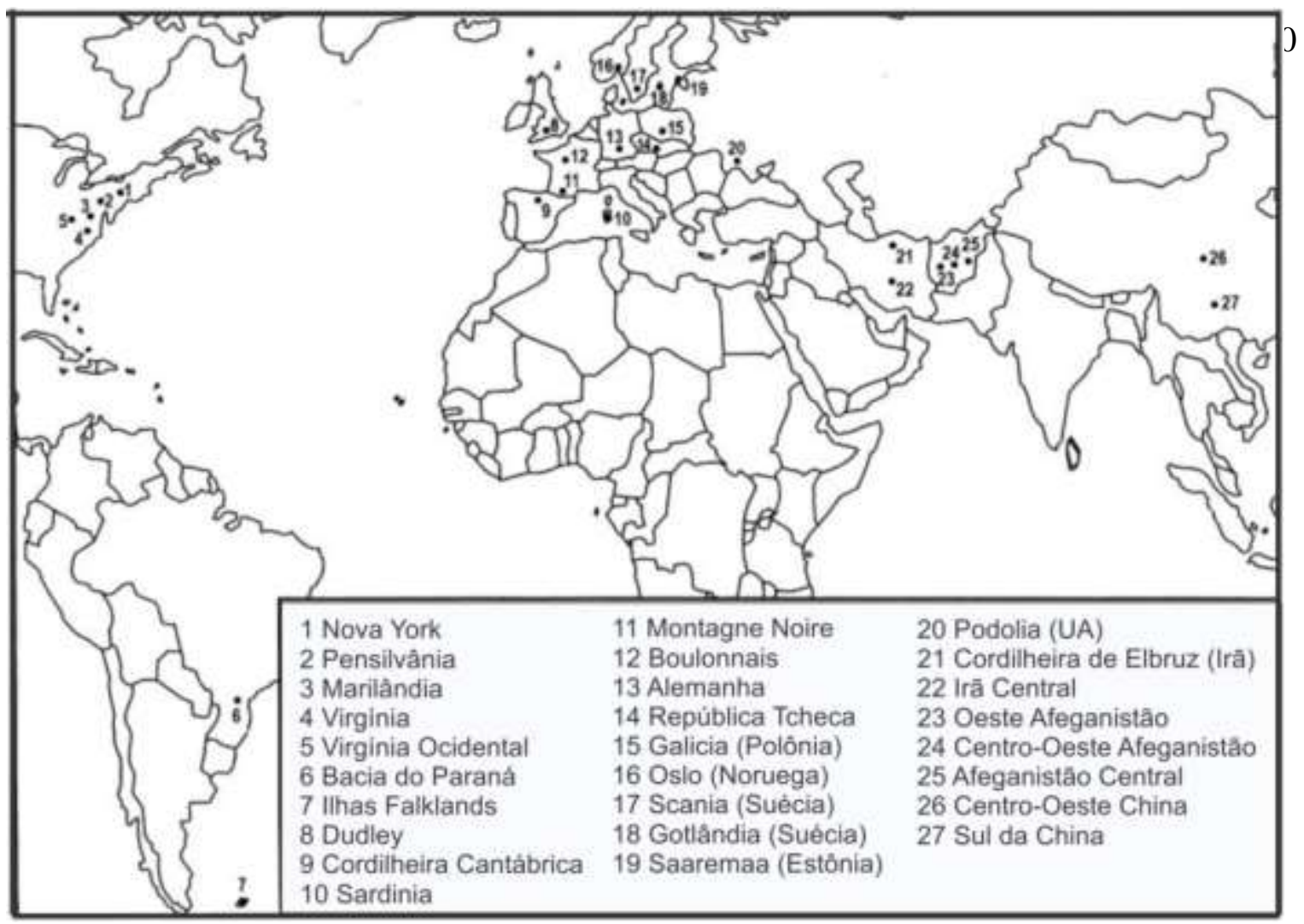

Figura 4. Distribuição mundial das formas larvais fósseis encontradas. (Modificado de FARSAN, 2005).

Nesse trabalho, Farsan (2005) apresenta uma nova classificação dos estágios ontogenéticos dos tentaculitoideos (Figura 5). Segundo Farsan (2005), a parte larval pode ser dividida em processo larval (sendo constituído pela parte prolarval e parte metalarval) e cone elíptico larval (contêm a parte epilarval). Para Farsan (2005) toda a parte larval mede aproximadamente $680 \mu \mathrm{m}$, destes: $520 \mu \mathrm{m}$ pertencem ao processo larval e $160 \mu \mathrm{m}$ ao cone elíptico larval.

A parte prolarval compreende cerca de $270 \mu \mathrm{m}$ de comprimento, sendo constituída por um longo e afiado espinho apical de aproximadamente $20 \mu \mathrm{m}$. A fase prolarval é construída quase que na sua totalidade a partir da primeira camada de composição calcária, com a presença de anéis bem espaçados. A parte metalarval compreende entre $250 \mu \mathrm{m}$ e $267 \mu \mathrm{m}$ de comprimento. Na parte epilarval coincide com o início de metamorfose que produz, em tentaculitida, uma concha assimétrica com uma seção elíptica e obliquidade da abertura ao longo eixo da concha (FARSAN, 2005). Farsan (2005) complementa que a mudança na geometria e da microestrutura da concha discutida acima é certamente uma indicação de alterações morfológicas das partes moles, em preparação para um novo modo de vida. Isso sugere para os tentaculitoideos, o final do período de natação e início do uma vida bentônica. Esta transformação 
permite, dessa forma, provavelmente, uma maior estabilidade em relação ao substrato de vida durante essa fase ontogenética.

Para Farsan (1994) a descoberta dos estágios iniciais ontogenéticos dos Tentaculitida pode indicar nova definição e descrição para o grupo.

\section{Homoctenida}

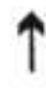

武
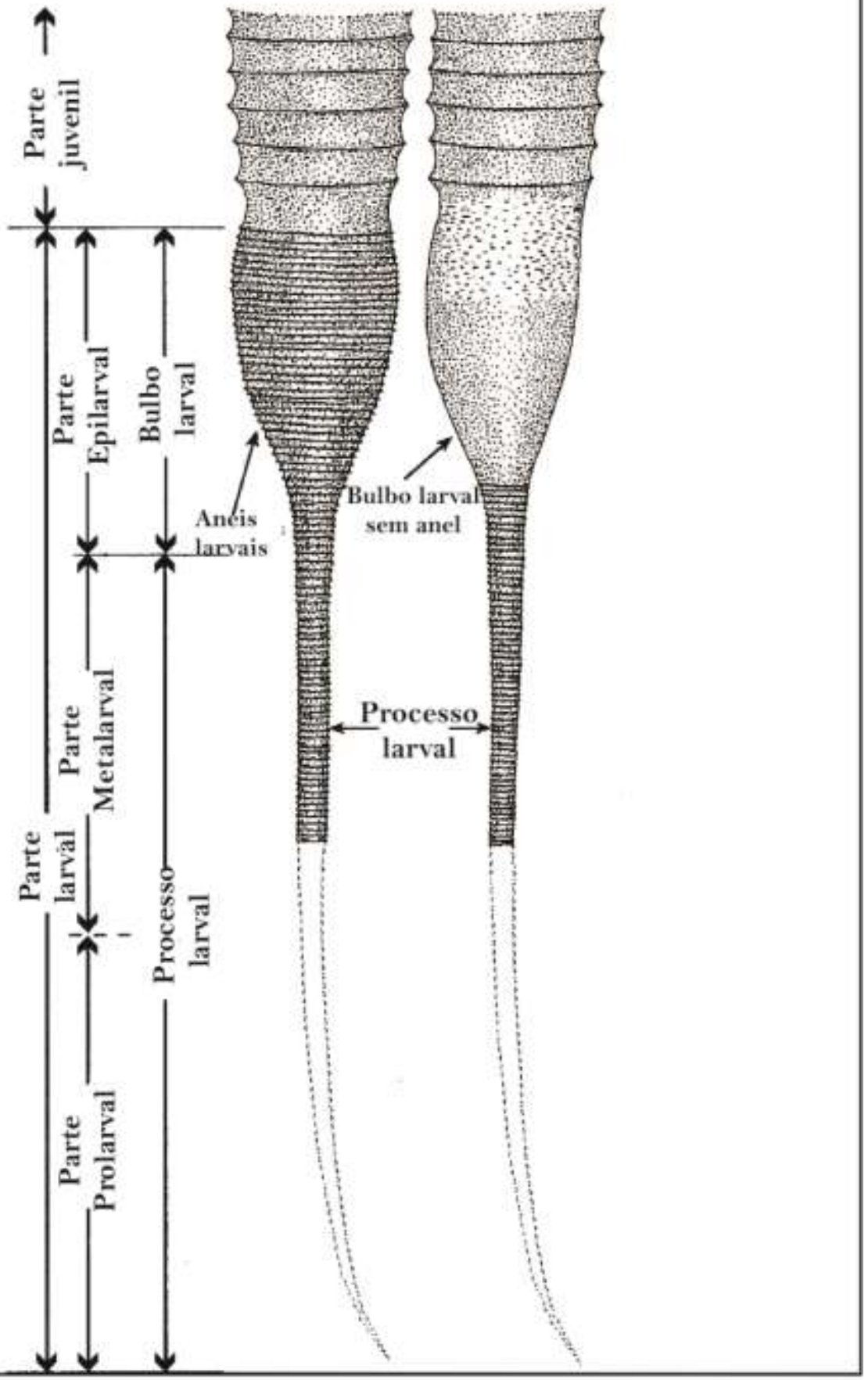

Figura 5. Reconstrução da concha com as partes do desenvolvimento da concha de tentaculitoideos (Modificado de FARSAN, 2005). 


\subsubsection{ECOLOGIA E MODO DE VIDA}

Até o presente momento as interpretações sobre a ecologia e o hábito de vida dos tentaculitoideos são bastante controversas (Figura 6).

Lyashenko (1959) sugere um modo de vida nectônico e a posição de vida vertical com a região da abertura voltada para a superfície da água. Afirma ainda que as câmeras eram necessárias para auxiliar no controle da orientação do animal. Segundo Lyashenko (1959) os tentaculitoideos poderiam ser encontrados em diversos tipos de ambiente.

Para Fisher (1962) os tentaculitoideos eram organismos pelágicos, os quais viviam paralelos ao substrato. Segundo o autor os tentaculitoideos não poderiam ser bentônicos ou com posição de vida com a abertura fixa ao substrato, visto que é refutada pela secção circular e a falta de qualquer desgaste nos anéis (e.g. abrasão). Além disso, a ausência de um opérculo, que proibiria a infiltração de lama e lodo, faria um habitat bentônico inviável. $\mathrm{O}$ autor ainda afirma que a presença de hábito nectônico parece ser provável, porém a presença dos anéis poderia impedir a natação. No caso dos dacryoconarídeos que possuem anéis mais arredondados ou são desprovidos de tais ornamentações, provavelmente estes anéis são desenvolvidos como uma estrutura de reforço que serviriam para combater as forças de águas agitadas. Segundo o autor, os tentaculitoideos ocorrem em diversos tipos de ambientes, porém em ambientes com siltitos argilosos e folhelhos sua abundância seja maior do que em ambientes arenosos, dolomíticos e recifes calcários. $\mathrm{O}$ autor complementa ser difícil imaginar como os Tentaculitida, que possuem conchas mais espessas, poderiam se movimentar ao longo do mar. $\mathrm{O}$ desenvolvimento das conchas mais espessas parece ter sido uma resposta às águas agitadas ou temperaturas elevadas.

Fisher (1962) afirma ainda que os dacryoconarídeos eram pelágicos (principalmente planctônicos) e os tentaculitida escavadores nectônico-bentônico em águas mais quentes e mais agitadas.

Bouček (1964) cita um modo de vida bentônico para os Tentaculitida e viviam em ambientes de águas rasas, iluminadas e quentes. Enquanto que os dacryoconarídeos seriam planctônicos. Outra questão levantada pelo autor seria de que as espécies de Uniconus seriam organismos que viviam deitados no fundo, onde havia correntes e as cristas dos anéis (a crista dos anéis, é o "pico" mais agudo do anel) voltados para a 
abertura, ficariam escavadas na parte inferior evitando assim as conchas de serem deslocadas.

Blind (1969) mostrou pela primeira vez a posição vertical da vida e modo de vida semi-infaunal na fase adulta. Blind (1970) registra a presença de uma colônia de briozoários na área da abertura da concha dos Tentaculitida durante a vida do animal, apoiando a sua interpretação de que os Tentaculitida foram orientados com a parte apical em direção ao fundo do mar ou foram enterrados com a ponta nele. Blind (1969) indica a presença de "tentáculos" na região da abertura, sugerindo assim um hábito alimentar. Porém, a presença de "tentáculos" não foi aceita na época, pela falta de registro que comprovassem tal artefato.

Lardeux (1969) implica a presença de anéis, parece ser incompatível com um estilo de vida nectônico. Presumivelmente, no entanto, que os anéis bem desenvolvidos poderiam favorecer a flutuação. Para Ciguel (1989), a ornamentação externa (anéis, microanéis e estrias) é adaptada à forma hidrodinâmica, apesar dos anéis constituírem atrito durante o deslocamento do animal, estes nunca estão voltados ao ápice, sugerindo condição hidrodinâmica. O autor ainda afirma que o deslocamento dos tentaculitoideos se dava, a partir do movimento de contração e distensão das partes moles do animal, com a expulsão da água. A repetição do movimento determinaria o deslocamento do animal. A velocidade deste movimento era determinada pela quantidade de gases encontrados nas câmaras de flutuação. Sugerindo assim um hábito nectônico para as três ordens de tentaculitoideos.

Segundo Lardeux (1969) os Tentaculitida são comuns em fácies neríticas. Esses organismos foram nadadores realmente talentosos para a vida; a sua conformação, bem como o seu modo de ocorrência sugerem antes modo de vida necto-bentônico ou possivelmente bentônico. Já os Homoctenídeos são abundantes em certas fácies calcárias ou folhelhos.

Walker e Laporte (1970) interpretaram os Tentaculitida como organismos de hábito bentônico vágil, os quais viviam deitados sobre a superfície do sedimento e foram detritívoros ou catadores. Yoder e Erdtman (1975) sugerem hábito nectobentônico para os tentaculitoideos.

Para Larsson (1979) bem como Bouček (1964), sugerem o hábito bentônico para os Tentaculitida e hábito planctônicos para os Dacryoconarida. O autor concorda com Blind (1969) sobre a ideia de que os tentaculitoideos tinham um modo de vida vertical com uma abertura dirigida para cima durante algumas fases da sua vida adulta. 
Complementa ainda que os tentaculitoideos são encontrados muitas vezes fragmentados, causa provável de ondas moderadas ou agitação de correntes, poderiam fragmentar as conchas em ambientes neríticos. Bem como a ação de organismos predadores poderiam fragmentar parcialmente as conchas.

Farsan (1994) apoiou a posição de vida na posição vertical com a ponta proximal enterrado no sedimento. Afirma que durante a última fase de desenvolvimento dos tentaculitida, os animais viveram com sua parte juvenil inicial ligeiramente curvada no sedimento, enquanto que as partes juvenis finais e adultas da concha permaneceram em pé na posição vertical ou quase vertical.

Ciguel (1989) e Farsan (1994) afirmam que os tentaculitoideos viveriam em ambientes de até $100 \mathrm{~m}$ de profundidade. Farsan (1994) complementa ainda que, os ambientes preferenciais para o tentaculitoideos seriam locais bem iluminados, oxigenado e em áreas com poucas correntes. $\mathrm{O}$ autor afirma ainda que as conchas deviam permanecer fixadas ao substrato, por um período, após a morte do animal. Outro fator apontado pelo autor, é que as partes adultas dos tentaculitoideos são facilmente preservadas, por serem regiões relativamente mais espessas compostas pelos septos, se comparadas com as partes larvais e iniciais juvenis, visto que estas regiões ainda são compostas por material orgânico. Segundo Farsan (1994) os organismos não sofreram longos transportes ou retrabalhamento, para o autor as feições encontradas nos fósseis seriam decorrentes do ataque de predadores, após a sua morte. Para o autor os tentaculitoideos sofreram poucos danos nas conchas, o que seria indicativo da ausência de transporte, o que não pode ser averiguado nas amostras aqui analisadas. Porém, quando encontradas as partes larvais juntas às partes juvenis, isso indicaria uma preservação em vida e próxima ao local onde vivia.

Estudos recentes (WITTMER; MILLER, 2011; SCHINDLER, 2012; WEI et al., 2012) sugerem que os representantes da ordem Tentaculitida são animais bentônicos, enquanto que os dacryoconarídeos e homoctenídeos são animais planctônicos. A Figura 6 mostra os hábitos de vida já propostos para os tentaculitoideos.

Schindler (2012) afirma que os Tentaculitida podem ser encontrados em ambientes com sedimentos siliciclásticos, arenitos e siltitos, enquanto que os homoctenídeos e dacryoconarídeos são encontrados em rochas sedimentares em ambientes mais profundos. 


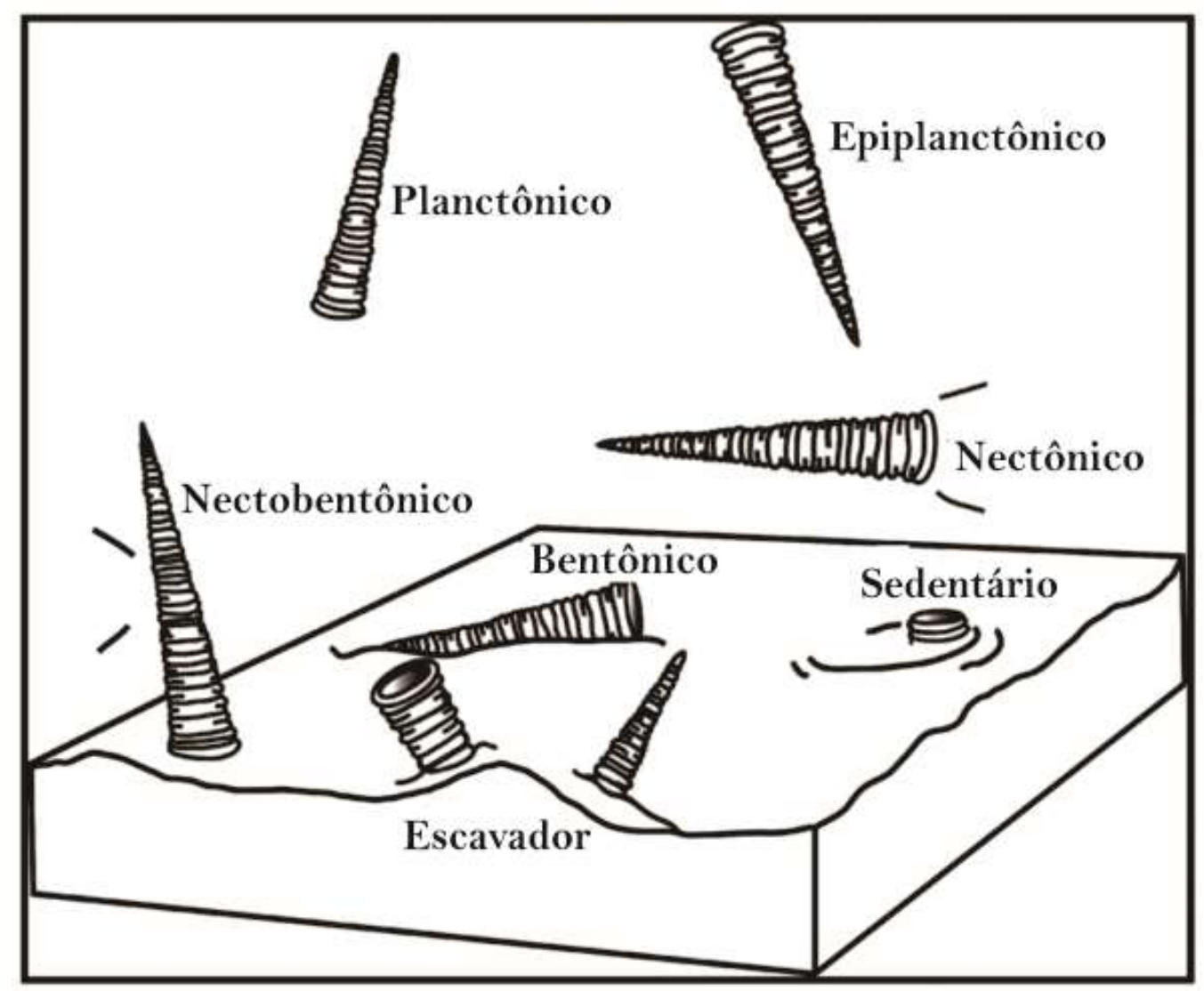

Figura 6. Na imagem acima, estão demonstrados os hábitos de vida dos tentaculitoideos já citados na literatura. Porém, hoje em dia sabe-se que os Tentaculitida são bentônicos e Homoctenida e Dacryoconarida são planctônicos (Modificado de WITTMER; MILLER, 2011).

\subsection{DISTRIBUIÇÃO GEOGRÁFICA E ESTRATIGRÁFICA}

A classe possui ampla distribuição geográfica (Figura 7), sendo encontrado na Austrália, Canadá, República Tcheca, Rússia, Brasil, Nova Zelândia, França, África do Sul, Ucrânia, Reino Unido, Líbia, Venezuela, Áustria, China, Espanha entre outras regiões (LYASHENKO, 1955, 1957, 1959; BLIND, 1969; BOUČEK, 1964; LARDEUX, 1969; ALBERTI, 1970，1993，2000; HAJÆASZ，1974，1976, 1993; LARSSON, 1979; FARSAN, 1984, 1994, 2005; LINDERMANN; YOCHELSON, 1984, 1992; YOCHELSON; KIRCHGASSER, 1986; LINDERMANN; MELYCHER, 1997; BERKYOVÁ et al., 2007; WITTMER; MILLER, 2011; SCHINDLER, 2012; WEI et al., 2012; COMNISKEY ET AL., 2015). Por esta ampla distribuição e por serem os animais de conchas pequenas com paredes finas, são encontrados preferencialmente em folhelhos pretos ao redor do Mundo, embora também ocorram em calcários cinzas e às vezes em diferentes preservações (WITTMER; MILLER, 2011). 


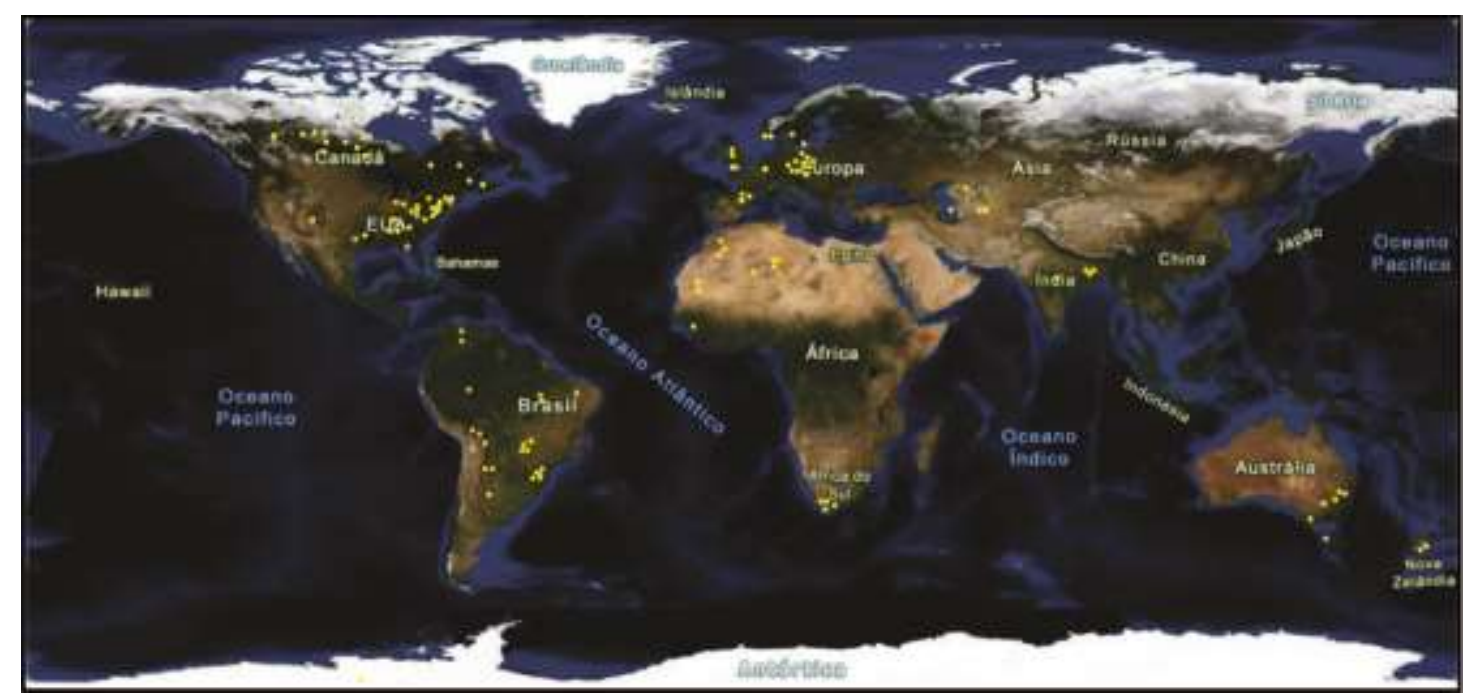

Figura 7. Registro da distribuição geográfica com as ocorrências da classe Tentaculitoidea. (modificado de <http://www.guiageo-mapas.com>. Acesso em: 01/05/2016).

O grupo é bem estudado no Hemisfério Norte e existe uma grande quantidade de gêneros e espécies conhecidas (LYASHENKO, 1955, 1957, 1959; BOUČEK, 1964; BLIND, 1969; LARDEUX, 1969; LARSSON, 1979; ALBERTI, 1970, 1993, 2000; HAJŁASZ, 1974, 1976, 1993; FARSAN, 1984, 1994, 2005; YOCHELSON; KIRCHGASSER, 1986; LINDERMANN; YOCHELSON， 1984， 1992; LINDERMANN; MELYCHER, 1997; BERKYOVÁ et al., 2007; WITTMER; MILLER 2011; SCHINDLER, 2012; WEI et al., 2012). No entanto, estudos sistemáticos deste grupo no Hemisfério Sul (e, principalmente, no que diz respeito aos animais Malvinocáfricos) são praticamente inexistentes na literatura. No Brasil são poucos os táxons encontrados no registro estratigráfico (HARTT; RATHBUN, 1875; CLARKE, 1899, 1913; MELO, 1985; CIGUEL, 1989; AZEVEDO-SOARES, 1999; COMNISKEY; GHILARDI, 2013; COMNISKEY et al., 2015).

A distribuição estratigráfica do grupo é ainda controversa, apesar de poucos autores citarem a ocorrência dos tentaculitoideos a partir do Siluriano, a maior parte dos autores relata a ocorrência do grupo desde o início do Ordoviciano se extinguindo no Devoniano na barreira Frasniano-Fameniano (FISHER, 1962; BOND, 2006; WITTMER \& MILLER, 2011; SCHINDLER, 2012; WEI et al., 2012).

Segundo Fisher e Young (1955), os primeiros registros de tentaculitoideos são do Ordoviciano Inferior da Formação Chepultepec, da Virginia (Tremadociano), com representantes da ordem Tentaculitida ocorrendo em abundância e ficando documentados no registro fossilífero até o término do Siluriano. O táxon dos dacryoconarídeos surge no Siluriano, mas torna-se excepcionalmente diverso no 
Devoniano inferior e médio (SCHINDLER, 2012). Já os homoctenídeos têm seu registro iniciado a partir do Devoniano e seu ápice evolutivo ocorre no Frasniano (BOND, 2006; SCHINDLER, 2012). Este período é caracterizado pela grande expansão da diversidade e da distribuição geográfica dos tentaculitoideos (WITTMER; MILLER, 2011; SCHINDLER, 2012). Schindler (1990, 2012) e Bond (2006) afirmam que os homoctenídeos foram os únicos tentaculitoideos que ultrapassaram a barreira da extinção Frasniano - Fameniano (FF).

Para Wittmer e Miller (2011) no início do Ordoviciano, o registro ocorre na Austrália, Malásia e Tailândia e, curiosamente, após esse período os tentaculitoideos não são documentados até o final do Ordoviciano. Neste período, muitas são as ocorrências da ordem Tentaculitida, existindo, no entanto, apenas um relato da ocorrência de Styliolina, marcando a primeira aparição dos Dacryoconarida.

O início do Siluriano é marcado por um notável aumento na diversidade de tentaculitoideos em todo o mundo (FISHER, 1962; WITTMER; MILLER, 2011; WEI et al., 2012).

Durante o Devoniano, o grupo mostra extensa disseminação global (FISHER, 1962; ALBERTI, 1993; WITTMER; MILLER, 2011; SCHINDLER, 2012; WEI et al., 2012). Segundo Wittmer e Miller (2011), no início do Devoniano as três ordens estavam presentes em proporções praticamente iguais. Os Dacryoconarida atingem o máximo de sua diversidade durante o Devoniano Médio (SCHINDLER, 2012), enquanto os Homoctenida têm seu ápice no Frasniano (BOND, 2006; SCHINDLER, 2012).

Entre os trabalhos que referem a distribuição geográfica dos tentaculitoideos durante o Ordoviciano, Siluriano e Devoniano, apenas o de Wittmer e Miller (2011) registra sua presença na América do Sul, com ocorrências somente a partir do Devoniano, porém sem maiores detalhes quanto à localização das ocorrências e andares estratigráficos. No entanto, Clarke (1899) cita a ocorrência de tentaculitoideos para o Siluriano da Bacia do Amazonas. Wei et al. (2012) afirmam ainda que não existem evidências convincentes quanto à presença de tentaculitoideos além dos trópicos.

Verificou-se que durante o Devoniano a diversidade de espécies da América do Sul é inferior à da Europa e da América do Norte. Como citado anteriormente, alguns autores acreditam que o grupo dos tentaculitoideos tivesse preferência por ambientes tropicais. Analisando os mapas (Figura 8) de reconstrução paleogeográfica apresentado por Wittmer e Miller (2011), verificou-se maior concentração dos registros do grupo em 
regiões mais tropicais, tais como Laurentia, Báltica e Avalonia, desde o Ordoviciano até o Devoniano.

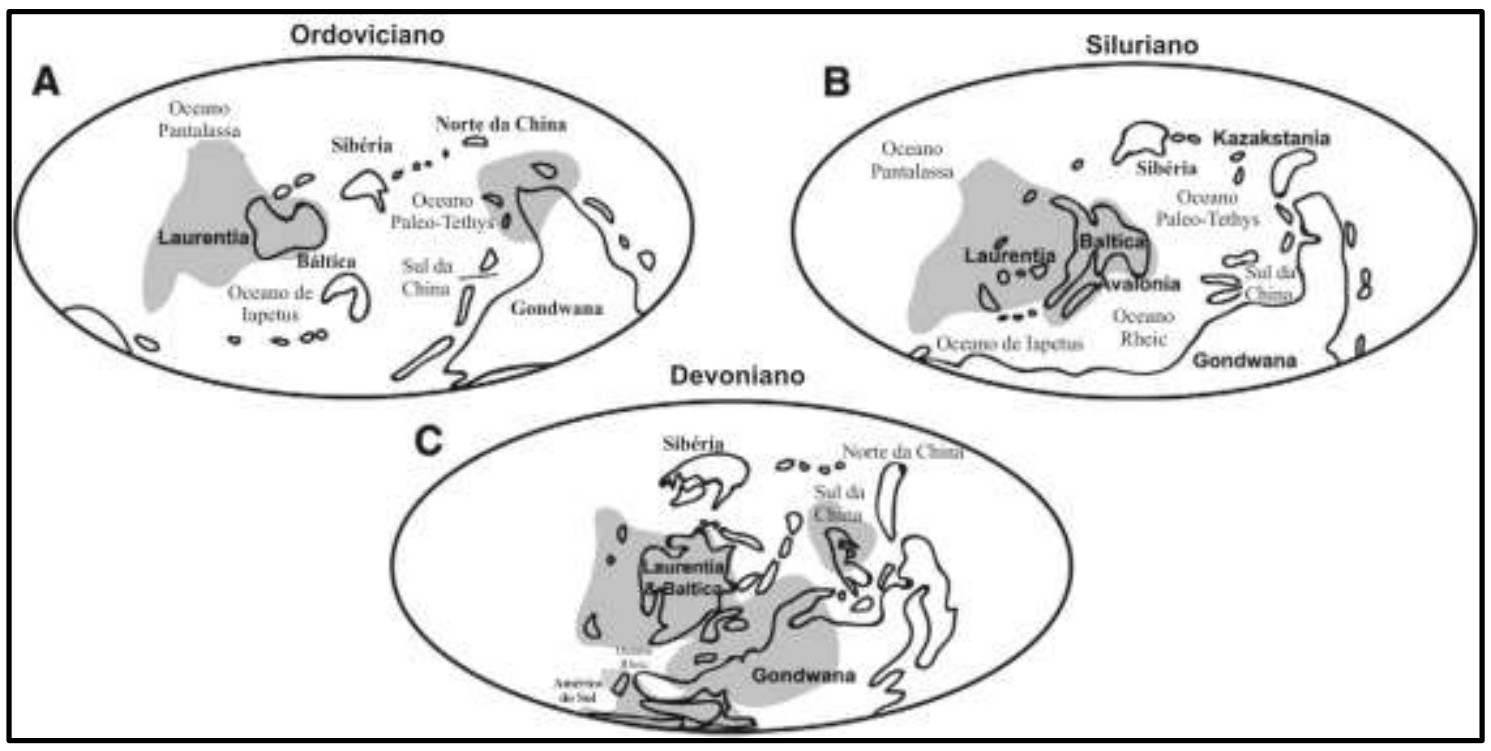

Figura 8. Distribuição paleogeográfica dos tentaculitoideos durante o Ordoviciano, Siluriano e Devoniano (Modificado de WITTMER; MILLER, 2011).

Na América do Sul, os tentaculitoideos mais antigos que se têm registro são do Siluriano, com ocorrências na Argentina, Brasil, Bolívia, Paraguai e Peru (CLARKE, 1899; ISAACSON et al., 1976; BOUCOT et al., 1980; CIGUEL, 1988, 1989; GRAHN, 1992; HEREDIA et al., 2007; MALANCA et al., 2010).

$\mathrm{Na}$ América do Sul, durante o Devoniano, os tentaculitoideos ocorriam na Argentina, Bolívia, Brasil, Chile, Peru e Uruguai (HARTT; RATHBUN, 1875; DERBY, 1890; ULRICH, 1893; VON AMMON, 1893; KATZER, 1897, 1903, 1933; KAYSER, 1897, 1900; SIEMIRADZKI, 1898; CLARKE, 1899, 1913; SCHUCHERT, 1906; KNOD, 1908; BOUCOT et al., 1980; CIGUEL, 1988, 1989).

No Brasil o trabalho de Hartt e Rathbun (1875), estudou o material coletado pela expedição Morgan (1870-1871), foi pioneiro nos estudos acerca dos tentaculitoideos brasileiros. Hartt e Rathbun (1875) estudaram os trilobitas e moluscos devonianos do Pará, neste trabalho descrevem a espécie Tentaculites eldredgianus, para o Devoniano da Bacia do Amazonas.

Pouco tempo depois Derby (1890) e Von Ammon (1893) relataram a ocorrência de um exemplar de Tentaculites em estratos do Devoniano, no estado de Mato Grosso, porém poucos detalhes quanto o espécime encontrado. Von Amon (1893) em seu trabalho com o Devoniano do Mato Grosso, Bacia do Paraná, cita a ocorrência da espécie Tentaculites bellulus Hall, 1879. Embora, esta espécie T. bellulus descrita por 
Hall (1879) para o Devoniano de Nova Iorque, não tenha sido reconhecida em nenhum dos materiais analisados.

Derby (1897) em um novo estudo "Reconhecimento do Rio Maecuru" dentre os fósseis por ele mencionados, o tentaculitoideo Tentaculites eldredgianus é referido para a região. Katzer (1897) lista toda a fauna devoniana do rio Maecuru (Bacia do Amazonas), dentre os tentaculitoideos citados: Tentaculites eldredgianus, Tentaculites crotalinus, Tentaculites bellulus Hall, 1879 e Sytiolina clavulus Barrande, 1882. Katzer (1897), ao citar a espécie $S$. clavulus, realiza a primeira menção de um Dacryoconarideo para o Devoniano das camadas brasileiras, até o presente momento apenas o gênero Tentaculites, havia sido mencionado.

Siemiradzki (1898) reconhece o gênero Tentaculites sp. para as camadas devonianas, encontradas na cidade de Ponta Grossa, Paraná, na Bacia do Paraná. Até o presente momento, poucos foram os trabalhos de cunho sistemático com o grupo.

Em 1899a, Clarke, em seu trabalho "Molluscos Devonianos do Estado do Pará, Brazil", apresenta um trabalho com todos os moluscos fósseis os quais foram coletados pela expedição da Comissão Geológica do Império do Brasil (1875-1877), ao longo das Margens do Rio Maecuru e Curuá (Formação Maecuru) durante o ano de 1876. Dentre os espécimes descritos por ele, duas novas espécies de tentaculitoideos são descritas para a região: Tentaculites stubeli e Tentaculites oseryi. Reconhece ainda a espécie Tentaculites eldredgianus Hartt e Rathbun, 1875.

Ainda em 1899b, Clarke descreve a fauna siluriana encontrada em mediações ao rio Trombetas, dentre essas a nova espécie Tentaculites trombetensis.

Katzer (1903) também faz um levantamento dos fósseis encontrados nas camadas devonianas da Bacia do Amazonas. Descreve a espécie Tentaculites tenellus, além de reconhecer as mesmas espécies propostas por Clarke (1899a).

Clarke (1899a) e Katzer (1903) reconhecem de forma pioneira a espécie Tentaculites crotalinus Salter 1856 para as bacias do Amazonas e Parnaíba. Tal espécie tem seu holótipo descrito no Grupo Bokkveld, na África. A presença desse táxon em camadas devonianas brasileiras indicaria uma provável comunicação remota entre essas bacias com o Grupo Bokkveld.

Após análises da diagnose original da espécie, observação de espécimes de $T$. crotalinus encontrados no Devoniano da Bacia do Paraná e examinar as figuras tipo, constatou-se que os espécimes descritos por Katzer $(1897,1903)$ não se referem a $T$. crotalinus, correspondendo apenas ao mesmo gênero Tentaculites sp. As descrições e as 
figuras apresentadas em Katzer $(1897,1903)$ não apresentam as mesmas características morfológicas descritas no original proposto por Salter (1856) como T. crotalinus. O mesmo fato ocorre com a espécie Tentaculites tenellus descrita por Katzer (1897), onde o autor apresenta uma diagnose pobre e figuras de baixa qualidade, o qual dificulta a visualização e análise da espécie. Verificou-se que o espécime não possui características morfológicas distintas o suficiente para a criação de uma nova espécie, com base na descrição da diagnose e na figura de baixa qualidade apresentada em seu trabalho, não foi reconhecida esta espécie em nenhuma das amostras analisadas.

Após um longo período sem trabalhos sobre os tentaculitoideos para as bacias sedimentares brasileiras, Clarke (1913) foi o primeiro a descrever espécies para o Devoniano da Bacia do Paraná: Tentaculites jaculus e Tentaculites crotalinus.

Aproximadamente cem anos se passaram da publicação de Clarke (1913), e seu trabalho ainda se mostra significativo nos estudos dos macroinvertebrados do Devoniano brasileiro. Em 2013 foi publicado o volume comemorativo (revista Terr@ Plural - UEPG) em homenagem ao centenário da publicação de John Mason Clarke (1857-1925).

Após o trabalho de Clarke em 1913, muitos anos se passaram sem a presença de trabalhos significativos para a classe. Foram publicados trabalhos apenas relatando a ocorrência desses organismos em camadas fossilíferas nas Bacias sedimentares brasileiras, tais como Petri (1948), Lange (1954), Lange e Petri (1967), Leonardi (1983) e Petri e Fúlfaro (1983). Kegel (1953) ao trabalhar com os fósseis da Bacia do Parnaíba relata a presença de Tentaculites aff. eldredgianus Hartt e Rathbun 1875, Tentaculites stubeli e Tentaculites sp., encontrados no Devoniano da Formação Pimenteiras.

A partir do começo dos anos 1980, trabalhos de José Henrique Godoy Ciguel ofereceram um grande avanço aos estudos da classe Tentaculitoidea para o Devoniano brasileiro. Seus trabalhos de cunho sistemático, bioestratigráfico e paleogeográfico intensificaram o conhecimento do grupo no Brasil.

Ciguel et al. (1984) após análises de amostras obtidas da Formação Ponta Grossa, registra a primeira ocorrência do gênero Styliolina sp. para a Bacia do Paraná. Melo (1985) trabalhou sobre o Domínio Malvinocáfrico do Devoniano do Brasil. Dentre os grupos de fósseis relatados pelo autor, as espécies Tentaculites sp., proveniente da Bacia do Paraná, Tentaculites sp. (cf. T. eldredgianus), da Bacia do Amazonas e Tentaculites sp. (cf. T. stubeli), para a Bacia do Parnaíba, foram mencionadas. 
Ciguel et al. (1985) apresentam novos estudos sobre a preservação parcial da concha de Tentaculites crotalinus. Por meio de análises com Microscópio Eletrônico de Varredura (MEV), pode ser observado que a concha é formada por carbonato de cálcio, sendo "foliada", constituída por lamelas sobrepostas. Essas características foram essenciais para se chegar à conclusão de que os tentaculitoideos pertencem ao grupo dos Moluscos. No trabalho também são citados, pela primeira vez, os gêneros Homoctenus e Volynites.

Azevedo-Soares (1999) propõe uma nova sistematização da classe Tentaculitoidea para a Formação Ponta Grossa (Bacia do Paraná). A autora afirma que os gêneros e espécies propostos por Ciguel (1989), apenas um gênero (Tentaculites) e duas espécies (T. crotalinus e T. jaculus) são efetivamente encontrados para a região. Segundo Azevedo-Soares (1999), a grande quantidade de gêneros e espécies propostos por Ciguel (1989) não seria viável. Segundo a autora, como o Devoniano estava localizado próximo a baixas latitudes, o que acarretaria um mar frio, não seria possível existir a grande quantidade de gêneros e espécies descritas por Ciguel (1989). Ainda complementa que o fato de serem encontradas amostras em diferentes fácies poderia indicar uma forma de deposição diferenciada, sendo a mesma espécie poderia estar preservada de diferente maneira.

Rodrigues et al. (2001) realizaram um estudo sobre o conteúdo de tentaculitoideos encontrados em afloramentos do município de Jaguariaíva, Formação Ponta Grossa, Devoniano da Bacia do Paraná. Durante a pesquisa, foram realizados estudos sistemáticos, bioestratigráficos e tafonômicos. Dentre as amostras analisadas, a única espécie reconhecida pelos autores foi Tentaculites crotalinus.

Ponciano (2011) realiza um levantamento dos fósseis de macroinvertebrados encontrados no Devoniano da Bacia do Amazonas, pertencentes à Formação Maecuru. Dentre os tentaculitoideos citados pela autora, estão: Tentaculites sp., T. stubeli, T. oseryi e Tentaculites tenellus. 


\section{OBJETIVOS}

O presente estudo tem por objetivos:

- Realizar a revisão sistemática da classe Tentaculitoidea no Devoniano brasileiro;

- Efetuar a elucidação da distribuição geográfica e paleogeográfica da classe;

- Elucidar a distribuição estratigráfica do grupo para as camadas devonianas do Brasil;

- As análises tafonômicas tiveram como objetivo estabelecer a questão da aloctonia ou autoctonia dos tentaculitoideos, indicação de mistura temporal e a distribuição paleobatimétrica dos organismos além das questões energéticas relacionadas à gênese das concentrações fossilíferas. 


\section{MATERIAIS E MÉTODOS}

Para as análises sistemáticas foi analisado material encontrado em coleções científicas, bem como material coletado em atividades de campo.

As coleções técnicas de universidades, museus e instituições de pesquisa analisadas no presente estudo foram:

- Laboratório de Paleontologia da Universidade de São Paulo - Ribeirão Preto (USP) - 12 amostras.

- Núcleo de estudos Paleontológicos e Estratigráficos da Universidade Federal do Rio de Janeiro (UFRJ) - 27 mostras.

- Departamento de Paleoinvertebrados, Setor de Geologia e Paleontologia, Museu Nacional/UFRJ - 55 amostras.

- Laboratório de Paleontologia da Universidade Federal do Paraná (UFPR) - 74 amostras.

- Laboratório de Paleontologia e Sistemática do Instituto de Geociências da Universidade de São Paulo (IGc - USP) - 101 amostras.

- Departamento Nacional de Produção Mineral (DNPM) - 40 amostras.

- Laboratório de Estratigrafia e Paleontologia da Universidade Estadual de Ponta Grossa (UEPG) - 251 amostras.

- Laboratório de Paleontologia de Macroinvertebrados (LAPALMA) da Universidade Estadual Paulista "Júlio de Mesquita Filho" (UNESPBauru) - 153 amostras.

- Laboratório de Estudos de Comunidades Paleozoicas da Universidade Federal do Estado do Rio de Janeiro (UNIRIO) - 97 amostras.

Durante as visitas as coleções, todos os fósseis os quais eram encontrados representantes dos tentaculitoideos foram analisados. $\mathrm{Na}$ maioria dos casos as instituições possuíam o controle de quantas amostras possuíam tentaculitoideos. Em muitas vezes o material encontrava-se com uma classificação a nível específico prévio. As amostras coletadas em campo foram medidas (quando possível), tiradas fotos e analisadas posteriormente no laboratório.

Além das amostras observadas em coleções, foram analisadas amostras coletadas em atividades de campo no município de Doverlândia (GO) e as fornecidas 
para a classificação sistemática pelo colega Msc. Fabio Augusto Carbonaro (FAPESP 2013/ 09683-3), onde desenvolve sua pesquisa de doutoramento.

Para as análises genéricas e específicas foram levados em consideração caracteres morfológicos bem como: formato da concha, presença ou não de anéis, a presença de macro e micro anéis, espessura dos anéis, formatos dos anéis, espaço interanular, formato da câmera embrionária e ângulo de crescimento.

Para as análises tafonômicas foram levadas em consideração apenas as amostras coletadas em novas atividades de campo ou observadas às amostras da coleção do Laboratório de Estratigrafia e Paleontologia da Universidade Estadual de Ponta Grossa (UEPG), onde a maioria das amostras apresentam dados de coleta seguindo técnicas tafonômicas.

Com o intuito de maior profundidade dos dados estratigráficos e tafonômicos, os trabalhos de campo para a coleta de novos exemplares em afloramentos da Bacia do Paraná foram realizados com ênfase em afloramentos do Devoniano Médio que já possuem interpretações embasadas em estratigrafia de sequências. Os novos materiais estão depositados no acervo da coleção Laboratório de Estratigrafia e Paleontologia da Universidade Estadual de Ponta Grossa (UEPG). Também foram realizadas atividades de campo nos municípios de Tibagi e Arapoti, localizados no estado do Paraná, Bacia do Paraná.

A análise tafonômica utilizada teve como objetivo a identificação e quantificação dos diferentes fenômenos que contribuíram para a introdução de tendenciamentos, procurando esclarecer a questão da aloctonia ou autoctonia dos fósseis e da resolução temporal, incluindo-se aí o problema do time-averaging (mistura temporal) na formação dos níveis fossilíferos.

Para as coletas a nível tafonômico, adotou-se o "Protocolo tafonômico/ paleoecológico" proposto por Simões e Ghilardi (2000), com o objetivo de se aprimorar o referencial de coleta de precisão (onde os dados são adquiridos $\mathrm{cm} \mathrm{a} \mathrm{cm} \mathrm{em}$ quadrículas previamente demarcadas, sempre da base ao topo da exposição da rocha, constituindo-se num processo de varredura dos bioclastos e fósseis) dos dados diretamente nos afloramentos, sendo necessários alguns procedimentos inéditos e diferenciados daqueles utilizados para a coleta com o objetivo de caracterização puramente taxonômica. O protocolo foi direcionado por Bosetti (2004), com as seguintes etapas: 
$1^{\text {a }}$ etapa: Envolvem atividades preliminares da pesquisa paleoecológica como, por exemplo, a delimitação do escopo de estudo, os tipos de concentrações fossilíferas, o intervalo estratigráfico e as fácies sedimentares envolvidas.

$2^{a}$ etapa: Inclui as atividades de coleta, localização e reconhecimento no campo.

$3^{\text {a }}$ etapa: Abrange as atividades de laboratório.

$4^{\mathrm{a}}$ etapa: Envolve análise qualitativa, como a descrição das feições tafonômicas.

$5^{\text {a }}$ etapa: Inclui análise quantitativa para os elementos de cada unidade estudada.

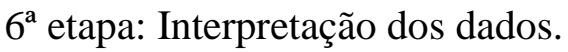

As amostras coletadas foram analisadas: posição em relação ao plano de acamamento, feições tafonômicas, biometria, local de procedência, observação das características morfológicas, como: presença de macroanéis, microanéis, anéis, estrias, presença ou não de câmara embrionária e linhas de crescimento, tipo de sedimento da rocha e associações fossilíferas.

Aproximadamente 10 amostras foram utilizadas para a realização de Espectroscopias de raios-X: Espectroscopia de Energia Dispersiva (MEV-EDS) e Energia Dispersiva de Fluorescência de Raios-X (EDXRF). Dentre as técnicas analíticas para investigar e caracterizar os elementos químicos presentes nos de diversos tipos de materiais, a espectroscopia de energia dispersiva (EDS) e a energia dispersiva por fluorescência de raios X (EDXRF) têm se mostrado muito eficazes, com aplicações bem estabelecidas em diversas áreas científicas. Estas técnicas possuem características vantajosas como a possibilidade de realizar análises em diferentes pontos sobre pequenas áreas, permitindo a comparação entre os elementos químicos dos vários locais de uma mesma amostra (FIGUEIREDO et al., 2011). Ambas as técnicas consistem na detecção de raios-X característicos emitidos pela amostra analisada. Na técnica EDS, a fonte de ionização do material é um feixe de elétrons, enquanto que no EDXRF são utilizados raios-X. As análises com EDXRF podem ser realizadas com equipamentos portáteis (PEDXRF) e/ou utilizando fontes de luz sincrotron. 


\section{GEOLOGIA DAS ÁREAS ESTUDADAS}

\subsection{BACIA DO PARANÁ}

A Bacia do Paraná possui natureza policíclica e uma área de aproximadamente 1.600.000 Km² (MILANI et al., 2007). Estende-se pelo território brasileiro, paraguaio, argentino e uruguaio. A Bacia sedimentar do Paraná (Figura 9) está localizada no continente sul-americano. No Brasil ocorre nos estados do Paraná, Santa Catarina, São Paulo, Rio Grande do Sul, Mato Grosso, Mato Grosso do Sul e Goiás.

De acordo com Assine (1996) a Bacia do Paraná durante o Devoniano estava compartimentada tectonicamente. Os dados de superfície e subsuperfície indicaram que durante aquele momento depositaram-se dois depocentros: a Sub-bacia de Alto Garças ao norte e Sub-bacia Apucarana ao sul (GRAHN et al., 2002). A Sub-bacia Apucarana ocupa áreas hoje correspondentes aos estados de São Paulo, Paraná e Santa Catarina, enquanto que a Sub-bacia Alto Garças ocupa grande parte dos estados do Mato Grosso, Mato Grosso do Sul e a parte sudoeste de Goiás (ASSINE, 1996; MELO, 1988). Melo (1988) afirma que as duas Sub-bacias voltam a ter uma comunicação após as transgressões ocorridas durante o Givetiano.

Segundo Milani e Ramos (1998), a Bacia do Paraná, devido aos aspectos inerentes ao seu posicionamento geotectônico atual e as suas características tectono sedimentares, é considerada uma típica bacia intracratônica. Originada como um golfo aberto para o Panthalassa tornou-se com o tempo uma depressão intracratônica aprisionada no interior do Gondwana (MILANI; RAMOS, 1998). A Bacia do Paraná evoluiu durante o Paleozoico e o Mesozoico e abriga um registro estratigráfico temporalmente posicionado entre neoOrdoviciano e neoCretáceo, documentando quase 400 milhões de anos da história geológica fanerozoica dessa região do planeta.

Milani et al. (2007) reconheceram no registro estratigráfico da bacia do Paraná seis unidades de ampla escala ou supersequências (VAIL et al., 1977), na forma de pacotes rochosos materializando cada um destes intervalos temporais com algumas dezenas de milhões de anos de duração e divididos por superfícies de discordância de caráter inter-regional: Supersequência Rio Ivaí (Ordoviciano-Siluriano), Supersequência Paraná (Devoniano), Supersequência Gondwana I (Carbonífero-EoTriássico), Supersequência Gondwana II (Meso a NeoTriássico), Supersequência Gondwana III 
(NeoJurássico-EoCretáceo) e Supersequência Bauru (NeoCretáceo). As três primeiras são representadas por sucessões sedimentares que definem os ciclos transgressivoregressivos ligados às oscilações do nível relativo do mar no Paleozoico, enquanto que as três últimas correspondem a pacotes de sedimentos continentais com rochas ígneas associadas.
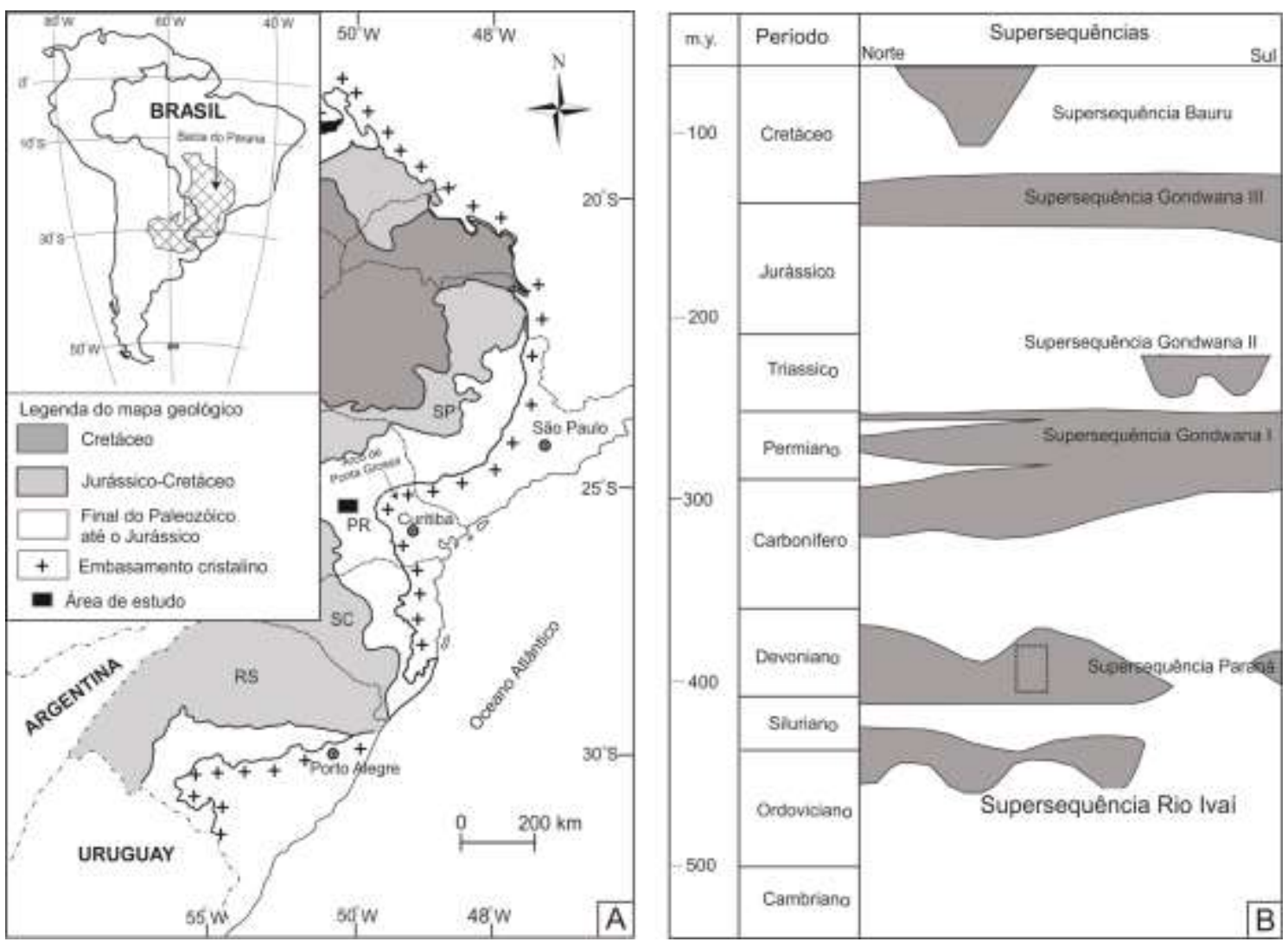

Figura 9. Mapa com a localização do ponto de coleta na Bacia do Paraná, Sub - bacia Apucarana (Modificado de MILANI et al., 2007).

As primeiras tentativas de organização dos estratos devonianos, Bacia do Paraná Sub-bacia Apucarana, do que hoje se compreende como Supersequência Paraná (MILANI, 1997) foram descritas pela primeira vez por Derby (1878). Para Oliveira (1912), é atribuída a pioneira divisão do pacote devoniano da região meridional da bacia, a partir da base em "Grés de Furnas", "Shistos de Ponta Grossa" e "Grés de Tibagi”. Petri (1948) formalizou as unidades devonianas de acordo com o Código Norte Americano de Nomenclatura Estratigráfica propondo as denominações Formações Furnas e Ponta Grossa. Lange e Petri (1967) formalizaram a litoestratigrafia do Devoniano paranaense caracterizando a Formação Furnas e a divisão tripartite da 
Formação Ponta Grossa, constituída, a partir da base, pelos membros Jaguariaíva, Tibagi e São Domingos.

Através de dados de subsuperfície, Northfleet et al. (1969) e Schneider et al. (1974) adotam a designação "Grupo Paraná", para englobar as duas formações, sem mencionarem membros ou fácies, tratando-as como indivisas. Melo (1985) com base na prioridade dos termos através dos dados conferidos por Maack (1947) redefine a unidade superior designando a Formação Santa Rosa com seus respectivos membros: Ponta Grossa, Tibagi e São Domingos (da base para o topo). No entanto, através de dados sedimentares de superfície e subsuperfície e datações relativas atualizadas, Grahn (1992, 2005), Grahn et al. (2000, 2002), Gaugris e Grahn (2006), Grahn et al. (2010a), Grahn et al. (2013) e Mendlowicz Mauller et al. (2009) reclassificaram a sucessão devoniana do estado do Paraná como Grupo Campos Gerais, sendo dividido a partir da base em Formação Furnas, Formação Ponta Grossa e Formação São Domingos (incluso o Membro Tibagi). Esta é a nomenclatura litoestratigráfica utilizada para o presente trabalho (Figura 10).

De acordo com Milani et al. (2007) a evolução da Sub-bacia Alto Garças (Figura 11) ocorreu de maneira distinta da Sub-bacia Apucarana. Embora o ambiente deposicional dessas Sub-bacias seja marinho, na Sub-bacia Alto Garças era mais raso, a qual apresenta, proporcionalmente, mais ocorrências de siltitos e de rochas arenosas (GRAHN et al., 2010b). 


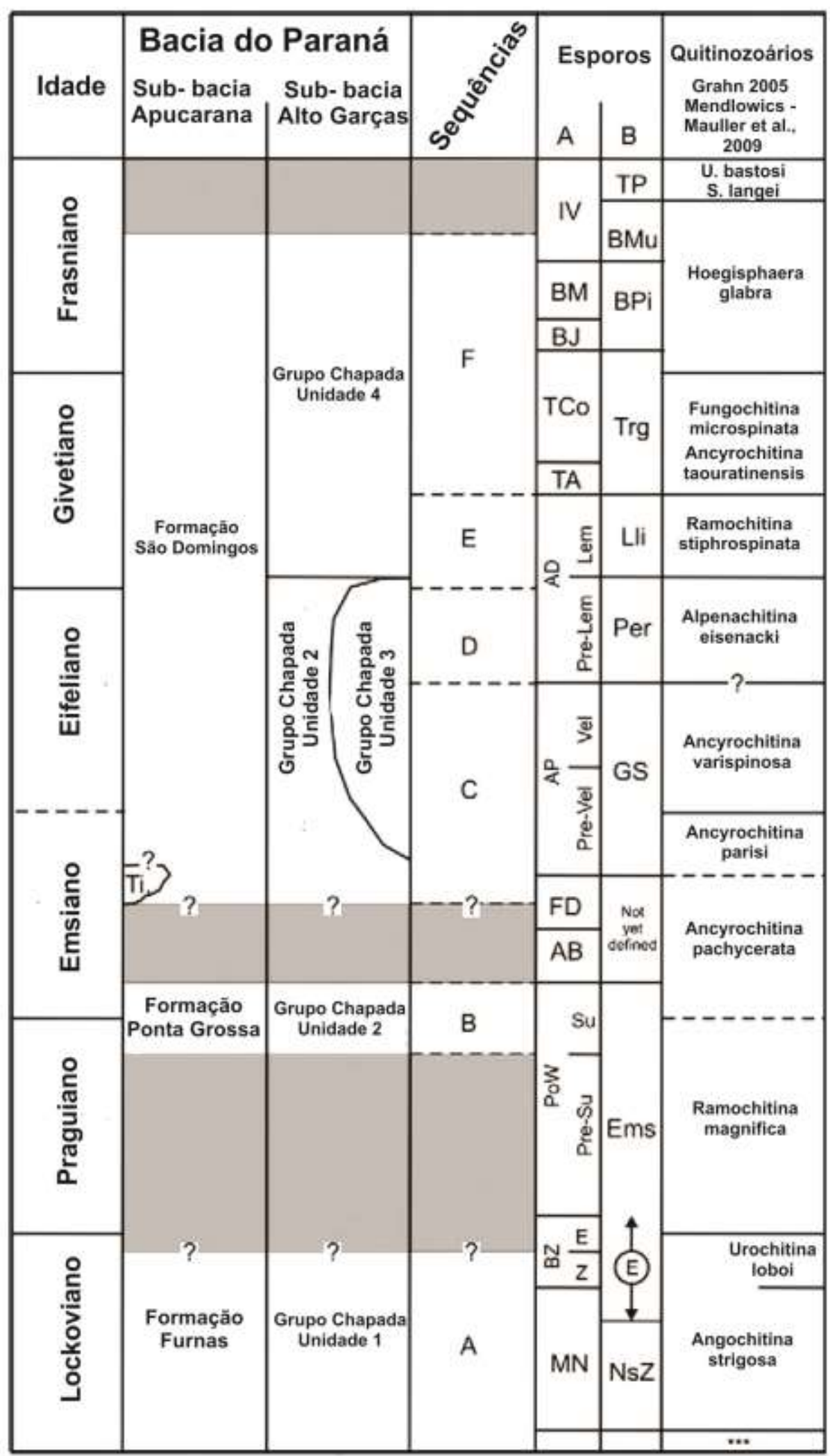

Figura 10. Posição estratigráfica das Sub-bacias Apucarana (Formação Furnas, Ponta Grossa e São Domingos) e Alto Garças (Unidades 1, 2, 3 e 4), de onde foram analisados os fósseis encontrados (Modificado de GRAHN et al., 2013). 


\subsubsection{Sub-bacia Apucarana}

\subsubsection{Formação Furnas}

Litologicamente é descrita como uma sequência de arenitos quartzosos brancos, de granulação média a grossa, feldspáticos e/ou caulínicos, portadores de estratificação cruzada, aos quais interestratificam-se níveis de conglomerados, sobretudo na porção basal (ASSINE, 1996). Grahn et al. (2010a) descrevem a porção superior da Formação Furnas (Figura 9) como um pacote de arenitos com intercalações de siltitos, representando ambiente fluvio/costeiro (GRAHN et al., 2010a).

A idade da formação corresponde ao intervalo Pridoliano-NeoLochkoviano (GRAHN, 1992; GRAHN et al., 2002; GAUGRIS; GRAHN, 2006; GRAHN et al., 2010a). Com base em evidências sedimentológicas e palinológicas um hiato (4 Ma) foi revelado entre a Formação Furnas e a sobrejacente Formação Ponta Grossa. O limite entre as formações Furnas e Ponta Grossa, constitui uma superfície de ravinamento gerada na transgressão entre o final do Praguiano e o início do Emsiano (GRAHN et al., 2010a).

\subsubsection{Formação Ponta Grossa}

A Formação Ponta Grossa sobrepõe-se à Formação Furnas e consiste em folhelhos argilosos cinzas, micáceos finamente laminados, localmente betuminosos intercalados por pacotes arenosos ou lentes de areia, com wavy ou estruturas do tipo hummocky (GRAHN et al., 2013). Evidencia um ambiente deposicional marinho (GRAHN et al., 2010a), contendo um rico conteúdo fossilífero.

Segundo Grahn (1992), Grahn et al. (2002), Gaugris e Grahn (2006) e Grahn et al. (2010a), a Formação tem idade entre o intervalo NeoPraguiano ao EoEmsiano (Figura 9).

\subsubsection{Membro Tibagi da Formação São Domingos}

O Membro Tibagi está litoestratigraficamente posicionado na base da Formação São Domingos (GRAHN et al., 2013). Este membro tem idade NeoEmsiana (sensu: OLIVEIRA, 1912; GRAHN, 1992; GRAHN et al., 2002; GAUGRIS; GRAHN, 2006; 
GRAHN et al., 2010a) é caracterizado pela presença de arenitos grossos a muito finos, lenticulares e fossilíferos, entremeados em folhelhos sílticos, refletindo um contexto regressivo de progradação de sistemas deltaicos provenientes da borda nordeste, onde é bastante expressivo o aporte dos termos arenosos (ASSINE, 1996; MILANI et al., 2007).

\subsubsection{Formação São Domingos}

A Formação São Domingos é a unidade de topo, sendo constituída por uma sucessão de folhelhos laminados de cor cinza, às vezes betuminosos, com intercalações de camadas de arenitos finos a grossos e de arenitos conglomeráticos. Ocorrem acamamento wavy e estruturas do tipo hummocky (GRAHN et al., 2013). Tem idade entre o NeoEmsiano a MesoFrasniano ( GRAHN et al., 2013). A passagem Eifeliano/Givetiano representa uma expansão do sítio deposicional, sendo o registro do pico máximo de transgressão no Devoniano da bacia evidenciado por meio de folhelhos pretos afossilíferos (GRAHN et al., 2013; HORODYSKI et al., 2014).

\subsubsection{Sub-bacia Alto Garças}

\subsubsection{Grupo Chapada}

Embora a denominação do Grupo Chapada (Figura 11) tenha sido introduzida por Evans (1894), o reconhecimento desta denominação veio muitos anos depois. Andrade e Camarço $(1980,1982)$ identificaram as unidades de Evan (1894), referindo se a elas como Formação Furnas (camadas inferiores) a Formação Ponta Grossa (membros superiores). Melo (1988) revalidou o Grupo Chapada e o dividiu em quatro unidades (Unidade 1, 2, 3 e 4), sendo as quatro unidades definidas anteriormente por Andrade e Camarço (1980). 


\subsection{Unidade 1}

A unidade 1 possui praticamente a mesma litologia da Formação Furnas, Subbacia Apucarana, porém difere por apresentar um padrão de paleocorrente é consistentemente para o noroeste (GRAHN et al., 2010b), sugerindo que as duas Subbacias já estavam diferenciadas antes da transgressão marinha ocorrida no Emsiano (MELO, 1988).

Grahn et al. (2010b) sugere idade Lockoviana para esta unidade.

\subsection{Unidade 2}

Esta unidade consiste de um conglomerado basal com arenitos e folhelhos, recoberta por arenitos avermelhados com siltitos e folhelhos intercalados, e para as camadas superiores de arenito cinzento-avermelhados (GRAHN et al., 2010b). Possui espessura aproximada de $270 \mathrm{~m}$.

Possui dois intervalos estratigráficos, na parte inferior da unidade idade NeoPraguiano - EoEmsiano e na parte superior de idade NeoEmsiano - Eifeliana (GRAHN et al., 2010b).

\subsection{Unidade 3}

Segundo Grahn et al. (2010b) a unidade 3 é restrita a parte nordeste da bacia, e é lateralmente substituída por folhelhos e arenitos da parte superior unidade 2 (final do Emsiano - início do Givetiano), em direção ao centro da Sub-bacia do Alto Garças.

Constituída por arenitos avermelhados com níveis conglomeráticos. Os arenitos representam um ambiente deltaico numa plataforma rasa fortemente influenciada por ondas (GRAHN et al., 2010b). A unidade tem espessura máxima de cerca de $250 \mathrm{~m}$ (MELO, 1988).

Idade da unidade 3 sugerida de NeoEmsiano ao Eifeliano (GRAHN et al., 2010b). 


\subsection{Unidade 4}

Consiste em folhelhos cinza escuro, intercalada de arenitos e siltitos argilosos. A espessura atinge cerca de $350 \mathrm{~m}$ na margem noroeste da bacia (GRAHN et al., 2010b).

Segundo Grahn et al. (2010b), as rochas dessa unidade possuem idade Givetiano - EoFrasniano.

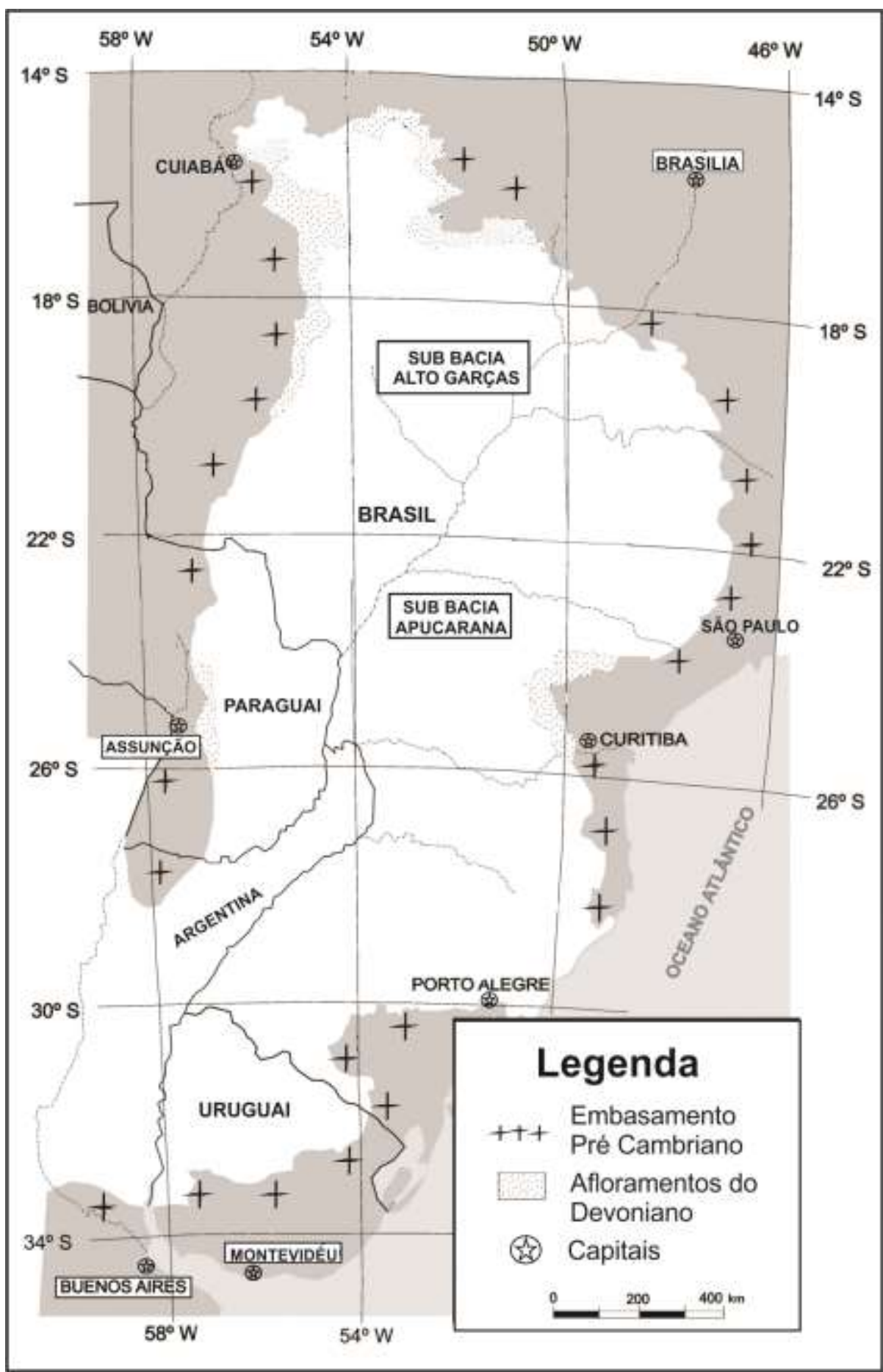

Figura 11. Localização dos afloramentos do Devoniano nas Sub - bacia Apucarana e Sub bacia Alto Garças. (Modificado de GRAHN et al., 2010a). 


\subsection{BACIA DO PARNAÍBA}

A Bacia do Parnaíba (Figura 12) ocupa uma área de aproximadamente 600.000 $\mathrm{km}^{2}$, abrangendo os estados do Piauí, Maranhão, Tocantins, Pará Ceará e Bahia (GOÉS; FEIJÓ, 1994). É limitada ao norte pelo Arco Ferrer - Urbano Santos, a noroeste pelo Arco de Tocantins e ao sul pelo Arco de São Francisco (LOBOZIAK et al., 2000; VAZ et al., 2007).

A Bacia da Parnaíba desenvolveu-se sobre um embasamento continental durante a estabilização da Plataforma Sul-Americana (ALMEIDA; CARNEIRO, 2004). A origem ou subsidência inicial da Bacia do Parnaíba provavelmente esteja ligada às deformações e eventos térmicos fini e pós- orogênicos do Ciclo Brasiliano ou ao Estádio de Transição da plataforma, utilizando-se a terminologia de Almeida e Carneiro (2004).

De acordo com Vaz et al. (2007) a sucessão de rochas sedimentares e magmáticas da Bacia do Parnaíba pode ser disposta em cinco supersequências: Siluriana (Grupo Serra Grande), Mesodevoniana-eoCarbonífera (Grupo Canindé), neoCarbonífera-eoTriássica (Grupo Balsas), Jurássica (Formação Pastos Bons) e Cretácea (formações Codó, Corda, Grajaú e Itapecuru), sendo delimitadas por discordâncias que se estendem por toda a bacia ou abrangem regiões extensas. $O$ Devoniano da Bacia do Parnaíba encontra-se com a maior expressão e o maior registro geocronológico das bacias paleozoicas brasileiras (MELO, 1985).

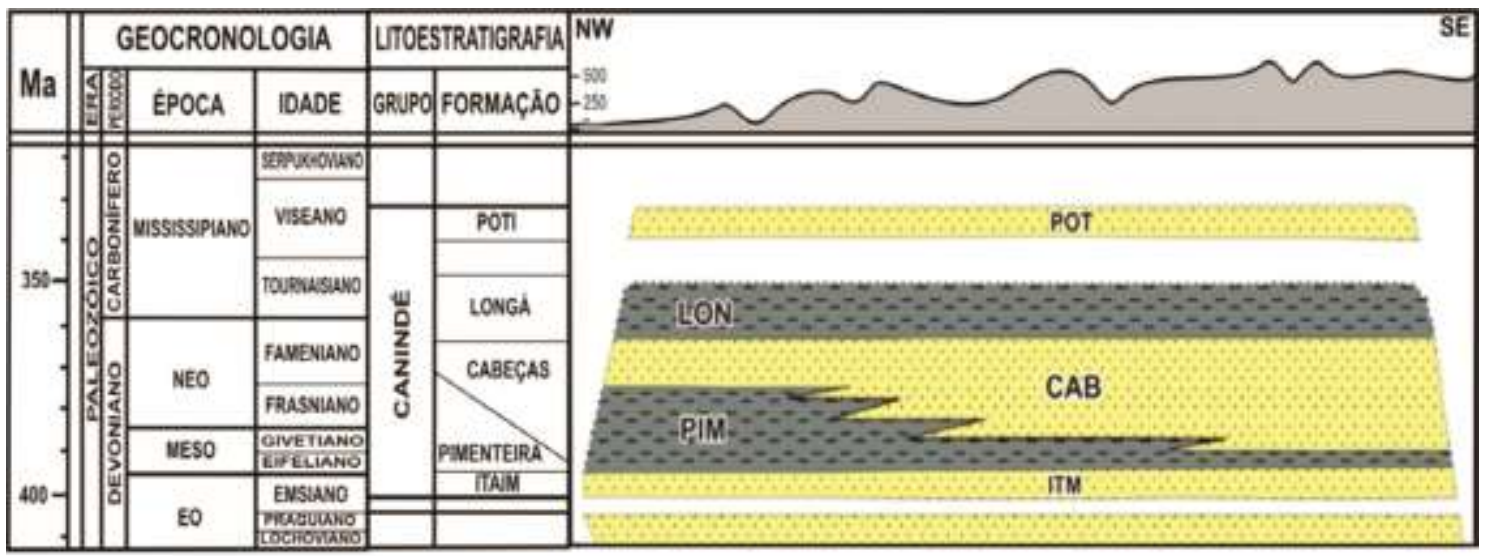

Figura 12. Carta estratigráfica da sucessão devoniana - carbonífera da Bacia do Parnaíba (Segundo SCHEFFLER, 2010). 


\subsubsection{Formação Pimenteira}

As seções aflorantes da Formação Pimenteira (Figura 13) são compostas por folhelhos cinza-escuros, esverdeados, em parte bioturbados, intercaladas com siltitos e arenitos grossos a finos, este normalmente apresentando estratificação cruzada do tipo hummocky (FONSECA, 2004; VAZ et al., 2007).

Constitui um trato de sistemas transgressivos depositados principalmente em ambientes marinhos rasos sob a influência eventual de ondas de tempestades, representando a ingressão marinha mais importante da bacia (FONSECA, 2004; SANTOS; CARVALHO, 2004; VAZ et al., 2007).

Os contatos das formações Pimenteira com as formações Itaim e Cabeças, respectivamente, são frequentemente interpretados como concordantes e gradacionais (CAPUTO, 1984; MELO, 1985; DELLA FÁVERA, 1990).

Conforme Grahn et al. (2006) a idade da Formação Pimenteira é do Eifeliano médio até o Fameniano inicial.

\subsubsection{Formação Cabeças}

Segundo Vaz et al. (2007) na passagem da Formação Pimenteira para a Formação Cabeças (Figura 13) as feições grafoelétricas indicam uma mudança de tendência transgressiva para regressiva.

Em Picos, Kegel (1953), definiu o limite inferior do Membro Passagem no primeiro banco espesso de arenito no perfil Picos-Oeira, que forma uma escarpa constituída por um arenito grosso, esbranquiçado, com estratificação cruzada em bancos espessos. Estes arenitos estão recobertos por aproximadamente $20 \mathrm{~m}$ de arenitos micáceos de granulometria fina a média, macrofossilíferos, amarelados e arroxeados, com delgadas intercalações de siltitos.

Grahn et al. (2006) determinam idade fameniana para a Formação Cabeças. 


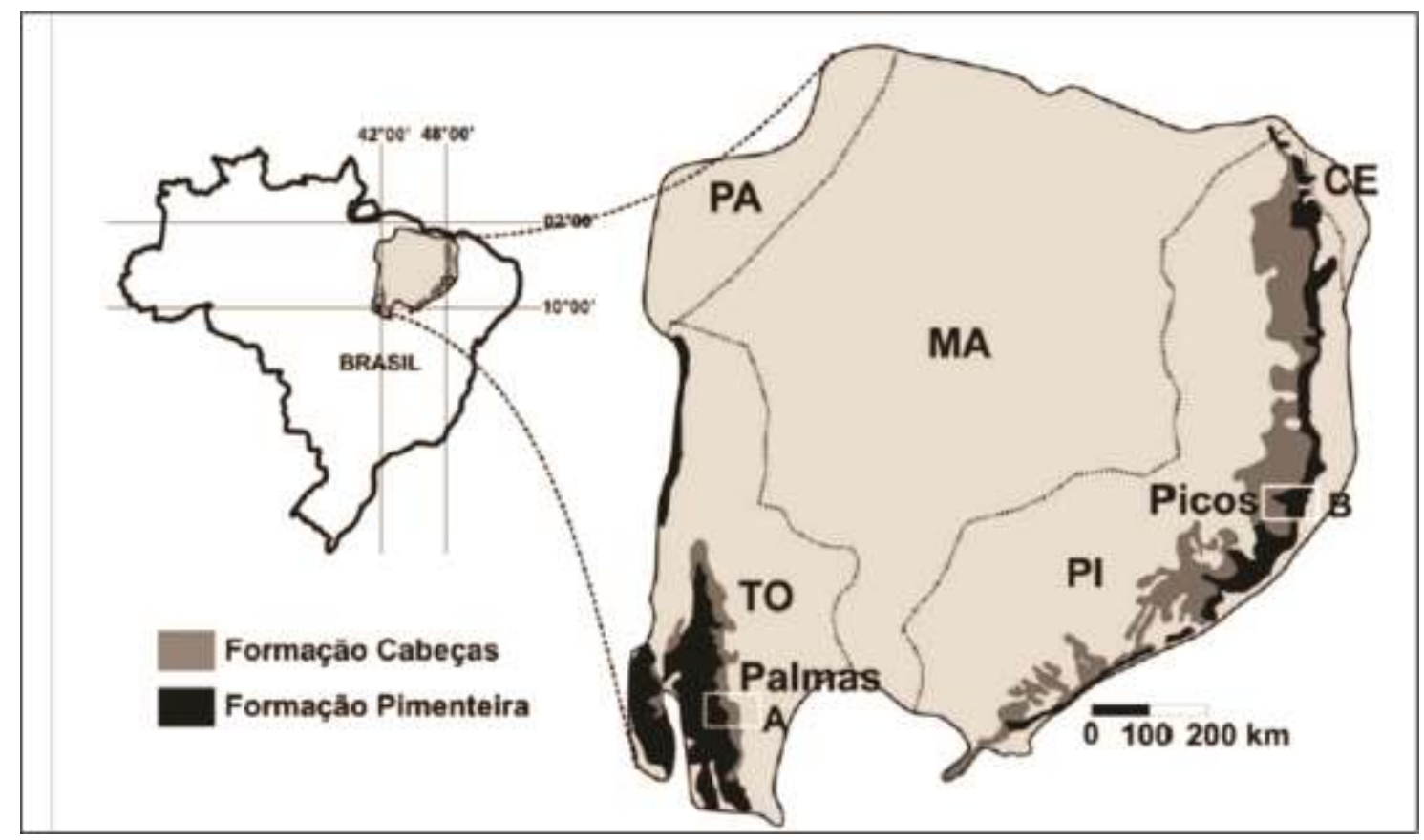

Figura 13. Mapa com a localização das Formações Cabeças e Pimenteiras na Bacia do Parnaíba. Informações cedidas pela prof. Dr. Deusana Machado (Modificado de SCHEFFLER, 2010).

\subsection{BACIA DO AMAZONAS}

A Bacia do Amazonas (Figura 14) está situada entre os crátons das Guianas ao norte e do Brasil ao Sul, possui área de aproximadamente $500.000 \mathrm{~km}^{2}$. Abrange parte dos estados do Amazonas e Pará e separa-se a leste da bacia tafrogênica do Marajó através do Arco de Guarupá, e a oeste da Bacia do Solimões pelo Arco de Purus (CUNHA et al., 2007).

Segundo Cunha et al. (2007) o registro sedimentar e ígneo da Bacia do Amazonas nada mais é que um reflexo tanto das variações eustáticas do nível do mar quantos dos eventos tectônicos paleozoicos ocorrentes na borda oeste da pretérita placa gondwânica. O arcabouço estratigráfico da Bacia do Amazonas apresenta duas importantes megassequências de primeira ordem, que totalizam cerca de $5.000 \mathrm{~m}$ de preenchimento sedimentar e ígneo. Supersequência paleozoica, constituída por rochas sedimentares de naturezas variadas, associadas a um grande volume de intrusões de diques e soleiras de diabásio mesozoicos, e uma mesozoico-cenozoica sedimentar (CUNHA et al., 2007). 


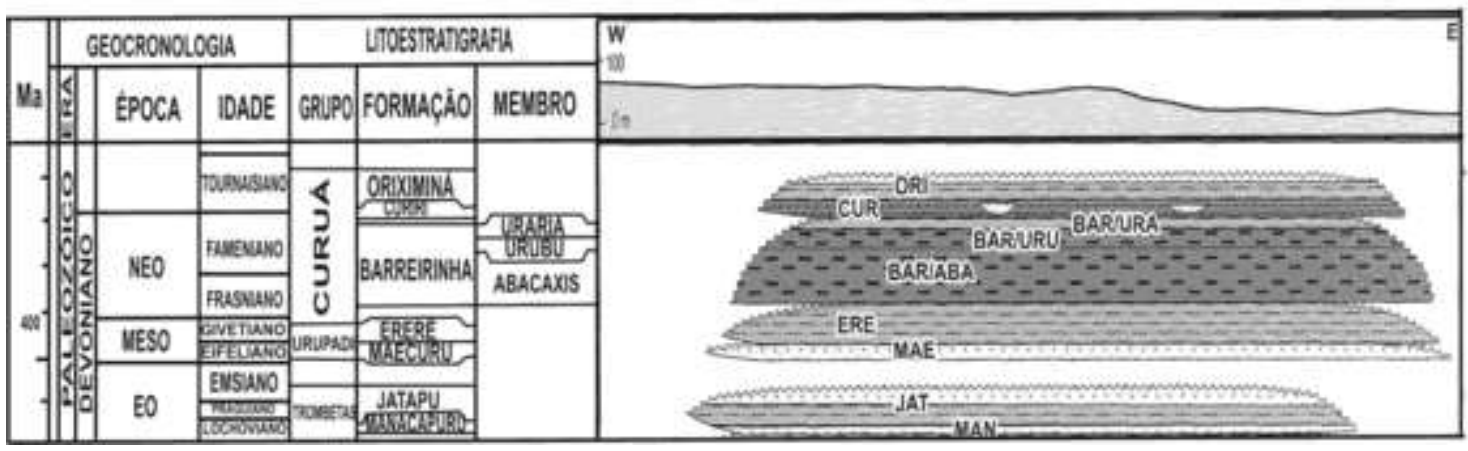

Figura 14. Carta estratigráfica da Bacia do Amazonas (Segundo SCHEFFLER, 2010).

Foram descritas as características gerais das Formações Maecuru e Ererê, onde foram encontrados representantes dos tentaculitoideos nesse estudo (Figura 15).

\subsubsection{Formação Maecuru}

Constituída por arenitos finos a grossos, ferruginosos, em parte bioturbados e fossilíferos, silificados, possuindo fácies flúvio-deltaica nas bordas da bacia, passando para finos de fácies estuarinas, ilhas de barreiras e shoreface dominado por onde em direção ao eixo deposicional da bacia (CUNHA et al., 2007).

Conforme datações palinológicas dos sedimentos flúvio-deltaicos a neríticos da Formação Maecuru, consideram-na de idade Emsiana a Eifeliana (LOBOZIAC; MELO, 2000, 2002).

\subsubsection{Formação Ererê}

Constituída por siltitos, arenitos e folhelhos fossilíferos bioturbados, comumente apresentado estruturas wavy-linsen e hummocky nos psamitos, com os pelitos predominando na porção meso-inferior e os psamitos na porção superior (CUNHA et al., 2007).

Segundo Cunha et al. (2007) apresenta distribuída por toda a bacia do Amazonas, inclusive aflorando nas bordas norte e sul, possuindo fácies de deltas e plataformas dominadas por tempestades.

Datações recentes indicam idade NeoEifeliana a EoGivetiana (LOBOZIAC; MELO, 2000; 2002). 


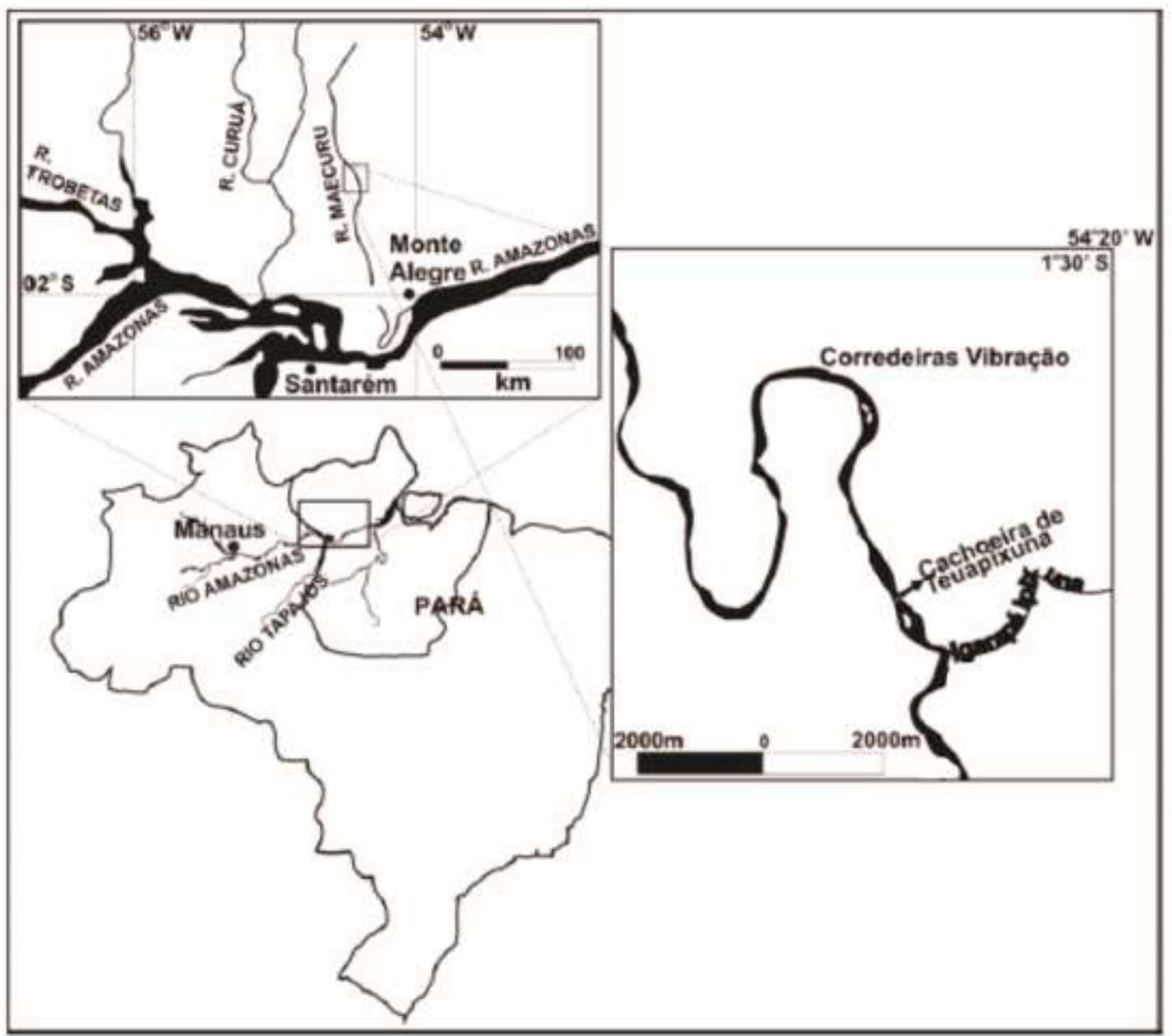

Figura 15. Localização dos afloramentos na Bacia do Amazonas onde foram encontrados amostras com tentaculitoideos. Informações cedidas pela prof. Dr. Deusana Machado (Modificado de SCHEFFLER, 2010). 


\section{RESULTADOS}

\subsection{PALEONTOLOGIA SISTEMÁTICA}

Após reanálise dos espécimes das coleções, a revisão sistemática dos tentaculitoideos brasileiros demonstrou 4 gêneros e 12 espécies, as quais serão discutidas abaixo.

Classe Tentaculitoidea Lyashenko, 1957

Ordem Tentaculitida Lyashenko, 1955

Família Tentaculitidae Walcott, 1886

Gênero Tentaculites Schlotheim, 1820

Tentaculites crotalinus Salter, 1856

Fig. 16

1856 Tentaculites crotalinus Salter, 1856, p. 222, estampa 25, figs. 15-18.

1913 Tentaculites crotalinus Clarke, 1913, p. 86-87, estampa 8, figs. 1-4.

1913 Tentaculites crotalinus Kozlowski, 1913, p. 11, estampa 2, fig. 15.

1925 Tentaculites crotalinus Reed, 1925, p. 118.

1933 Tentaculites crotalinus Katzer, 1933, p. 190, fig. 27a, b.

1989 Uniconus crotalinus Ciguel, 1989, p. 80, fig. 34.

1999 Tentaculites crotalinus Azevedo-Soares, 1999, p. 82, estampa 1 e 2 , figs. 1-6.

Espécie tipo: Tentaculites crotalinus Salter, 1856.

Holótipo: Salter (1856). Pl. XXV, figuras 15 - 18.

Ementa específica: Tubos ornamentados comprimentos variando entre 0,9 a 2,5 cm. Os espécimes apresentavam anéis discoides arredondados, salientes, assimétricos, pouco espessos, os quais vão aumentando o tamanho da parte proximal a parte distal de maneira gradual. Os interespaços são levemente côncavos a planos, e aumentam de tamanho proporcionalmente da região proximal até a região da distal. Os interespaços correspondem aproximadamente duas a três vezes a espessura dos anéis na região adulta e na abertura, enquanto na região juvenil aproximadamente uma a duas vezes. Averiguou a presença de microanéis nas regiões adulta e da abertura. Verificou-se que 
em alguns espécimes os anéis da região adulta encontram-se levemente oblíquos, se comparados com os anéis da região juvenil. A anelação inicia-se logo no final da parte apical. Em alguns casos nota-se a região juvenil e a parte apical levemente encurvada. No final da região da abertura nota-se que nesta região apresenta-se "reta", sem ser encurvada como em outras espécies que serão descritas posteriormente. A câmara embrionária afunilada com formato fortemente pontiagudo. Não foram encontradas estrias em nenhum dos espécimes. Ângulo de crescimento entre 3 a 7 graus.

Discussão: Clarke (1899) e Katzer (1903) reconhecem de forma pioneira a espécie Tentaculites crotalinus para as bacias do Amazonas e Parnaíba. Assim como Clarke (1913) reconhece a espécie para a Bacia do Paraná. Tal espécie tem seu holótipo descrito para o Devoniano do Grupo Bokkveld, na África (SALTER, 1856). Apesar do não reconhecimento da espécie pelo árduo trabalho de Ciguel (1989), os espécimes analisados possuem os anéis arredondados regulares, nítidos, interespaços de tamanhos iguais, que são caracteres do táxon. Ciguel (1989) propõe a transferência para o gênero Uniconus Lyashenko (1955), porém a característica marcante deste gênero seriam os anéis assimétricos voltados para a região da abertura, o que não foi verificado em nenhuma das amostras relacionadas por Ciguel (1989). Dessa forma, prefere-se pontuar a existência dessa espécie dentro do domínio Malvinocáfrico devoniano brasileiro. Difere das outras espécies de Tentaculites descritos nesse trabalho, por apresentar espessamento dos anéis gradativo, porém proporcionalmente, e também o fato de serem encontrados alguns anéis na região da abertura com certo grau de obliquidade, demonstram essas características marcantes para esta espécie.

Distribuição Geográfica: Afloramentos nos municípios de Jaguariaíva (afloramento estrada de ferro Jaguariaíva-Arapoti (S 240 14' 05', W 49 42' 34'”)), Palmeira (afloramento Rio Caniú (S $25^{0} 18$ ' 48', W $50^{\circ} 05^{\prime}$ 32',)) Tibagi e Ponta Grossa (afloramentos Vila Francelina (S 25 04' 55', W $50^{\circ} 06^{\prime}$ 54',; Fazenda Rivadávia (S $25^{0} 15^{\prime} 05,47^{\prime}$; W W $\left.50^{\circ} 03^{\prime} 06,21^{\prime \prime}\right)$ )). Já registrada em afloramentos do Devoniano da África do Sul, Bolívia e Paraguai.

Distribuição Estratigráfica: NeoPraguiano - NeoEmsiano

Material estudado: As amostras estão depositadas na coleção da Universidade Federal do Paraná, UFPR, (NR 1751, 6057, 7420 e 9840), Instituto de Geociências da Universidade de São Paulo, Igc- USP, (GP/ 1E 1301, 1308 e 1312), Universidade Federal do Estado do Rio de Janeiro, UNIRIO (Unirio 94), Laboratório de Estratigrafia e Paleontologia, UEPG (MPI 1078, 2077, 8644, 8711, 9276, 9840, e 9842), 
Departamento Nacional de Produção Mineral (DGM 1881 e 353) e Laboratório de Paleontologia de Macroinvertebrados, UNESP (CCLP 1, 11, 21, 31, 39, 52).

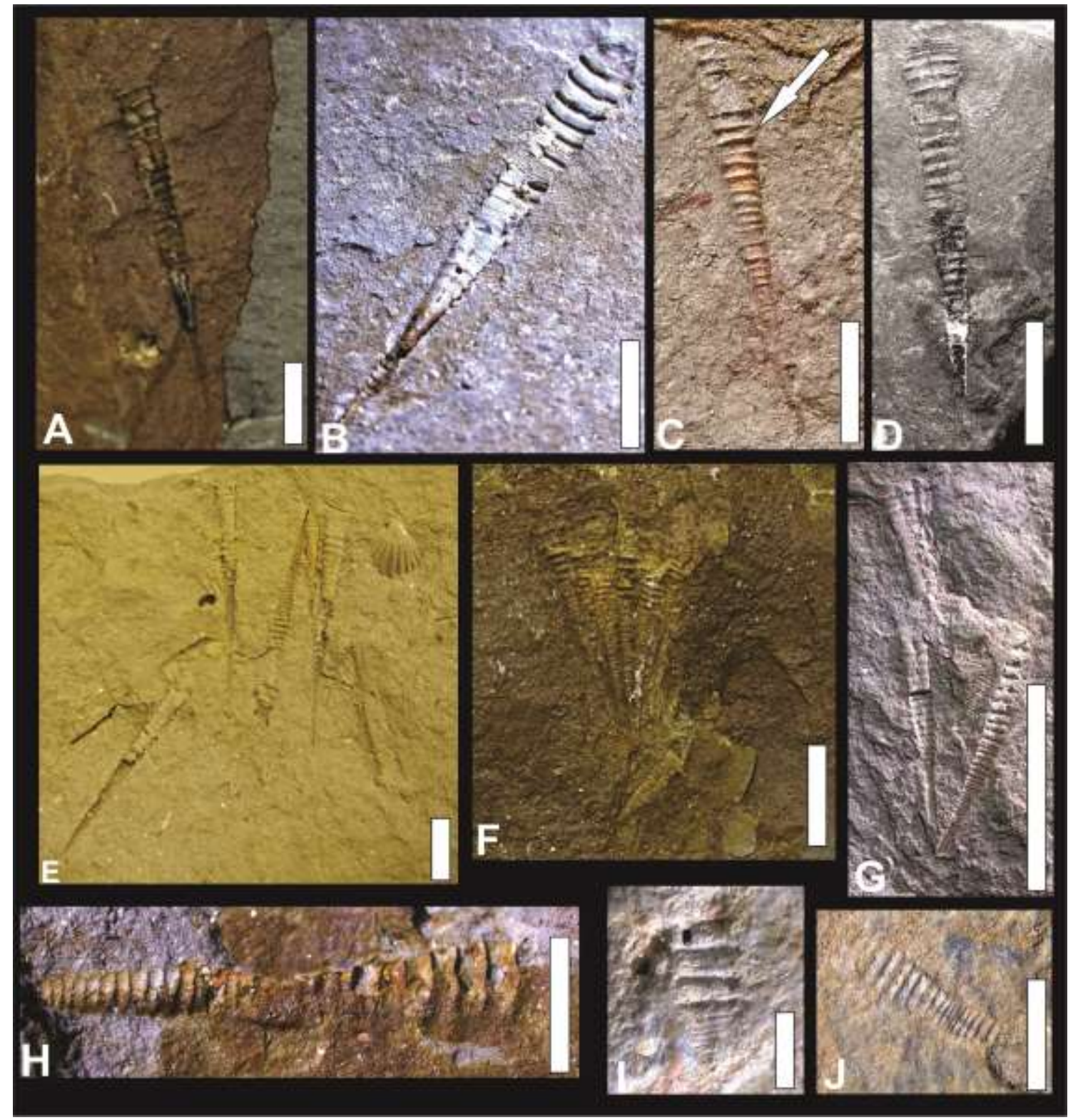

Figura 16. Espécimes de Tentaculites crotalinus observados em coleções científicas. A) Igc 1/E 1308. B) CCLP 11. C) NR 7420. D) NR 6057. E) NR 8634. F) CCLP 23. H) CCLP 21. I) MPI 9842. Na figura $\mathrm{C}$, a flecha demonstra os macroanéis dispostos irregularmente e de tamanhos irregulares, característica encontrada nesta espécie. (Escala 0,5 cm).

Tentaculites jaculus Clarke, 1913

Fig. 17

1913 Tentaculites jaculus Clarke, 1913, p. 88-89, estampa, figs. 5-6.

1989 Seretites jaculus Ciguel, 1989, p. 74, fig. 31. 
1999 Tentaculites jaculus Azevedo-Soares, 1999, p. 88-90, estampa 3, figs. 1-6.

Espécie tipo: Tentaculites jaculus Clarke, 1913.

Holótipo: Clarke (1913). Estampa VIII, figs 5 e 6.

Ementa específica: Conchas com comprimento aproximado entre 1,1 a 3,7 cm. Anéis discoides arredondados, inexpressivos, dispostos em tamanhos irregulares ao longo da concha. A presença da ornamentação começa próximo ao meio da concha. Interespaços rasos, lisos. Os interespaços correspondem, praticamente, a mesma espessura que os anéis, estão dispostos irregularmente, sendo que alguns momentos os interespaços da região adulta mostram-se maiores. Raros microanéis, quando aparecem estão na região adulta e da abertura. O diâmetro das partes distal é maior do que em $T$. crotalinus. A região apical encontra-se desprovida de ornamentações. Câmara embrionária pontiaguda, porém não tão afunilada como outros representantes desse gênero. Ângulo de crescimento aproximado de 8 a 9 graus.

Discussão: Ciguel (1989), sinonimiza esta espécie proposta por Clarke (1913) como sendo pertencente ao gênero Seretites Lyashenko (1969). Azevedo-Soares (1999) cita em sua dissertação a não concordância com esta mudança de gênero, reconhecendo a espécie como Tentaculites jaculus. Após análise do holótipo e parátipos da espécie, aqui é reafirmado que o táxon possui características morfológicas adequadas para pertencer ao gênero Tentaculites, e não ao gênero Seretites. Segundo Ciguel (1989), Seretites apresentaria a região da câmara embrionária e juvenil lisa, sendo esta uma característica autapomórfica ao gênero, porém esta característica morfológica não é apresentada na diagnose do gênero e em nenhum dos espécimes, já descritos. Sendo assim, os presentes autores optaram em manter a espécie Tentaculites jaculus Clarke, 1913, não realizando a transferência do gênero como proposta por Ciguel (1989). A espécie $T$. jaculus difere da espécie $T$. crotalinus, pela disposição da ornamentação na concha, diâmetro distal maior, interespaços menores e câmara embrionária com ângulo de crescimento mais elevado do que em $T$. crotalinus.

Distribuição Geográfica: Afloramento dos municípios de Jaguariaíva (afloramento estrada Jaguariaíva-Arapoti (S 24 14' 05', W $49^{0} 42^{\prime}$ 34')), Palmeira (afloramento Rio Caniú (S $25^{0} 18$ ' 48', W $50^{0} 05^{\prime}$ 32' ')), Tibagi e Ponta Grossa (afloramentos Aeroporto (S $25^{\circ} 08$ ' 57, 94', W 50 08' 43, 16", e Fazenda Rivadávia (S $25^{0} 15^{\prime} 05,47^{\prime}$; W $50^{0} 03^{\prime} 06,21^{\prime}$ '))). Esta espécie já foi descrita para o Devoniano do Paraguai e Peru. 
Distribuição Estratigráfica: NeoPraguiano - NeoEmsiano.

Material estudado: As amostras estão depositadas na coleção da Universidade Federal do Paraná, UFPR, (NR 1751 e 3401), Laboratório de Estratigrafia e Paleontologia, UEPG (MPI 9812, 9821, 9835, 9836, 9837 e 9842), Departamento Nacional de Produção Mineral (DGM 1540 e 3), Instituto de Geociências da Universidade de São Paulo, Igc- USP, (GP/ $1 E 1292$ e 3602), Museu Nacional, Universidade Federal do Rio de Janeiro, UFRJ (MN 2744, 6453 e 7052) e Núcleo de estudos Paleontológicos-UFRJ (13te).

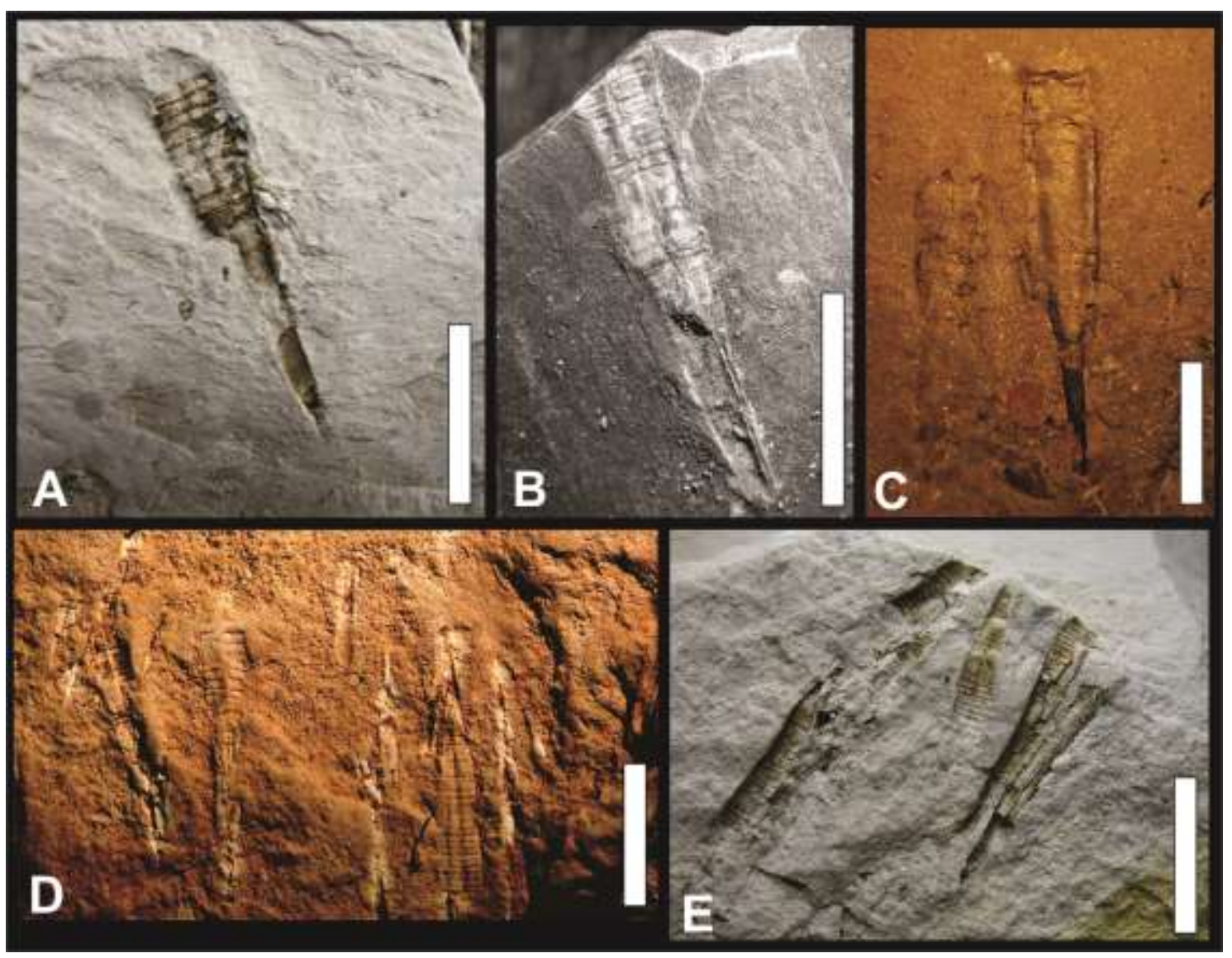

Figura 17. Tentaculites jaculus observados nas coleções científicas. A) UNIRIO 104 te. B) MPI 9836. C) MN 6453. D) MN 7042. E) UNIRIO 1 te. (Escala 1,0 cm).

Tentaculites kozlowskius sp. nov.

Fig. 18

1989 Tentaculites kozlowskiensis Ciguel, 1989, p. 52, fig. 16.

Espécie tipo: Tentaculites kozlowskius sp. nov. 
Holótipo: MPI 9837 depositadas no acervo do Laboratório de Estratigrafia e Paleontologia, Universidade Estadual de Ponta Grossa (UEPG).

\section{Diagnose:}

Concha cuneiforme anelada. Anéis discoides arredondados, espessos salientes, homomorfos, heterolongitudinais com crescimento proporcional. Espaços profundos, côncavo a suavemente côncavo, distância e crescimento proporcional. Microanéis pouco comuns, porém quando ocorrem distribuem se irregularmente na região da abertura e mediana. Ápice cônico tenuemente anelado. Câmara embrionária pontiaguda. (Ciguel, 1989. p. 52).

Ementa específica: Concha cuneiforme ornamentada, de poucas dimensões. Comprimento varia de 0,6 até $1,2 \mathrm{~cm}$. Possuem anéis discoides arredondados, levemente salientes, anéis dispostos com pouco aumento de tamanho da região proximal até a região distal. Outra característica marcante, em alguns espécimes os interespaços na região juvenil eram bem menores se comparados com os interespaços da região adulta. Na região adulta os interespaços podem chegar a duas vezes o tamanho dos anéis. Bem como, uma maior concentração de anéis na região juvenil. Espaço interanular planos a levemente côncavos. Os microanéis são raros, quando ocorrem, aparecem na região da adulta e da abertura. A região apical é geralmente anelada. Câmera embrionária levemente pontiaguda, mais parecida com a câmera de T. jaculus, do que com $T$. crotalinus. Possuem ângulo de crescimento de aproximadamente entre 7 a 8 graus.

Discussão: A espécie T. kozlowskius possui características como anéis espessos e proeminentes, interespaços côncavos com distâncias irregulares ao longo da concha isso que o distinguem de outros táxons analisados. A nomenclatura proposta pelos autores foi mantida, apesar das espécies que estão sendo descrito apenas em dissertações, para evitar interpretações erradas. O sufixo do epíteto específico foi alterado para precisão gramatical. Esta espécie difere de T. crotalinus por apresentar interespaços menores, anéis dispostos irregularmente e ângulo de crescimento maior. O espécime difere é Tentaculites eldredgianus por apresentar anéis através da concha. Também diferem de Tentaculites trombetensis por apresentar anéis maiores, finos e menos expressivos e de Tentaculites oseryi para apresentar anéis mais finos e mais espaços mais largos. 
Etimologia: Homenagem a Roman Kozlowski, pesquisador polonês que estudou os fósseis devonianos do Paraná em 1913.

Distribuição Geográfica: Afloramento dos municípios de Jaguariaíva, Jaguariaíva (afloramento estrada de ferro Jaguariaíva-Arapoti (S $24^{0} 14^{\prime} 05^{\prime}$ '; W $49^{0}$ 42' 34',)), Palmeira (afloramento Rio Caniú (S $25^{\circ} 18^{\prime} 48^{\prime \prime}$; W $50^{0} 05^{\prime} 32$ '’)) e Ponta Grossa (afloramentos Fazenda Rivadávia (S $25^{0} 15^{\prime}$ 05, 47', W $50^{0} 03$ ' 06, 21',) e Curva I (S 25 03' 34, 56'; W 50 08' 04, 09'”)).

Distribuição Estratigráfica: NeoPraguiano - NeoEmsiano

Material estudado: A amostra "05 te" está depositada no Núcleo de estudos paleontológicos e estratigráficos da Universidade Federal do Rio de Janeiro (UFRJ), GP/ 1E 1285 e 1293 deposited in Instituto de Geociências da Universidade de São Paulo, Igc - USP, Laboratório de Estratigrafia e Paleontologia, UEPG (MPI 1159, 2077, 9832, 9837, 9864 e 10335). 


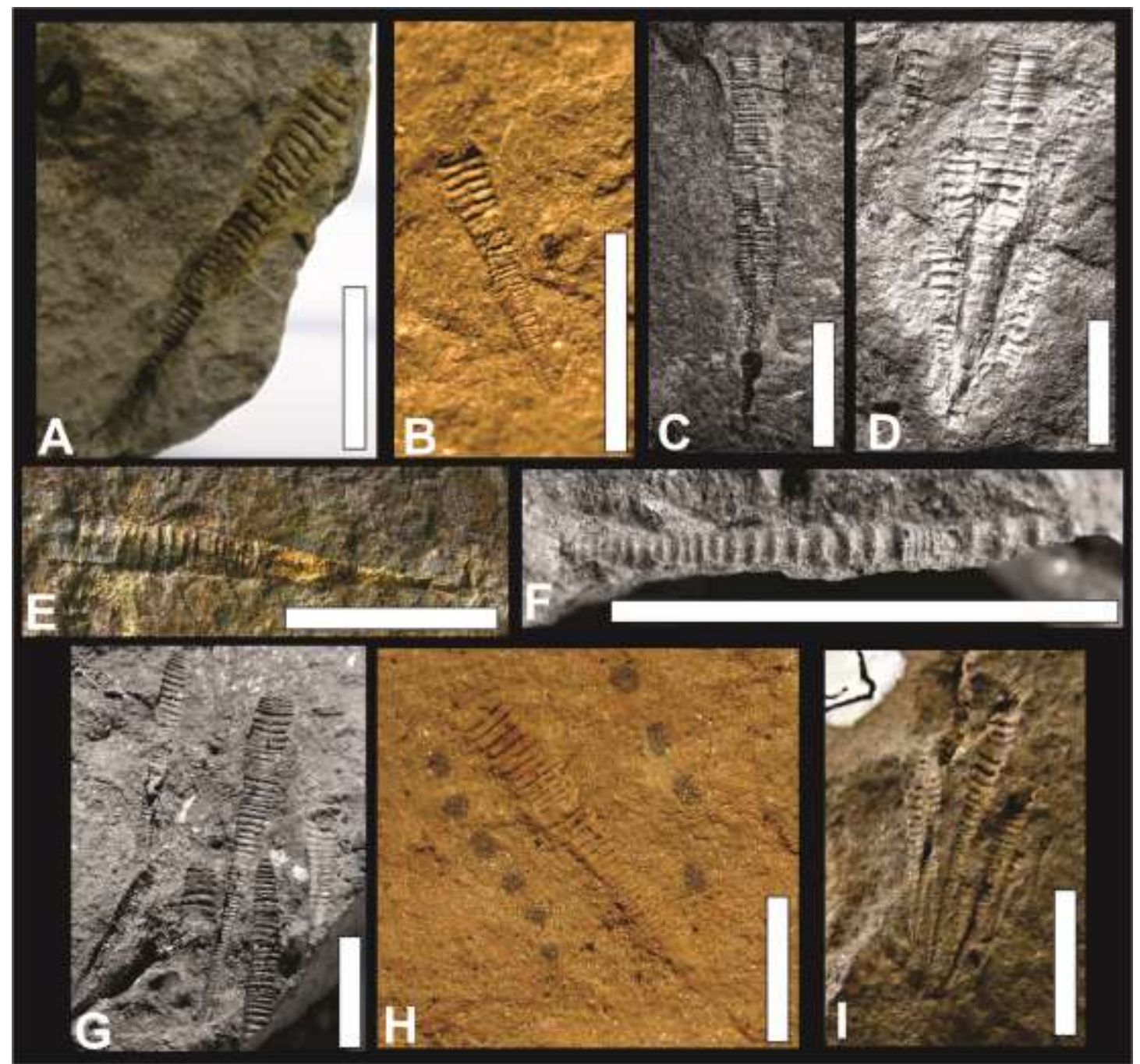

Figura 18. Espécimes de Tentaculites kozlowskius. A) Igc 1/E 1285. B) MPI 2077. C) MPI 9837. D) MPI 9832. E) CCLP 29. F) CCLP 52. G) MN 7030. H) MN 7034. I) UFRJ 05 te. (Escala $0,5 \mathrm{~cm}$ ).

Tentaculites eldredgianus Hartt \& Rathbun, 1875

Fig. 19

1899 Tentaculites eldredgianus Clarke, 1899, p. 80-81, pl. IV, figs. 29-31,

1933 Tentaculites eldredgianus Katzer, 1933, p. 252, pl. XIII, figs. 25 - 26.

Espécie tipo: Tentaculites eldredgianus Hartt e Rathbun, 1875.

Neótipo: Amostra UNIRIO 41, depositada na Universidade Federal do Rio de Janeiro (UNIRIO). 
Ementa específica: Concha de pequeno tamanho, com comprimento variando entre 0,6 e 1,8 cm. Anéis arredondados, proeminentes, pouco espessos, dispostos irregularmente, crescimento ao longo da concha apresenta-se com pouca variação. Interespaços rasos possuem duas a três vezes o tamanho dos anéis, sendo maiores na região adulta e da abertura. Não foi registrada a presença de microanéis. Região apical anelada. Câmara embrionária levemente arredondada. Ângulo aproximado de 3 a 5 graus.

Discussão: As amostras analisadas encontram-se mal preservadas e em muitas vezes sem a presença da câmara embrionária. O fato dos espécimes terem sido encontrados preservados no arenito, o que indica ambientes altamente energéticos, não foi favorável para uma boa fossilização. Esta espécie diferencia da espécie T. crotalinus por não apresentar uma variação no tamanho dos anéis como a da Bacia do Paraná apresenta bem como a câmara embrionária na espécie $T$. crotalinus é fortemente afunilada e pontiaguda, aqui no caso de T. eldredgianus é levemente arredondada. Diferencia da espécie T. kozlowskius por apresentar uma disposição anelar mais regular e da espécie $T$. jaculus pelo tamanho do diâmetro distal, por apresentar câmera embrionária mais afunilada e pela presença de anéis desde a região apical.

Distribuição Geográfica: A) Rio Maecuru, margem direita à 400m a montante da cachoeira Teuapixuna ou Alagação. Coletadas pela expedição Orville Adelbert Derby, em 1986. B) Localizado no lado norte de uma curva da BR 316 (Picos - Teresina), a cerca de $5 \mathrm{~km}$ do trevo de Picos em direção a Oeiras, dentro de uma propriedade particular, no município de Picos (informação verbal prof ${ }^{\mathrm{a}}$. Deusana Machado UNIRIO, 2014). Anteriormente descrita para o Devoniano da Colômbia.

Distribuição Estratigráfica: Formação Maecuru (Eifeliano) e Formação Cabeças (Givetiano).

Material: Amostras de número 35, 41, 45, 47, 49, 51, 52 e 55 que estão depositadas na Universidade Federal do Estado do Rio de Janeiro (UNIRIO). 


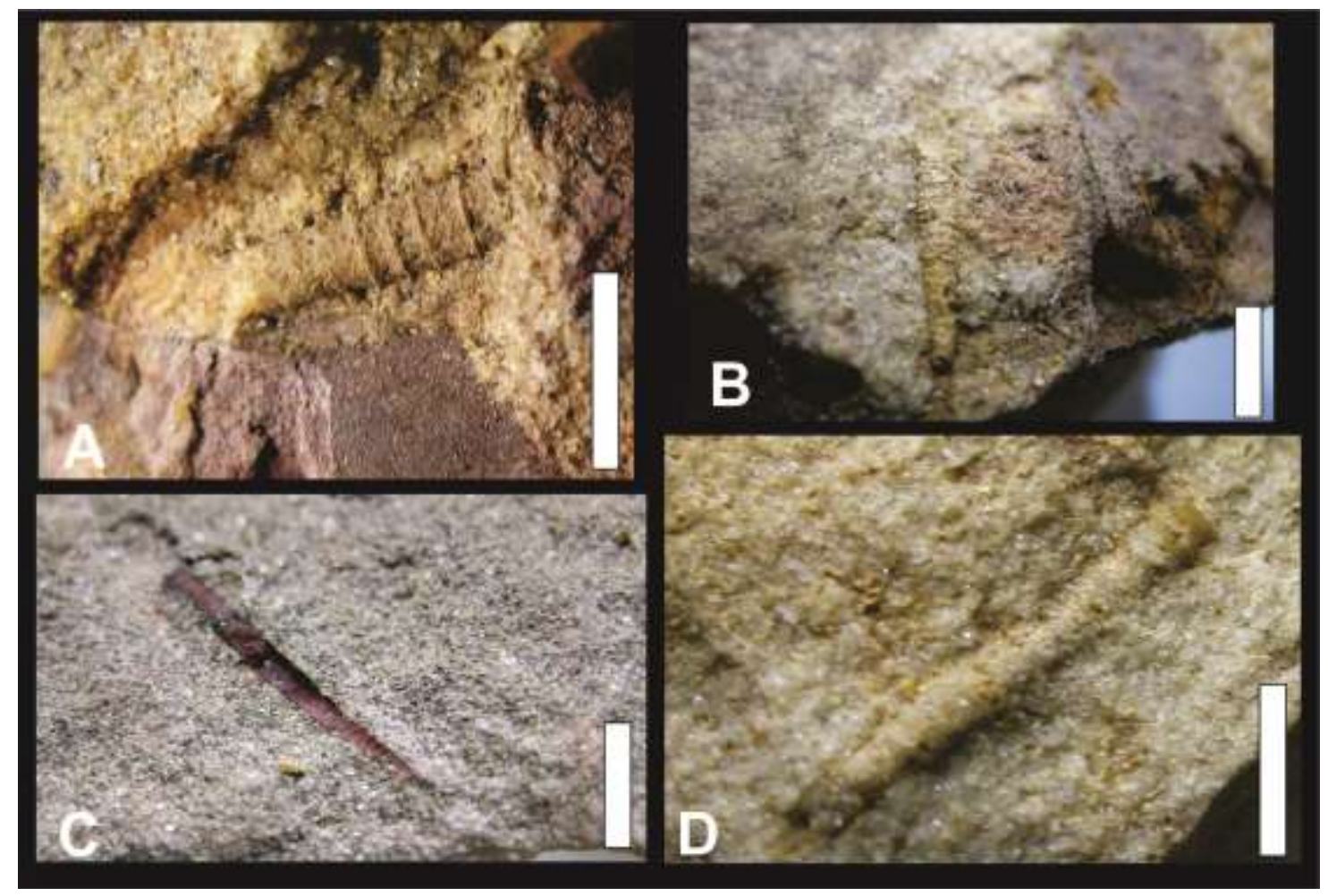

Figura 19. Espécimes representantes da espécie Tentaculites eldredgianus. A) UNIRIO 41. B) UNIRIO 41. C) UNIRIO 55. D) UNIRIO 35. (Escala de 0,5 cm).

Tentaculites stubeli Clarke, 1899

Fig. 20

1899 Tentaculites stubeli Clarke, 1899, p. 80-81, pl. 4, figs. 24-28.

Espécie tipo: Tentaculites stubeli Clarke, 1899.

Neótipo: Amostra UNIRIO 05, depositada na Universidade Federal do Rio de Janeiro (UNIRIO).

Ementa específica: Concha com comprimento entre 0,7 e $1,8 \mathrm{~cm}$. Anéis arredondados a angulosos, pouco espessos, aumento do tamanho dos anéis da parte proximal até a parte distal é pouco significativo. Os anéis perto da região da abertura estão dispostos de maneira inclinada (oblíqua), ou seja, os anéis não estão dispostos paralelamente à concha. Os interespaços são côncavos, irregulares, porém apresentam espaçamento de duas a três vezes maiores do que o tamanho dos anéis. Região apical desprovida de anéis. Câmara embrionária termina abruptamente, ligeiramente 
arredondada. Não foram encontrados espécimes com microanéis. Ângulo de crescimento aproximado de 3 a 5 graus.

Discussão: Esta espécie possui alguns anéis, os que estão localizados próximos à região da abertura, apresentando leve inclinação se comparado aos outros anéis da concha. Esta feição não foi encontrada em nenhuma outra espécie descrita aqui. Difere da espécie T. eldredgianus por apresentar a região apical desprovida de ornamentação e uma câmera embrionária mais arredondada se compara a T. eldredgianus. Diferem das espécies descritas para a Bacia do Paraná, pelo pequeno tamanho, pela disposição regular dos anéis se comparada a T. kozlowskius, pelo aumento gradual e pelo formato da câmera embrionária de $T$. crotalinus e pelo ângulo de crescimento, disposição anelar e diâmetro da região distal de T. jaculus.

Distribuição Geográfica: Encontrada no afloramento da Margem direita do Rio Maecuru cerca de $400 \mathrm{~m}$ a montante da cachoeira de Teapuxina ou Alagação e aproximadamente $1,5 \mathrm{~km}$ a montante da foz do Igarapé Ipixuna. Encontrada também no Devoniano do Paraguai.

Distribuição Estratigráfica: Formação Ererê (NeoEifeliana - EoGivetiana)

Material: Amostras de número 5, 46 e 48 que estão depositadas na Universidade Federal do Estado do Rio de Janeiro (UNIRIO), amostra DGM 2912, depositada na coleção do Departamento Nacional de Produção Mineral (DNPM) e amostra MN 2697 depositadas no acervo do Laboratório de Paleontologia de Invertebrados, Museu Nacional (UFRJ).

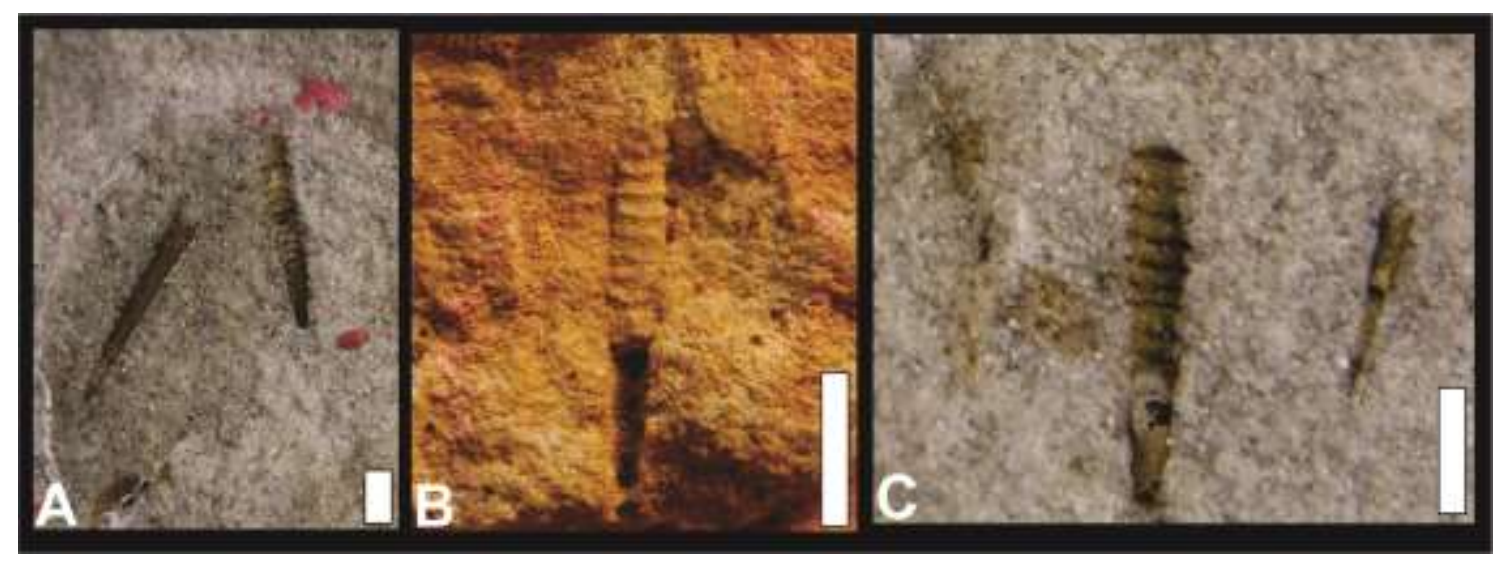

Figura 20. Exemplares de Tentaculites Stubeli. A) UNIRIO 05. B) DGM 2912. C) UNIRIO 05. (Escala 0,5 cm). 
Tentaculites oseryi Clarke, 1899

Fig. 21

1899 Tentaculites oseryi Clarke, 1899, p. 80.

Espécie tipo: Tentaculites oseryi Clarke, 1899.

Neótipo: amostra 58. Depositada na coleção do Laboratório de Estudos de Comunidades Paleozoicas (UNIRIO).

Ementa específica: Concha anelada, com comprimento variando entre 0,7 e 1,4 $\mathrm{cm}$. Anéis arredondados, finos e inexpressivos, aumentam de tamanho de maneira gradativa e regular. Interespaços estreitos, em muitos casos o tamanho dos anéis é o mesmo dos interespaços. Aumentam de tamanho de forma gradativa e regular. Em algumas amostras a presença de anéis estende-se até o ápice, em outros casos a região apical encontra-se sem ornamentação. Não foi encontrado material com a câmara embrionária preservada, sendo assim, também não pode fazer uma estimativa do ângulo de crescimento desta espécie.

Discussão: Esta espécie é bem característica quanto à ornamentação na sua superfície. Os anéis e os interespaços encontram-se "praticamente" unidos um ao outro, esta característica não havia sido descrita para nenhum tentaculitoideo brasileiro. A espécie T. oseryi difere de T. crotalinus, T. kozlowskius, T. eldredgianus e T. stubeli pela distribuição dos interespaços e dos anéis estarem próximos, de maneira quase inexpressiva. Ainda pode ser diferenciado de T. stubeli pelo formato dos anéis e pelo tamanho dos interespaços em T. eldredgianus.

Distribuição Geográfica: A) Afloramento localizado no lado norte de uma curva da BR 316 (Picos - Teresina), a cerca de 5 km do trevo de Picos em direção a Oeiras, dentro de uma propriedade particular, no município de Picos. B) Situado numa curva da estrada de terra em direção ao povoado de Oiti, a $800 \mathrm{~m}$ do entroncamento desta com a PI-120 (trecho Valença do Piauí - Pimenteiras), no município de Pimenteiras, PI. (Informações cedidas pela prof ${ }^{\mathrm{a}}$. Deusana Machado - UNIRIO, 2014).

Distribuição Estratigráfica: Formação Cabeças (Givetiano).

Material: Amostras de número 55, 58, 59, 101 e 102 que estão depositadas na Universidade Federal do Estado do Rio de Janeiro (UNIRIO) e amostra DGM 2912 na coleção do Departamento Nacional de Produção Mineral (DNPM). 


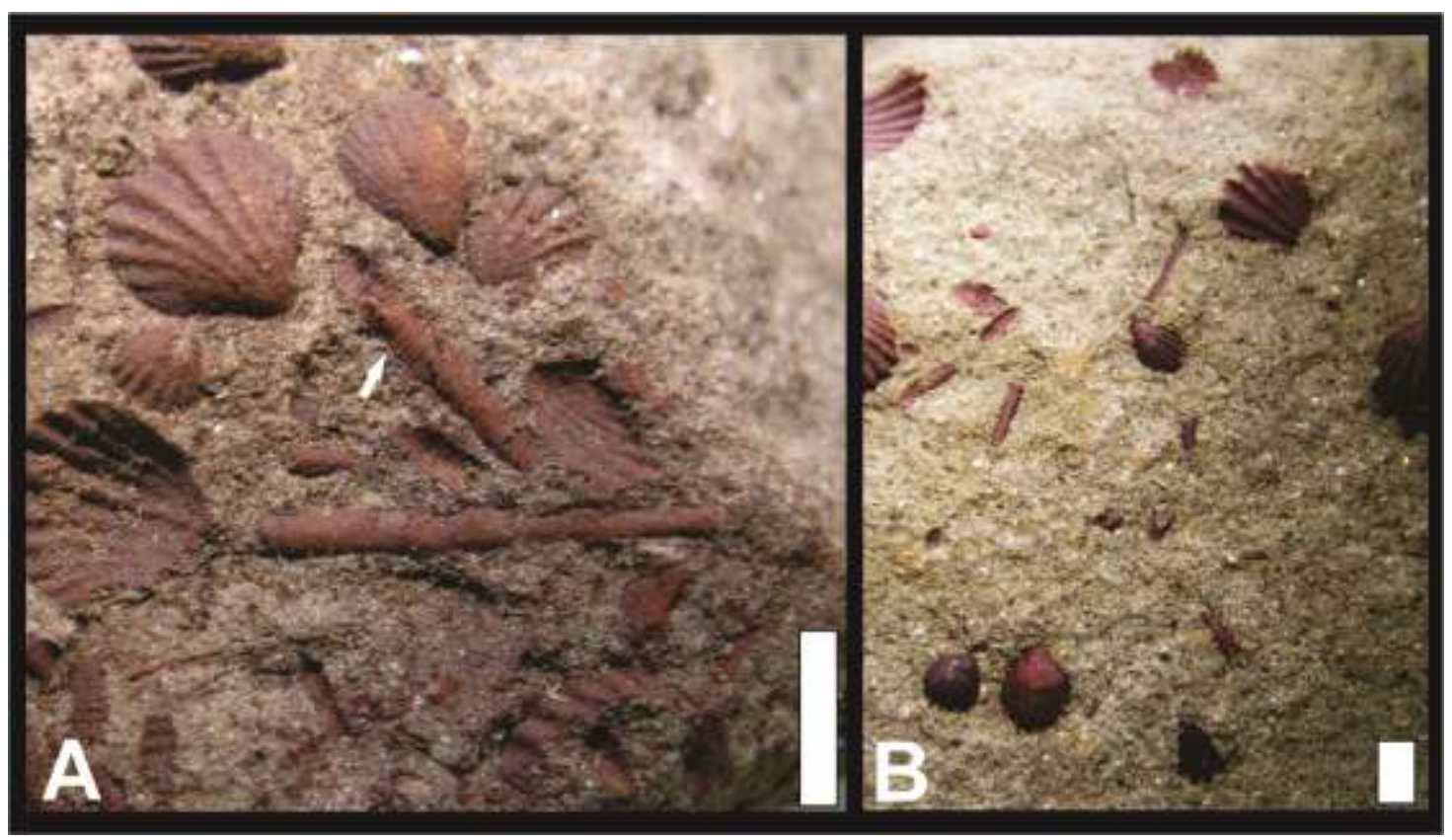

Figura 21. Espécimes da espécie Tentaculites oseryi. A) UNIRIO 58. B) UNIRIO 59. Na figura $\mathrm{A}$, a flecha indicando como os anéis e interespaços encontram-se dispostos praticamente com a mesma espessura (Escala $0,5 \mathrm{~cm}$ ).

\section{Tentaculites trombetensis Clarke, 1899}

Fig. 22

1899 Tentaculites trombetensis Clarke, 1899, p. 38, pl. 2, figs. 26-27.

1989 Tentaculites trombetensis Ciguel, 1989, p. 64- 66, pl. 24-25

Espécie tipo: Tentaculites trombetensis Clarke, 1899

Neótipo: Amostra MN 2697. Depositada no acervo do Laboratório de Paleontologia de Invertebrados, Museu Nacional (UFRJ). Ementa específica: Concha pequena, com tamanho aproximado de 0,7 a 1,5 cm. Anéis arredondados a angulosos, expressivos. Interespaços espessos e côncavos, apresentando quase o dobro do tamanho dos anéis. A quantidade dos anéis e os interespaços aumentam da região proximal até a região distal regularmente. A região apical não apresenta qualquer tipo de ornamentação. Não foram visualizados microanéis em nenhum dos espécimes analisados. A câmara embrionária é levemente pontiaguda a arredondada.

Discussão: Esta espécie não se assemelha com $T$. eldredgianus, visto que $T$. trombetensis possui anéis mais angulosos e mais proeminentes. Embora não apresente 
ornamentação na região juvenil, tal como T. stubeli, as semelhanças param por aqui. $T$. trombetensis possui anéis angulosos e câmara embrionária mais pontiaguda do que $T$. stubeli. Em comparação com as espécies encontradas na Bacia do Paraná, esta espécie é bem menor do todas já descritas. Em comparação com T. crotalinus, a disposição anelar entre as espécies, nada se assemelha. Visto que os anéis em T. crotalinus são dispostos irregularmente e aumentando à medida que se aproximam da região da abertura, enquanto que em T. trombetensis o tamanho pouco se altera. A região da câmara embrionária é mais pontiaguda e extensa em $T$. crotalinus do que em $T$. trombetensis. A espécie $T$. jaculus apresenta características que diferem de $T$. trombetensis como a concha mais espessa, câmara embrionária mais arredondada, anéis pouco proeminentes e interespaços rasos.

Distribuição Geográfica: A) Rio Maecuru, margem direita à 400m a montante da cachoeira Teuapixuna ou Alagação, coletadas pela Expedição Orville A. Derby. B) Localizado no lado norte de uma curva da BR 316 (Picos - Teresina), a cerca de $5 \mathrm{~km}$ do trevo de Picos em direção a Oeiras, dentro de uma propriedade particular, no município de Picos (Informações cedidas pela prof ${ }^{\mathrm{a}}$. Deusana Machado - UNIRIO 2014). Encontrado também no Devoniano da Bolívia e Paraguai.

Distribuição Estratigráfica: Formação Maecuru (Eifeliano) e Formação Cabeças (Givetiano).

Material: Amostras 37, 38 e 50 estão depositadas na Universidade Federal do Estado do Rio de Janeiro (UNIRIO). Amostra MN 2697 depositadas no acervo do Laboratório de Paleontologia de Invertebrados, Museu Nacional (UFRJ), amostra DGM 2865 na coleção do Departamento Nacional de Produção Mineral (DNPM) e amostra GP/ 1E 1448 depositada no Instituto de Geociências da Universidade de São Paulo (IgcUSP).

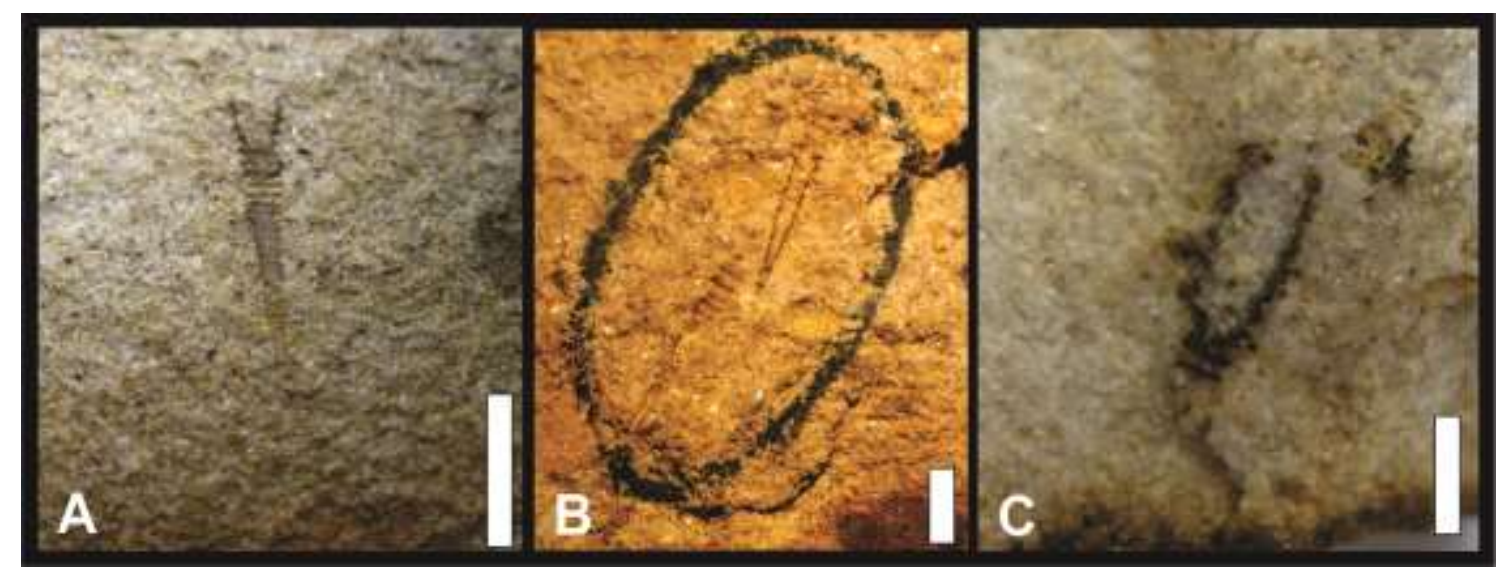


Figura 22. Alguns exemplares de Tentaculites trombetensis. A) UNIRIO 38. B) MN 2697. C) UNIRIO 37. (Escala de 0,5 cm).

\section{Tentaculites paranaensis sp. nov}

Fig. 23

Espécie tipo: Tentaculites paranaensis sp. nov.

Holótipo: GP/1E 3242 depositada na coleção do acervo do Laboratório de Paleontologia e Sistemática, Igc - USP.

Diagnose: Concha cuneiforme anelada. Anéis discoides angulosos, finos, inexpressivos, homomorfos, homolongitudinais. Espaço interanular plano, raso, liso com distância crescente e proporcional. Microanéis ocorrem de forma aleatória e irregularmente em número, predominantemente na região da abertura. Ápice tenuemente curvo e liso. Câmara embrionária cônica pontiaguda.

Descrição: Comprimento da concha varia de 1,0 a $2,8 \mathrm{~cm}$. Anéis discoides angulosos, pouco salientes, relativamente finos e simétricos. Os anéis crescem de tamanho de maneira regular e homogênea, pouca a diferença entre os anéis da parte proximal da parte distal. O mesmo caso ocorre com os interespaços, os quais aumentam de tamanho da região proximal até a região distal de maneira homogênea. Os interespaços são suavemente côncavos (raras as exceções, os interespaços encontram-se profundamente côncavos). Na maioria dos casos os interespaços da região adulta e da abertura, são até três vezes o tamanho dos anéis. Enquanto que na região juvenil, os interespaços são ligeiramente maiores que os anéis, bem como algumas vezes são do mesmo tamanho. Os microanéis ocorrem em alguns espécimes, quando encontrados, localizam-se na região da abertura, caracterizados por microestruturas finas $\mathrm{e}$ inexpressivas. A câmara pontiaguda a arredondada, em alguns casos foi observado à presença do espinho apical. Ângulo de crescimento varia entre 3 a 6 graus.

Discussão: As espécies Tentaculites barbosensis, Homoctenus carvalhensis $e$ Tentaculites rathbuensis, informalmente proposto por Ciguel (1989), têm diagnóstico específico semelhante e diferem um do outro pelo tamanho do anel. Neste caso, os táxons tornam-se sinônimos, e a espécie Tentaculites paranaensis é proposto por possuir anéis discoides e angulares e uma câmara embrionária pontiaguda, que o distingue de outros táxons analisados. As espécies Tentaculites paranaensis difere 
Homoctenus krestovnikovi (Lyashenko, 1955) por apresentar anéis mais amplos e interespaços, uma concha em linha reta e maior. A espécie Tentaculites paranaensis apenar de parecida, difere da U. ciguelius por apresentar anéis angulosos mais espessos, a disposição dos anéis de maneira homogênea e o aumento gradual e homogêneo dos interespaços.

Etimologia: Nome dado em referência ao grande número de fósseis de tentaculitoideos encontrados nas camadas devonianas no estado do Paraná, da Bacia do Paraná.

Distribuição Geográfica: Municípios de Jaguariaíva (afloramento estrada de ferro Jaguariaíva-Arapoti (S $24^{0} 14^{\prime} 05^{\prime}$ '; W $49^{0} 42^{\prime}$ 34' ')) e Ponta Grossa (Fazenda Rivadávia (S $25^{0} 15^{\prime} 05,47^{\prime}$ '; W $50^{\circ} 03^{\prime} 06,21^{\prime \prime}$ ), Curva I (S $25^{0} 03$ ' 34, 56”'; W $50^{\circ}$ 08'04, 09',) e Desvio Ribas - Tibagi (S $25^{0} 12$ ' 02,73',; W 50 03' 58,55'’)).

Distribuição Estratigráfica: NeoPraguiano - NeoEmsiano

Material estudado: As amostras estão depositadas na Universidade Federal do Paraná, UFPR, (NR 4784, 6030, 6497, 6589, 7137, 7425 e 7470), Instituto de Geociências da Universidade de São Paulo, Igc- USP, (GP/ 1E 1287, 3242, 3363, 3409 e 3414), Museu Nacional, Universidade Federal do Rio de Janeiro, UFRJ (MN 7011), Laboratório de Paleontologia de Macroinvertebrados, UNESP (CCLP 28), Universidade Federal do Estado do Rio de Janeiro, UNIRIO (7, 90, 91 e 95 ten) e Laboratório de Estratigrafia e Paleontologia, UEPG (MPI 9184). 


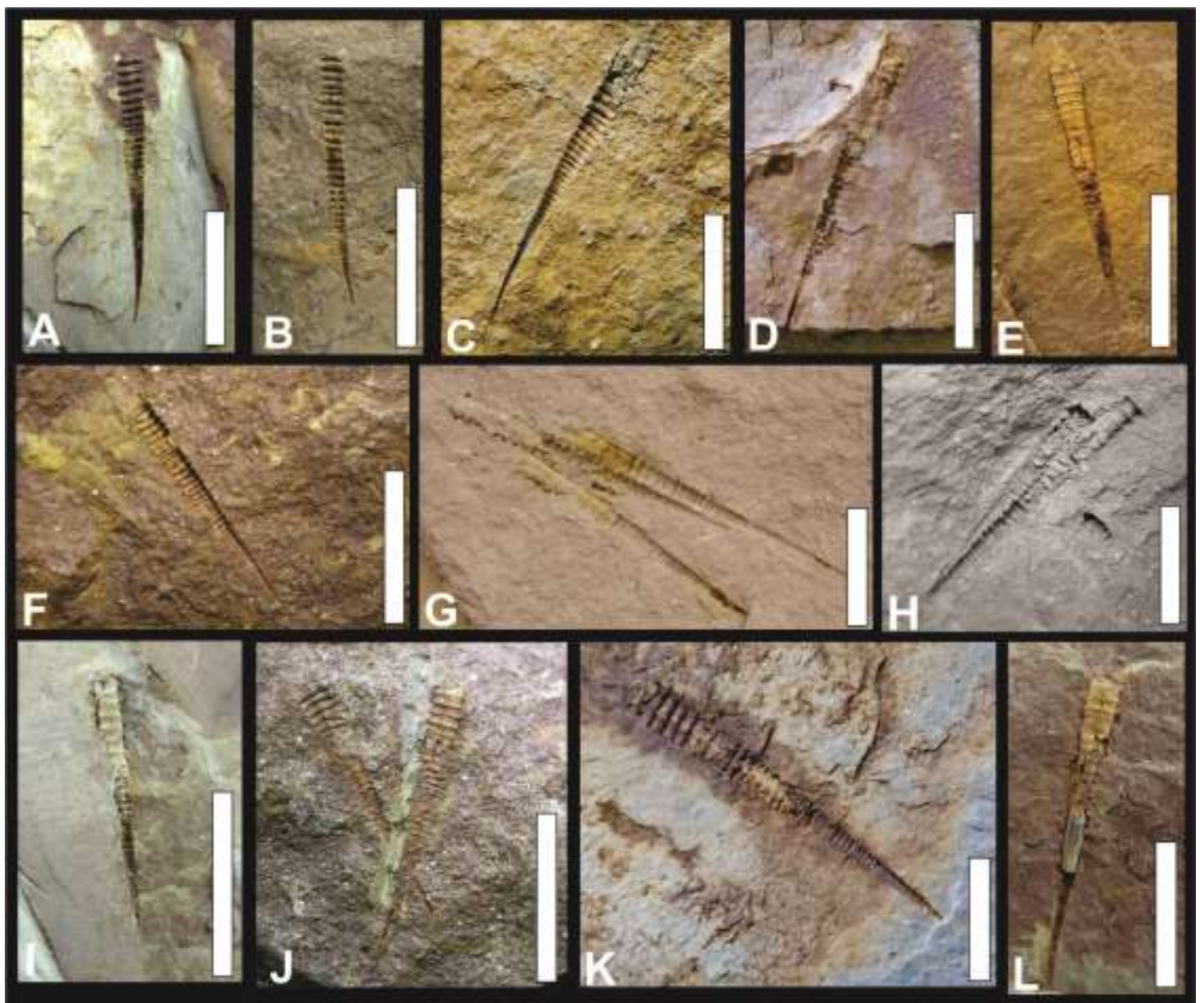

Figura 23. Alguns dos espécimes de Tentaculites paranaensis. A) Igc 1/E 3242. B) Igc 1/E 1287. C) NR 7137. D) NR 7458. E) NR 4784. F) UNIRIO 97. G) NR 5466. H) UNIRIO 90. I) Igc 1/E 3247. J) Igc 1/E 1296. K) NR 6115. L) Igc 1/E 3414. (Escala 1,0 cm).

Ordem Tentaculitida Lyashenko, 1955

Família Uniconidae Lyashenko, 1955

Gênero Uniconus Lyashenko, 1955

\section{Uniconus ciguelius sp. nov.}

Fig. 24

Espécie tipo: Uniconus ciguelius sp. nov.

Holótipo: Amostra MPI 10152, depositada no acervo do Laboratório de Estratigrafia e Paleontologia, Universidade Estadual de Ponta Grossa (UEPG).

Diagnose: Concha cuneiforme anelada. Anéis assimétricos angulosos, voltados para a região da abertura, salientes, homomorfos com espessura média, 
heterolongitudinais com crescimento proporcional. Espaços regular, liso, raso e suavemente côncavo. Microanéis escassos. Câmara pontiaguda.

Descrição: Concha cuneiforme ornamentada. Possuem comprimento aproximado de 0,8 a 2,2 cm. Anéis assimétricos angulosos. Os anéis da região distal da concha estão voltados para a região da abertura da concha. Em alguns casos passam a impressão de ser composto por sucessivos cones, um encaixado no outro. Os anéis são salientes, pouco espessos, o tamanho dos anéis aumenta gradativamente desde a região proximal até a região distal. Os interespaços vão de suavemente côncavos a fortemente côncavos, aumentam gradativamente e pouco regulares. Quando presente, os microanéis estão dispostos na região da abertura. Ápice tenuemente anelado. Apenas poucos exemplares apresentavam a câmara embrionária pontiaguda. Ângulo de crescimento entre 3 e 8 graus.

Discussão: A espécie possui caracteres de Uniconus tais como anéis assimétricos proeminentes voltados em direção à abertura que o distinguem dos outros gêneros. Este é o primeiro registro do gênero a partir do Devoniano do Brasil. A nova espécie Uniconus ciguelius difere Uniconus liwanensis Lyashenko, 1955 por apresentar formato mais assimétrico dos anéis, interespaços maiores e irregulares e concha com comprimento mais longo.

Etimologia: O nome da espécie é uma homenagem a José Henrique Godoy Ciguel, o maior estudioso da classe Tentaculitoidea do Brasil que teve morte precoce durante trabalho de campo no interior do estado do Paraná em decorrência de acidente automobilístico.

Distribuição Geográfica: Afloramento dos municípios de Jaguariaíva (afloramento estrada de ferro Jaguariaíva-Arapoti (S 24 $14^{\prime}$ '05', W $49^{0} 42^{\prime}$ 34',) e Ponta Grossa (Fazenda Rivadávia (S $25^{0} 15^{\prime}$ 05, 47',; W 50 03' 06, 21'’))).

Distribuição Estratigráfica: NeoPraguiano - EoEmsiano.

Material estudado: GP/ 1E 1305, 1309, 1297, 3322 e 3247 depositadas no Instituto de Geociências da Universidade de São Paulo (Igc- USP), Universidade Federal do Paraná, UFPR (NR 3800, 5466, 6560, 7138, 7153 e 7403), Laboratório de Estratigrafia e Paleontologia, UEPG (MPI 10152 e 1095), Departamento Nacional de Produção Mineral, DNPM (DGM 1923) e Universidade Federal do Rio de Janeiro, UFRJ ( 2 e 22 te). 


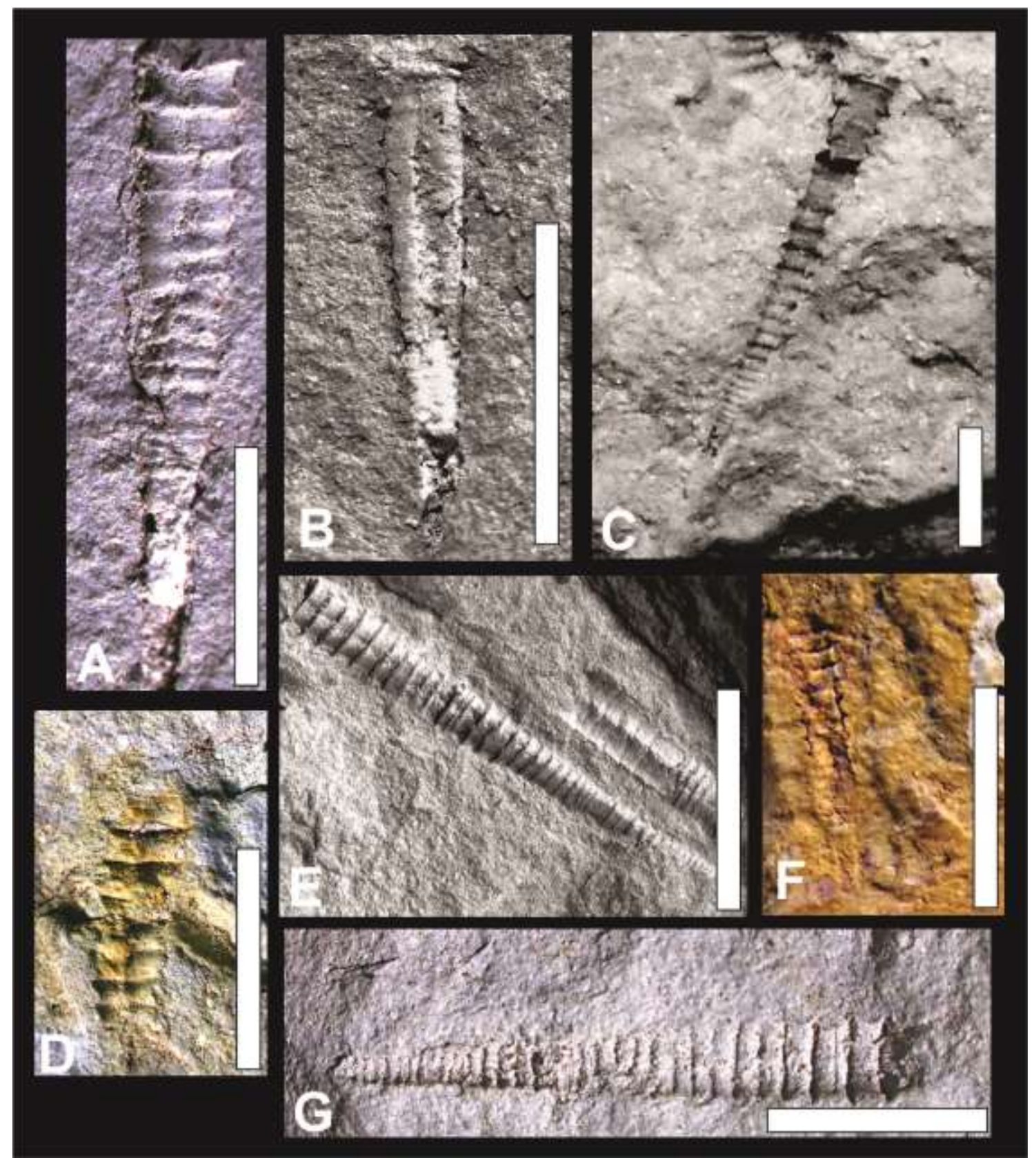

Figura 24. Espécimes de Uniconus ciguelius observadas nas análises. A) CCLP 39. B) CCLP 40. C) UFRJ 22te. D) CCLP 22. E) MPI 10152. F) DGM 1923. G) CCLP 39. (Escala 0,5 cm).

Ordem Homoctenida Bouček, 1964

Família Homoctenidae Lyashenko, 1955

Gênero Homoctenus Lyashenko, 1955

Homoctenus katzerius sp. nov.

Fig. 25 
1989 Homoctenus katzerensis Ciguel, 1989, pg. 95, fig. 39.

Espécie tipo: Homoctenus katzerius sp. nov.

Holótipo: MN 7030 depositada na coleção do Museu Nacional, Universidade Federal do Rio de Janeiro (UFRJ).

\section{Diagnose:}

Concha cuneiforme anelada com a região apical encurvada. Anéis discoides arredondados com elevada espessura. Homomorfos, homolongitudinais, pouco salientes, simétricos. Espaço interanular com alta concavidade, distância crescente, irregular e proporcional. Microanéis na região da abertura e mediana. Ápice tenuemente cônico anelado. Câmara embrionária pontiaguda. (Ciguel, 1989. p. 92).

Ementa específica: Concha cuneiforme ornamentada. Concha variando de 0,8 a $1,5 \mathrm{~cm}$ de comprimento. Anéis arredondados a angulosos, aumento gradual e homogêneo. Interespaços ligeiramente côncavo. Interespaços com aproximadamente duas vezes o tamanho dos anéis na região adulta e da abertura, enquanto que na região juvenil não chegando a duas vezes. Com esporádicos microanéis, distribuindo se irregularmente em forma e quantidade. Microanéis apareceram na região adulta e da abertura. Apresenta maior espessura da parte distal da concha, se comparado ao Tentaculites paranaensis. Apresentam anelação desde a região apical. Câmara embrionária ligeiramente abrupta e arredondada. Ângulo de crescimento entre 5 a 8 graus.

Discussão: As espécies Homoctenus katzerensis e Homoctenus siemiradzkiensis informalmente propostas por Ciguel (1989) apresentam diagnose específica similar sendo diferenciada por detalhes de caráter subjetivo. Aqui sinonimiza-se os táxons propondo a validação de Homoctenus katzerensis por esse táxon possuir características tais como anéis discoides ondulados, homolongitudinais, homomorfos, ápice curvo. Altera-se o sufixo do epíteto específico para adequação gramatical. As espécies Homoctenus katzerius difere Tentaculites paranaensis e Homoctenus krestovnikovi Lyashenko, 1955 por apresentar concha maior, anéis mais robustos e interespaços menores, apresentando anéis até a região embrionária. Em comparação com a espécie de Tentaculites paranaensis, a H. katzerius apresenta maior diâmetro distal, tamanho de 
concha menor, anéis menos angulosos e mais finos e câmara embrionária mais arredondada.

Etimologia: Homenagem a Friedrich Katzer que publicou lista de fósseis devonianos até 1898 no Estado do Paraná. Efetuou comparações com a fauna do Maecuru (Bacia do Amazonas) e que ambas poderiam corresponder à porção inferior do Devoniano Médio da América do Norte.

Distribuição Geográfica: Jaguariaíva (afloramento estrada de ferro JaguariaívaArapoti (S 24 $14^{\prime}$ '05', W W $49^{0} 42^{\prime} 34^{\prime \prime}$ )), Palmeira (afloramento Rio Caniú (S $25^{\circ} 18^{\prime}$ $48^{\prime \prime}$ e W $50^{\circ} 05^{\prime} 32^{\prime \prime}$ )) e Ponta Grossa (Fazenda Rivadávia (S $25^{\circ} 15^{\prime} 05,47^{\prime \prime}$; W $50^{\circ}$ 03 '06, 21',)).

Distribuição Estratigráfica: NeoPraguiano ao NeoEmsiano

Material estudado: As amostras NR 1772, 6116 e 7257 estão depositadas no Laboratório de Paleontologia da UFPR. As amostras 4 e 7 te estão depositadas na Universidade Federal do Rio de Janeiro (UFRJ), Laboratório de Estratigrafia e Paleontologia, UEPG (MPI 1090), Instituto de Geociências da Universidade de São Paulo, Igc-USP, (GP/1E 3340, 3411, 3624, 3633, 3638, 3643 e 3647), Laboratório de Paleontologia de Macroinvertebrados, UNESP (CCLP 8, 10, 21, 25, 28, 30 e 39) e Museu Nacional, Universidade Federal do Rio de Janeiro, UFRJ (MN 1762, 7021 e 7030). 


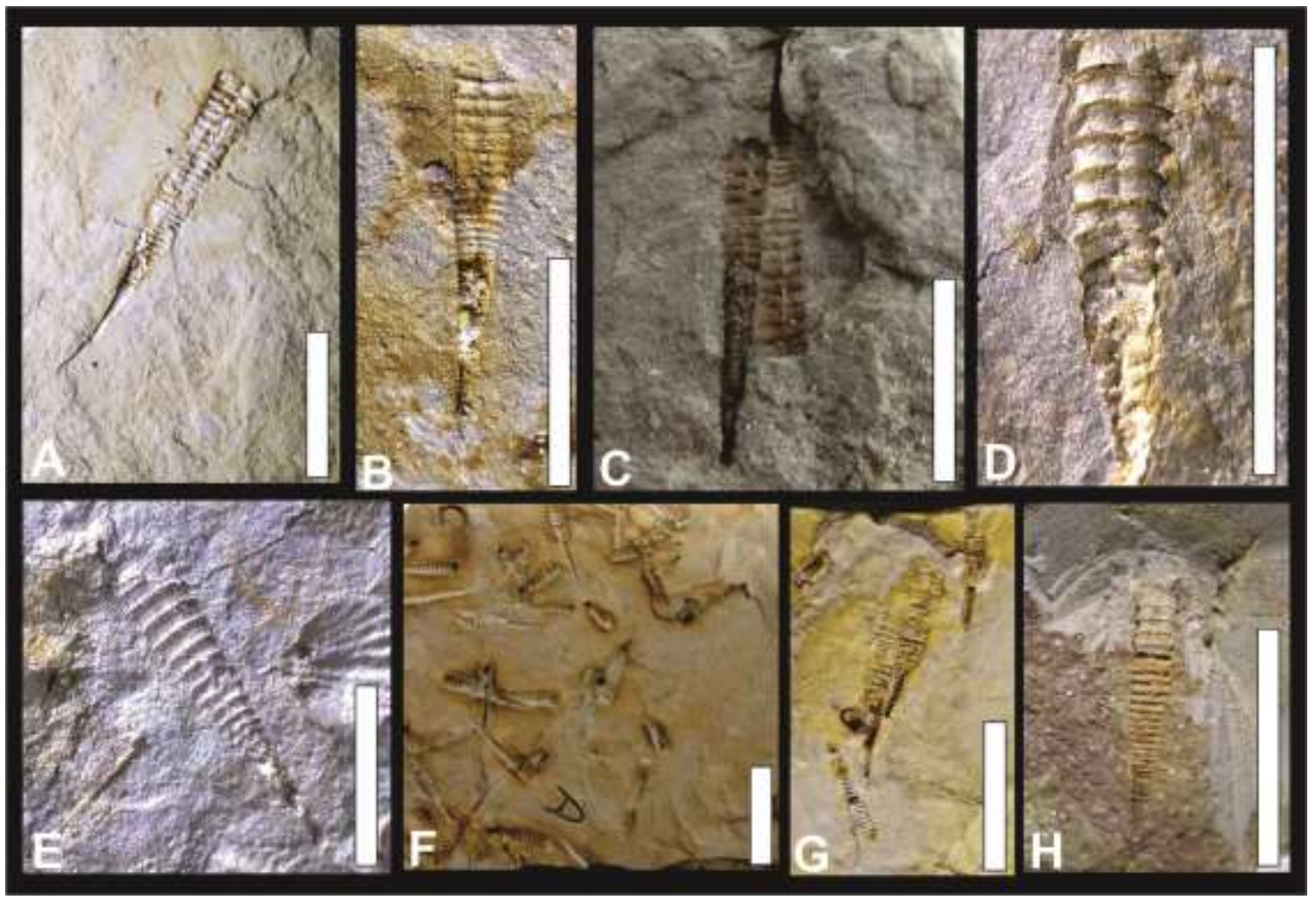

Figura 25. Homoctenus katzerius. A) Igc 1/E 1294. B) CCLP 25. C) Igc 1/E 3411. D) CCLP 10. E) CCLP 21. F) Igc 1/E 3633. G) UFRJ 07 te. H) Igc 1/E 3428. (Escala 0,5 cm).

Ordem Dacryoconarida Fisher, 1962

Família Stylionidae Gabrau \& Shimer, 1910

Gênero Styliolina Karpinsky, 1884

Styliolina cf. Styliolina fissurella Hall, 1843

Fig. 26

1843 Tentaculites fissurella. Hall, 1843, p. 182. Fig. 71/10

1879 Styliola fissurella Hall, 1879, p. 178-9, pl. 31a, fig. 4-10, 18-22, 29-30, 33

1904 Styliolina fissurella Chapman, 1904, p. 338. Pl. 31, fig. 4.

1941 Styliolina fissurella (Hall); Gill, 1941, p. 149. Pl. 4, figs. 3-4.

1964 Styliolina fissurella (Hall); Bouček, 1964, p.127-131. Pl. 31. Fig 1 e 2.

1969 Styliolina fissurella (Hall); Lardeux, 1969, p. 159-160. Pl. 48. Figs 122, 133.

2004 Styliolina fissurella (Hall); Berkyová, 2004, p. 152. Fig. 4a.

Espécie tipo: Tentaculites fissurella Hall, 1843

Lectótipo: Espécime figurado por Hall (1879), pl. 31a, fig. 13. 
Ementa específica: Concha cuneiforme desprovido de ornamentações. Comprimento varia entre 0,8 a $1,8 \mathrm{~cm}$. Algumas apresentam marcas de linhas de crescimento. Câmara embrionária goticular. Apresenta alto valor de diâmetro quando comparado aos outros tentaculitoideos analisados. Parede interna, molde liso. Ângulo de crescimento varia entre 5 e 13 graus.

Discussão: Styliolina cf. Styliolina fissurella possui características como ser desprovida de ornamentações e câmara embrionária em forma goticular. Essa espécie distinguiu de todos os outros táxons analisados. Esta espécie difere de Styliolina clavulus encontrada na Bacia do Amazonas e Parnaíba, por apresentar concha com maior diâmetro na parte distal, ângulo de crescimento maior, câmara embrionária mais arredondada e goticular. Em comparação com Styliolina clavulus tem ângulo de crescimento menor e também tem concha mais comprida. A amostra analisada é reconhecida como Styliolina cf. Styliolina fissurella por possuir a concha estreita e cônica, em linha reta, ângulos de crescimento variando entre 7 e $9^{0}$ como descrita na diagnose da espécie por Hall, 1843. Embora este gênero seja reconhecido por apresentar pequenos tamanhos, as características morfológicas aqui verificadas, foram possíveis chegar a nível genérico.

Distribuição Geográfica: encontradas em afloramentos dos municípios de Tibagi (afloramento Km 220 (S $24^{0} 38^{\prime}$ 02,19', W $50^{0}$ 27' 40,35',) e Ponta Grossa (afloramento Aeroporto (S $25^{0} 08^{\prime}$ 57, 94', W $50^{0} 08^{\prime} 43,16^{\prime \prime}$ ))). Sendo encontrada também no Devoniano da América do Norte, Austrália, Nova Zelândia, Inglaterra e Rússia.

Distribuição Estratigráfica: Meso-NeoEmsiano.

Material Estudado: NR 5914, 6231, 6545 e 6782 está depositada no Laboratório de Paleontologia da UFPR, Instituto de Geociências, USP (GP/ 1T 1283, 3446, 3582 e 3587), Laboratório de Estratigrafia e Paleontologia, UEPG (MPI 460, 6951, 9802 e 9812), Museu Nacional, Universidade Federal do Rio de Janeiro, UFRJ (MN 6449 e 7030), Universidade Federal do Estado do Rio de Janeiro, UNIRIO (3, 4, 5, 16, 22 e 23) e Departamento Nacional de Produção Mineral, DNPM (DGM 1703). 


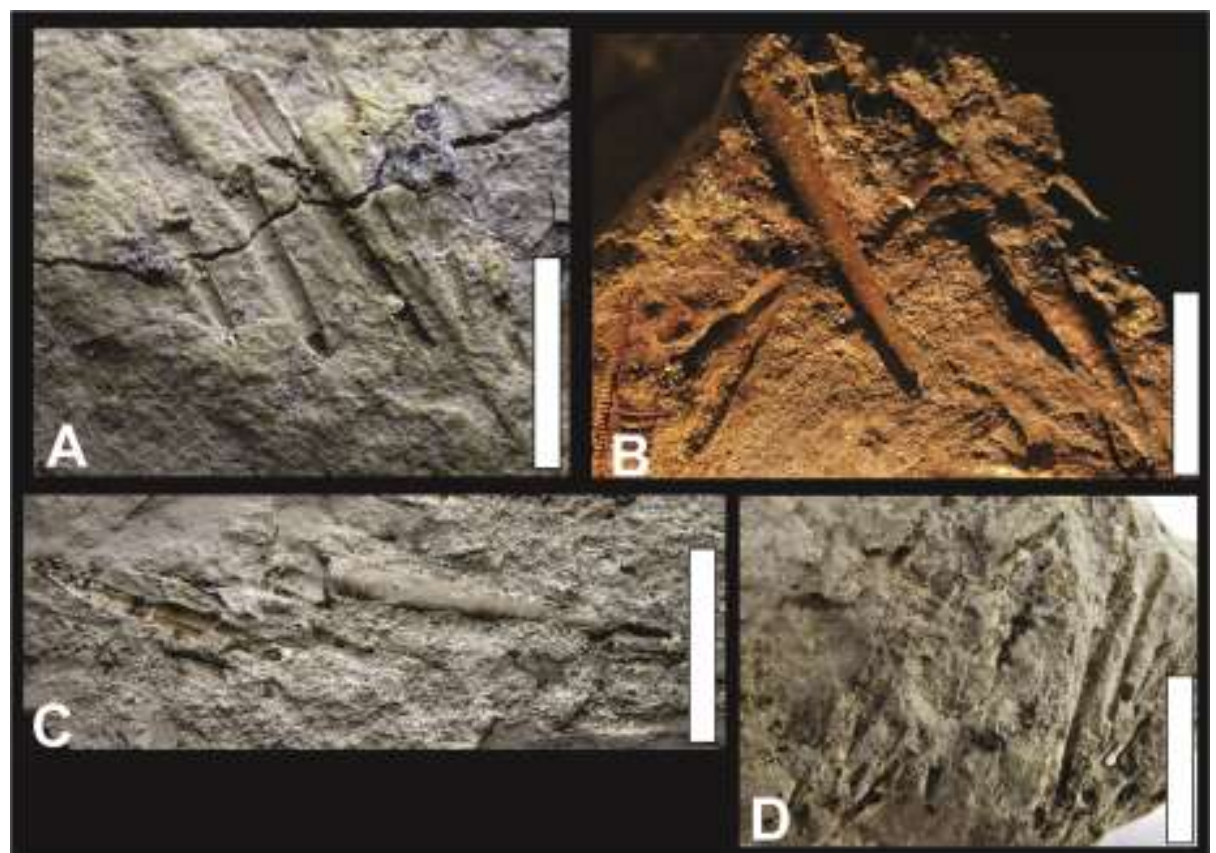

Figura 26. Espécimes de Styliolina cf. Styliolina fissurella. A) UNIRIO 16. B) MN 7430. C) UNIRIO 22. D) UNIRIO 107. (Escala 1,0 cm).

Styliolina clavulus Barrande, 1867

\section{Fig. 27}

1882 Styliola clavulus Barrande, 1867, p. 59, pl. 13, fig. 27-30

1897 Styliola clavulus Katzer, 1897, p. 1021, figs, 481-7/7

1933 Styliolina clavulus Katzer, 1933, p. 190, pl.8, fig.29a

1952 Styliolina clavulus Prantl, 1952, p. 195.

1952 Styliolina clavulus Skácel, 1952, p. 18-19, fig. 1.

1952 Styliolina clavulus Tröger, 1952, p. 754, fig. 10.

1962 Styliolina clavulus Fisher, 1962, p. 166, fig. 55/2

Espécie tipo: Tentaculites clavulus Barrande, 1882.

Holótipo: Barrande, 1867, estampa 14, fig. 28-29.

Ementa específica: Concha com tamanho aproximado entre 0,9 e 2,0 cm, reta e sem a presença de anelações. Em alguns casos ocorre a presença de tênues estrias de crescimento. Distância distal pequena quando comparada a outros dacryoconarídeos. Câmara embrionária com forma goticular, embora a região apical seja levemente 
afunilada. Nota-se um leve afunilamento na região apical. Ângulo de crescimento com aproximadamente entre 4 a 8 graus.

Discussão: Esta espécie se difere dos Tentaculitida e Homoctenida por não apresentar ornamentação ao longo da concha e por possuir uma câmera embrionária goticular, enquanto que homoctenídeos e tentaculitidas possuem câmara arredondada a pontiaguda. Esta espécie apresenta algumas características que a diferem da espécie Styliolina cf. Styliolina fissurella, tais como menores dimensões, possui câmara embrionária menos goticular e arredondada, visível afunilamento da região apical, diâmetro distal menor e ângulo de crescimento inferior.

Distribuição Geográfica: A) Rio Maecuru, margem direita à 400m a montante da cachoeira Teuapixuna ou Alagação, coletadas pela Expedição Orville A. Derby, 1986. B) Afloramento localizado no lado norte de uma curva da BR 316 (Picos - Teresina), a cerca de $5 \mathrm{~km}$ do trevo de Picos em direção a Oeiras, dentro de uma propriedade particular, no município de Picos (Informações cedidas pela prof ${ }^{\mathrm{a}}$. Deusana Machado UNIRIO).

Distribuição Estratigráfica: Formação Maecuru (Eifeliano) e Formação Cabeças (Givetiano).

Material estudado: As amostras analisadas estão depositadas no acervo da Universidade Federal do Estado do Rio de Janeiro, UNIRIO (36, 39, 42, 43, 44 e 60).

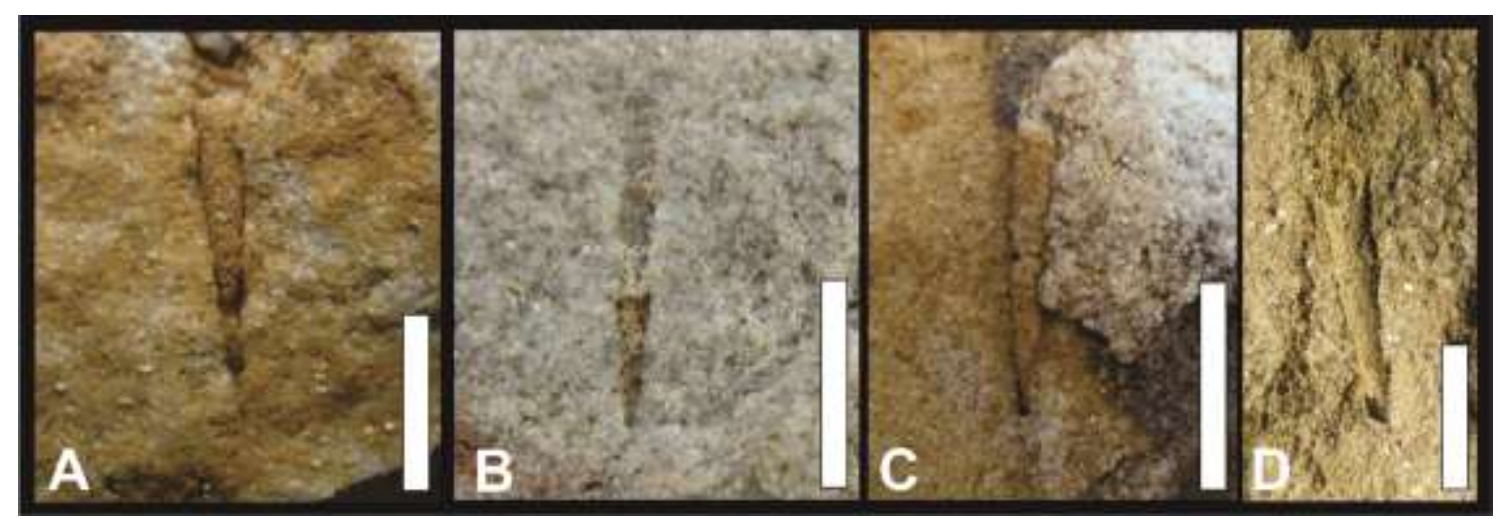

Figura 27. Styliolina clavulus. A) UNIRIO 36. B) UNIRIO 43. C) UNIRIO 44. D) UNIRIO 42. (Escala 1,0 cm). 


\subsubsection{NOVOS ACHADOS}

Durante as atividades de campo em afloramentos no Devoniano médio (NeoEifeliano-EoGivetiano), foi constatada a presença de amostras contendo organismos parecidos com tentaculitoideos, porém com preservações peculiares, tais como anéis fortemente deformados, conchas compridas e encurvadas, em alguns casos apenas os moldes internos dos anéis são preservados, sem a presença dos interespaços e organismos fossilizados, provavelmente, enterrados ao substrato.

As amostras foram submetidas a análises taxonômicas e de Espectroscopia de Energia Dispersiva (MEV-EDS), para visualização quanto à constituição da estrutura da concha. As análises demonstraram uma composição de carbonato de cálcio. Tentou-se analisar a diferença da composição dos anéis e dos interespaços, para verificar se havia diferença entre essas partes, a qual justificasse a preservação mais "encurvada" dessas amostras, porém, não apareceram resultados satisfatórios. Farsan (1994) descreveu que os tentaculitoideos possuem a concha "encurvada" durante os primeiros estágios de formação da concha primária. As amostras foram encontradas todas fragmentadas e em ambientes com baixo índice de oxigênio (como explicado anteriormente).

Esses organismos já foram abordados como "roll marks", marcas de rolamento de cefalópodes, (BOSETTI et al., 2010) ?Ctenoceras (BOSETTI et al., 2011; HORODYSKI et al., 2014) e tentaculitoideos. Esses espécimes encontram-se visivelmente preservados de maneira diferente do que os outros tentaculitoideos já encontrados (Figura 28). 


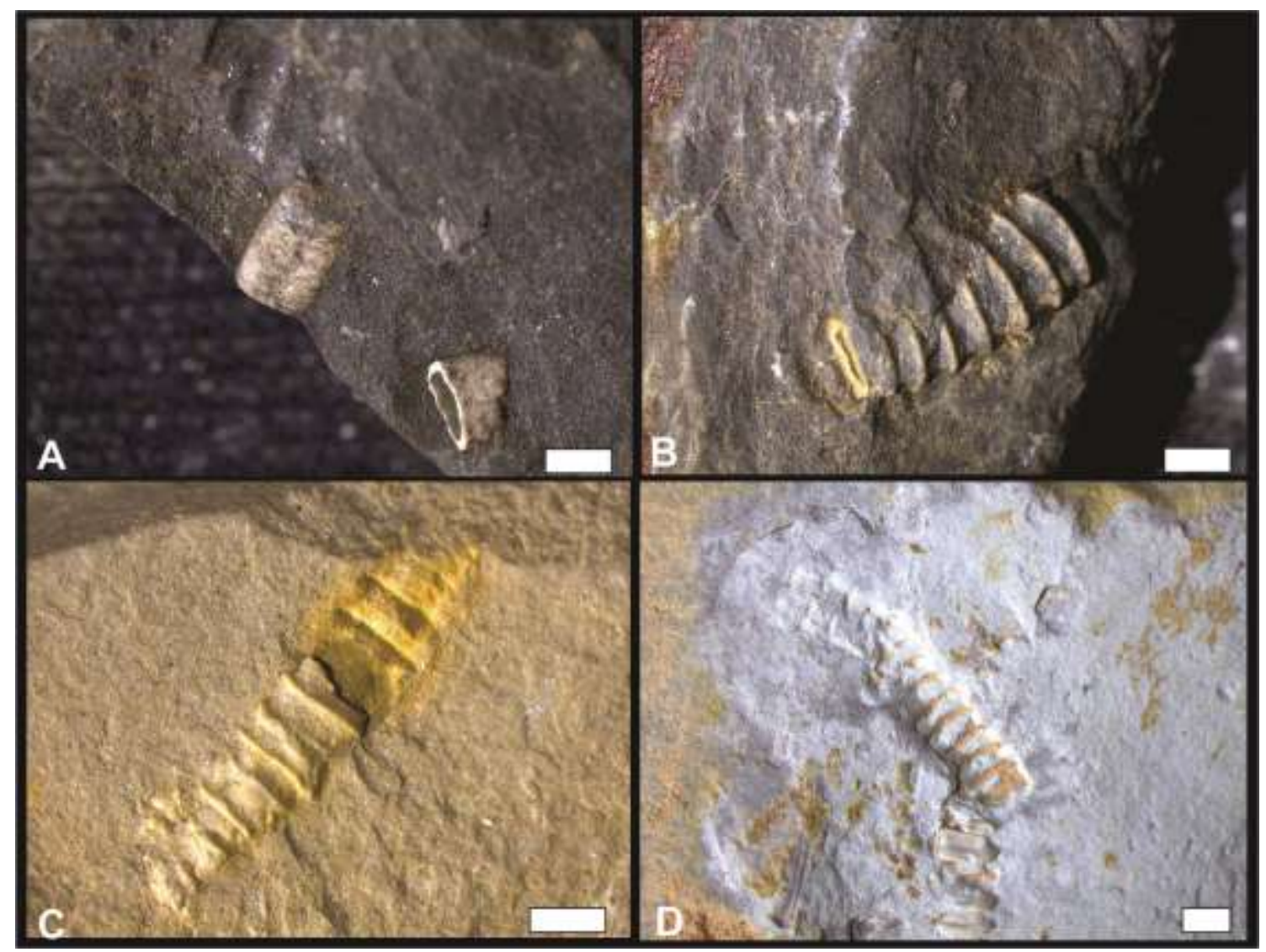

Figura 28. Estampa ilustrativa de prováveis tentaculitoideos encontrados em afloramentos do Devoniano médio, Bacia do Paraná. A e B (UEPG, sem numeração). C) MPI 8628. D) MPI 9298 (Escala de 1mm).

Como este organismo é encontrado frequentemente nos afloramentos e não há consenso quanto a sua classificação taxonômica, buscou-se ajuda com outros pesquisadores para possíveis elucidações quanto ao material encontrado.

Porém, novos achados em afloramento no município de Tibagi, coletados durante o ano de 2013 sugerem uma linha de raciocínio nova onde esses organismos podem ser considerados tubos de vestimentíferos cilíndricos longitudinalmente irregulares, flexionados, sem septos, túbulos internos ou extremidade aboral visível (BOSETTI et al., 2014). Neste trabalho os autores afirmam que a cimentação de carbonato precipitado na parte interna e nas partes externas dos tubos, com isso os organismos se projetariam verticalmente na coluna d'agua sendo explicada a aparente articulação dos tubos. Os tubos vestimentíferos (Figura 29) seriam semelhantes ao Lamellibrachia atual. Complementam ainda, que o fato de possuírem preservação diferenciada, demonstrando um formato mais "curvo", demonstra que esses tubos seriam mais flexíveis. 


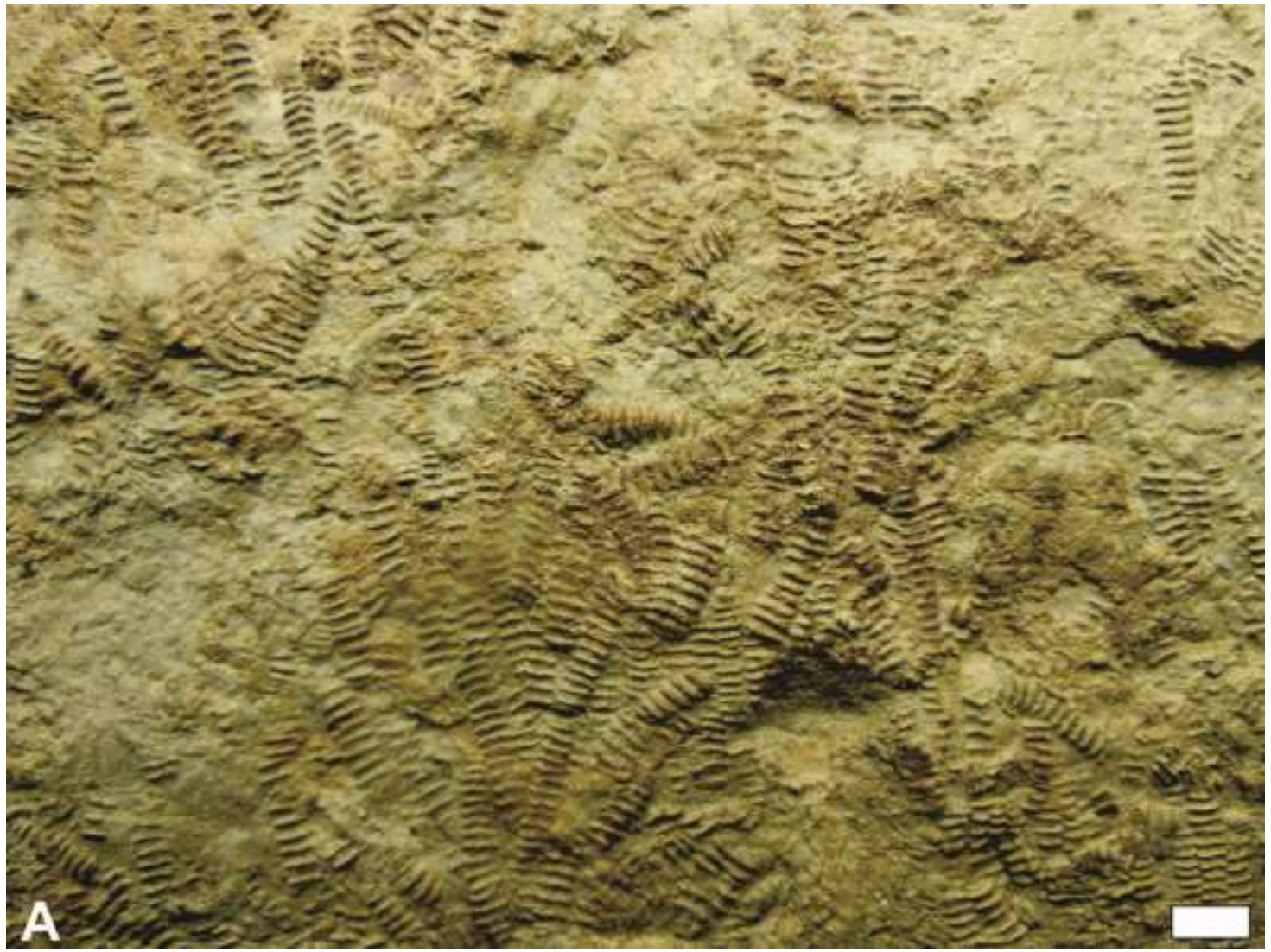

Figura 29. Amostra com prováveis tubos vestimentíferos. (UEPG, amostra sem numeração. Escala $1 \mathrm{~mm})$. 


\subsection{ANÁLISES TAFONÔMICAS}

As análises tafonômicas tiveram como objetivo estabelecer a questão da aloctonia ou autoctonia dos tentaculitoideos, indicação de mistura temporal e a distribuição paleobatimétrica dos organismos além das questões energéticas relacionadas à gênese das concentrações fossilíferas.

Para as análises foram verificadas as feições estratigráficas, feições sedimentológicas e feições bioestratinômicas.

Feições bioestratinômicas como abrasão, bioerosão, predação e incrustação, já foram registradas em tentaculitoideos de bacias sedimentares não brasileiras. $\mathrm{O}$ mesmo não foi ainda registrado para o Brasil.

Berkyová et al. (2007) descrevem a provável ocorrência de predação em tentaculitoideos em alguns exemplares do Devoniano da Polônia. Larsson (1979) e Farsan (1994) verificaram a presença de incrustação por epizoários na região da abertura em alguns tentaculitoideos.

Os trabalhos de Brett e Baird (1986), Kidwell et al. (1986), Holz e Simões (2002), Rodrigues et al., (2003), Ghilardi (2004), Simões et al. (2010), Zabini et al., (2010), Zabini et al., (2012) e Horodyski (2014) foram essenciais para a proposição das classes tafonômicas descritas abaixo.

Segundo Brett e Baird (1986) as análises de alguns fenômenos bioestratinômicos e diagenéticos, podem auxiliar na determinação de fácies tafonômicas. Kidwell et al. (1986) descrevem diversas interpretações sobre as análises de concentrações fossilíferas. Enquanto que Speyer e Brett (1986) no seu trabalho sobre a tafonomia de trilobitas do Devoniano introduzem o conceito de "tafofácies". Tafofácies consiste em uma associação fossilífera com assinaturas tafonômicas distintas em um determinado nível sedimentar que evidencia com maior segurança a história deposicional dos restos esqueléticos em estudo (HORODYSKI, 2014).

O bioclasto apresentará uma gama considerável de padrões de preservação refletindo diferenças substanciais em suas características tafonômicas. Após análise das amostras, foi possível verificar a presença de dois conjuntos preservacionais tafonômicos distintos: amostras com espécimes isolados e agrupados. Foi possível a elaboração de 6 classes tafonômicas (Figura 30). Verificaram-se associações com outros grupos de invertebrados: artrópodes, anelídeos e moluscos bivalves. 


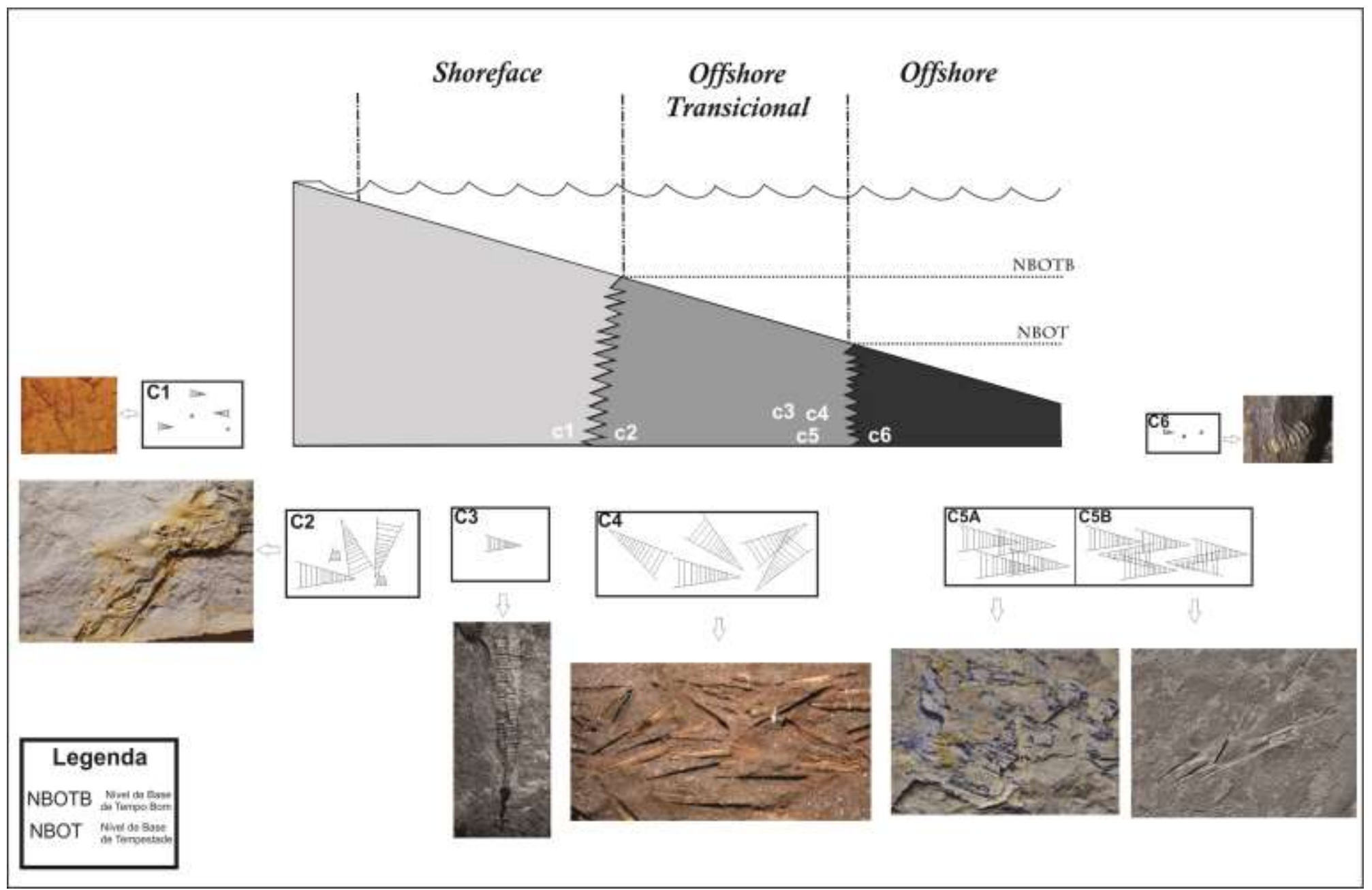

Figura 30. Demonstração das classes tafonômicas descritas, em níveis paleobatimétrica. Classe $\mathrm{C} 1$ ocorrentes no shoreface. Classes $\mathrm{C} 2$ encontrada no offshore transicional, logo abaixo do NBOTB. As classes C3, C4, e C5 encontram-se acima do Nível de Base de Tempo Bom (NBOT), no offshore transicional. Enquanto que a classe C6 localiza-se abaixo do Nível de Base de Tempestade (NBOT), no offshore. 
Levando em consideração que os espécimes inteiros possuem todas as partes da concha: embrionária, juvenil e adulta e os espécimes agrupados quando encontrados de 5 indivíduos.

\section{Classe 1}

Descrição: correspondem a organismos isolados e sem fratura longitudinal da concha. Ocorrem em Siltitos arenosos. Sem orientação preferencial. Todos os fósseis encontrados concordantes ao plano de acamamento (Figura 30).

Os espécimes encontrados pertencem ao gênero Tentaculites. Foram encontrados em afloramentos dos municípios de Jaguariaíva (Jaguariaíva) e Ponta Grossa (Campus). Encontram-se distribuídos no início da Sequência B e no final da Sequência D.

Interpretação: São encontrados na base do Trato de Sistema Transgressivo (TST), sequência B. Esta classe tafonômica ocorre em ambientes de shoreface, ambientes de águas rasas predominantes, situados acima no Nível de Base de Tempo Bom (NBOTB). Configura uma região de alta energia do ambiente, os organismos encontravam-se fragmentados, sem fraturas ao longo da concha e em alguns casos inteiros. A fragmentação podem indicar ambientes altamente energéticos ou tempos prolongados de retrabalhamento (BRETT; BAIRD, 1986). São organismos alóctones (KIDWELL et al., 1986). De acordo com Kidwell et al. (1986) ambientes acima do Nível de Base de Tempo Bom (NBOTB) são ambientes altamente energéticos, ocorrendo o retrabalhamento das concentrações em algum momento.

\section{Classe 2}

Descrição: Composta por organismos inteiros e fragmentados, agrupados e sem fratura longitudinal. Os tentaculitoideos encontrados nessas subclasses são: Homoctenus sp., Tentaculites sp., e Styliolina sp. Orientação polimodal preferencial. São preservados em siltitos médios (raras as amostras preservadas em siltitos fino). Todos os organismos encontram-se dispostos concordantes ao plano de acamamento. Verificaram-se concentrações na forma de pavimento e em cluster (maior predominância). Associados a Australoscoelia sp., Derbyina sp., Lingulídeos infaunais e bivalves indeterminados. Em algumas amostras foram encontrados indivíduos inteiros bem como fragmentados, indicando mistura temporal. Amostras densamente empacotada (Figura 30). 
Encontrados nos afloramentos de Jaguariaíva, Boa Vista, Sim da B, Aeroporto, Desvio Ribas e Placidina. Registrados na sequência B com 33 espécimes e no início da C com aproximadamente 86 casos registrados.

Interpretação: esta classe está localizada no offshore transicional logo abaixo do Nível de Base de Tempo Bom (NBOTB), ambiente relativamente energético. $\mathrm{O}$ alto grau de empacotamento pode refletir na acentuada seleção hidráulica ou baixa taxa de sedimentação. Neste caso são encontrados indivíduos inteiros e fragmentados, isso indica que o evento deposicional que gerou esta tafocenose, reuniu diferentes fases de retrabalhamento dos tentaculitoideos. Os fragmentos estavam no ambiente a mais tempo do que os indivíduos inteiros, os quais foram, provavelmente, incorporados durante o evento que gerou o depósito sedimentar (KIDWELL et al., 1986; HOLZ; SIMÕES, 2002). São considerados indivíduos parautóctones a alóctones (KIDWELL et al., 1986).

\section{Classe 3}

Descrição: Espécimes inteiros, isolados e sem fratura longitudinal. Esta classe foi encontrada em uma quantidade maior localidades, sendo encontradas em siltitos médios e argilosos. Associados a fauna de Australoscoelia sp., Gigadiscina sp., Australospirifer sp., Derbyina sp. e Lingulídeos infaunais.

Foram registrados em diversos afloramentos: Jaguariaíva, São bento, Desvio Ribas, Rivadávia, Sítio Wolff, Caniú, Xaxim, Curva 1, SIM da B, Fazenda da Guarda, Alto do amparo, Fazenda Fortaleza, Estrela e Vila Placidina.

O registro estratigráfico é o mais amplo de todas as classes, sendo encontrados 79 espécimes (Tentaculites sp., Homoctenus sp., Uniconus sp. e Styliolina sp.) na sequência $\mathrm{B}$, no início da sequência $\mathrm{C}$ ocorre uma diminuição de $73 \%$ desta subclasse. Volta a ocorrer no final da sequência D e no início da E com aproximadamente 54 espécimes (Figura 30).

Interpretação: Os organismos são encontrados preferencialmente no offshore transicional, localizada entre o Nível de Base de Tempo Bom (NBOTB) e o Nível de Base de Tempestade (NBOT). Onde foram preservados inteiros, sem fragmentação longitudinal. Sendo considerado um ambiente calmo, baixa energia do meio, porém, em alguns momentos ocorrem distúrbios decorridos de tempestades. Os organismos desta 
classe são parautócnes e alóctones (KIDWELL et al., 1986). Os fósseis ocorrem na sequência $\mathrm{B}$, início da $\mathrm{C}$ e sequência $\mathrm{E}$.

\section{Classe 4}

Descrição: classe constituída por indivíduos inteiros, agrupados, sem orientação preferencial, sem fratura longitudinal. Foram encontrados em siltitos médios. A única espécie encontrada para esta subclasse foi à espécie Homoctenus katzerius e alguns representantes do gênero Homoctenus, sem possível identificação específica. Todos os organismos estão dispostos concordantemente ao plano de acamamento, direcionados de maneira polimodal e geometria do tipo pavimento. A maioria das amostras possui frouxo grau de empacotamento. Associações com Australoscoelia sp. e Derbyina sp. A classe 4 encontra-se em afloramentos de Ponta Grossa (Caniú e Curva 1), sendo encontrada no início da Sequência B e no início da Sequência C (Figura 30).

Interpretação: Esta classe encontra-se no offshore transicional, localizada entre o Nível de Base de Tempo Bom (NBOTB) e o nível de base de tempestade (NBOT). Aparecem em siltitos cinzas e siltitos argilosos amarelados. A distribuição polimodal observada é decorrente de ambiente com fluxos de energia com velocidade inferior à necessária para movimentar os bioclastos ou a presença de fluxo turbulento durante a formação de assembleias fossilíferas (HOLZ; SIMÕES, 2002). São considerados organismos parautóctones (KIDWELL et al., 1986). O fato dos organismos estarem dispostos com frouxo grau de empacotamento corrobora com a ideia de serem encontrados em ambientes com baixo nível energético, visto que este tipo de feição é característica de ambientes com pouco retrabalhamento (KIDWELL et al., 1986; HOLZ; SIMÕES, 2002).

\section{Classe 5}

Descrição: corresponde a organismos inteiros, agrupados e possuem reorientação preferencial uni ou bidirecional. Esta classe pode ser dividida em subclasse 5A (organismos unidirecionais) e subclasse 5B (organismos bidirecionais). Os exemplares foram encontrados em grande abundância em siltitos médios e apenas uma amostragem em siltitos arenosos. Foram encontrados representantes do gênero Homoctenus e Tentaculites. Da totalidade de amostras analisadas para esta subclasse, $64,3 \%$ encontravam-se redirecionadas bidirecionalmente e $35,7 \%$ de maneira 
unidirecional. De acordo com a geometria das formas unidirecionais, aproximadamente $80 \%$ da amostragem encontrou-se disposta em cluster (Figura 30).

Da totalidade de amostras encontradas na subclasse $5 \mathrm{~A}, 83,5 \%$ destas encontravam-se aparentemente, unidas na parte proximal dos tentaculitoideos, aqui chamadas de preservação em "buque", visto que a preservação dos organismos apresenta um formato de buque. Todos os organismos encontravam-se dispostos em concordância ao plano de acamamento. Não foi encontrado nenhum grupo de macroinvertebrados associados a esta subclasse.

Ambas as subclasses são registradas nos mesmos afloramentos de Jaguariaíva (afloramento Jaguariaíva) e Tibagi (afloramento conhecido como SIM da B). Esta é encontrada na sequência B (NeoPraguiano ao EoEmsiano) e no início da sequência C (NeoEmsiano).

Interpretação: Esta classe é encontrada em ambientes de offshore transicional, acima do Nível de Base de Tempestade (NBOT). Os organismos desta classe encontram-se em ambientes calmos, com atividade de fluxos oscilatórios de energia. As correntes oscilatórias atingem o fundo, retrabalha o sedimento para gerar formas de leito simétrico e podem alinhar os restos orgânicos (BRETT; BAIRD, 1986; HOLZ; SIMÕES, 2002). O mesmo tipo de preservação descrita na subclasse 5A, já foi relatado por Ciguel (1989) como sendo provável incrustação da concha no substrato ou em conchas de outros animais. Porém, não foram encontrados resquícios de conchas ou de um substrato diferente. Uma hipótese alternativa seria que esse padrão de preservação ocorre quando existiu um evento com correntes unidirecionais (LANGE; PETRI, 1967), diferente do padrão apresentado na subclasse 4 (descrita acima), em que todos os espécimes encontram-se sem direção definida e muitas vezes fragmentada, o que, nesse caso, sugere um fluxo energético oscilante. São considerados parautóctones (KIDWELL et al., 1986).

\section{Classe 6}

Descrição: Representado por organismos inteiros e fragmentados e isolados. Ocorrem em folhelhos negros. Todos os organismos encontram-se dispostos concordantes ao plano de acamamento. Não foi possível a identificação dos espécimes a nível genérico ou específico. Registou-se a presença em afloramentos dos municípios Ponta Grossa (Vila Placidina) e Tibagi (São Bento). Em alguns casos foi encontrado 
associações com Nuculites sp. São encontrados na base da sequência B e no início da sequência E (Figura 30).

Interpretação: esta classe é encontrada em ambientes de offshore, abaixo do Nível de Base de Tempestade (NBOT). Os fósseis aqui encontrados encontram-se isolados inteiros e/ou fragmentados. As fraturas longitudinais devem ser causadas pela compactação da concha durante os processos diagenéticos. A presença de pirita nos fósseis é indicativa de ambientes com baixo teor de oxigênio (anóxicos). No caso dos tentaculitoideos registrados, provavelmente, trata-se de organismos que sofreram transporte por correntes marinhas, sendo depositados em ambientes de offshore. São alóctones (KIDWELL et al., 1986). 


\subsection{BIOESTRATIGRAFIA E EXTINÇÃO DA CLASSE}

Foram analisadas 800 amostras, com aproximadamente 4.818 espécimes. Sendo, 13 amostras provenientes de afloramentos do Devoniano da Bacia do Parnaíba, 27 da Bacia do Amazonas e 757 da Bacia do Paraná. Na Bacia do Paranaíba foram contabilizados 143 espécimes, na Bacia do Amazonas 99 espécimes e na Bacia do Paraná com aproximados 4.576 espécimes.

As análises das amostras demonstraram 12 espécies no Devoniano brasileiro (Figura 31). Na Bacia do Paraná foram reconhecidas as espécies: T. crotalinus, $T$. jaculus, T. kozlowskius, T. paranaensis, U. ciguelius, H. katzerius e Styliolina cf. Styliolina fissurella. Enquanto na Bacia do Amazonas: T. stubeli, T. trombetensis, T. eldredgianus e $S$. clavulus. Para a Bacia do Parnaíba as espécies encontradas foram: $T$. oseryi, T. trombetensis, T. eldredgianus e $S$. clavulus.

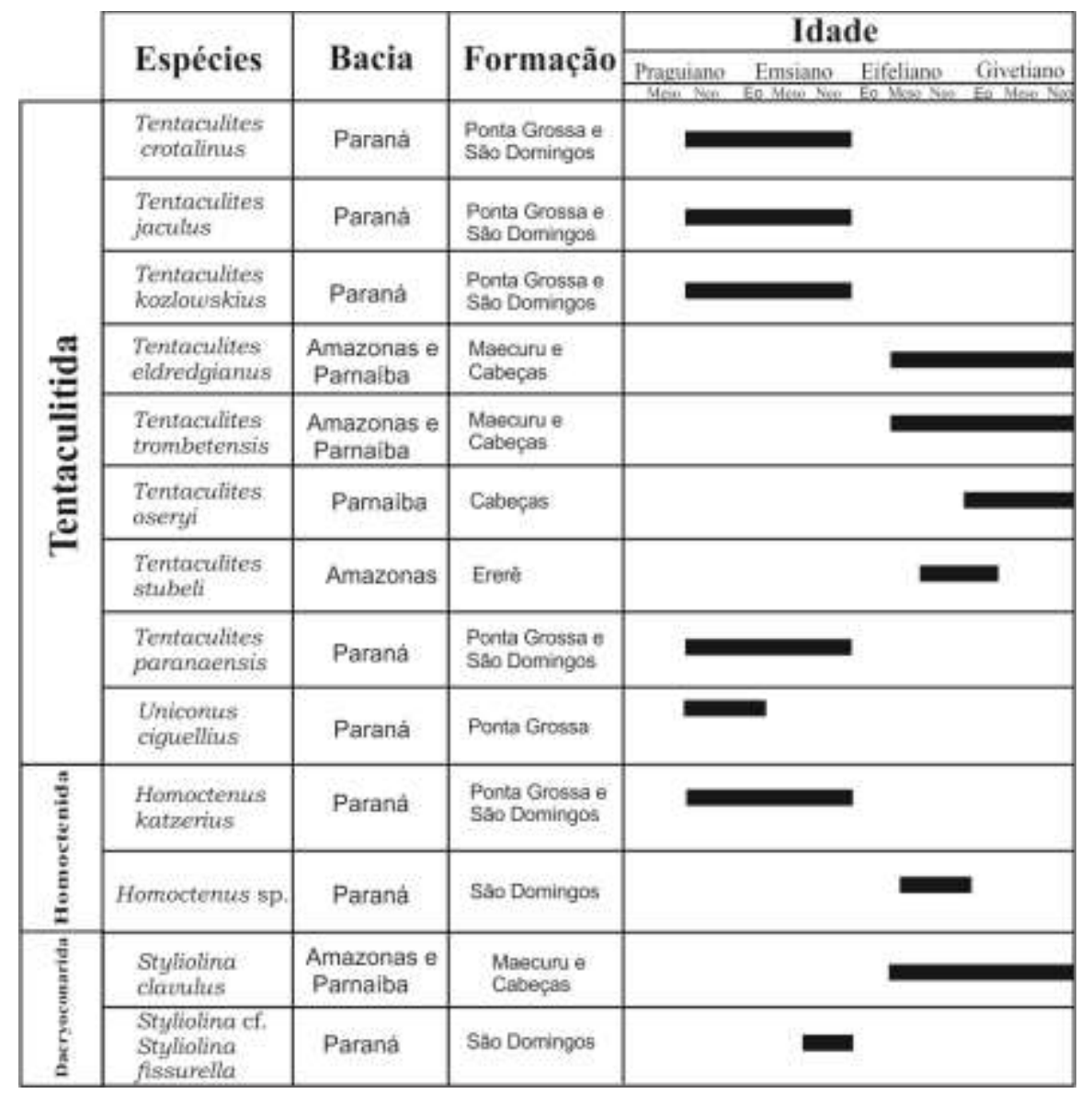

Figura 31. Distribuição bioestratigráfica das espécies de tentaculitoideos encontrados nas Bacias do Paraná, Amazonas e Parnaíba. As espécies da Bacia do Paraná possuem um registro desde o final do Praguiano, enquanto que as espécies da Bacia do Amazonas e Parnaíba iniciam sua distribuição apenas durante o Eifeliano. 


\section{DISCUSSÃO}

\subsection{SISTEMÁTICA PALEONTOLÓGICA}

No trabalho de Ciguel (1989), o autor trabalhou com 51 espécies, dentre elas 31 espécies novas para o Devoniano da Bacia do Paraná e 1 para a Bacia da Amazonas. No trabalho, o autor descreveu também novas espécies para a Argentina, Bolívia e Peru, porém estas amostras não se encontram em território brasileiro.

O autor descreveu uma grande quantidade de espécies das três ordens conhecidas de tentaculitoideos, sendo elas: 15 espécies para a ordem Tentaculitida (14 para a Bacia do Paraná e 1 para a Bacia do Amazonas), 9 Homoctenídeos (Bacia do Paraná) e 8 Dacryoconarídeos (Bacia do Paraná). Foi possível a observação das amostras descritas pelo autor e depositadas nos acervos da coleção Instituto de Geociências (IGc - USP), no Departamento Nacional de Produção Mineral (DNPM), Laboratório de Paleontologia de Invertebrados do Museu Nacional (MN). As amostras depositadas no Centro de Pesquisas e Desenvolvimento Leopoldo A. Miguez de Mello, Petrobrás (CENPES) também foram observadas, quando encontradas.

Porém, algumas das amostras citadas pelo autor, não foram encontradas nas coleções onde o autor referiu o seu depósito. Segundo Ivone Cardoso Gonzales, curadora da coleção (informação verbal) do Instituto de Geociências (IGc - USP) algumas numerações citadas por Ciguel (1989), não são compatíveis com a numeração da coleção.

A dissertação de Ciguel (1989) foi um marco para o começo dos trabalhos com os tentaculitoideos ocorrentes no Devoniano brasileiro. Embora o trabalho tenha sido pioneiro, sendo que dessa forma, verificou-se necessária uma revisão das espécies propostas pelo autor, visto a grande quantidade de novas espécies descritas por ele. A não publicação destas espécies propostas pelo autor, segundo o código de nomenclatura zoológica, torna estas espécies não válidas sistematicamente.

Ciguel (1989) em sua dissertação, sinonimiza a espécie Tentaculites jaculus proposta por Clarke (1913) como sendo pertencente ao gênero Seretites Lyashenko, 1969. Segundo Ciguel (1989), Seretites apresentaria a região da câmara embrionária e juvenil lisa, sem ornamentações, sendo esta uma característica autapomórfica ao gênero. Porém esta característica morfológica não é apresentada na diagnose do gênero e em nenhum dos espécimes, já descritos (LYASHENKO, 1969). Sendo assim, optou-se em 
manter a espécie Tentaculites jaculus, não realizando a transferência do gênero como proposta por Ciguel (1989).

A espécie Tentaculites crotalinus Salter, 1856 foi reconhecida por Clarke (1899) e Katzer (1903) de forma pioneira para as bacias do Amazonas e Parnaíba. Assim como Clarke (1913) reconhece a espécie para a Bacia do Paraná. Entretanto, Ciguel (1989) propõe a transferência de gênero da espécie Tentaculites crotalinus para Uniconus crotalinus. Após análises das amostras de Tentaculites crotalinus citadas por Clarke (1913) e amostras estudadas por Ciguel (1989), verificou-se que a principal característica do gênero Uniconus não era encontrada nas espécies descritas por Ciguel (1989). O gênero Uniconus é reconhecido por apresentar os anéis da região posterior voltado para a região da abertura, o que não foi verificado em nenhuma das amostras relacionadas por Ciguel (1989). Dessa forma, prefere-se assumir a existência da espécie T. crotalinus como válida dentro do Domínio Malvinocáfrico do devoniano brasileiro.

Os espécimes encontrados e analisados são resultados de amostras inteiras e fragmentadas das partes juvenis e adulta dos tentaculitoideo. Entretanto, foi registrada uma ocorrência (COMNISKEY; GHILARDI, 2014) contendo os estágios larvais dos tentaculitoideos. A amostra foi encontrada em afloramento do Devoniano da Bacia do Paraná. No exemplar analisado, apesar de fragmentado, observa-se a presença das regiões metalarval, epilarval e o início da fase juvenil de um tentaculitoideo (Figura 32).

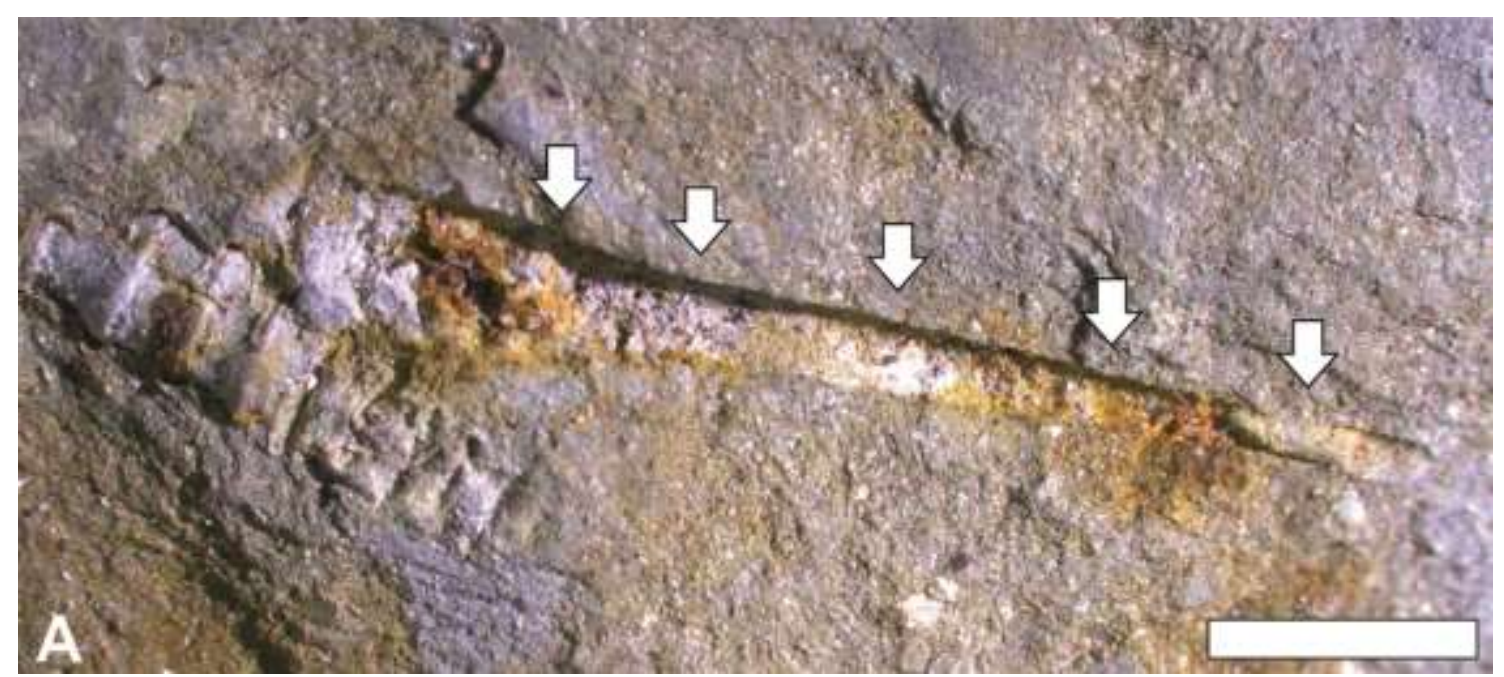

Figura 32. A figura acima mostra uma forma larval de tentaculitoideo encontrado no município de Jaguariaíva, Devoniano da Bacia do Paraná. As setas em branco demonstram a parte larval da concha. (Amostra CCLP 15, UNESP-Bauru. Escala 4mm). 


\subsection{ANÁLISES TAFONÔMICAS}

A interpretação das classes tafonômicas para tentaculitoideos é dificultada pela falta de consenso quanto à ecologia do animal. Dessa forma a identificação em relação aos os organismos estarem in situ ou em posição de vida é comprometida. Como não há consenso sobre o hábito de vida dos tentaculitoideos, a interpretação da batimetria com base nos bioclastos fica também dificultada. Embora exista esta dificuldade, especula-se que os tentaculitoideos possuem preferência a ambientes de baixa energia, provavelmente em ambientes de offshore transicional, entre o Nível de Base de Tempo Bom (NBOTB) e o Nível de Base de Tempestade (NBOT), onde foram descritas 3 das 6 classes tafonômicas nomeadas.

Como já referido anteriormente, verificou-se grande diversidade de tipos de preservação, não sendo possível identificar a preferencial. Entretanto, duas classes são dominantes: bioclastos isolados e bioclastos agrupados.

A classe tafonômica 1 foi encontrada em ambientes proximais, onde a preservação é mais rara, visto a alta energia do ambiente e o alto índice de fragmentos de valvas. Esta classe tafonômica é dominada por turbulência ou influenciada por ondas e tempestades, são os agentes mais efetivos na fragmentação das carapaças de organismos marinhos (SIMÕES et al., 2010). Esta classe encontra-se na base dos Tratos de Sistema Transgressivo (TST), consiste em fragmentos de valvas e organismos com transporte, a qual corresponde com ambientes de alta energia e baixas taxas de sedimentação.

A classe 2 é caracterizada por organismos de diversos tamanhos associados a fragmentos de concha, isso indica alta energia. A mistura temporal, provavelmente, ocorre mesmo que em baixo grau. Este fenômeno resulta da bioturbação dos sedimentos e da compactação dos mesmos, entretanto, principalmente do retrabalhamento dos substratos por agentes hidráulicos, tais como as tempestades e ondas, sob regime de baixa taxa de sedimentação (SIMÕES et al., 2010). De fato, eventos raros de tempestade, abaixo do NBOTB, podem ser responsáveis pelo transporte de fragmentos de valvas até o offshore distal, misturando os fragmentos com as valvas inteiras de tentaculitoideos.

A base da sequência B (NeoPraguiano) é caracterizada por um Trato de Sistemas Transgressivo (TST), caracteriza-se pelo início da retrogradação, ou seja, o mar adentra o continente (BERGAMASCHI, 1999). As porções finais do TST são características de 
um ambiente de baixa energia. O TST é caracterizado pelo aumento das taxas de acomodação e aumentando da profundidade da coluna de água. Verificou-se que as classes 2, 3, 4 e 5 foram registradas na porção mediana e superiores do TST na sequência B. Como já destacado por Zabini et al. (2012) as partes medianas e superiores do TST representam momentos de baixa a média diversidade de espécies e menores taxas de sedimentação. Este mesmo fato foi verificado nos espécimes analisadas, visto que a sua diversidade diminui aproximadamente $37 \%$ se comparada com a diversidade das porções iniciais do TST.

A classe 6 possui registro restrito as camadas de offshore, encontram-se abaixo do NBOT, onde demonstram índice fragmentação e fraturamento dos fósseis, onde são resultados de transporte e processos de compactação da concha durante as fases da diagênese. Não foram encontradas amostras com bioerosão e incrustação. Esta classe ocorre no início da sequência E que corresponde por a uma superfície transgressiva (GRAHN et al., 2013). Algumas amostras encontradas no limite da sequência D-E (NeoEifeliano-EoGivetiano), foram utilizadas para realização de Espectroscopias de raios-X: Espectroscopia de Energia Dispersiva (MEV-EDS) e Energia Dispersiva de Fluorescência de Raios-X (EDXRF). As análises mostraram a presença de ferro, enxofre e pirita e ainda revelaram que as conchas estão intimamente associadas com minerais de argila. Em conjunto, as análises indicam, portanto, ambientes profundos pobres em oxigênio. Esse fato corrobora a hipótese de que esses tentaculitoideos possam estar relacionados a uma grande extinção global já que as amostras analisadas foram encontradas em afloramentos onde foi registrada a ocorrência do evento Kačák para a Bacia do Paraná (BOSETTI et al., 2011). O evento Kačák é uma das principais crises bióticas globais ocorridas no Devoniano durante a passagem Eifeliana/Givetiana (BOSETTI et al., 2011; HORODYSKI et al., 2014). O evento já foi registrado na República Tcheca, Marrocos, Austrália, Escócia, Inglaterra, China, Alemanha, Estados Unidos e Brasil (BOUCOT, 1990; TRUYOLS-MASSON et al., 1990; MAY, 1995; WALLISER et al., 1995; House, 1996; BOSETTI et al., 2011; GRAHN et al. 2013; HORODYSKI et al., 2014; HORODYSKI 2014). No Brasil foram reconhecido nos estratos devonianos da Bacia do Paraná por Bosetti et al. (2011), Grahn et al. (2013), Horodyski et al. (2014) e Horodyski (2014).

O período é característico pela hipoxia global seguido por depósitos de folhelhos pretos (HOUSE, 1996). Para Truyols-Masson et al. (1990) existe um grande consenso sobre o fato de que o evento começou com um aumento rápido e grande do de nível do 
mar, que introduz abruptamente condições anóxicas que resultaram em depósitos de folhelho preto. House (1996) complementa ainda que o pico transgressivo associado com o evento Kačák causou mudanças drásticas no meio ambiente, incluindo a alteração na temperatura, oxigenação e na produção primária.

Ademais, os tentaculitoideos estão relacionados a outro evento de extinção, descrito para o Hemisfério Norte, conhecido como Crise Kellwasser (no limite Frasniano - Fameniano) onde também há relatos de anoxia (SCHINDLER 1990, 1993, 2012; BOND, 2006; WITTMER; MILLER, 2011; WEI et al., 2012).

Farsan (1994) descreve que os bioclastos de tentaculitoideos estudados por ele viveram em ambientes de profundidade de até 100 metros e que apresentam pouco ou nenhum transporte, visto que suas conchas não apresentam sinais de tais feições. Para o autor as feições são decorrentes de predadores, após a morte do animal. Essas afirmações não foram comprovadas neste trabalho. Ambientes com aproximadamente 100 metros de profundidade, são locais onde a energia do ambiente é baixa, nas análises foram encontrados organismos fragmentados e raros os casos de organismos inteiros neste tipo de ambiente. Vale observar ainda que para Farsan (1994) propõe um modo de vida séssil para estes organismos. Para que os organismos mantivessem fixos no substrato deveria existir algum mecanismo que fixasse a concha ao substrato, porém tal estrutura não foi relatada por nenhum autor até o presente. A única menção a estruturas de partes moles dos tentaculitoideos foi feita por Blind (1969) quando descreve a presença de "tentáculos" na região da abertura dos tentaculitoideos, para o autor este mecanismo era utilizado para facilitar a alimentação do animal e não a sua sustentação. Larsson (1979) desconsidera o registro dos prováveis tentáculos, visto que as fotos apresentadas por Blind (1969) apenas apresentam imagens de fósseis mal preservados, sem a presença de características conclusivas.

Segundo Farsan (1994), a preservação de tentaculitoideos com preferência a reorientação das ondas seria raro. Tal hipótese, contudo, não parece válida visto que diversos autores (BRETT; BAIRD, 1986; KIDWELL et al., 1986; CIGUEL, 1989; HOLZ; SIMÕES, 2002; COMNISKEY; GHILARDI, 2013) já verificaram este tipo de preservação em tentaculitoideos do Devoniano. 


\subsection{BIOESTRATIGRAFIA E EXTINÇÃO DA CLASSE}

Poucos são os trabalhos que citam as espécies de tentaculitoideos encontradas no Devoniano da América do Sul (THOMAS, 1905; DAVILA; RODRIGUEZ, 1967; ISAACSON et al., 1976; LAUBACHER et al., 1982; MALETZ et al., 2002; PRESSER et al., 2004; MALANCA et al., 2010; RACHEBOEUF et al., 2010).

O material analisado e utilizado para a bioestratigrafia do grupo são amostras procedentes de coletas de campo e/ou observados na coleção técnica (do acervo da UEPG) da Bacia do Paraná (Sub-bacia Apucarana), pois apresentavam um maior detalhamento estratigráfico, visto que todas as amostras eram derivadas de afloramentos com datações realizadas (GRAHN et al., 2010, 2013). Os espécimes analisados da Bacia do Amazonas e Parnaíba, as informações estratigráficas dos afloramentos, foram retirados através de literatura especializada (GRAHN et al., 2010; SCHEFFLER, 2010).

As espécies descritas para a Bacia do Paraná, possuem distribuição estratigráfica do NeoPraguiano ao NeoEmsiano, entretanto fragmentos de Homoctenus sp. foram registrados para as camadas do final do Eifeliano e início do Givetiano. Entretanto, não foi possível a identificação específica destes espécimes, apenas a nível genérico. Apesar das espécies não serem contemporâneas cronoestratigraficamente, todas elas extinguemse do registro no início do Givetiano.

As espécies $T$. crotalinus, $T$. jaculus, $T$. kozlowskius, $T$. paranaensis e H. katzerius possuem distribuição do NeoPraguiano ao NeoEmsiano. Já $U$. ciguelius tem distribuição entre o NeoPraguiano ao EoEmsiano. Por fim, Styliolina cf. Styliolina fissurella tem sua distribuição entre o Meso e NeoEmsiano.

As espécies de tentaculitoideos encontrados na Bacia do Paraná são diferentes das espécies encontradas na Bacia do Amazonas e Parnaíba.

$\mathrm{Na}$ Bacia do Amazonas a distribuição estratigráfica inicia no MesoEifeliano até EoGivetiano. As espécies encontradas nessa bacia são T. eldredgianus, T. trombetensis e S. clavulus, que possuem distribuição estratigráfica no MesoEifeliano e T. stubeli encontrada no NeoEifeliano ao EoGivetiano.

$\mathrm{Na}$ Bacia do Parnaíba os espécimes encontram-se distribuídos do MesoEifeliano ao EoGivetiano. As espécies reconhecidas para essa bacia (T. eldredgianus, $T$. trombetensis e S. clavulus) possuem distribuição estratigráfica no MesoEifeliano. A espécie T. oseryi foi encontrada apenas durante Givetiano (Figura 33). 
Após as análises sistemáticas foi possível a confecção de mapas (Figuras 33 e 34) para visualizar da distribuição geográfica dos espécimes encontrados no Brasil.

Verificou-se que durante o Devoniano Inferior (Figura 33) apenas as espécies da Bacia do Paraná foram encontradas, tais como: T. crotalinus, T. jaculus, T. kozlowskius, T. paranaensis, H. katzerius, U. ciguelius e Styliolina cf. Styliolina fissurella.

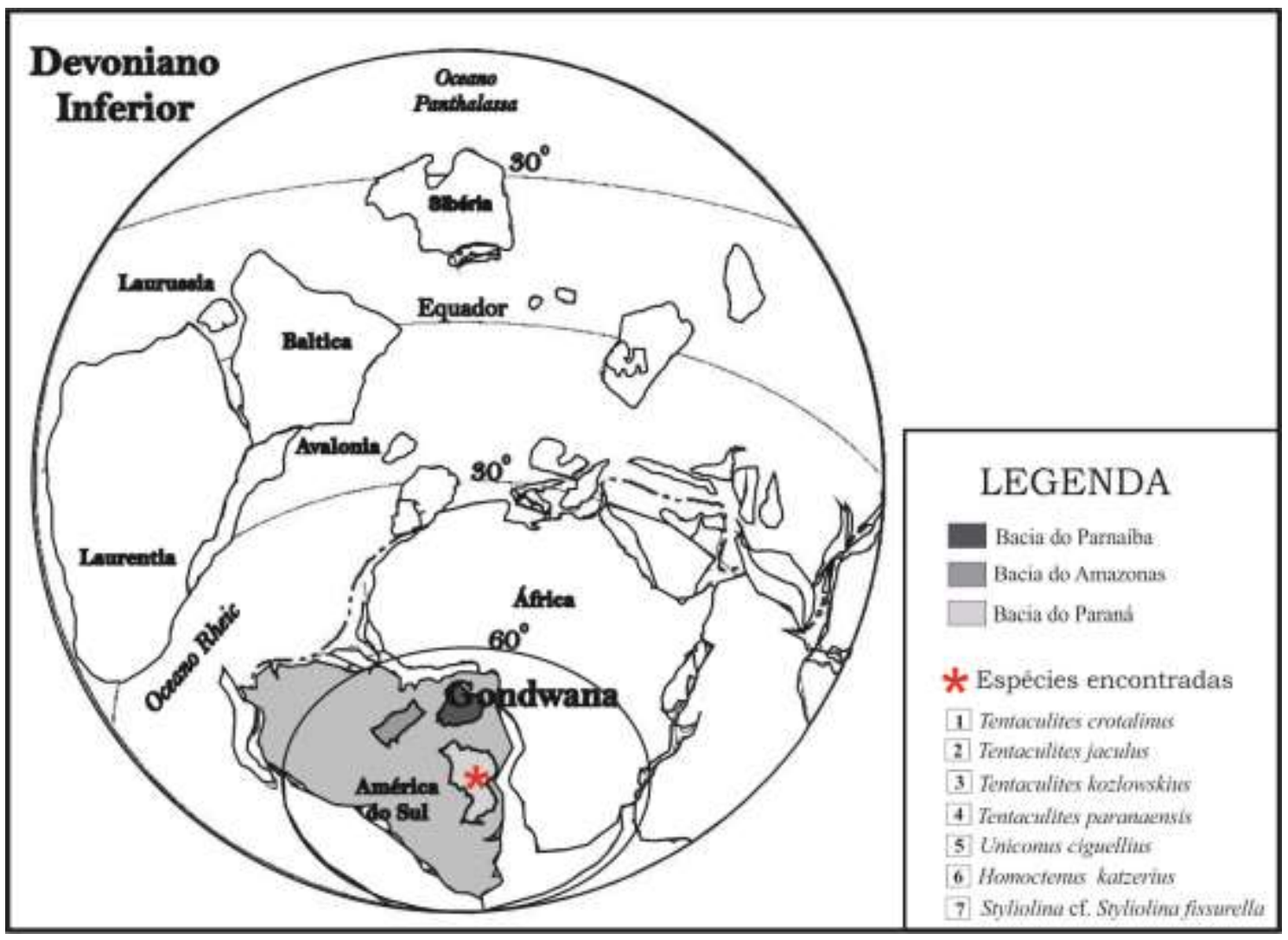

Figura 33. A figura demonstra a distribuição paleogeográfica das espécies brasileiras encontradas durante o Devoniano Inferior. Em vermelho as espécies encontradas durante o Devoniano Inferior (Modificado de TORSVIK; COCKS, 2004).

Durante o Devoniano Médio (Figura 32) verifica-se um decréscimo da diversidade de tentaculitoideos da Bacia do Paraná, o único representante são Homoctenus sp. encontrados nos afloramentos do final do Eifeliano e início do Givetiano. Enquanto que as espécies provenientes da Bacia do Amazonas e Parnaíba aparecem no registro estratigráfico. 


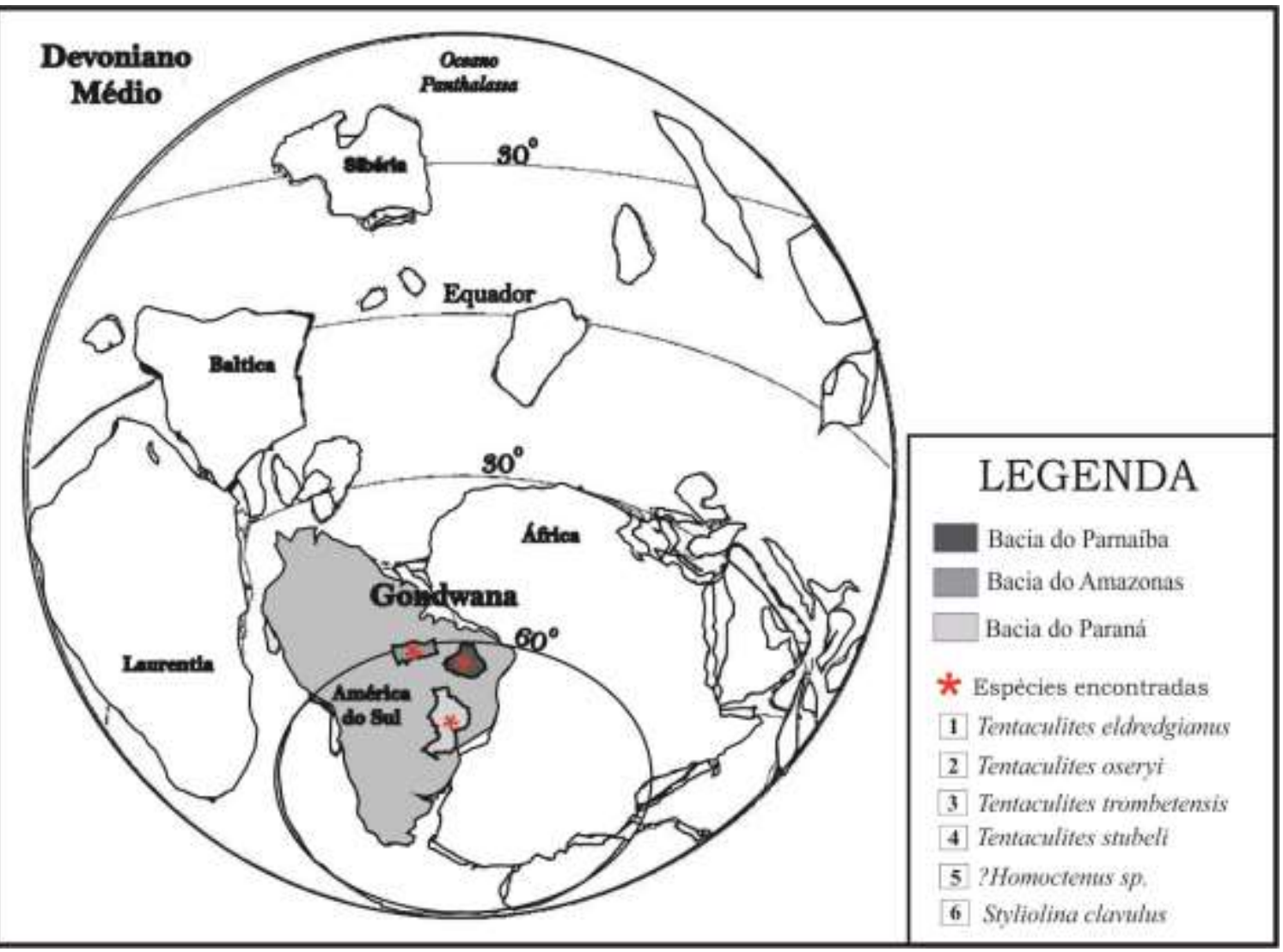

Figura 34. A figura demonstra a distribuição paleogeográfica das espécies brasileiras encontradas durante o Devoniano Médio. Em vermelho as espécies encontradas durante o Devoniano Médio (modificado de TORSVIK; COCKS, 2004).

Alguns registros das espécies descritas originalmente para os estratos devonianos brasileiros foram reconhecidos em outros países da América do Sul. As espécies $T$. crotalinus e $T$. trombetensis foram registradas no Devoniano da Bolívia e Paraguai (DAVILA; RODRIGUEZ, 1967; PRESSER et al., 2004). A espécie T. jaculus foi encontrada no registro no Paraguai e Peru (BOUCOT et al., 1980; PRESSER et al., 2004). Enquanto que a espécie T. stubeli tem registro apenas para o Devoniano do Paraguai (PRESSER et al., 2004). T. eldredgianus foi reconhecido para Devoniano da Colômbia (FORERO, 1983).

Como citado em alguns trabalhos (BOND, 2006; BERKYOVÁ et al., 2007; WITTMER; MILLER, 2011; SCHINDLER, 2012; WEI et al., 2012), a extinção dos tentaculitoideos ainda é motivo de discussões. A grande parte dos autores afirma que a extinção total dos tentaculitoideos ocorre no final do Devoniano, no limite Frasniano Fameniano, porém as causas ainda são controversas. Lyashenko (1967) afirma que representantes do gênero Homoctenus ocorrem no início do Fameniano e são os últimos de que se tem registro deste grupo para o Devoniano. 
Bond (2006) afirma que os homoctenídeos apresentam seu ápice no Devoniano Médio e que durante o limite Frasniano - Fameniano ocorre sua extinção, junto com a extinção total do grupo. Segundo Schindler (1990, 1993, 2012), Bond (2006) e Wittmer e Miller (2011) a extinção do grupo ocorre concomitantemente a um evento de extinção conhecido como "crise de Kellwasser". Essa crise é considerada uma das mais importantes extinções ocorridas no final do Devoniano (SCHINDLER, 1990, 1993, 1996; MAY, 1995; WALLISER, 1996; WEDDIGE, 1996; MCGHEE, 2001), no limite entre o Frasniano e Fameniano.

Hoje em dia sabe se que a crise de Kellwasser não ocorreu de maneira abrupta e sim decorrente de diversos eventos. Em 1850, Roemer identificou os calcários de Kellwasser na Alemanha e reconheceu-o como sendo amplamente distribuída por intercalações de calcários betuminosos pretos e folhelhos têm sido frequentemente mencionados na literatura geológica (SCHINDLER, 1990). No passar dos anos esses sedimentos foram conectados a crise de Kellwasser que ocorreu durante o limite do Frasniano e Fameniano (SCHINDLER, 1990; WALLISER, 1996).

Posteriormente, a crise de Kellwasser foi registrada em afloramentos da França e Marrocos (SCHINDLER, 1990). Nos afloramentos pode verificar a presença de dois horizontes, identificando assim, os primeiros eventos da crise de Kellwasser, bem como os últimos. Os horizontes foram divididos em Baixo Horizonte (= Lower Kellwasser Event), onde corresponde aos primeiros efeitos da crise e Alto Horizonte (= Upper Kellwaser Event), estágio final da crise (SCHINDLER 1990, 1993; MAY, 1995; SCHINDLER; KÖNIGSHOF, 1996; WALLISER, 1996).

A comparação da fauna antes do Baixo Horizonte e após o final do Alto Horizonte, verifica-se que 60 a 75\% de grupos marinhos extinguiram-se ou tiveram um decréscimo acentuado, tais como corais de recifes, trilobitas, ostracodes, tentaculitoideos, conodontes e alguns braquiópodes (SCHINDLER, 1990; MAY, 1995). A crise Kellwasser afetou primeiramente comunidades bentônicas por meio da anoxia. Eventuais pulsos anóxicos subsequentes reduziriam a extensão das áreas de ocorrência dos organismos pelágicos (WITTMER; MILLER, 2011).

Schindler (1990) afirma que dentre os tentaculitoideos, a extinção durante esta crise, também foi gradual, ou seja, as ordens não se extinguiram ao mesmo tempo. Para o autor, os dacryoconarídeos desaparecem do registro após o Baixo Horizonte, enquanto que os Homoctenídeos são os únicos tentaculitoideos que são encontrados durante o 
Alto Horizonte. Segundo o autor os Tentaculitida não são registrados durante o Fameniano.

Apesar do consenso de que esta crise causou diversos danos à comunidade faunística, não existe consenso quanto a suas possíveis causas. Diversas hipóteses ao longo dos anos vêm sido propostas, tais como: o impacto de meteoritos, mudanças na temperatura, com a passagem do Devoniano para o Carbonífero, período de glaciação, aumentos da temperatura no oceano, regressões ou transgressões e eventos de anoxia (SCHINDLER 1990, 1993; MAY, 1995; SCHINDLER; KÖNIGSHOF, 1996; WALLISER, 1996).

Berkyová et al. (2007) considera o período Devoniano com passagens de grandes mudanças nas biosferas terrestre e marinha, o que resultou em perturbações nos grupos de organismos planctônicos. Para os autores, os dacryoconarídeos representavam o grupo mais comum de zooplâncton durante o Devoniano, surgem no Lockoviano e chegam ao seu ápice durante o Praguiano, quando atingem grande diversidade de cerca de 20 gêneros e subgêneros, e uma distribuição cosmopolita. Segundo os autores, os dacryoconarídeos constituíam um grande reservatório de energia disponível na coluna de água, e, portanto, eram uma das principais fontes de alimento para organismos pelágicos ou predadores nectônicos. Ademais, para os autores a mudança na dinâmica evolutiva de dacryoconarídeos, no final do Devoniano inferior, coincide com o aparecimento de antigos gastrópodes.

No trabalho de Berkyová et al. (2007), os autores demonstram diversas evidências de predações, bem e mal sucedidas, em Dacryoconarida. Os autores explicam que a determinação do predador é altamente especulativa, visto que o oceano durante o Devoniano era ocupado por diversos predadores em busca de alimento. Os autores não afirmam novas hipóteses para extinção dos tentaculitoideos, porém, afirmam que a presença de predadores durante o final do Devoniano, poderia ter afetado a abundância destes.

Existem hipóteses, tais como Wei et al. (2012), que apesar de concordarem em que os tentaculitoideos tenham se extinguido na barreira F-F, introduzem novas ideias. Para o autor, o impacto de asteroides reportados durante o Emsiano, Givetiano e Frasniano, não foram a causa da extinção dos tentaculitoideos, visto que a diversidade do grupo se manteve durante estes períodos. Afirma ainda, que o "resfriamento" proposto como causa da crise durante o F-F é controverso ou questionável, ressalva que o resfriamento deve ter sido regional e não global. $\mathrm{O}$ autor ainda debate sobre as 
regressões marinhas e sobre condições anóxicas. Admite o decréscimo da diversidade dos tentaculitoideos ocasionado pelas regressões, porém a diminuição do grupo não foi intensa o suficiente para causar sua extinção. Afirma ainda que os tentaculitoideos não poderiam ser extintos por condições anóxicas promovidas pelos mares do Frasniano, visto que os homoctenídeos e dacryoconarídeos eram adaptados a ambientes anóxicos (característica já citada por FISHER, 1962).

Segundo Wei et al. (2012) a provável extinção do grupo decorreu com a presença de espécies invasoras durante o final do Devoniano. Afirmam ainda que durante o Devoniano Médio e Superior, o aumento progressivo do nível do mar, acentuou a migração de espécies invasoras em ambientes marinhos. Para os autores, fatores abióticos não foram à chave para a extinção dos tentaculitoideos, mas fatores bióticos como a entrada de espécies invasoras tenha contribuído para a extinção do grupo.

Apesar do declínio da abundância dos tentaculitoideos no início do Devoniano médio, o grupo não se extingue no final do Emsiano, com grande parte dos invertebrados da província Malvinocáfrica no Devoniano médio da Bacia do Paraná.

Os tentaculitoideos podem ser considerados um grupo resistente a esta extinção (GHILARDI et al., 2015). O estabelecimento e a proliferação de tentaculitoideos, no contexto de extinções de outros grupos, em adição à sua conservação em diferentes tipos de paleoambientes, pode revelar um comportamento oportunista em tentaculitoideos. Este intervalo (NeoPraguiano ao NeoEmsiano) de tempo coincide com processos orogenia que podem ter afetado a estabilidade dos ecossistemas, favorecendo a proliferação de táxons oportunistas. Na verdade, o registro do Devoniano na Bacia do Paraná é marcado por vários eventos de transgressão e regressão, o que pode ter culminado em ecossistemas desestabilizadores, levando muitos grupos à extinção. Isso corrobora com as extinções de outros táxons associadas com a proliferação de tentaculitoideos também em outras partes do mundo. É possível que os tentaculitoideos sejam um grupo com maior plasticidade ecológica para frente a estas mudanças. Além disso, nas conchas dos tentaculitoideos do Givetiano da Bacia do Paraná foram encontrados traços de cromo (Figura 35). É bem conhecido que a oxidação de cromo é indiretamente mediada pela síntese microbiana de óxidos de manganês. Este elemento pode estar associado com atividades tectônicas e possíveis alterações na química do oceano durante o período de extinção da fauna Malvinocáfrico, incluindo esse grupo (GHILARDI et al., 2015). 


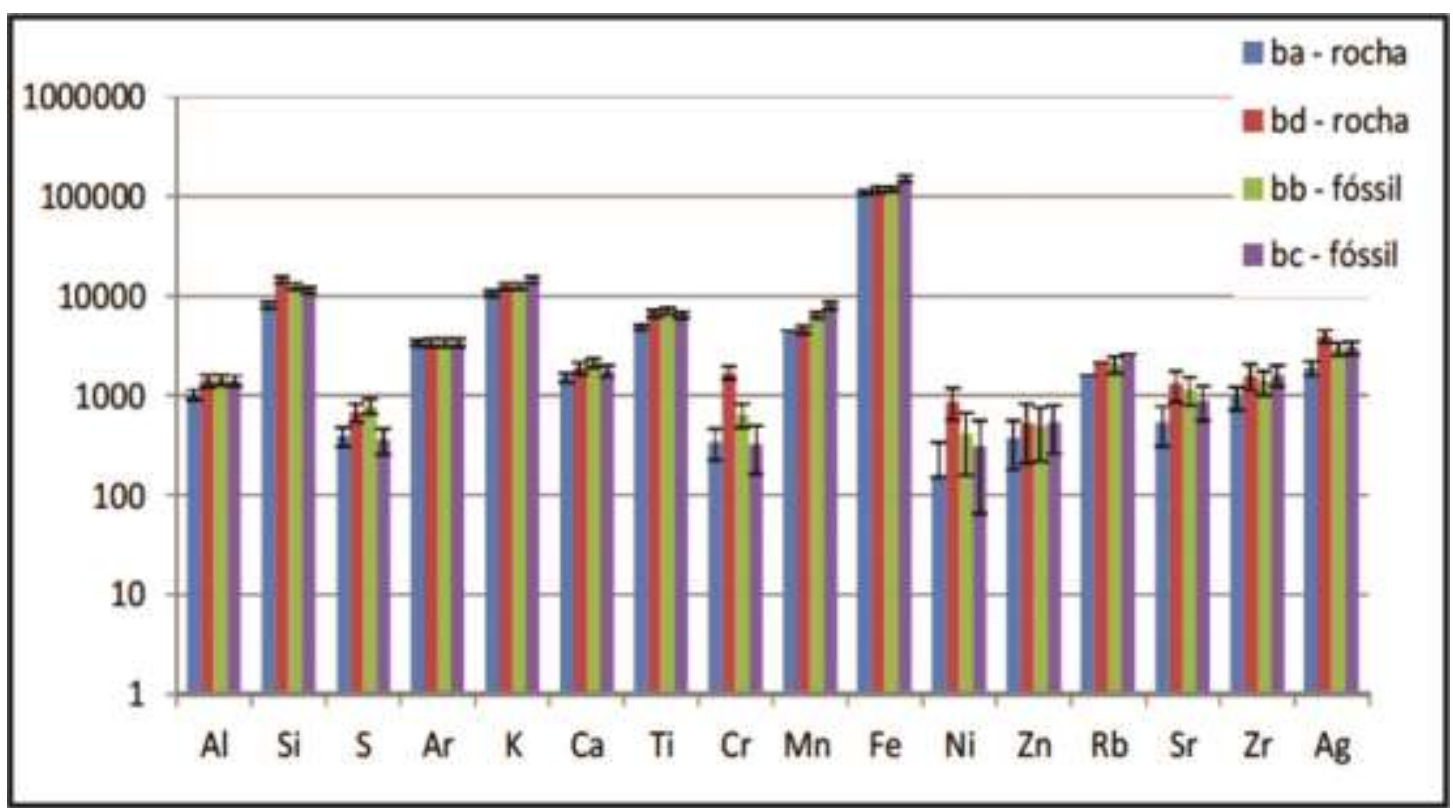

FIGURA 35. Análise de duas amostras de tentaculitoideos verifica se os altos índices de cromo.

Existem ainda relatos de tentaculitoideos, que provavelmente, ultrapassaram o Fameniano, como o caso de Li (2000) registra a ocorrência de homoctenídeos e dacryoconarídeos provenientes do meio e final do Fameniano, para o Sul da China. Schindler (2012) refuta esta nova ocorrência, afirmando que as amostras sofreram retrabalhamento, o que foi negado por $\mathrm{Li}$ (2000).

Embora Niko (2000) tenha descrito um novo gênero e uma nova espécie de tentaculitoideo, ocorrente no limite Carbonífero-Permiano, esta nova ideia de que o grupo tenha ultrapassado o Devoniano, não foi aceita entre a totalidade dos pesquisadores (SCHINDLER, 2012).

Para Wittmer e Miller (2011) e Schindler (2012) apesar das tentativas de se estabelecer um novo limite estratigráfico para os tentaculitoideos, o consenso de que os tentaculitoideos são extintos no final do Devoniano é bem embasado. Schindler (2012) ressalta ainda que com a falta de dados sedimentológicos mais acurados para incluir ou excluir a possibilidade de retrabalhamento, o entendimento sobre a idade dos tentaculitoideos é questionável no trabalho de Niko (2000).

A extinção do grupo se mantém em discussão, visto a diversidade de estudos quanto as prováveis hipóteses. Os tentaculitoideos analisados nas Bacias do Paraná, Amazonas e Parnaíba possuem um registro estratigráfico até o Frasniano, sem ocorrências durante o Fameniano. Também não foram verificadas, na literatura especializada, ocorrência de tentaculitoideos nas camadas do Fameniano para o Brasil. 


\section{CONCLUSÕES}

* Foram reconhecidas 12 espécies de tentaculitoideos para o Devoniano brasileiro: Tentaculites crotalinus, Tentaculites jaculus, Tentaculites kozlowskius, Tentaculites eldredgianus, Tentaculites trombetensis, Tentaculites stubeli, Tentaculites oseryi, Uniconus ciguelius, Homoctenus katzerius, Tentaculites paranaensis, Styliolina cf. Styliolina fissurella e Styliolina clavulus.

* Das 33 espécies de tentaculitoideos descritos por Ciguel (1989) para a Bacia do Paraná, apenas as espécies T. kozlowskius e H. katzerius descritas por Ciguel (1989) foram consideradas espécies válidas.

* Após análises sistemáticas, duas novas espécies de tentaculitoideos foram descritas (T. paranaensis e U. ciguelius) para os estratos devonianos da Bacia do Paraná.

* As espécies Tentaculites crotalinus (Salter, 1856) e Tentaculites jaculus (Clarke, 1913), se mantém válidas para o Devoniano brasileiro.

* Após análises verificou-se que as espécies Tentaculites crotalinus e Tentaculites jaculus, são espécies válidas e ocorrentes na Bacia do Paraná.

* A distribuição estratigráfica dos tentaculitoideos da Bacia do Paraná inicia no NeoPraguiano até o EoGivetiano.

* As espécies T. crotalinus, T. jaculus, T. kozlowskius, T. paranaensis e $H$. katzerius possuem distribuição do NeoPraguiano ao NeoEmsiano. Enquanto a espécie U. ciguelius do NeoPraguiano ao EoEmsiano e Styliolina cf. Styliolina fissurella distribuição estratigráfica do Meso ao NeoEmsiano.

* A distribuição estratigráfica das espécies na Bacia do Amazonas e Parnaíba começa no Eifeliano até Givetiano.

* As espécies T. eldredgianus, T. trombetensis e S. clavulus possuem distribuição estratigráfica do Eifeliano ao Givetiano. T. stubeli encontrado durante o NeoEifelianoEoGivetiano e T. oseryi apenas no Givetiano.

* Os espécimes encontrados nos estratos devonianos brasileiros são formas juvenis ou adultas do táxon. Entretanto, foi registrada a ocorrência de um espécime na forma larval, na Bacia do Paraná.

* As análises por MEV/EDS e EDXRF, demonstraram a presença de cromo e pirita o que são indicativas de ambientes profundos com baixa concentração de 
oxigênio, corroborando com a hipótese da extinção dos tentaculitoideos de que talvez estejam relacionados a uma grande extinção global.

* Foram verificados dois padrões de preservação: isolados e agrupados.

* Foram elaboradas 6 classes tafonômicas, as quais foram distribuídas em níveis paleobatimétricos. Com tudo, verificou-se que os tentaculitoideos analisados (Bacia do Paraná, Sub-bacia Apucarana) possuem preferência por ambientes de offshore transicional, situados logo acima do Nível de Base de Tempestade (NBOT).

* Verificou-se uma grande abundância em diversidade de tentaculitoideos durante o início do Devoniano (início da sequência B). Durante o meio e o final da sequência B é caracterizado por ambientes deposicionais de Trato de Sistema Transgressivo (TST), sendo observado um decréscimo da abundância dos tentaculitoideos. Como já foi detectado por outros autores, as partes medianas e superiores de um TST são representadas por momentos de baixa a média diversidade de espécies e menores taxas de sedimentação.

* Os últimos registros de tentaculitoideos no Brasil são provenientes do Givetiano. 


\section{REFERÊNCIAS BIBLIOGRÁFICAS}

ANDRADE, S. D.; CAMARÇO, P. E. N. Estratigrafia dos sedimentos devonianos do flanco nordeste da Bacia do Paraná. In: CONGRESSO BRASILEIRO DE GEOLOGIA, 31, 1980. Anais, Balneário de Camboriú, 1980. p. 2828-2834.

ANDRADE, S. M.; CAMARÇO, P. E. N. Sequências sedimentares pré-carboníferas dos flancos nordeste da Bacia do Paraná e sudoeste da Bacia do Parnaíba e suas possibilidades uraníferas. In: 32 CONGRESSO BRASILEIRO DE GEOLOGIA, 1982. Anais, Salvador: SBG. 1982. p. 2132-2144.

ALBERTI, G. K. B. Unterdevonische Tentaculiten aus Oberfranken. Paläontologische Zeitschrift, v. 44, n. 3-4, p. 161-170. 1970.

ALBERTI, G. K. B. Zur paläobiogeographischen Verbreitung unter-und mitteldevonischer Dacryoconarida (Tentaculiten). Courier Forschungsinstitut Senckenberg, v. 92, p. 161-176, 1987.

ALBERTI, G. K. B. Stratigraphische Untergliederung einiger Lochkovium/Pragium Grenzprofile (Unter-Devon) in NW - Marokko, Oberfranken und Vic to ria (SE Australien) auf grund von Dacryoconariden und Conodonten. Senckenbergiana lethaea, v. 68, n. 5-6, p. 479-493, 1988.

ALBERTI, G. K. B. Dacryoconariden und homocteniden Tentaculiten des Unter-und Mittel-Devons I. Courier Forschungsinstitut Senckenberg, v. 158, 1-230, 1993.

ALBERTI, G. K. B. Planktonische Tentakuliten des Devon. II. Dacryoconarida Fisher 1962 aus dem Unter- und Mittel-Devon. Mit einem mikrofaziellen Beitrag von TC Hüsken. Palaeontographica Abteilung A, v. 256, p. 1-32, 1997.

ALBERTI, G. K. B. Homoctenus antecessor n. sp. (planktonische Tentaculiten, Homoctenida) aus der unteren Taravale-Formation (Unter-Zlichovium) von Victoria (Australien, Devon). Senckenbergiana lethaea, v. 79, n. 1, p. 297-300, 1999.

ALBERTI, G. K. B. Planktonische Tentakuliten des Devon. IV. Dacryoconarida FISHER 1962 aus dem Unter-Devon. Palaeontographica Abt A, v. 256, p. 1-23, 2000 .

ALMEIDA, F. F. M.; CARNEIRO, C. D. R. Inundações marinhas fanerozóicas no Brasil e recursos minerais associados. In: MANTESSO-NETO, V.; BARTORELLI, A; CARNEIRO, C. D. R.; BRITO-NEVES, B. B. (Ed.) Geologia do continente 
sul-americano: evolução da obra de Fernando Flávio Marques de Almeida. São Paulo: Beca, 2004.p. 43-60.

ASSINE, M. L. Aspectos da Estratigrafia de Sequências pré-carboníferas da Bacia do Paraná no Brasil. 1996. 206 f. Tese (Doutorado em Geociências) - Instituto de Geociências, Universidade de São Paulo, São Paulo. 1996.

AZEVEDO-SOARES, H. L. C. Classe Tentaculita na Formação Ponta Grossa: uma proposta de sistematização. 1999. 117 f. Dissertação (Mestrado em Análise de Bacias e Faixas Móveis) - Universidade do Estado do Rio de Janeiro, Rio de Janeiro. 1999.

BERGAMASCHI, S. Análise estratigráfica do Siluro-Devoniano (Formações Furnas e Ponta Grossa) da sub-bacia de Apucarana, Bacia do Paraná, Brasil. 1999. 167 f. Tese (Doutorado em Geociências) - Instituto de Geociências, Curso de Pós-Graduação em Geociências, Universidade de São Paulo, São Paulo, 1999.

BERKYOVÁ, S. Middle Devonian Tentaculitoidea from the late generation of fillings of the neptunian dyke in the Koneprusy area (Prague Basin, Czech Republic)/Tentaculitoidea z mladsí výplne neptunické zíly v devonu konepruské oblasti (strední Devon, prazská pánev, Ceská republika). Journal of Geosciences, v. 49, n. 3-4, p. 147, 2004.

BERKYOVÁ, S.; FRYDA, J.; LUKES, P. Unsuccessful predation on Middle Paleozoic plankton: shell injury and anomalies in Devonian dacryoconarid Tentaculites. Acta Palaeontologica Polonica, v. 52, n. 2, p. 407, 2007.

BLIND, W. Die systematiche Stellung der Tentakuliten. Palaeontographica Abt. A, v. 133, p. $101-145.1969$.

BOND, D. The fate of the homoctenids (Tentaculitoidea) during the FrasnianFamennian mass extinction (Late Devonian). Geobiology, v. 4, p. 167-177, 2006.

BOSETTI, E. P. Tafonomia de alta resolução das fácies de offshore da sucessão devoniana da Bacia do Paraná, Brasil. 2004. 200 f. Tese (Doutorado em Geociências) - Programa de Pós Graduação em Geociências, Universidade Federal do Rio Grande do Sul, Porto Alegre, 2004.

BOSETTI, E. P.; ZABINI, C.; HORODYSKI, R. S. 2010a. Earliest Givetian Cephalopoda "roll marks" in the Paraná Basin. In: SIMPOSIO LATINOAMERICANO DE ICNOLOGIA, 2010, São Leopoldo. Resúmenes. São Leopoldo: Unisinos, 2010. v. 1. p. 25. 
BOSETTI, E. P.; GRAHN, Y.; HORODYSKI, R. S.; MAULLER, P. M.; BREUER, P.; ZABINI, C. An earliest Givetian "Lilliput Effect" in the Paraná Basin, and the collapse of the Malvinokaffric shelly fauna. Paläontologische Zeitschrift, v. 85, n. 1, p. 49-65, 2011.

BOSETTI, E. P.; GRAHN, Y.; HORODYSKI, R. S.; MAULlER, P. M. The first recorded decline of the Malvinokaffric Devonian fauna in the Paraná Basin (southern Brazil) and its cause; taphonomic and fossil evidences. Journal of South American Earth Sciences, v. 37, p. 228-241, 2012.

BOSETTI, E. P.; HORODYSKI, R. S.; COMNISKEY, J. C.; GHILARDI, R. P.; SEDORKO, D. Tubos vestimentíferos no eoGivetiano da Formação São Domingos, Bacia do Paraná. In: II SIMPÓSIO BRASILEIRO DE PALEOINVERTEBRADOS, 2014, Ponta Grossa. Boletim de Resumos. Ponta Grossa: ED. UEPG, 2014. p. 107.

BOUČEK, B. V. The Tentaculites of Bohemia: their morphology, taxonomy, ecology, Phylogeny and biostratigraphy. Czechoslovak Academy of Sciences. 215p. 1964. BOUCOT, A. J.; ISAACSON, P. E.; LAUBACHER, G. An early Devonian, eastern Americas realm faunule from the coast of southern Peru. Journal of Paleontology, v. 54, n. 2 , p. $359-365,1980$.

BOUCOT, A. J. Silurian and pre-Upper Devonian bio-events. In: Kauffman, E. G.; WALLISER, O. H. (Ed.). Extinction Events in Earth History. Springer Berlin Heidelberg, 1990. cap. 11. p. 125-132.

BRETT, C. E.; BAIRD, G. C. Comparative taphonomy: a key for paleoenvironmental reconstruction. Palaios, v. 1, p. 207-227, 1986.

CAPUTO, M. V. Stratigraphy, tectonics, palaeoclimatology and palaeogeography of northern basins of Brazil. 1984. 583 f. Tese (Doutorado) - Santa Barbara: University California, 1984.

CIGUEL, J. H. G.; ROSLER, O.; CAMINEIRO, D. Tentaculitoidea da formação Ponta Grossa no estado do Paraná. In: CONGRE. BRAS. DE GEOL., 33, 1984. Rio de Janeiro. Anais. Rio de Janeiro: SBG. 1984. p. 655-669.

CIGUEL, J. H. G.; ROSLER, O. Caracterização das formas brasileiras de Tentaculites crotalinus Salter, 1856. Anais da Academia Brasileira de Ciências, v. 57, n. 1, p. 116, 1985. 
CIGUEL, J. H. G.; ROSLER, O.; HOFMEISTER, R. M. Preservação parcial da concha de Tentaculites crotalinus, da Formação Ponta Grossa (Devoniano). Boletim IgUSP. Série Científica, v. 18, p. 17-26. 1987.

CIGUEL, J. H. G. Tentaculites itacurubiensis n. sp., dos depósitos regressivos do Paraguai oriental, Siluriano Inferior da Bacia do Paraná. Revista Brasileira de Geociências, v. 18, p. 86-92, 1988.

CIGUEL, J. H. G. Bioestratigrafia dos Tentaculitoidea no flanco oriental da Bacia do Paraná e sua ocorrência na América do Sul. 1989. 237 f. Dissertação (Mestrado em Geociências) - Instituto de Geociências, Universidade de São Paulo, São Paulo, 1989.

CLARKe, J. M. Moluscos devonianos do Estado do Pará, Brasil. Archivos Museu Nacional, v. 10, p. 49-174, 1899a.

CLARKE, J M. A fauna siluriana superior do Rio Trombetas. Archivos do Museu Nacional, v. 10, p. 1-48, 1899b.

CLARKE, J. M. Fósseis Devonianos do Paraná. Monographias do Serviço Geológico e Mineralógico do Brasil. Rio de Janeiro, 1913. 353p.

COMNISKEY, J. C.; GHILARDI, R. P. Levantamento histórico da Classe Tentaculitoidea no Devoniano brasileiro: principais características e padrões de preservação.Terr@ Plural, v. 7, p. 115-126, 2013.

COMNISKEY, J. C.; GHILARDI, R. P. Novos achados de formas larvais de tentaculitídeos da Bacia do Paraná. In: II SIMPÓSIO BRASILEIRO DE PALEOINVERTEBRADOS, 2014, Ponta Grossa. Resumos, Ponta Grossa, UEPG 2014. p.111.

COMNISKEY, J. C.; GHILARDI, R. P.; BOSETTI, E. P. Conhecimento atual sobre os tentaculitoideos devonianos das bacias do Amazonas e Parnaíba, Brasil, depositados em instituições brasileiras. Boletim do Museu Paraense Emilio Goeldi, v. 10, n. 1, p. 49-61, 2015.

CUNHA, P. R. C.; MELO, J. H. G.; SILVA O. B. Bacia do Amazonas. Boletim de Geociências da Petrobrás, v. 15, n. 2, p. 227-251, 2007.

DAVILA, J.; RODRIGUEZ, E. The Devonian System in Bolivia and the problem of its base. In: INTERNATIONAL SYMPOSIUM ON THE DEVONIAN SYSTEM, II, 1967, Calgary. Anais. Calgary, 1967. p.921-935.

Della fÁverA, J. C. Tempestitos da Bacia do Parnaíba: um ensaio holístico. 1990. 243 f. Tese (Doutorado em Geociências) - Instituto de Geociências, 
Universidade Federal do Rio Grande do Sul, Porto Alegre, 1990.

DERBY, O. A. Contribuições para a geologia da região do baixo Amazonas. Archivos do Museu Nacional, v. 2, p. 77-107, 1878.

DERBY, O. A. Nota sobre a geologia e paleontologia de Matto Grosso. Imprensa nacional, v. 5050, 1890.

DERBY, O. A. Reconhecimento do Rio Maecuru. Boletim do Museu Paraense, v. 2, n. 2, p. 192-204, 1897.

EVANS, J. W. The geology of Matto Grosso (particularl y the region drained by the Upper Paraguay). Quarterly Journal of the Geological Society of London, v. 50, n. 85, p.104, 1894.

FARSAN, N. M. Middle Devonian (Givetian) Tentaculites from West Afghanistan. Palaeontographica Abteilung A, p. 89-105, 1981.

FARSAN, N. M. Die Tentakuliten aus dem Frasnium (Ober-Devon) von Ghuk (westliches Zentral-Afghanistan). Paläontologische Zeitschrift, v. 58, n. 1-2, p. 51-77, 1984.

FARSAN, N. M. Tentaculiten: Ontogenese, Systematik, Phylogenese, Bioestratonomie und Morphologie. Abhandlungen der Senckenbergischen Naturforschenden Gesellschaft, v. 547, p. 1-128, 1994.

FARSAN, N. M. Description of the early ontogenic part of the tentaculitids, with implications for classification. Lethaia, v. 38, n. 3, p. 255-270, 2005.

FILIPIAK, P.; JARZYNKA, A. Organic remains of tentaculitids: new evidence from Upper Devonian of Poland. Acta Palaeontologica Polonica, v. 54, n. 1, p. 111$116,2009$.

FISHER, D. W. Small connoidal shells of uncertain affinities. In: MOORE, R. C. (Ed.).Treatise on invertebrate paleontology. Part W Miscellanea 1. Geological Society of America e University of Kansas Press, 1962. p. 98 - 130.

FISHER, D. W.; YOUNG, R. S. The oldest known tentaculitid: from the Chepultepec Limestone (Canadian) of Virginia. Journal of Paleontology, p. 871-875, 1955.

FONSECA, V. M. M. Chonetoidea (Brachiopoda) do Devoniano Médio das Bacias do Amazonas e Parnaíba, Brasil. Arquivos do Museu Nacional, v. 62, n. 2, 193-215, 2004.

FORERO S, A. Primer registro en Colombia de Tentaculites del Devoniano. Geologia Norandina: v. 7, p. 39-42, 1983. 
GAUGRIS, K. A.; GRAHN, Y. New chitinozoan species from the Devonian of the Paraná Basin, south Brazil, and their biostratigraphic significance. Ameghiniana, v. n. 43 , p. 293-310, 2006.

GHILARDI, R. P. Tafonomia comparada e paleoecologia dos macroinvertebrados (ênfase em trilobites), da Formação Ponta Grossa (Devoniano, Sub-bacia Apucarana), Estado do Paraná, Brasil. 2004. 113 f. Tese (Doutorado em Geociências) - Instituto de Geociências, Universidade de São Paulo, São Paulo, São Paulo, 2004.

GHILARDI, R. P.; COMNISKEY, J. C.; PACHECO, M. L. A. F.; KERBER, B. B. 'Explosion' of opportunistic taxa during the extinction events of Devonian in the Paraná Basin. In: XXIV CONGRESSO BRASILEIRO DE PALEONTOLOGIA, 2015, Crato-CE. Boletim de Resumos (Paleontologia em Destaque - Edição Especial). Porto Alegre: Sociedade Brasileira de Paleontologia, 2015. v. 1. p. 161161.

GÓES, A. M. O.; FEIJÓ, F. J. Bacia do Parnaíba. Boletim de Geociências da Petrobrás, v. 8, n. 1, p. 57-67, 1994.

GRAHN, Y. Revision of Silurian and Devonian Strata of Brazil. Palynology, v. n. 16, p. 35-61, 1992.

GRAHN, Y.; PEREIRA, E.; BERGAMASCHI, S. Silurian and Lower Devonian chitinozoan biostratigraphy of the Paraná Basin in Brazil and Paraguay. Palynology, v. 24, p. 143-172, 2000.

GRAHN, Y.; PEREIRA, E.; BERGAMASCHI, S. Middle and Upper Devonian chitinozoan biostratigraphy of the Paraná Basin in Brazil and Paraguay. Palynology, v. 26, p. 135-165, 2002.

GRAHN, Y. Devonian chitinozoan biozones of Western Gondwana. Acta Geologica Polonica, v. 55, n. 3 p. 211-227, 2005.

GRAHN, Y.; MELO, J. H.; LOBOZIAK, S. Integrated Middle and Late Devonian miospore and chitinozoan zonation of the Parnaíba Basin, Brazil: an update. Revista Brasileira de Paleontologia, v. 9, n. 3, p. 283-294, 2006.

GRAHN, C. Y.; MAULLER, P. M.; BREUER, P.; BOSETTI, E. P.; BERGAMASCHI, S.; PEREIRA, E. The Furnas/Ponta Grossa contact and the age of the lowermost Ponta Grossa Formation in the Apucarana Sub-basin (Paraná Basin, Brazil): integrated palynological age determination. Revista Brasileira de Paleontologia ICR, v. 13, p. 89-102, 2010. 
GRAHN， Y.; MENDLOWICZ-MAULLER， P.; PEREIRA， E.; LOBOZIAK， S. Palynostratigraphy of the Chapada Group and its significance in the Devonian stratigraphy of the Parana' Basin, South Brazil. Journal of South American Earth Sciences, v. 29, p. 354-370, 2010.

GRAHN, Y.; MENDLOVICZ-MAULLER, P.; BERGAMASCHI, S.; BOSSETI, E. P. Palynology and sequence stratigraphy of three Devonian rock units in the Apucarana Sub-basin (Paraná Basin, south Brazil): Additional data and correlation. Review of Palaeobotany and Palynology, v. 198, p. 27-44, 2013.

HAJŁASZ, B. Tentaculites of the Upper Silurian and Lower Devonian of Poland. Acta Palaeontologica Polonica, v. 19, n. 4, p. 455-500, 1974.

HAJŁASZ, B. Tentakulity i ich znaczenie dla stratygrafii (dolny dewon). Geological Quarterly, v. 20, n. 2, p. 273-292, 1976.

HAJŁASZ, B. Tentaculites from the Givetian and Frasnian of the Holy Cross Mountains. Acta Palaeontologica Polonica, v. 37, n. 2-4, p. 385-394, 1993.

HARTT, C. F.; RATHBUN, R. Morgan expedition, 1870-1871: on the Devonian trilobites and mollusks of Ererê, Province of Para, Brazil. Annals of the Lyceum of Natural History of New York, v. 11, n. 13, p. 110-127, 1875

HEREDIA, S., MESTRE, A. \& MILANA, J. P. Reappraisal of the Silurian stratigraphy at Cerro del Fuerte section (San Juan, Argentina). Anais do Congresso de Paleontología y Bioestratigrafía de Latinoamérica, v. 4, p. 195-200, 2007.

HOLZ, M.; SIMÕES, M. G. Elementos fundamentais de tafonomia. Porto Alegre Ed. Universidade/UFRGS, 231p, 2002. ISBN: 85-7025-618-3.

HORODYSKI, R. S.; HOLZ, M.; GRAHN, Y.; BOSETTI, E. P. Remarks on sequence stratigrapgy and taphonomy of the Malvinokaffric shelly fauna during the Kačák Event in the Apucarana Sub-basin (Paraná Basin), Brazil. International Journal of Earth Sciences, v. 103, n. 1, p. 367-380, 2014. Doi: 10.1007/s00531-013-0954-9. 2014.

HORODYSKI, R. S. Análise tafonômica, bioestratigráfica e paleoambiental dos invertebrados marinhos da Região De Tibagi-PR (Devoniano Inferior e Médio da Bacia do Paraná). 2014. 205 F. Tese (Doutorado em Geociências) - Programa de Pós Graduação em Geociências, Universidade Federal do Rio Grande do Sul, Porto Alegre, 2014.

HOUSE, M.R. The middle Devonian Kačák event. Read at the Annual Conference of the Ussher Society, January 1996, p. 79-84, 1996. 
ISAACSON, P. E.; ANTELO, B.; BOUCOT, A. J. Implications of a Llandovery (early Silurian) brachiopod fauna from Salta Province, Argentina. Journal of Paleontology, v. 50, n. 6, p. 1103-1112, 1976.

KATZER, F. As camadas fossilíferas mais antigas da região amazônica. Boletim do Museu Goeldi (Museu Paraense) de Historia Natural e Ethnographia, v. 1, n. 4, p. 436-438, 1896.

KATZER, F. Das Amazonas-Devon und seine Beziehungen $\mathrm{zu}$ den anderen Devongebieten der Erde. Verlag der Königl. Böhmischen Gesellschaft der Wissenschaften, p. 1-58, 1897.

KATZER, F. 1903. Grundzuge der Geologie des unteren Amazonasgebietes (dês Staates Pará in Brasilien). Leipzig: Max Weg. 298 p.

KATZER, F. 1933. Geologia do Pará (Brasil). Boletim do Museu Paraense Emilio Goeldi, v. 9, 270 p.

KAYSER, E. Beiträge zur Kenntniss einiger paläozoischer Faunen Süd-Amerikas. Zeitschrift der Deutschen Geologischen Gesellschaft, p. 274-317, 1897.

KAYSER, E. Alguns fósseis paleozóicos do Estado do Paraná. Revista do Museu Paulista, v. 4, p. 301-311, 1900.

KEGEL, W. Contribuição para o estudo do Devoniano da Bacia do Parnaíba. Bol. Ministério da Agricultura, Departamento de Produção Mineral, n. 141, p. 3-48 1953.

KIDWELL, S. M.; FUERSICH, F. T.; AIGNER, T. Conceptual framework for the analysis and classification of fossil concentrations. Palaios, p. 228-238, 1986.

KNOD, R. Devonische faunen boliviens. Neues Jahrbuch für Geologie und Paläontologie Beilage, v. 25, p. 493-601, 1908.

KOZLOWSKI, R. Fósiles Dévoniensis de l' état de Paraná (Brésil). Annales de Paleontologie, v. 8, n. 3, p. 1-19, 1913.

LANGE, F. W. Paleontologia do Paraná. Comissão de Comemoração do Centenário do Paraná. 1954. 210 p.

LANGE, F. W.; PETRI, S. The Devonian of Paraná Basin. Boletim Paranaense de Geociências, v. 21, n. 22, p. 5-55, 1967.

LARDEUX, H. Les Tentaculites d'Europe occidentale et d'Afrique du Nord. Éditions du Centre national de la recherche scientifique. 1969.

LARSSON, K. Silurian tentaculitids from Gotland and Scania. Fossil and Strata, v. 11, p. 1-180, 1979. 
LAUBACHER, G.; BOUCOT, A. J.; ORSTOM, J. G. Additions to Silurian stratigraphy, lithofacies, biogeography and paleontology of Bolivia and southern Peru. Journal of Paleontology, p. 1138-1170, 1982.

LEONARDI, G. Notopus petri nov. gen., sp.: Une empreinte d'amphibien Du dévonien au Paraná (Brésil). Geobios, v. 16, n. 2, p. 233-9, 1983.

LI, Y. X. Famennian tentaculitids of China. Journal of Paleontology, v. 74, n. 05, p. 969-975, 2000.

LINDEMANN, R. H.; YOCHELSON, E. L. Styliolines from the Onondaga Limestone (Middle Devonian) of New York. Journal of Paleontology, v. 58, n. 5, p. 1251$1259,1984$.

LINDEMANN, R. H.; YOCHELSON, E. L. Viriatellina (Dacryoconarida) from the Middle Devonian Ludlowville Formation at Alden, New York. Journal of Paleontology, v. 66, n. 2, p. 193-199, 1992.

LINDEMANN, R. H.; MELYCHER, D. A. Tentaculites (Tentaculitoidea) from the Manlius Limestone (Lower Devonian) at Schoharie, New York. Journal of Paleontology, v. 71, n. 3, p. 360-368, 1997.

LOBOZIAK, S.; MELO, J. H. G. Miospores events from late Early to Late Devonian strata of Western Gondwana. Geobios, v. 33, n. 4, p. 399-407, 2000.

LOBOZIAK, S.; MELO, J. H. G. Devonian miospores successions of Western Gondwana: update and correlation with Southern Euroamerican miospores zones. Review of Paleobotany and Palynology, v. 121, p. 133-148, 2002.

LUKEŠ, P. Tentaculites from the Pragian/ Zlichovian boundary beds at Svatý Jan pod Skalou (Barrandian area). Vestnik Ustrednikho Ústavu Geologickeho, v. 57, n. 2, p. 71-80. 1982.

LUKEŠ, P. Some Dacryoconarida Tentaculites from the lower Zlichovian of the Barrandian area (Czechoslovakia). Bulletin of the Geological Survey, Prague, v. 59, p. 111-114, 1984.

LUKEŠ, P. Dacryoconarid tentaculites of the Lochkovian stage (Lower Devonian) of the Barrandian. Časopis pro mineralogii a Geologii, v. 30, p. 121-132, 1985.

LUKEŠ, P. Tentaculitids from the lower/middle Devonian section in Praha-Barrandov. Vestnik Ustrednikho Ústavu Geologickeho, v. 64, n. 4, p. 193-210, 1989.

LUKEŠ, P. The oldest faunas of dacryoconarid tentaculites in the Barrandian. Věstník Ústř̌edního ústavu geologického, v. 66, p. 287-294, 1991. 
LUKEŠ, P. Devonian tentaculites from `Celechovice na Hané, Moravia. Bulletin of the Czech Geological Survey, v. 68, n. 3, p. 9-13, 1993.

LYASHENKO, G. New facts on the systematics of Tentaculitids, Nowakids and Stylionids. Bulleten Moskovskogo Obshchestva Ispytatelei Prirody, Otdelenie Geologichskoye, Novaia Seriya, v. 30, n. 3, p. 94-95, 1955.

LYASHENKO, G. P. New species from Middle Devonian tentaculites and styliolinids from the central part of the Russian Platform. The All-Russian Research Institute of Oil (VNIGN1), v. 8, p. 212-233, 1957. [Em russo].

LYASHENKO, G. P. Devonian Conoconchia of the central and eastern parts of the Russian Platform. Moscow: The All-Russian Research Institute of Oil (VNIGN1), 220pp, 1959. [Em russo].

LYASHENKO, G. P. New Paleozoic Conoconchia from Arctic. The All-Russian Research Institute of Oil Geology, v. 93, p. 102-108, 1969. [Em Russo].

MAACK, R. Breves notícias sobre a geologia dos estados do Paraná e Santa Catarina. Arquivos de Biologia e Tecnologia, v. 2, n. 63, p.154, 1947.

MALANCA, S.; ARIS, M. J.; BOSO, M. A.; GALLARDO, E.; BRANDÁN, E. M.; FERNÁNDEZ, J. C. Invertebrados fósiles de la formación Lipeón (Silúrico superior) del área Bermejo-los Toldos, noroeste argentino. Revista de La Asociacíon Geológica Argentina, v. 66, n. 1, p. 171-177, 2010.

MALETZ, J.; SORUCO, R. S.; EGENHOFF, S. O. Silurian (Wenlock-ludlow) Graptolites from Bolivia. Palaeontology, v. 45, n. 2, p. 327-341, 2002.

MARSHALL, J. E. A.; TELNOVA, O. P. Tentaculitids in palynological preparations: New evidence from the Famennian (Late Devonian) of Southern Timan. Paleontological Journal, v. 46, n. 3, p. 228-230, 2012.

MAY, A. Relationship among sea-level fluctuation, biogeography, and bioevents of the Devonian: an attempt to approach a powerful, but simple model for complex longdistribution control of biotic crises. Geolines, v. 3, p. 38-49, 1995.

MCGHEE, G. R. The 'multiple impacts hypothesis' for mass extinction: a comparison of the Late Devonian and the late Eocene. Palaeogeography, Palaeoclimatology, Palaeoecology, v. 176, n. 1, p. 47-58, 2001.

MELO, J. H. G. A Província Malvinocáfrica no Devoniano do Brasil. 1985. 1200 f. Dissertação (Mestrado em Geociências) - Instituto de Geociências, Universidade Federal do Rio de Janeiro, Rio de Janeiro, 1985. 
MELO, J. H. G. The Malvinokaffric Realm in the Devonian of Brazil. In: MCMILLAN, N. J.; EMBRY, A. F.; GLASS, D. J. (Eds.) Devonian of the World. Canadian Society of Petroleum Geologists (Memoir 14), 1988. p. 669-703.

MENDLOWICZ-MAULLER， P.; GRAHN， Y.; MACHADO-CARDOSO， T. R.

Palynostratigraphy from the Lower Devonian of the Paraná Basin, South Brazil, and a revision of contemporary Chitinozoan biozones from Western Gondwana. Stratigraphy, v. 6, p. 313-332, 2009.

MILANI, E. J. Evolução tectono-estratigráfica da Bacia do Paraná e seu relacionamento com a geodinâmica fanerozóica do Gondwana sul-ocidental. 1997. 255 f. Tese (Doutorado em Geociências) - Universidade Federal do Rio Grande do Sul, Porto Alegre, 1997

MILANI, E. J.; RAMOS, V. A. Orogenias paleozóicas no domínio sul-ocidental do Gondwana e os ciclos de subsidência da Bacia do Paraná. Revista Brasileira de Geociências, v. 28, n. 4, p. 473-484, 1998.

MILANI, E. J; MELO, J. H. G.; SOUZA, P. A.; FERNANDES, L. A.; FRANÇA, A. B. Bacia do Paraná. Boletim de Geociências da Petrobrás, v. 15, p. 265-287, 2007.

NIKO, S. Youngest record of tentaculitoids: Hidagaienites new genus from near the Carboniferous-Permian boundary in central Japan. Journal of Paleontology, v. 74, n. 3, p. 381-385, 2000.

NORTHFLEET, A. A.; MEDEIROS, R. A.; MULLMANN, H. Reavaliação dos dados geológicos da Bacia do Paraná. Boletim Técnico da Petrobrás, v. 12, n. 3, p. 291346, 1969.

OLIVEIRA, E. P. O terreno Devoniano do sul do Brasil. Annaes da Escola de Minas de Ouro Preto, v. 14, p. 31-41, 1912.

PETRI, S. Contribuição ao estudo do Devoniano Paranaense. Boletim DNPM, DGM, v. 129, p. 1-125, 1948.

PETRI, S.; FÚLFARO, V. J. Geologia do Brasil. São Paulo. Edusp, 1983. 631 p.

PONCIANO, L. C. M. O. Fósseis devonianos da Bacia do Amazonas. 8. ed. Florianópolis: Editora Bookess, 2011. 138 p.

PRESSER, J. L. B.; BUONGERMINI, E.; AMÁBILE, V. O. F.; CROSSA, V. F.; ALMADA, A. B. B.; LIMA, P. R. Z.; MIGONE, O. O. Algunos antecedentes paleontológicos del Paraguay. Boletin del Museo Nacional de Historia Natural de Paraguay, v. 15, n. 1-2, p. 95-110, 2004. 
RACHEBOEUF, P. R.; CASIER, J. G.; PLUSQUELLEC, Y.; TORO, M.; MENDOZA. D.; CARVAlHO M. G. P.; LE HERISSE, A., PARIS, F.; FERNANDEZMARTINEZ, E.; TOURNEUR, F.; BROUTIN, J.; CRASQUIN, S.; JANVIER, P. New data on the Silurian-Devonian palaeontology and biostratigraphy of Bolivia. Bulletin of Geosciences, v. 87, n. 2, p. 269-314, 2012.

RODRIGUES, M. A. C.; AZEVEDO-SOARES, H. L. C.; BERGAMASCHI, S. Horizontes de mortalidade em massa de Tentaculita na Formação Ponta Grossa (Devoniano, Bacia do Paraná) e seu significado estratigráfico. In: MELO, J. H. G.; TERRA, G. J. S. (Eds.). Correlação de seqüências Paleozóicas Sul-Americanas. Ciência-Técnica-Petróleo, p. 73-79, 2001.

RODRIGUES, S. C.; SIMÕES, M. G.; LEME, J. M. Tafonomia comparada dos Conulatae (Cnidaria), Formação Ponta Grossa (Devoniano), Bacia do Paraná, Estado do Paraná. Brazilian Journal of Geology, v. 33, n. 4, p. 381-390, 2003.

ROEMER, F. A. Beiträge zur geologischen Kenntniss des nordwestlichen

Harzgebirges. Theodor Fischer. 368p.1850. ISBN-13: 978-1179939193

SANTOS, M. E. C. M.; CARVAlHO, M. S. S. 2004. Paleontologia das bacias do

Parnaíba, Grajaú e São Luís. Rio de Janeiro: Programa Levantamentos Geológicos Básicos do Brasil - PLGB, CPRM-Serviço Geológico do Brasil/DIEDIG/DEPAT, 226p.

SCHEFFLER, S. M. Crinóides e blastóides do Devoniano brasileiro. 2010. $243 \mathrm{f}$.

Tese (Doutorado em Geologia) - Programa de Pós-Graduação em Geologia, Instituto de Geociências, Universidade Federal do Rio de Janeiro, 2010.

SCHINDLER, E. The late Frasnian (Upper Devonian) Kellwasser crisis. In: KAUFFMAN, E. G.; WALliSER, O. H. (Eds.). Extinction Events in Earth History. Springer Berlin Heidelberg, 1990. cap. 14, p. 151-159.

SCHINDLER, E. Event-stratigraphic markers within the Kellwasser Crisis near the Frasnian/Famennian boundary (Upper Devonian) in Germany. Palaeogeography, Palaeoclimatology, Palaeoecology, v. 104, n. 1, p. 115-125, 1993.

SCHINDLER, E.; KÖNIGSHOF, P. Sedimentology and microfacies of Late Devonian Kellwasser limestones in relation to palaeobathymetry (Upper Kellwasser horizon, late Frasnian). Zbl Geol Paläont Teil I, n. 5/6, p. 597-607, 1996

SCHINDLER, E. Tentaculitoids: An Enigmatic group of Paleozoic Fossils. In: TALENT, J. A. (Ed.). Earth and Life. Springer Netherlands, 2012. cap. 14, p. 479490. 
SCHNEIDER, R. L.; MÜHLMANN, H.; TOMMASI, E.; MEDEIROS, R. D.; DAEMON, R. F.; NOGUEIRA, A. A. Revisão estratigráfica da Bacia do Paraná. In: CONGRESSO BRASILEIRO DE GEOLOGIA, 28, 1974, Porto Alegre. Anais. Rio Grande do Sul: Universidade Federal do Rio Grande do Sul, 1974, p. 41-65.

SCHLOTHEIM, E. F. Die Petrefactenkunde auf ihrem jetzigen Standpunkte durch die Beschreibung: Seiner Sammlung versteinerter und fossiler überreste des thier-und pflanzenreichs. In der Becker'schen Buchandlung. 432p. 1820.

SCHUCHERT, C. Geology of the Lower Amazon region. The Journal of Geology, v. 14, n. 8, p. 722-746, 1906.

SIEMIRADZKI, J. Geologische reisebeobachtungen in Südbrasilien. Aus Der Kaiserlich-Königlichen Hof- und Staatsdruckerei, v. 107, n. 1, p. 23-40, 1898.

SIMÕES, M. G.; GHILARDI, R. P. Protocolo tafonomico/ paleoautoecológico como ferramenta nas análises paleossinecologicas de invertebrados: exemplos de aplicação em concentrações fossilíferas do paleozóico da Bacia do Paraná, Brasil. Pesquisas em Geociências, v. 27, n. 2, p. 3-13, 2000.

SIMÕES, M.G.; RODRIGUES, S. C.; BERTONI-MACHADO, C.; HOLZ, M. Tafonomia: Processos e Ambientes de Fossilização. In: CARVALHO, I. S. (Ed.). Paleontologia. Interciência, Rio de Janeiro, 2010. cap. 3, p. 19-51.

SPEYER, S. E.; BRETT, C. E. Trilobite taphonomy and Middle Devonian taphofacies. Palaios, p. 312-327, 1986.

THASSANAPAK, H.; UDCHACHON, M.; BURRETT, C. Devonian radiolarians and tentaculitids from central Laos. JOURNAL OF ASIAN EARTH SCIENCES, v. 60, p. 104-113, p. 2012.

THOMAS, I. Neue Beiträge zur Kenntnis der devonischen Fauna Argentiniens. Universitat Marburg. 1905. 60 p.

TOWE, K. M. Tentaculites: evidence for a brachiopod affinity?. Science, v. 201, n. 4356, p. 626-628, 1978.

TORSVIK, T. H.; COCKS, L. R. M. Earth geography from 400 to 250 Ma: a palaeomagnetic, faunal and facies review. Journal of the Geological Society, v. 161, n. 4, p. 555-572, 2004.

TRUYOLS-MASSONI, M., MONTESINOS，R., GARCIA-ALCALDE，J. L., \& LEYVA, F. (1990). The Kacak-otomari event and its characterization in the Palentine domain (Cantabrian Zone, NW Spain). In: KAUFFMAN, E. G.; 
WALLISER, O. H. (Eds.). Extinction Events in Earth History. Springer Berlin Heidelberg, 1990. cap. 12, 133-143.

ULRICH, A. Palaeozoische Versteinerungen aus Bolivien. Neues Jahrbuch, Beil. Band, v. 8, p. 60-64, 1893.

VAIL, P. R.; MITCHUM, R. M.; THOMPSON, S. Seismic stratigraphy and global changes of sea level, part 3: relative changes of sea level from coastal onlap. In: PAYTON, C. E. (Ed.). Seismic stratigraphy: applications to hydrocarbon exploration. Tulsa: American Association of Petroleum Geologists, 1977. p. 63-81.

VAZ, P. T.; REZENDE, N. G. A. M.; WANDERLEY FILHO, J. R.; TRAVASSOS, W. A. S. Bacia do Parnaíba. Boletim de Geociências da Petrobrás, v. 15, n. 2, p. 253-263, 2007.

VINN, O.; TAYLOR, P. D. Microconchid tubeworms from the Jurassic of England and France. Acta Palaeontologica Polonica, v. 52, n. 2, p. 391, 2007.

VINN, O; MÕTUS, M.-A. The earliest endosymbiotic mineralized tubeworms from the Silurian of Podolia, Ukraine. Journal of Paleontology, v. 82, n. 2, p. 409-414, 2008 .

VINN, O.; MUTVEI, H. Calcareous tubeworms of the Phanerozoic. Estonian Journal of Earth Sciences, v. 58, n. 4, p. 286-296, 2009.

VINN, O. Adaptive strategies in the evolution of encrusting tentaculitoid tubeworms. Palaeogeography, Palaeoclimatology, Palaeoecology, v. 292, n. 1, p. 211$221,2010$.

VINN, O.; ZATOŃ, M. Phenetic phylogenetics of tentaculitoids-extinct, problematic calcareous tube-forming organisms. GFF, v. 134, n. 2, p.145-156, 2012.

VINN, O. Cornulitid tubeworms from the Ordovician of eastern Baltic. Carnets de Geologie-Notebooks on Geology, p.1-6, 2013.

VON AMMON, L. Devonische Versteinerungen von Lagoinha in Matto Grosso (Brasilien). Zeitschrift der Gesellschaft für Erdkunde zu Berlin, v. 28, p. 352-366, 1893.

WALCH, J. Von einer noch unbekannten Tubulitenart. Der Naturforscher, v. 7, p. $211-213,1775$.

WALKER, K. R.; LAPORTE, L. F. Congruent fossil communities from Ordovician and Devonian carbonates of New York. Journal of Paleontology, p. 928944, 1970. 
WALLISER, O. H.; BULTYNCK, P.; WEDDIGE, K.; BECKER, R. T.; HOUSE, M. R. Definition of the Eifelian-Givetian stage boundary. Episodes, v. 18, p. 107-115, 1995.

WALLISER, O. H. Global events in the Devonian and Carboniferous. In: WALliSER, O. H. (Eds.). Global events and event stratigraphy in the Phanerozoic. Springer Berlin Heidelberg, 1996. cap. 11, p. 225-250.

WEDDIGE, K. Devon-Korrelationstabelle. Senckenbergiana lethaea, v. 76, n. 12, p. 267-286, 1996.

WEEDON, M. J. Microstructure and affinity of the enigmatic Devonian tubular fossil Trypanopora. Lethaia, v. 24, n. 2, p. 227-234, 1991.

WEI, F.; GONG, Y.; YANG, H. Biogeography, ecology and extinction of Silurian and Devonian tentaculitoids. Paleogeography, Paleoeclimatology, Paleoecology, v. 358, p. 40-50, 2012.

WITTMER, J. The paleoecology of tentaculitids from the Silurian Arisaig Group, Nova Scotia, Canada. In: $20^{\mathrm{TH}}$ ANNUAL KECK RESEARCH SYMPOSIUM IN GEOLOGY PROCEEDINGS, 2007. Abstract. Ohio, 2007. pp. 283-289

WITTMER, J. M. The Regional and Global Diversity of Tentaculitoids: A New Look at the Spatio-Temporal and Paleogeographic History of an Enigmatic Group. 2009. 200 f. Thesis (Doctoral in Geology) - University of Cincinnati, 2009.

WITTMER, J. M.; MILER, S. I. Dissecting the global diversity trajectory of an enigmatic group: The paleogeographic history of Tentaculitoids. Paleogeography, Paleoclimatology, Paleoecology, v. 312, p. 54-65, 2011.

YOCHELSON, E. L.; KIRCHGASSER, W. T. The youngest styliolines and nowakiids (Late Devonian) currently known from New York. Journal of Paleontology, p. 689-700, 1986.

YOCHELSON, E. L. Middle Devonian Styliolina obtusa (Hall) (Incertae sedis) and Styliolina spica (Hall) ("Vermes") from western New York, reconsidered. Journal of Paleontology, v. 60, n. 03, p. 680-688, 1986.

YODER, R. L.; ERDTMANN, B. D. Tentaculites attenuatus Hall and T. bellulus Hall; a redescription and interpretation of these species as dimorphs. Journal of Paleontology, v. 49, n. 2, p. 374-386, 1975.

ZABINI, C.; HOLZ, M.; BOSETTI, E. P.; MATSUMURA, W. M. K.; HORODYSKI, R. S. Sequence stratigraphy and taphonomic signatures of marine 
invertebrates: a Devonian (Pragian/Eifelian) example of the Paraná Basin, Brazil. Journal of South American Earth sciences, v. 33, n. 1, p. 8-20, 2012.

ZATOŃ, M.; TAYLOR, P. D. Microconchids (Tentaculita) from the Middle Jurassic of Poland. Bulletin of Geosciences, v. 84, n. 4, p. 653-660, 2009. 
9. ANEXOS.

9.1.“COMNISKEY, J. C.; GHILARDI, R. P. Levantamento histórico da Classe Tentaculitoidea no Devoniano brasileiro: principais características e padrões de preservação. Terr@ Plural, v. 7, p. 115-126, 2013.” 


\title{
Levantamento histórico da Classe Tentaculitoidea no Devoniano brasileiro: principais características e padrões de preservação
}

\author{
Historical survey of the Class Tentaculitoidea in the Devonian \\ of the Brazil: main features and preservation standards
}

\author{
Estudio histórico de la clase Tentaculitoidea en Devónico \\ brasileño: principales características y normas de conservación
}

\author{
Jeanninny Carla Comniskey \\ jcomniskey@usp.br \\ Universidade de São Paulo \\ Renato Pirani Ghilardi \\ ghilardirp@gmail.com \\ Universidade Estadual de São Paulo
}

\begin{abstract}
Resumo: O presente trabalho trata do levantamento histórico da classe para as camadas devonianas, características gerais e padrões de preservação tafonômicos associados ao grupo. Foram analisados exemplares localizados em coleções científicas de museus e universidades brasileiras. O grupo taxonômico é representado por quatro gêneros nas bacias do Paraná, do Parnaíba e do Amazonas: Tentaculites, Homoctenus, Styliolina e Volynites. Os tentaculitídeos ocorrem desde o Ordoviciano até o Devoniano e atingiram seu ápice no Devoniano Médio. A Classe possui três ordens conhecidas: Tentaculitida, animais de hábito bentônico, Homoctenida e Dacryconarida, animais de hábito planctônico. Notou-se a presença de dois padrões de preservação tafonômico: espécimes isolados e agrupados.
\end{abstract}

Palavras-chave: Tentaculitídeos. Bacia do Paraná. Emsiano. Padrões tafonômicos.

\begin{abstract}
This work deals with the historical survey of the class for the Devonian layers, general characteristics of the group and taphonomic preservation standards associated with the group. It was analyzed specimens of scientific collections from brazilian museums and universities. The taxonomic group is represented by four genera in the basins of Parana, Parnaiba and Amazon: Tentaculites, Homoctenus, Styliolina and Volynites. The tentaculitids occur from Ordovician to the Devonian, having its peak in the Middle Devonian. The class has three known orders: Tentaculitida, animals of benthic habit, Homoctenida and Dacryoconarida, animals of habit planktonic. It was also noticed the presence of two patterns of taphonomic conservation: isolated and grouped specimens.
\end{abstract}

Keywords: Tentaculitids. Parana Basin. Emsian. Standards Taphonomical. 
Resumen: Este trabajo aborda el estudio histórico de la clase de las capas del Devónico, las características generales y las normas de preservación tafonómicos asociados con el grupo. Se analizaron las muestras localizadas en colecciones científicas Museos y universidades brasileñas. El grupo taxonómico está representado por cuatro géneros de las cuencas del Paraná, Parnaíba y Amazon: Tentaculites, Homoctenus, Styliolina y Volynites. Los tentaculitídeos ocurren del Ordovícico al Devónico y alcanzó su punto máximo en el Devónico Medio. La clase tiene tres órdenes conocidas: Tentaculitida, animales de costumbres bentônicas, Homoctenida y Dacryconarida, animales de costumbres planctónicas. Notamos la presencia de dos patrones de tafonómico conservación: ejemplares aislados y agrupados.

Palabras clave: Tentaculitídeos, Cuenca Del Parana, Emsiano Normas tafonómicos.

\section{INTRODUÇÃO}

A classe Tentaculitoidea (LJASCHENKO, 1955) corresponde a fósseis de invertebrados marinhos extintos, apresentando distribuição estratigráfica do Ordoviciano ao Devoniano Superior. Entretanto, no Brasil são encontrados em estratos do Siluriano e Devoniano. Há autores que posicionam os primeiros tentaculitídeos no Ordoviciano, a grande maioria, no entanto, admite que esses organismos encontram-se bem estabelecidos no Siluriano, persistindo seu registro até o final do Devoniano (FISHER, 1962; AZEVEDO-SOARES, 1999, WITTMER \& MILLER, 2011; SCHINDLER, 2012).

A posição sistemática da classe Tentaculitoidea permaneceu de maneira incerta por mais de um século, sendo que apenas no último meio século chegou-se a um consenso com relação ao assunto. Vale ressaltar que a classificação sistemática do grupo leva em consideração a morfologia e a ornamentação da concha (AZEVEDO-SOARES, 1999). O táxon já foi posicionado em grupos tão diversos como os pterópodes (AUSTIN, 1845, apud Fisher, 1962), anelídeos (MORRIS \& SALTER, 1969, apud Fisher, 1962), equinodermos, braquiópodes, foraminíferos (KEYSERLING, 1846, apud Fisher, 1962) e cefalópodes (ABICH, 1858, apud Fisher, 1962). Porém, foram Boucek (1964) e Farsan (1994), que estabeleceram que a Classe Tentaculitoidea pertence ao Filo Mollusca.

A sistemática do grupo no Hemisfério Norte é relativamente bem conhecida. Contudo, para a região do Gondwana os trabalhos sistemáticos são escassos, limitados a dissertações, teses e resumos de congresso que versam sobre essa temática. É notória, portanto, a não validação nomenclatural dos táxons propostos para o Hemisfério Sul, tornando-se tal feito um catalisador para a necessidade de estudos mais profundos e embasados do grupo. Dessa forma, fica evidente o negligenciamento que esse grupo tem nos estudos paleontológicos brasileiros.

Os trabalhos que relatam a ocorrência de tentaculitídeos para os estratos devonianos brasileiros se iniciaram com o trabalho de Hartt \& Rathbun (1875). Embora os primeiros trabalhos tratando sobre os tentaculitídeos tenham sido relatados para as Bacias do Amazonas e Parnaíba, foi o trabalho de Clarke (1913) que se inicia um aumento significativo para os estudos dos tentaculitídeos. 


\section{MATERIAL E MÉTODOS}

Foram observadas 318 amostras, com aproximadamente 2.141 espécimes, pertencentes a diferentes coleções científicas de museus e universidades brasileiras, tais como: Laboratório de Paleontologia da Universidade Federal do Paraná (UFPR), Laboratório de Paleontologia de Invertebrados do Museu Nacional - Universidade Federal do Rio de Janeiro (UFRJ), Departamento Nacional de Produção Mineral (DNPM), Acervo do Núcleo de Estudos Paleontológicos e Estratigráficos da UFRJ (Departamento de Geologia), Laboratório de Paleontologia e Sistemática, Instituto de Geociências da Universidade de São Paulo (IGC-USP) e Laboratório de Estratigrafia e Paleontologia da Universidade Estadual de Ponta Grossa (UEPG).

Apenas nas amostras que encontram-se depositadas na UEPG foi levado em conta o posicionamento estratigráfico. Totalizam 90 amostras com aproximadamente 418 espécimes de tentaculitídeos, provenientes dos afloramentos localizados nos municípios paranaenses de Tibagi (São Bento, Alto do Amparo, Sítio Wolff, Ponto Estrela, Desvio Ribas e Fazenda Fazendinha), de Ponta Grossa (Campus, Rivadavia, Boa Vista e Curva 1) e de Jaguariaíva (RODRIGUES et al, 2001; GRAHN et al, 2013) (figura 1).

\section{GEOLOGIA DA ÁREA DE ESTUDO}

A bacia sedimentar do Paraná é classificada como uma bacia cratônica intercontinental de natureza policíclica, possuindo uma área que se aproxima de 1,5 milhão de quilômetros quadrados (MILANI et al. 2007). É representada por dois depocentros, as Sub-Bacias Alto Garças e Apucarana, que ocorrem na porção meridional da América do Sul. Milani et al. (2007) reconheceram, no registro estratigráfico dessa bacia, seis unidades de ampla escala (VAIL et al. 1977) na forma de pacotes rochosos, que representam períodos deposicionais com algumas dezenas de milhões de anos de duração, envelopados por superfícies de discordância de caráter inter-regional. A supersequência Paraná, cujos fósseis são objeto de investigação do presente estudo, é representada por sucessões sedimentares que definem ciclos transgressivo-regressivos ligados a oscilações do nível relativo do mar (MILANI et al. 2007). As localidades investigadas fazem parte de um conjunto de rochas siluro-devonianas pertencentes ao Grupo Campos Gerais (GRAHN et al. 2000; GAUGRIS \& GRAHN, 2006; MENDLOWICZ MAULLER et al. 2009; GRAHN et al. 2013). O Grupo Campos Gerais é composto, da base para o topo, pelas formações Furnas, Ponta Grossa e São Domingos (incluso o Membro Tibagi). Um hiato regional é registrado durante final do Emsiano inicial e o Início do Emsiano tardio, resultante de atividade tectônica durante a epirogenia da Pré-Cordilheira Andina (GRAHN et al. 2013), separando as formações Ponta Grossa e São Domingos. As formações Ponta Grossa e São Domingos (Figura 1) são constituídas por uma superposição de folhelhos, folhelhos sílticos, arenitos e siltitos cinza-escuros a pretos, localmente carbonosos, fossilíferos e micáceos, que registram depósitos marinhos de plataforma interna e externa (PETRI \& 
FULFARO, 1983). A estrutura sedimentar predominante é a laminação plano-paralela, mas em certos intervalos, observam-se estratificações do tipo hummocky cross stratification (HCS) de pequeno e médio porte, laminação flaser, marcas onduladas, bioturbação e estruturas de escorregamento.

Figura 1: Mapa geológico da área de estudo (adaptado de GRAHN et al, 2013)

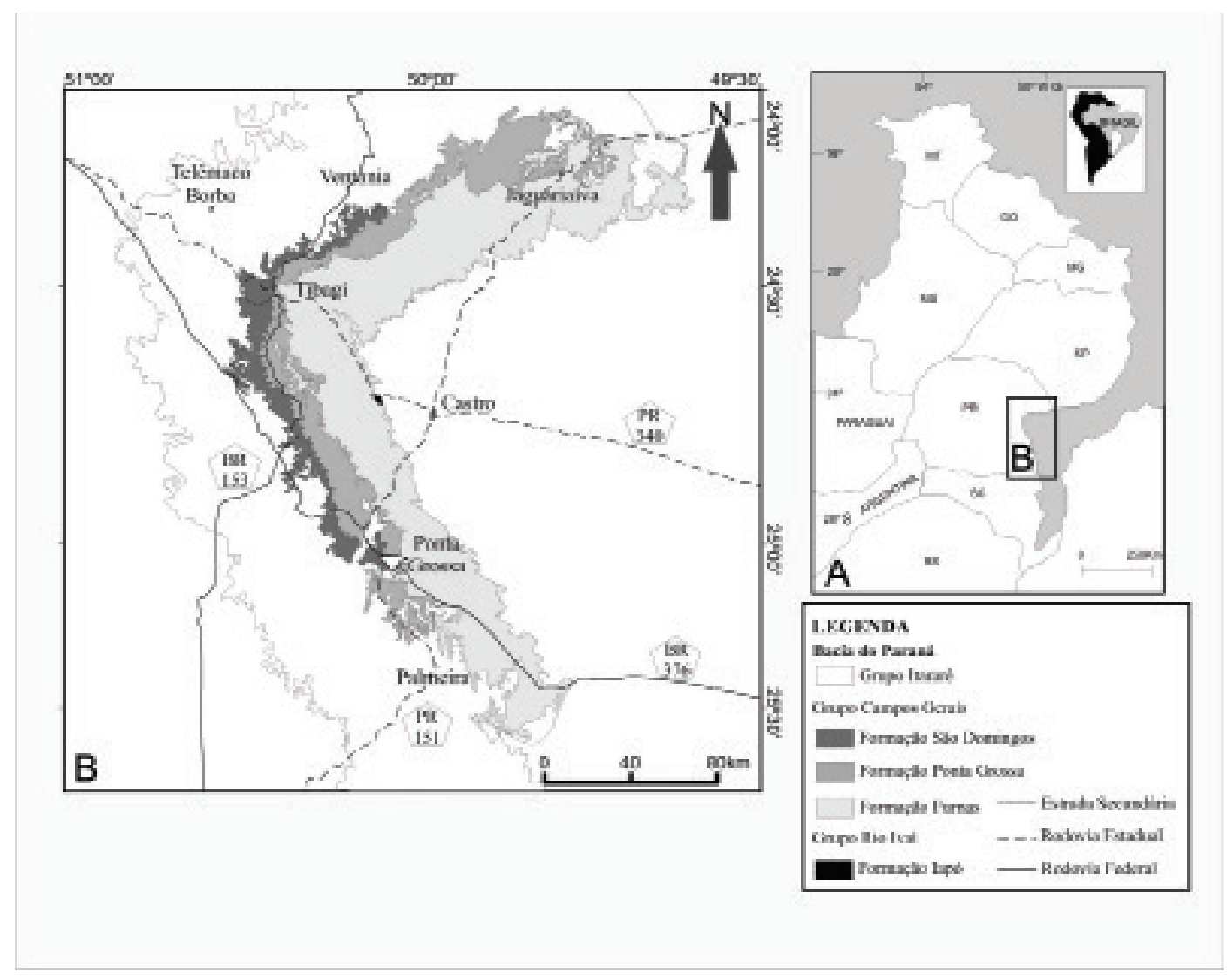

\section{CLASSE TENTACULITOIDEA}

Corresponde a um grupo de animais providos de concha cuneiforme, sendo esta carbonática com variação milimétrica a centimétrica (CLARKE, 1913; CIGUEL, 1989; AZEVEDO-SOARES 1999). A maioria apresenta a concha reta, poucos apresentam concha encurvada e até mesmo enrolada (SCHINDLER, 2012). Podem possuir uma concha lisa ou com ornamentação, sendo que, nesse último caso, apresentam anéis, microanéis, macroanéis, estrias e espaços interanulares. A classificação dos tentaculitídeos é baseada, exclusivamente, em aspectos morfológicos da concha, a partir da ornamentação externa.

Ademais, essa classe possui ampla distribuição geográfica, sendo encontrada na Austrália, Canadá, República Tcheca, Rússia, Brasil, Nova Zelândia, França, África do Sul, Ucrânia, Reino Unido, Líbia, Venezuela, Áustria, China, Espanha entre outros países (LJASCHENKO, 1955; FISHER, 1962; LARDEUX, 1964 e BLIND, 1969). Por essa ampla distribuição e por serem os animais de conchas pequenas com paredes finas, são facilmente encontrados em folhelhos pretos ao redor do mundo, porém também ocorrem em 
calcários cinzas e às vezes em diferentes preservações (WITTMER \& MILLER, 2011). Nas camadas em estudo no presente trabalho, o grupo é ainda encontrado em arenitos.

A Classe Tentaculitoidea é dividida em três ordens (Figura 2): Tentaculitida Ljaschenko (1955), Homoctenida Boucek (1964) e Dacryoconarida Fisher (1962). Os representantes da ordem Dacryoconarida são animais geralmente pequenos, conchas finas e ápice em formato bulboso. O ápice bulboso representa o estágio embrionário do organismo, que se expande para dentro da câmara larval (WITTMER \& MILLER, 2011). Os representantes dessa ordem podem ou não possuir ornamentações na concha. A ordem Tentaculitida é composta por animais de conchas com paredes grossas, que possuem anéis e ápice pequeno e estreito. Essa ordem inclui o gênero de tentaculitideo mais comum, Tentaculites (WITTMER \& MILLER, 2011). A ordem também possui representantes com tamanho aproximado de $1 \mathrm{~mm}$ a $80 \mathrm{~mm}$ de comprimento e aproximadamente $6 \mathrm{~mm}$ de diâmetro, os quais possuem concha reta ou levemente encurvada (LJASCHENKO, 1955). A ordem Homoctenida apresenta paredes finas. A concha possui forma de cone estreito, suavemente encurvada na região apical. Apresenta câmara embrionária cônica. A ornamentação da concha consiste de anéis, frequentemente numerosos, de perfil anguloso (LJASCHENKO, 1955).

As ordens Homoctenida e Dacryoconarida são inferidas como de hábito de vida planctônico, enquanto os representantes da Ordem Tentaculitida seriam bentônicos.

O surgimento dos primeiros tentaculitídeos procede do Ordoviciano, com os primeiros representantes da ordem Tentaculitida. No Siluriano, aparecem os dacryoconarideos, e os homoctenideos surgem apenas no Devoniano. O Devoniano é caracterizado por uma radiação extensiva da diversidade e da distribuição geográfica dos tentaculitídeos (WITTMER \& MILLER, 2011; SCHINDLER, 2012).

Os representantes da ordem Tentaculitida são bastante abundantes e bem documentados no Siluriano e Devoniano. Os Dacryoconarida se tornam excepcionalmente diversos no Devoniano inferior e médio, enquanto os Homoctenida atingem o seu ápice durante o Frasniano (SCHINDLER, 2012).

Schindler $(1990,2012)$ e Bond (2006) afirmam que os homoctenideos foram os únicos tentaculitídeos que ultrapassam a barreira da extinção Frasniano - Fameniano (FF). No entanto, Bond (2006) afirma que a extinção dos Homoctenida ocorre concomitantemente com essa grande extinção, momento em que ocorreria a extinção total da classe. 
Figura 2: Representantes da Ordem Tentaculitida (A), Homoctenida? (B) e Dacryoconarida? (C e D). Modificado de Wittmer \& Miller (2011).

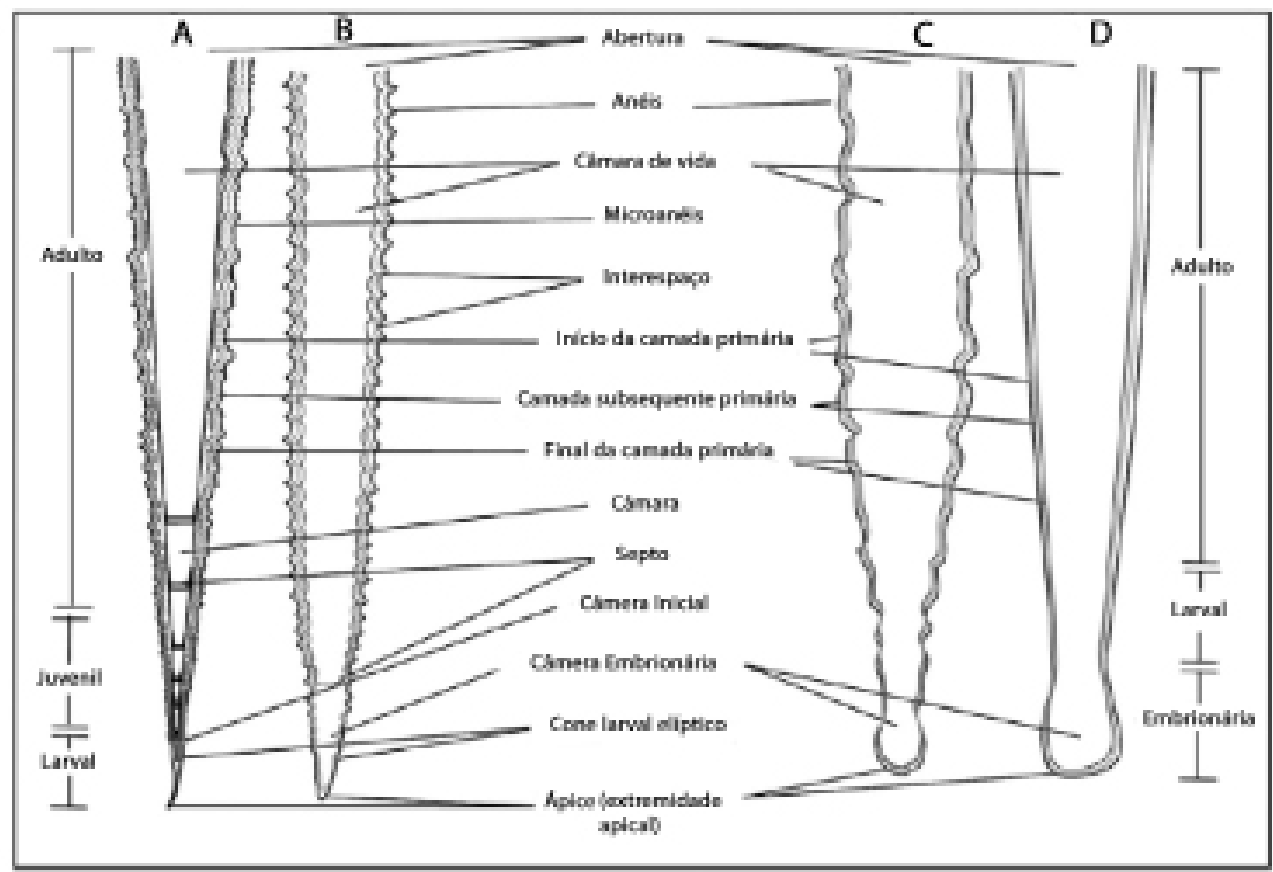

\section{HISTÓRICO DAS PESQUISAS NO BRASIL}

No Brasil, foram encontrados representantes da Classe Tentaculitoidea nas Bacias do Paraná (CLARKE, 1913; KOZLOWSKI, 1913; LANGE, 1954; CIGUEL et al., 1984; CIGUEL et al., 1985; MELO, 1985; CIGUEL et al., 1987; CIGUEL, 1989; AZEVEDO-SOARES, 1999 e RODRIGUES et al, 2001), Parnaíba (KEGEL, 1953 e MELO, 1985) e Amazonas (CLARKE, 1899; KATZER, 1896, 1903, 1933; PONCIANO, 2011).

Apesar de no Hemisfério Norte um grande número de gêneros e espécies ser conhecido, no Brasil, são poucos os taxa encontrados no registro estratigráfico.

A Bacia do Amazonas foi pioneira nos estudos acerca dos Tentaculitídeos no país. Hartt \& Rathbun (1875) trabalharam com materiais coletados nas expedições Morgan de 1870 e 1871, provenientes do Devoniano do Pará, descrevendo trilobitas e moluscos, entre eles o tentaculitídeo Tentaculites eldredgianus, observando o fato de que os autores já apontavam o organismo como formas com afinidades com os moluscos.

Orville A. Derby (1890) cita a ocorrência do gênero Tentaculites e Von Ammon (1893) relata a espécie Tentaculites bellulus, ambos para os estratos devonianos no Estado do Mato Grosso.

Em 1899, Clarke, em seu trabalho "Molluscos Devonianos do Estado do Pará, Brazil", apresenta um trabalho com todos os moluscos fósseis os quais foram coletados pela expedição da Comissão Geológica do Império do Brasil (1875-1877), ao longo das Margens do Rio Maecuru e Curuá (Formação Maecuru) durante o ano de 1876. 
Dentre os espécimes descritos por ele, encontram-se duas novas espécies (Tentaculites stubeli e Tentaculites osseryi) e reconhece para a região o Tentaculites eldregianus, descrito anteriormente por Hartt \& Rathbun (1875).

Katzer (1903) descreve uma nova espécie Tentaculites tenellus para as camadas Maecuru da Bacia do Amazonas. Além de reconhecer as mesmas espécies que Clarke (1899) descreve em seu trabalho, identifica também Tentaculites crotalinus, T. eldredgianus e Styliolina clavulus.

Clarke (1913), ao descrever a abundante fauna devoniana do Estado do Paraná, refere-se aos Tentaculitídeos, como incertae sedis. Além da descrição da nova espécie (Tentaculites jaculus), Clarke relata que a espécie tratada por Von Ammon (1893) como Tentaculites bellulus, trata-se da espécie Tentaculites crotalinus.

Após o trabalho de Clarke em 1913, muitos anos se passaram sem a presença de trabalhos significativos para a classe. Surgiram trabalhos apenas relatando a ocorrência desses organismos em camadas fossilíferas nas Bacias sedimentares brasileiras, tais como Petri (1948), Lange (1954), Lange \& Petri (1967), Petri \& Fúlfaro (1983), Leonardi (1983). A partir do começo dos anos 1980, trabalhos de José Henrique Godoy Ciguel deram um grande avanço nos estudos da Classe Tentaculitoidea no Brasil.

Em 1953, Kegel relata a presença de Tentaculites aff. Eldredgianus (HARTT \& RATHBUN), Tentaculites stubeli e Tentaculites sp., na Formação Pimenteiras, Devoniano inferior e a espécie Tentaculites sp. para a Formação Longá.

Ciguel et al. (1984) analisa as amostras encontradas na Formação Ponta Grossa (sensu: Lange e Petri, 1967), além das espécies de tentaculitídeos já registradas (Tentaculites) e o primeiro registro de Styliolina sp. para a Bacia do Paraná. Melo (1985), em sua dissertação de mestrado, trabalhou sobre o Domínio Malvinocáfrico do Devoniano do Brasil. Dentre os grupos de fósseis relatados pelo autor, as espécies Tentaculites sp., proveniente da Bacia do Paraná, Tentaculites sp. (cf. T. eldredgianus), da Bacia do Amazonas e Tentaculites sp. (cf. T. stubeli), para a Bacia do Parnaíba, foram relatadas.

Em 1985, Ciguel e colaboradores apresentam novos estudos com os tentaculitídeos da Bacia do Paraná sobre a preservação parcial da concha (Ciguel et al., 1985). O espécime Tentaculites crotalinus, coletado pelos autores em anos anteriores, serviu de base para essas novas pesquisas. Por meio de análises com Microscópio Eletrônico de Varredura (MEV), pode ser observado que a concha é formada por carbonato de cálcio, sendo "foliada", constituída por lamelas sobrepostas. Essas características foram essenciais para se chegar à conclusão de que os tentaculitídeos pertencem ao grupo dos Moluscos. No trabalho também são mencionados, pela primeira vez, os gêneros Homoctenus e Volynites.

Em 1989, Ciguel apresenta sua dissertação de mestrado Bioestratigrafia dos Tentaculitoidea no Flanco Oriental da Bacia do Paraná e sua ocorrência na América do Sul. Como já citado anteriormente, poucos são os trabalhos de cunho sistemático, tafonômico e paleoecológico do grupo, e essa dissertação acrescenta novas e valiosas informações sobre os tentaculitídeos brasileiros. Nesse trabalho, o autor apresenta 13 gêneros e 45 novas espécies de tentaculitídeos da Bacia do Paraná, sendo 28 encontradas no Brasil. 
Azevedo-Soares (1999) propõe uma sistematização da classe Tentaculitoidea para a Formação Ponta Grossa. A autora afirma que dos gêneros e espécies propostos por Ciguel (1989), citados anteriormente, apenas um gênero (Tentaculites) e duas espécies (T. crotalinus e T. jaculus) são efetivamente encontrados. Segundo Azevedo-Soares, o fato de serem encontradas amostras em diferentes fácies pode indicar uma forma de deposição diferenciada.

Em 2001, Rodrigues et al. realizaram um estudo sobre o conteúdo de tentaculitídeos encontrados em afloramentos do município de Jaguariaíva, Formação Ponta Grossa, Devoniano da Bacia do Paraná. Foram realizados estudos sistemáticos, bioestratigráficos e tafonômicos. A única espécie reconhecida pelos autores foi Tentaculites crotalinus.

Ponciano (2011) realiza um levantamento dos fósseis de macroinvertebrados encontrados no Devoniano da Bacia do Amazonas, pertencentes à Formação Maecuru. Dentre os tentaculitídeos, estão presentes: Tentaculites sp., T. stubeli, T. oseryi e Tentaculites tenellus.

\section{PADRÕES DE PRESERVAÇÃO}

Nos exemplares analisados de tentaculitídeos, nota-se a presença de dois conjuntos preservacionais tafonômicos distintos: amostras com espécimes isolados (Figura 3) e agrupados (Figura 4).

Figura 3: espécimes isolados de tentaculitídeos. Amostras de número: A) NR 4784, B) 03te e C) NR 7137. Escala de $0,5 \mathrm{~cm}$.

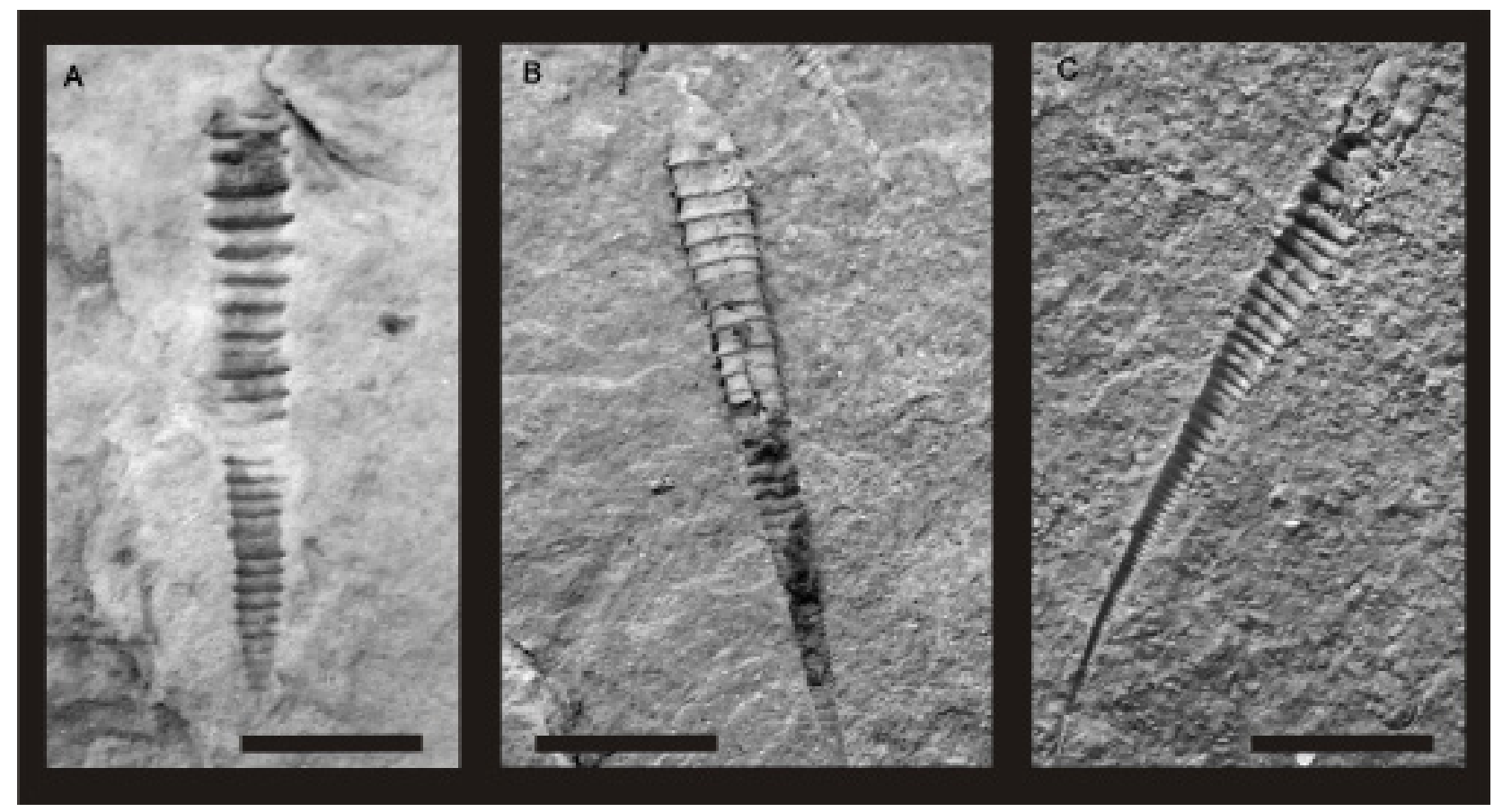


Dentre as amostras estudadas, 73 apresentaram espécimes isolados que exibiam a concha completa (região embrionária, juvenil e adulta), fragmentada e algumas vezes com fratura longitudinal. Das 17 amostras restantes, o padrão observado foi o agrupamento entre os espécimes, onde foram encontradas conchas inteiras, fragmentadas e com fratura longitudinal. Nos padrões de preservação agrupados ou isolados, quando os espécimes eram encontrados com conchas inteiras, todos os espécimes da mesma amostra encontravam-se da mesma maneira, o mesmo acontecia para espécimes que se encontravam fragmentados, porém em ambos os casos, não eram todos os espécimes de todas as amostras que se encontravam com fratura longitudinal.

Nota-se a presença de associações (34 amostras) com outros animais (Figura 4A), tanto nos espécimes isolados quanto nos espécimes em agrupamento, dentre eles: Lingulídeos infaunais, Orbiculoidea, Gigadiscina, Nuculites, Derbyina, Australospirifer, Schuschertella e Australocoelia.

Figura 4. A) Agrupamento e associações com outros grupos animais; e B) Agrupamento de tentaculitídeos. Escala de 0,5 cm

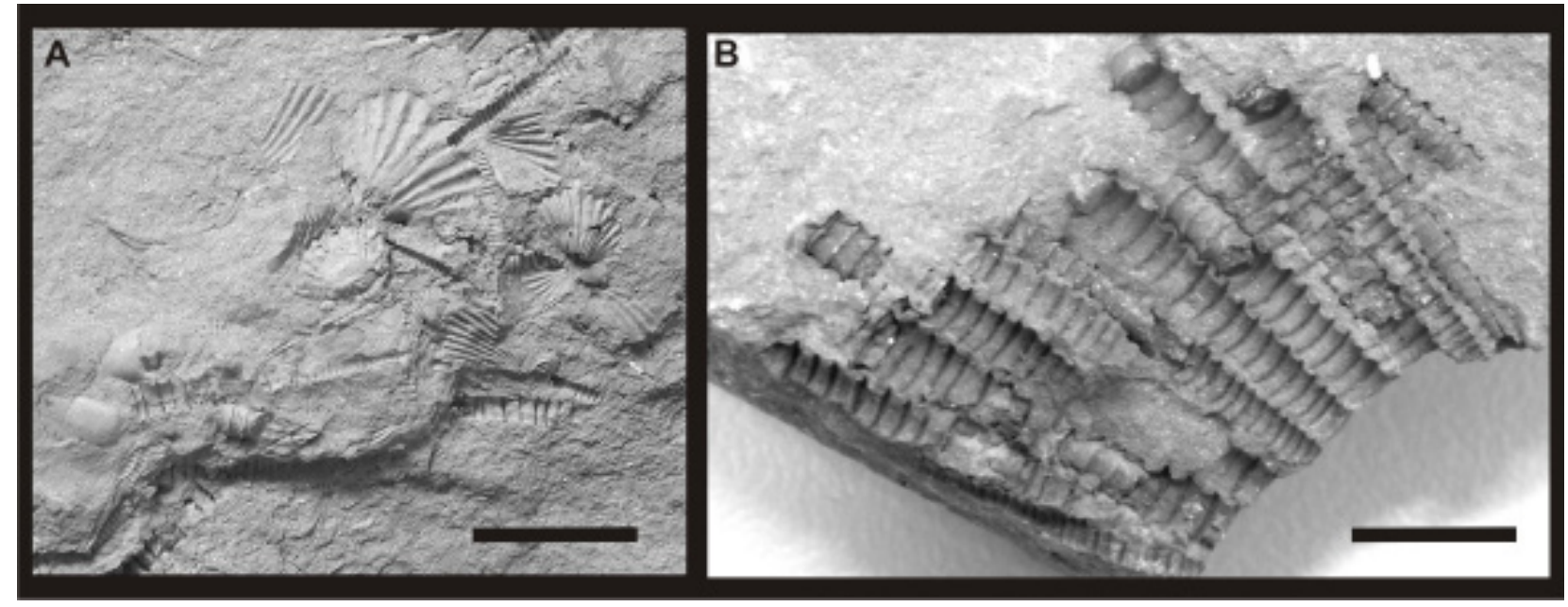

Na figura 4B, é observado um padrão de preservação pouco comum para os tentaculitídeos, foram encontradas 5 amostras. Nesse caso específico, as conchas dos animais estão voltadas para um lado apenas, sendo unidirecionais; esse tipo de preservação, já foi relatada por Ciguel (1989) como sendo provável incrustação no substrato ou em conchas de outros animais. Porém, não foram encontrados resquícios de conchas ou de um substrato diferente. Uma hipótese alternativa seria que esse padrão de preservação ocorre quando existiu um evento com correntes unidirecionais (LANGE \& PETRI, 1967), diferente do padrão apresentado na figura 4A, em que todos os espécimes encontram-se sem direção definida e muitas vezes fragmentados, o que, nesse caso, sugere um fluxo energético oscilante.

Fica evidente que o táxon apresenta uma gama considerável de padrões de preservação refletindo diferenças substanciais em suas características tafonômicas. 


\section{CONSIDERAÇÕES FINAIS}

O primeiro registro de tentaculitídeos para as camadas devonianas do Brasil ocorre no final do século XIX, com o trabalho de Hartt \& Rathbun (1875). Clarke (1899; 1913) descreve novas espécies de tentaculitídeos para a Bacia do Amazonas e Paraná, respectivamente. Porém, é com o trabalho de Ciguel (1989) que a classe começa a tomar maior notoriedade, não apenas em nível sistemático, mas também paleoecológico, tafonômico e bioestratigráfico.

Os tentaculitídeos ocorrentes pertencem às Bacias do Paraná, do Parnaíba e do Amazonas. Hartt \& Rathbun $(1875)$ e Clarke $(1899,1913)$ fazem menção apenas a espécimes do gênero Tentaculites, enquanto Katzer (1903) cita a ocorrência de Tentaculites e Styliolina.

Com o trabalho de Ciguel et al. (1985), começam a aparecer outros gêneros, tais como: Homoctenus e Volynites. Além disso, somente a partir dos trabalhos de Ciguel et al. $(1984 ; 1987)$ e Azevedo-Soares (1999) que se trata os tentaculitídeos como pertencentes ao Filo Molusca.

Observaram-se dois tipos de padrões de preservação: espécimes isolados e agrupados. Nos dois tipos de preservação, observou-se a associação com outros grupos de animais.

Apesar de ser um grupo amplamente encontrado nos estratos devonianos brasileiros, desde o trabalho pioneiro de Clarke (1913) o grupo continua mal compreendido em suas relações taxonômicas, demonstrando a dificuldade de trabalho devido, entre outras coisas, aos parcos estudos tafonômicos relacionados ao grupo.

\section{AGRADECIMENTOS}

J.C.C. agradece à FAPESP pela bolsa de Doutorado concedida e também ao CNPq pelo financiamento do projeto 401796/2010-8.

\section{REFERÊNCIAS}

AZEVEDO-SOARES, Hilda Leonor Coevas. Classe Tentaculita na Formação Ponta Grossa: uma proposta de sistematização. 1999. Dissertação de mestrado. Universidade do Estado do Rio de Janeiro. 117 p.

BLIND, Wolfram. Die systematiche Stellung der Tentakuliten. Palaeontographica Abt. A, v. 133, p. 101145. 1969.

BOND, David. The fate of the homoctenids (Tentaculitoidea) during the Frasnian-Famennian mass extinction (Late Devonian). Geobiology, 4, p. 167-177. 2006.

BOUCEK, Bedrick V. The Tentaculites of Bohemia: their morphology, taxonomy, ecology, Phylogeny and biostratigraphy. Czech. Acad. Sci, p. 1- 215. 1964.

CIGUEL, José Henrique Godoy; ROSLER, Oscar \& CAMINEIRO, Daniel. Tentaculitoidea da formação Ponta Grossa no estado do Paraná. In: CONGRE. BRAS. DE GEOL., 33, Anais. Rio de Janeiro: SBG, p. 655669. 1984. 
CIGUEL, José Henrique Godoy \& ROSLER, Oscar. Caracterização das formas brasileiras de Tentaculites crotalinus Salter, 1856. Anais da Academia Brasileira de Ciências, 57, 1, p. 116. 1985.

CIGUEL, José Henrique Godoy; ROSLER, Oscar; HOFMEISTER, Robin. M. Preservação parcial da concha de Tentaculites crotalinus, da Formação Ponta Grossa (Devoniano). Boletim Ig-USP. Ser. Cient. 18, p. 17-26. 1987.

CIGUEL, José Henrique Godoy. Bioestratigrafia dos Tentaculitoidea no flanco oriental da Bacia do Paraná e sua ocorrência na América do Sul. 2v. Dissertação de Mestrado. Universidade de São Paulo, Instituto de Geociências. 1989.

CLARKE, John Mason. Moluscos devonianos do Estado do Pará, Brasil. Archos. Mus. Nacio. n. 10, est. 3-8, p. 49-174. 1899.

CLARKE, John Mason. Fósseis Devonianos do Paraná. Monographias do Serviço Geológico e Mineralógico do Brasil. Rio de Janeiro, , f: 1-353, pl. 1-27. 1913.

DERBY, Orville Adelbert. Nota sobre a geologia e paleontologia de Matto Grosso. Vol. 5050. Imprensa nacional, 1890.

FARSAN, Noor Mohammad. Tentaculiten: Ontogenese, Systematik, Phylogenese, Bioestratonomie und Morphologie. Abh. Senkenb. Naturforsch. Ges, v. 547, p. 1-128. 1994.

FISHER, Donald W. Small conoidal shells of uncertain affinities. Treatise on invertebrate paleontology. Boulder, Geological Society of America; Lawrence: University of Kansas Press, Part W Miscellanea 1 - XX: p. 98-130. 1965.

GAUGRIS, Kariny A. \& GRAHN, Yngve. New chitinozoan species from the Devonian of the Paraná Basin, south Brazil, and their biostratigraphic significance. Ameghiniana, 43, p. 293-310. 2006.

GRAHN, Yngve; PEREIRA, Egberto; BERGAMASCHI, Sérgio. Silurian and Lower Devonian chitinozoan biostratigraphy of the Paraná Basin in Brazil and Paraguay. Palynology, 24, 143-172, 2000.

GRAHN, Yngve; MENDLOVICZ MAULLER, Paula; BERGAMASCHI, Sergio; BOSSETI, Elvio P. Palynology and sequence stratigraphy of three Devonian rock units in the Apucarana Sub-basin (Paraná Basin, south Brazil): Additional data and correlation. Review of Palaeobotany and Palynology, 198, p. 27-44. 2013.

HARTT, Charles Frederick \& RATHBUN, Richard. Morgan expedition, 1870-1871: on the Devonian trilobites and mollusks of Erere, Province of Para, Brazil. Ann. Lyceum. Nat. Hist., v. 11, n. 13, p. 110-127. 1875 .

KATZER, Friedrich. As camadas fossilíferas mais antigas da região amazônica. Bol. Mus. Par. Hist. Nat. Ethnog., v. 1, n. 4, p. 436-438. 1896.

KATZER, Friedrich. Grundzuge der Geologie des unteren Amazonasgebietes (dês Staates Pará in Brasilien). Leipzig: Max Weg. est. 1-16, 1903. 298 p.

KATZER, Friedrich. Geologia do Pará (Brasil). Bol. Mus. Par. Emilio Goeldi. v. 9, 1933. 270 p.

KEGEL, Willem. Contribuição para o estudo do Devoniano da Bacia do Parnaíba. Bol. Div. Geol. Min. DNPM, n. 141, 1953. 59 p.

KOZLOWSKI, Roman. Fósiles Dévoniensis de l' état de Paraná (Brésil). Annales de Paleontologie, Paris, v. 8 n. 3, p. 1-19. 1913.

LANGE, Frederico Waldemar. Paleontologia do Paraná. Comissão de Comemoração do Centenário do Paraná. 1954. 210 p.

LANGE, Frederico Waldemar; PETRI, Setembrino. The Devonian of Paraná Basin. Boletim Paranaense de Geociências. Curitiba, fig. 1-5, n. 21-22, p. 5-55, 1967.

LARDEUX, Hubert. Nouvelles donnés sur la morphologie des Tentaculitoidea. C.R. Acad.Sci. Fr., 258, 24, p. 5939-42. 1964. 
LEONARDI, Giorgio. Notopus petri nov. gen., sp.: Une empreinte d'amphibien Du dévonien au Paraná (Brésil). Geobios. 16, 2, p. 233-9. 1983.

LJASCHENKO, G. New facts on the systematics of Tentaculitids, Nowakids and Stylionids. Byull. Mosk. Ova. Ispyt. Prir. Otd. Geol. Ser. Geol. Moscow, v. 30, n. 3, p. 94-95. 1955.

MELO, José Henrique Gonçalves. A Província Malvinocáfrica no Devoniano do Brasil. 1985. Dissertação de Mestrado. Instituto de Geociências, Universidade Federal do Rio de Janeiro, Rio de Janeiro. 1200 p.

MENDLOWICZ MAULLER, Paula; GRAHN, Yngve; MACHADO CARDOSO, T.R., Palynostratigraphy from the Lower Devonian of the Paraná Basin, South Brazil, and a revision of contemporary Chitinozoan biozones from Western Gondwana. Stratigraphy 6, p. 313-332. 2009.

MILANI, Edson J; MELO, José HG.; SOUZA, Paulo A.; Fernandes Luiz A, FRANÇA, Almério B. Bacia do Paraná. Boletim de Geociências da Petrobrás, 15, p. 265-287. 2007.

PETRI, Setembrino. Contribuição ao estudo do Devoniano Paranaense. Boletim DNPM, DGM, 129, p. 1-125. 1948.

PETRI, Setembrino \& FÚLFARO, Vicente José. Geologia do Brasil. São Paulo. Edusp. 1983. 631 p.

PONCIANO, Luiza C. M. O. Fósseis devonianos da Bacia do Amazonas. 8. ed. Florianópolis: Bookess Editora, 2011.

RODRIGUES, Maria Antonieta da Conceição; AZEVEDO-SOARES, Hilda Leonor Coevas \& BERGAMASCHI, Sérgio. Horizontes de mortalidade em massa de Tentaculita na Formação Ponta Grossa (Devoniano, Bacia do Paraná) e seu significado estratigráfico. In: Melo, J. H. G. \& Terra, G. J. S. (Eds) Correlação de seqüiências Paleozóicas Sul-Americanas. Ciência-Técnica-Petróleo, p. 73-79. 2001.

SCHINDLER, Eberhard. The late Frasnian (Upper Devonian) Kellwasser Crisis. Lec Notes Earth Sci, 30, p. 151-159. 1990.

SCHINDLER, Eberhard. Tentaculitoids: An Enigmatic group of Paleozoic Fossils. Earth and Life. Talent, J. A. p. 479-490. 2012.

VAIL, Peter R.; MITCHUM, Robert M.; THOMPSON, S. Seismic stratigraphy and global changes of sea level, part 3: relative changes of sea level from coastal onlap. In: PAYTON, C. E. (Ed.). Seismic stratigraphy: applications to hydrocarbon exploration. Tulsa: American Association of Petroleum Geologists, p. 63-81. 1977.

VON AMMON, Ludwig. Devonische Versteinerungen von Lagoinha in Matto Grosso (Brasilien). Zeitschrift der Gesellschaft für Erdkunde zu Berlin, v. XXVIII, p. 352-366. 1893.

WITTMER, Jacalyn M., MILER, Arnold. Dissecting the global diversity trajectory of an enigmatic group: The paleogeographic history of tentaculitoids. Paleogeography, Paleoeclimatology, Paleoecology. 312, p. 54-65. 2011.

Recebido em 09/10/2013

Aceito para publicação em 02/12/2013 
9. 2. COMNISKEY, J. C.; GHILARDI, R. P.; BOSETTI, E. P. Conhecimento atual sobre os tentaculitoideos devonianos das bacias do Amazonas e Parnaíba, Brasil, depositados em instituições brasileiras. Boletim do Museu Paraense Emilio Goeldi, v. 10, n. 1, p. 49-61, 2015. 


\title{
Conhecimento atual sobre os tentaculitoideos devonianos das bacias do Amazonas e Parnaíba, Brasil, depositados em instituições brasileiras Current knowledge about Devonian tentaculitoids of Amazonas and Parnaíba basins, Brazil, deposited in Brazilian institutions
}

\author{
Jeanninny Carla Comniskey', Renato Pirani Ghilardi", Elvio Pinto BosettillI \\ Universidade de São Paulo. Ribeirão Preto, São Paulo, Brasil \\ "Universidade Estadual Paulista "Júlio de Mesquita Filho". Bauru, São Paulo, Brasil \\ I'U Universidade Estadual de Ponta Grossa. Ponta Grossa, Paraná, Brasil
}

\begin{abstract}
Resumo: Os tentaculitoideos são encontrados em afloramentos do Devoniano das bacias do Paraná (Formações Ponta Grossa e São Domingos), Amazonas (Formações Maecuru e Ererê) e Parnaíba (Formação Cabeças). Foram analisadas 39 amostras de coleções científicas provenientes do Devoniano Médio das bacias do Amazonas e do Parnaíba, com principal objetivo de realizar uma revisão sistemática e refinar o conhecimento acerca da distribuição estratigráfica e paleogeográfica do grupo. As espécies encontradas foram: Tentaculites trombetensis, Tentaculites stubeli, Tentaculites eldredgianus, Tentaculites oseryi e Styliolina clavulus. As espécies T. eldredgianus, T. trombetensis e S. clavulus foram encontradas em afloramentos do Eifeliano até o Givetiano, enquanto T. oseryi apenas no Givetiano e T. stubeli no Eifeliano. As primeiras ocorrências de tentaculitoideos para a América do Sul são registradas no Siluriano, o que corrobora a hipótese de que durante o Siluriano Inferior ocorreu um grande aumento da diversidade e quantidade de tentaculitoideos no mundo.
\end{abstract}

Palavras-chave: Tentaculitoidea. Sistemática. Devoniano. Paleobiogeografia. Bacia do Amazonas. Bacia do Parnaíba.

\begin{abstract}
The Tentaculitoids are commonly found in the outcrops of the Devonian of the Paraná Basin (Ponta Grossa and São Domingos Formation), the Amazon Basin (Maecuru and Ererê Formation) and Parnaíba Basin (Cabeças Formation). We analyzed 39 samples of scientific collections from the middle Devonian of the Amazon and Parnaíba Basin, with main objective to conduct a systematic review to refine the knowledge on the stratigraphic and paleogeographic distribution of the group. The species found were: Tentaculites trombetensis, Tentaculites stubeli, Tentaculites eldredgianus, Tentaculites oseryi and Styliolina clavulus. The species T. eldredgianus, T. trombetensis and S. clavulus were found in outcrops of Eifelian to the Givetian. While T. oseryi only during Givetian and T. stubeli during Eifelian. The first occurrences of tentaculitoids in South America are related to the Silurian, which corroborates the hypothesis that during the Early Silurian, there was a large increase in the diversity and quantity of tentaculitoids in the world.
\end{abstract}

Keywords: Tentaculitoidea. Systematic. Devonian. Palaeobiogeography. Amazonas Basin. Parnaíba Basin.

COMNISKEY, J. C., R. P. GHILARDI \& E. P. BOSETTI, 2015. Conhecimento atual sobre os tentaculitoideos devonianos das bacias do Amazonas e Parnaíba, Brasil, depositados em instituições brasileiras. Boletim do Museu Paraense Emílio Goeldi. Ciências Naturais 10(1): 49-61. Autor para correspondência: Jeanninny Carla Comniskey. Universidade de São Paulo. Pós-Graduação em Biologia Comparada. Av. Bandeirantes, 3900 - Monte Alegre. Ribeirão Preto, SP, Brasil. CEP 14040-901 (comniskey@gmail.com).

Recebido em 18/11/2014

Aprovado em 14/05/2015

Responsabilidade editorial: Hilton Tulio Costi

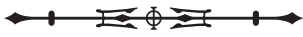




\section{INTRODUÇÃO}

O estudo da classe Tentaculitoidea tem avançado muito no decorrer dos anos, porém pouco se sabe sobre o animal que habita a concha ou em qual reino animal o táxon deve ser incluído. Segundo Wei et al. (2012), existem duas principais ideias quanto à posição taxonômica do grupo. A primeira seria uma afinidade com os moluscos devido à semelhança com a concha e as paredes dela (Bouček, 1964; Blind, 1969; Lardeux, 1969; Farsan, 1994; Schindler, 2012). Já a segunda linha de pesquisas reconhece os tentaculitoideos como um grupo irmão dos microconchídeos (Weedon, 1991; Vinn \& Taylor, 2007; Zatoń \& Taylor, 2009; Vinn, 2010; Vinn \& Zatoń, 2012; Vinn, 2013). Embora estas duas hipóteses ainda sejam muito discutidas, prefere-se adotar, neste trabalho, a primeira hipótese taxonômica para este grupo.
Dessa forma, os tentaculitoideos são invertebrados extintos que possuem concha carbonática coniforme de tamanho milimétrico. A maioria apresenta a concha reta, sendo que poucos apresentam concha encurvada e até mesmo enrolada (Schindler, 2012). Podem possuir uma concha lisa ou com ornamentação e, neste último caso, apresentam anéis, microanéis, macroanéis, estrias e espaços interanulares (Figura 1). A classificação dos tentaculitoideos é baseada, exclusivamente, em aspectos morfológicos da concha, a partir da ornamentação externa (Ciguel, 1989; Azevedo-Soares, 1999; Comniskey \& Ghilardi, 2013). A classe Tentaculitoidea Lyashenko, 1957 (= Cricoconarida Fisher, 1962) é dividida em três ordens: Tentaculitida Ljashenko, 1955, Homoctenida Bouček, 1964 e Dacryoconarida Fisher, 1962.

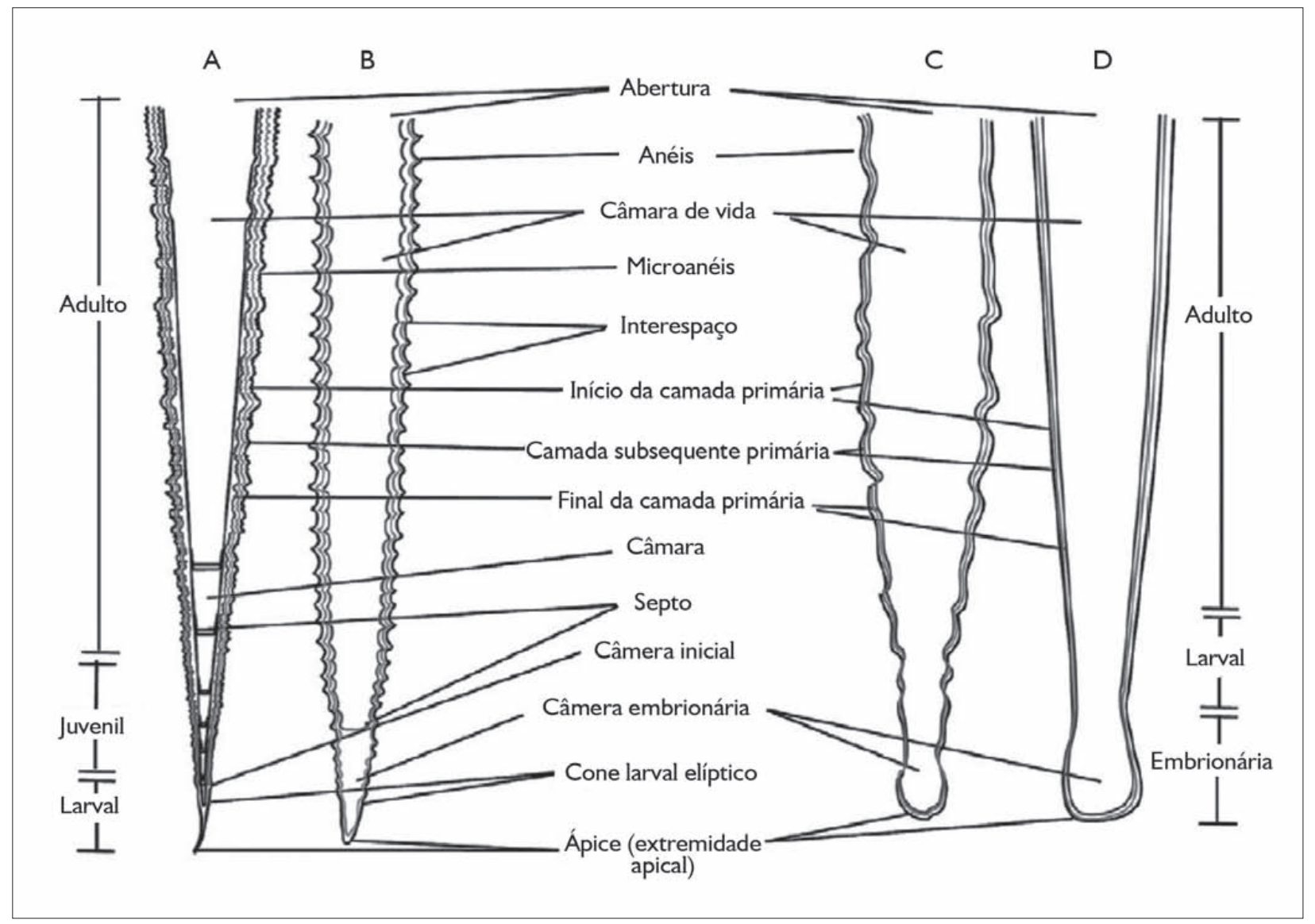

Figura 1. Representantes das ordens Tentaculitida (A), Homoctenida? (B) e Dacryoconarida? (C e D). Modificado de Wittmer \& Miller (2011).

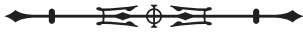


Segundo Fisher \& Young (1955), os primeiros registros de tentaculitídeos são do Ordoviciano Inferior da Formação Chepultepec, da Virginia (Tremadociano), com representantes da ordem Tentaculitida ocorrendo em abundância e ficando documentados no registro fossilífero até o término do Siluriano. O táxon dos dacryoconarideos surge no Siluriano, mas torna-se excepcionalmente diverso no Devoniano Inferior e Médio (Schindler, 2012). Já os homoctenídeos têm seu registro iniciado a partir do Devoniano e seu ápice evolutivo ocorre no Frasniano (Bond, 2006; Schindler, 2012). Este período é caracterizado pela grande expansão da diversidade e da distribuição geográfica dos tentaculitoideos (Wittmer \& Miller, 2011; Schindler, 2012). Schindler (1990, 2012) e Bond (2006) afirmam que os homoctenideos foram os únicos tentaculitoideos que ultrapassaram a barreira da extinção Frasniano - Fameniano (FF).

No Brasil, os tentaculitoideos são encontrados nas bacias do Paraná, Amazonas e Parnaíba. Na Bacia do Paraná, foi registrada a maior descrição de gêneros Tentaculites, Homoctenus, Uniconus, Multiconus, Dicricoconus, Volynites e Styliolina, enquanto que nas bacias do Amazonas e do Parnaíba apenas os gêneros Tentaculites e Styliolina são registrados. Apesar de ser um grupo cosmopolita no Devoniano brasileiro, há poucos trabalhos que lidam com a sistemática do grupo. Os trabalhos de Hartt \& Rathbun (1875), Clarke (1899a, 1899b) e Katzer (1903) foram os pioneiros na descrição de espécies do grupo para o Siluriano e Devoniano. Porém, após as primeiras descrições de espécies, poucos são os trabalhos de caráter taxonômico desses táxons e, conforme indicado em Comniskey \& Ghilardi (dados não publicados), os realizados não seguem os critérios relacionados no Código Internacional de Nomenclatura Zoológica, tornado-os, em sua maioria, inválidos (ver Ciguel et al., 1984; Ciguel \& Rosler, 1985; Ciguel et al., 1987; Ciguel, 1989; Azevedo-Soares, 1999, para exemplos na Bacia do Paraná). Nas bacias do Amazonas e Parnaíba, os trabalhos atuais relatam apenas a ocorrência dos tentaculitoideos, sem tratar especificamente sobre sua sistemática (Melo, 1985; Fonseca, 2004; Ponciano \& Machado, 2007; Ponciano, 2011; Ponciano et al., 2012).

Levando em consideração a falta de trabalhos sobre a sistemática do grupo, realizou-se uma revisão para as bacias do Amazonas e do Parnaíba, indicando as ocorrências das espécies ou formas aparentadas em outras localidades no mundo. Através da revisão realizada, foi possível correlacionar as ocorrências dos táxons encontrados entre as bacias sedimentares paleozoicas brasileiras e na região sul-americana, bem como atualizar e ampliar as informações paleobiogeográficas que esses táxons possam trazer.

\section{MATERIAL E MÉTODOS}

Foram realizadas visitas a coleções técnicas de universidades, museus e instituições de pesquisa. As coleções analisadas foram: Núcleo de Estudos Paleontológicos da Universidade Estadual do Rio de Janeiro (UERJ), Laboratório de Paleontologia de Invertebrados do Museu Nacional, Universidade Federal do Rio de Janeiro (MN/UFRJ), Departamento Nacional de Produção Mineral (DNPM) e Laboratório de Estudos de Comunidades Paleozoicas, da Universidade Federal do Estado do Rio de Janeiro (UNIRIO). Foram escolhidas estas coleções científicas em razão de os autores terem realizado contato com os seus curadores e, entre elas, foi verificada a presença dos holótipos do material dos trabalhos de Clarke (1899a, 1899b) e uma quantidade razoável de fósseis de tentaculitoideos. Não foi possível localizar os exemplares do trabalho de Hartt \& Rathbun (1875), nem consultando o banco de dados de fósseis de invertebrados catalogados no museu Paleontological Research Institution da Universidade de Cornell (Ithaca, Estados Unidos), nem por meio do contato com os responsáveis pela coleção.

Foram observadas 39 amostras, com aproximadamente 153 espécimes (34 da Bacia do Amazonas e 119 da Bacia do Parnaíba). O material analisado é proveniente de afloramentos do Devoniano Médio das Formações Maecuru e Ererê (Bacia do Amazonas) e da Formação 
Cabeças (Bacia do Parnaíba). Em algumas amostras, não foi possível chegar ao nível genérico ou específico, pela falta de caracteres morfológicos ou má preservação dos espécimes. Ressalta-se aqui que a maioria dos exemplares analisados foi coletada durante expedições do século passado, sem a preocupação com um registro estratigráfico mais detalhado. Todo o material analisado encontra-se depositado nas instituições de pesquisas visitadas (Figura 2).
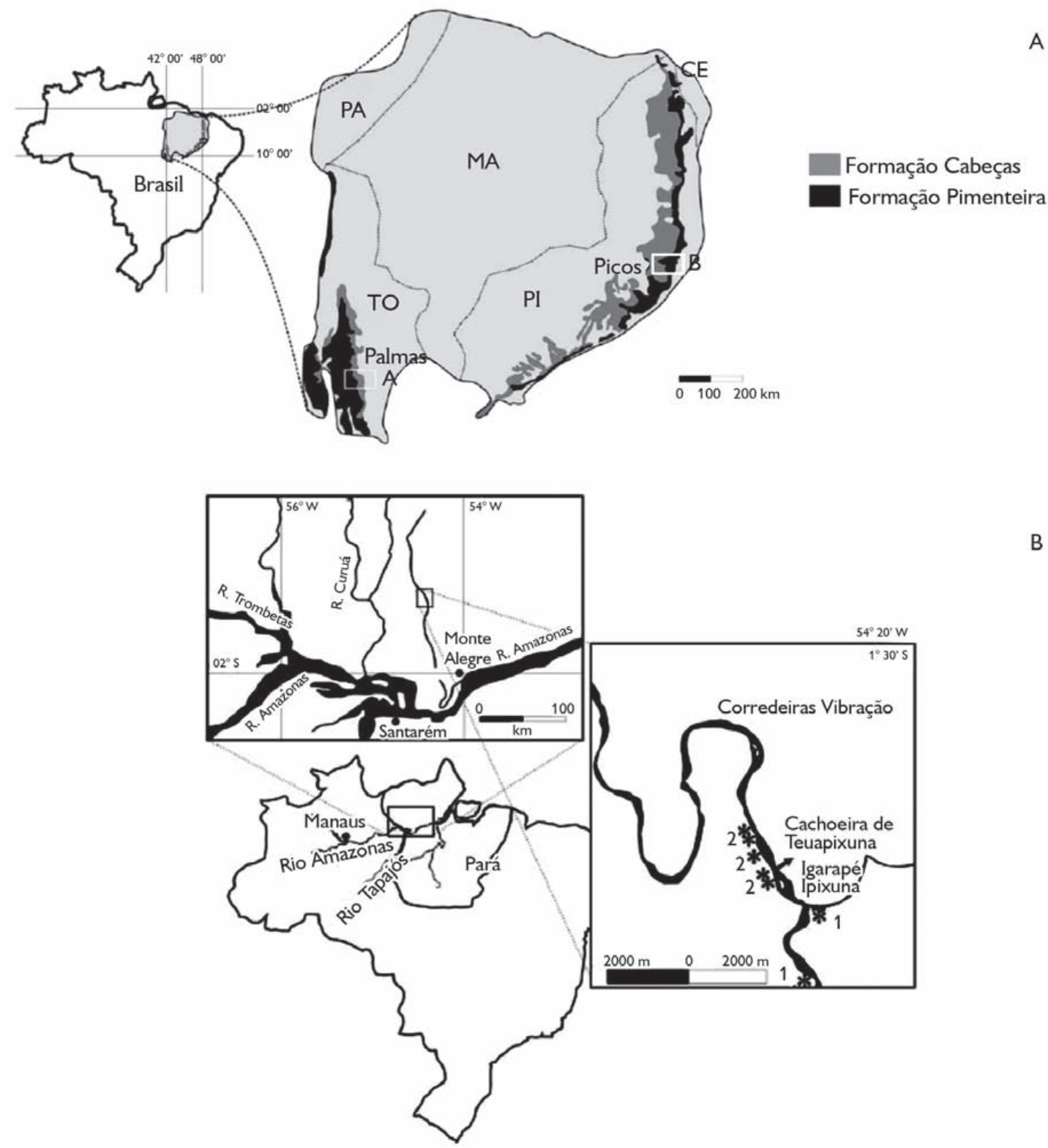

Figura 2. Localização dos afloramentos: A) Bacia do Parnaíba, localização das Formações Cabeças e Pimenteiras; B) Bacia do Amazonas, o ponto de número 1 refere-se aos afloramentos da Formação Ererê e os pontos de número 2 correspondem aos afloramentos da Formação Maecuru (modificado de Scheffler, 2010).

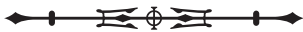




\section{SISTEMÁTICA PALEONTOLÓGICA}

Classe Tentaculitoidea Lyashenko, 1957

Ordem Tentaculitida Lyashenko, 1955

Família Tentaculitidae Walcott, 1886

Gênero Tentaculites Schloteim, 1820

Espécie-tipo Tentaculites scalaris Schlotheim, 1820

Tentaculites eldredgianus Hartt \& Rathbun, 1875 (Figura 3D)

1899 - Tentaculites eldredgianus Clarke, 1899, p. 80-81, plate IV, figuras 29-31

1933 - Tentaculites eldredgianus Katzer, 1933, p. 252, plate XIII, figuras 25-26

Diagnose específica:

Shell small, rather long, straight, circular in crosssection, at least $1 \mathrm{~mm}$ in diameter at the larger end, and tapering very gradually to an acute point. Length of the most perfect specimen, a fragment, about $16 \mathrm{~mm}$. Annulations narrow, quite prominent, an angular or slightly rounded of the summit; the interspaces are generally about twice as wide as the annulations, though they vary somewhat in width, and are flattened or a little rounded in the bottom; they are ornamented by fine annular raised lines, of which there are about four or five in each interspace, near the larger end of the specimen. The annulations decrease in size, but become more numerous toward the apex. There are about 5 to 7 in the space of $3 \mathrm{~mm}$ near the larger end (Hartt \& Rathbun, 1875).

Descrição: com tamanho aproximado de $1,8 \mathrm{~cm}$. Anéis arredondados, bastante proeminentes. Interespaços maiores na região adulta e da abertura, sendo aproximadamente duas vezes maiores do que os anéis. Anelamento irregular, podendo ocorrer áreas com pequeno espaçamento entre os anéis ou espaços com quase o tamanho dos anéis, também podendo ocorrer grandes áreas sem anéis. Câmara embrionária levemente arredondada.

Material: amostras de número 41 e 55, depositadas na Universidade Federal do Estado do Rio de Janeiro (UNIRIO).
Distribuição geográfica: A) rio Maecuru, margem direita, 400 m à montante da cachoeira Teuapixuna ou Alagação, coletadas pela expedição Orville Adelbert Derby, em 1986; B) localizado no lado norte de uma curva da BR-316 (Picos - Teresina), a cerca de 5 km do trevo de Picos, em direção a Oeiras, dentro de uma propriedade particular, no município de Picos (Deusana Machado, comunicação pessoal, 2014).

Distribuição estratigráfica: Formação Maecuru (Eifeliano) e Formação Cabeças (Givetiano).

Holótipo: o depósito do material descrito por Hartt \& Rathbun (1875), seja de seu holótipo, parátipos ou síntipos, não possui registro. Apesar de provavelmente estarem depositados na Cornell University, Estados Unidos, contatos realizados não foram suficientes para localizá-los. Dessa forma, é necessário, para validação da espécie, determinar seu neótipo.

Tentaculites stubeli Clarke, 1899 (Figura 3B)

Diagnose específica:

Concha um tanto robusta, estreitando-se rapidamente. A parte superior é cruzada por anneis mais ou menos oblíquos, muitas vezes irregulares, e separados por intervallos um tanto desiguaes. $\mathrm{Na}$ superfície externa estes anneis apresentam uma encosta superior comprida e uma costa inferior vertical ou mesmo côncava; nos moldes internos elles parecem agudamente angulares, com encostas iguaes em ambas as direções. Os intervallos são lisos e tornam-se mais estreitos para baixo, desapparecendo totalmente os anneis a uma distancia considerável do ápice. A parte apical da concha, na distancia de um terço a um quarto do comprimento total do tubo, é lisa (Clarke, 1899a).

Descrição: concha de tamanho médio de $2 \mathrm{~cm}$. Esta foi a maior espécie entre as analisadas. Anéis levemente oblíquos na região da abertura e interespaços irregulares. Anéis arredondados. Interespaços mais lisos e mais largos na região adulta e de abertura. Região apical lisa.

Material: amostras de número 5, 46 e 48 que estão depositadas na Universidade Federal do Estado do Rio de Janeiro (UNIRIO). 
Distribuição geográfica: encontrada no afloramento da Margem direita do rio Maecuru cerca de 400 m à montante da cachoeira de Teapuxina ou Alagação e cerca de 1,5 km à montante da foz do igarapé Ipixuna.

Distribuição estratigráfica: Formação Ererê (Neoeifeliana - Eogivetiana).

Holótipo: o material analisado por Clarke (1899a), seja de seu holótipo, parátipos ou síntipos, não possui registro. As figuras 24-28, estampa IV, do trabalho de Clarke (1899a) ficam designadas como síntipos. Apesar de provavelmente estarem depositados no Museu Nacional do Rio de Janeiro, contatos realizados não foram suficientes para localizá-los. Dessa forma, é necessário, para validação da espécie, determinar seu neótipo.

\section{Tentaculites oseryi Clarke, 1899 (Figura 3E)}

Diagnose específica:

\begin{abstract}
Esta espécie é menor do que T. stubeli ou T. trombetensis, e tem a superfície coberta de anneis regulares apertados, que são arredondados e separados por intervallos muito estreitos do que os anneis. Em algumas amostras os anneis se estendem quase até o ápice, em outras há um espaço considerável junto ao ápice que é liso. Os intervallos entre os anneis são fortemente côncavos e lisos. A maior amostra observada tem $9 \mathrm{~mm}$ de comprimento, e apresenta 23 anneis que se tornam rapidamente mais finos para baixo (Clarke, 1899a).
\end{abstract}

Descrição: anéis praticamente do tamanho dos espaços. Anéis arredondados, levemente espessos. Em alguns casos, região apical lisa. Interespaços fortemente côncavos e lisos. Em algumas amostras, a presença de anéis estende-se até o ápice, em outros casos ele está sem ornamentação. Tamanho aproximado de 1,3 cm. Clarke (1899a) afirma que esta espécie é menor do que $T$. trombetensis, porém, nas amostras analisadas, verificou-se o contrário.

Material: amostras de número 54, 58, 59 e 101, depositadas na Universidade Federal do Estado do Rio de Janeiro (UNIRIO).
Distribuição geográfica: A) afloramento localizado no lado norte de uma curva da BR-316 (Picos - Teresina), a cerca de $5 \mathrm{~km}$ do trevo de Picos em direção a Oeiras, dentro de uma propriedade particular, no município de Picos; B) situado em uma curva da estrada de terra em direção ao povoado de Oiti, a 800 m do entroncamento desta com a PI-120 (trecho Valença do Piauí - Pimenteiras), no município de Pimenteiras, Piauí (Deusana Machado, comunicação pessoal, 2014).

Distribuição estratigráfica: Formação Cabeças (Givetiano).

Holótipo: o material descrito por Clarke (1899a), seja de seu holótipo, parátipos ou sintipos, não possui registro. Apesar de provavelmente estarem depositados no Museu Nacional do Rio de Janeiro, contatos realizados não foram suficientes para localizá-los. Dessa forma, é necessário, para validação da espécie, determinar seu neótipo.

Tentaculites trombetensis Clarke, 1899 (Figura 3A)

1989 - Tentaculites trombetensis Ciguel, 1989, p. 64- 66, plates 24 e 25

Diagnose específica:

É uma concha pequena, recta, nunca flexuosa, e estreitando-se muito gradualmente. A superfície é coberta com annulações fortes e simples, cujos lados se inclinam de modo igualmente abrupto por cima e por baixo, e são separados por sulcos um tanto largos e fundos. Tanto as annullações como os sulcos se tornam mais estreitos e menores à medida que se approximam do ápice, e uma particularidade especial desta espécie é o forte desenvolvimento destas feições desde o começo da concha. Os sulcos intersticiaes são destituídos de ornamentação. O comprimento de uma amostra de tamanho médio, e provavelmente inteira, é de $11 \mathrm{~mm}$; a largura na abertura é de $1 \mathrm{~mm}$ (Clarke, 1899b).

Descrição: concha pequena, com tamanho aproximado de $0,8 \mathrm{~cm}$. Anéis arredondados. Interespaços largos e fundos. Anéis e espaços maiores na região da abertura. Ápice geralmente liso. Câmara embrionária levemente arredondada. 
Distribuição geográfica: A) rio Maecuru, margem direita a $400 \mathrm{~m}$ à montante da cachoeira Teuapixuna ou Alagação, coletadas pela Expedição Orvile A. Derby; B) localizado no lado norte de uma curva da BR-316 (Picos - Teresina), a cerca de $5 \mathrm{~km}$ do trevo de Picos, em direção a Oeiras, dentro de uma propriedade particular, no município de Picos (Deusana Machado, comunicação pessoal, 2014).

Distribuição estratigráfica: Formação Maecuru (Eifeliano) e Formação Cabeças (Givetiano).

Holótipo: o material analisado por Clarke (1899b), seja de seu holótipo, parátipos ou síntipos, não possui registro. As figuras 26-27, estampa II, do trabalho de Clarke (1899b) ficam designadas como síntipos. Apesar de provavelmente estarem depositados no Museu Nacional do Rio de Janeiro, contatos realizados não foram suficientes para localizá-los. Dessa forma, é necessário, para validação da espécie, determinar seu neótipo.

Classe Tentaculitoidea Lyashenko, 1957

Ordem Dacryoconarida Fisher, 1962

Família Stylionidae Grabau \& Shimer, 1910

Gênero Styliolina sp. Karpinsky, 1884

Espécie-tipo Styliola nucleata Karpinsky, 1884

Styliolina clavulus Barrande, 1852 (Figura 3C)

Diagnose específica:

La plupart des spécimens de cette espèce sont écrasés dans les roches schisteuses de nos bandes g 2-h 1. Cependant, on en découvre quelques uns qui permettent de reconnaitre la forme naturelle, conique et régulière de la coquille, dont la section transverse semble circulaire. La surface de ce test n'a conservé aucune trace d'ornemens. Dimensions. La longueur de la plupart des spécimens varie entre 1 et $3 \mathrm{~mm}$. Mais nous en rencontrons quelques uns qui atteignent $5 \mathrm{~mm}$. et dont le diamètre est d'environ $1 / 2 \mathrm{~mm}$ (Barrande et al., 1852).

Descrição: concha com tamanho aproximado de $1,8 \mathrm{~cm}$, reta, lisa e sem a presença de anelações. Em alguns casos, ocorre a presença de tênues estrias de crescimento. Câmara embrionária com forma goticular.

Distribuição geográfica: A) rio Maecuru, margem direita, $400 \mathrm{~m}$ à montante da cachoeira Teuapixuna ou Alagação, coletadas pela Expedição Orville A. Derby, 1986; B) afloramento localizado no lado norte de uma curva da BR-316 (Picos - Teresina), a cerca de $5 \mathrm{~km}$ do trevo de Picos em direção a Oeiras, dentro de uma propriedade particular, no município de Picos (Deusana Machado, comunicação pessoal, 2014).

Distribuição estratigráfica: Formação Maecuru (Eifeliano) e Formação Cabeças (Givetiano).

\section{DISCUSSÃO}

Os tentaculitoideos possuem uma ampla distribuição geográfica, sendo encontrados em locais como Afeganistão, África do Sul, Alemanha, Áustria, Argentina, Bolívia, Canadá, China, Estados Unidos, Paraguai, Peru, Polônia, República Tcheca e Suécia (Knod, 1908; Fisher \& Young, 1955; Ljashenko, 1955, 1957, 1959; Fisher, 1962; Bouček, 1964; Lardeux, 1969; Larsson, 1979; Lindemann \& Yochelson, 1992; Alberti, 1993; Lindemann \& Melycher, 1997; Azevedo-Soares, 1999; Wittmer \& Miller, 2011; Schindler, 2012; Wei et al., 2012), e apresentando distribuição estratigráfica do Ordoviciano ao Devoniano, possuindo ápice da classe no Devoniano Médio e extinção total da classe no limite Frasniano-Fameniano (Bond, 2006; Wittmer \& Miller, 2011; Schindler, 2012).

No Hemisfério Norte, uma grande quantidade de gêneros e espécies é conhecida, enquanto no Brasil são poucos os táxons encontrados no registro estratigráfico (Ciguel, 1989; Azevedo-Soares, 1999; Comniskey \& Ghilardi, 2013).

Os trabalhos referentes ao surgimento, apogeu e extinção dos tentaculitoideos são controversos. Autores como Wittmer \& Miller (2011) e Schindler (2012) citam a ocorrência dos primeiros tentaculitoideos no início do Ordoviciano. Porém ocorre uma lacuna no registro de tentaculitoideos durante o Ordoviciano Médio, que voltam a aparecer no final do Ordoviciano. Segundo 

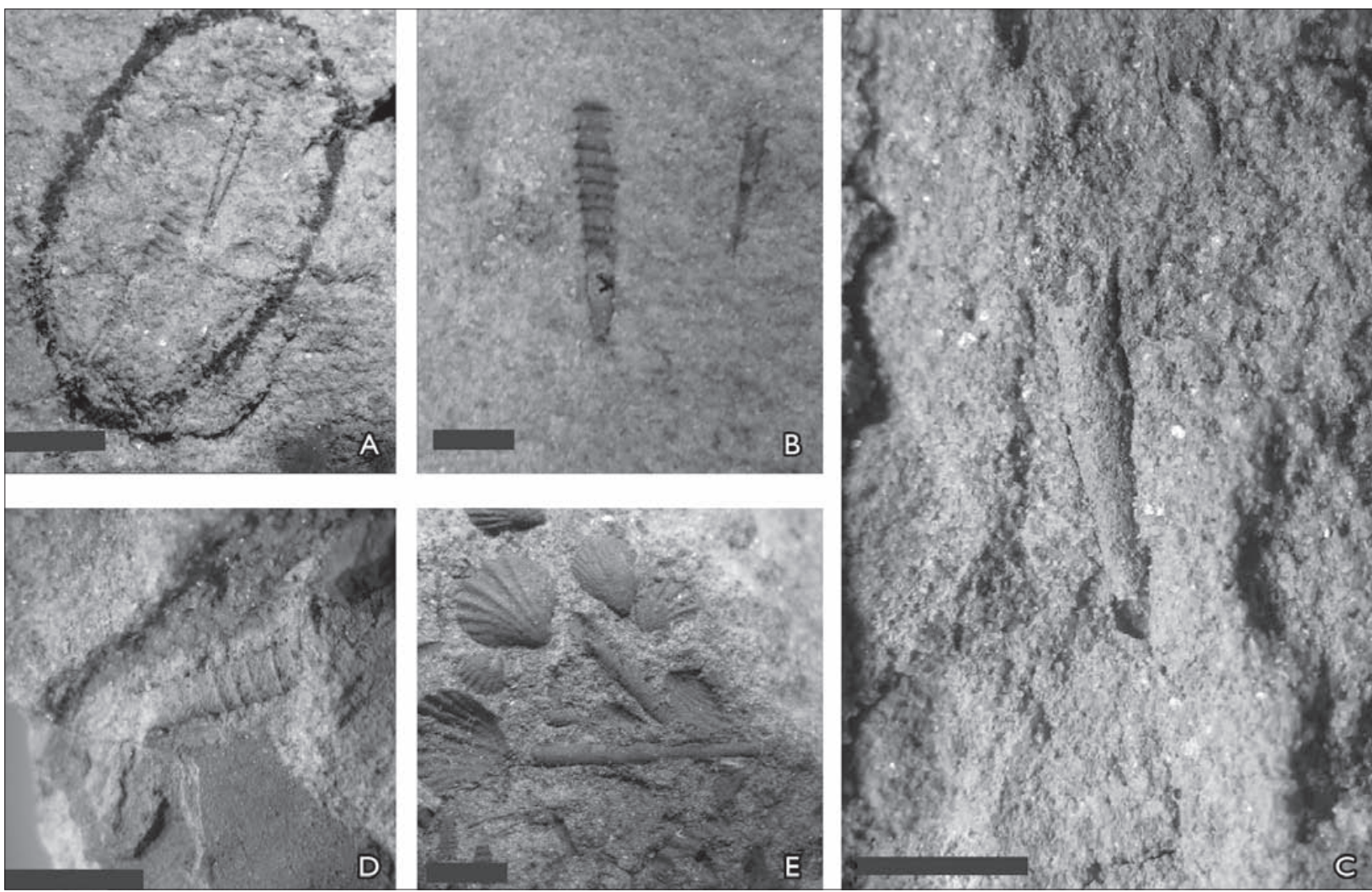

Figura 3. Tentaculitoideos das bacias do Amazonas e do Parnaíba: A) Tentaculites trombetensis (MN 2697), nota-se que os interespaços são mais largos e fundos do que o normal, sendo a característica principal desta espécie; B) Tentaculites stubeli (UNIRIO 5), os anéis oblíquos são características-chave nesta espécie; C) Styliolina clavulus (UNIRIO 42), a falta de ornamentação na concha caracteriza este gênero; D) Tentaculites eldredgianus (UNIRIO 41), os interespaços são maiores na região da abertura, como mostra a figura; E) Tentaculites oseryi (UNIRIO 58), anéis e interespaços com o mesmo tamanho são característicos nesta espécie. Escala $=0,5 \mathrm{~cm}$.

Wittmer \& Miller (2011), no início do Ordoviciano, o registro ocorre na Austrália, Malásia e Tailândia e, curiosamente, após esse período os tentaculitoideos não são documentados até o final do Ordoviciano. Neste período, muitas são as ocorrências da ordem Tentaculitida, existindo, no entanto, apenas um relato da ocorrência de Styliolina, marcando a primeira aparição dos Dacryoconarida.

O início do Siluriano é marcado por um notável aumento na diversidade de tentaculitoideos em todo o mundo (Fisher, 1962; Wittmer \& Miller, 2011; Wei et al., 2012).

Durante o Devoniano, o grupo mostra extensa disseminação global (Fisher, 1962; Alberti, 1993; Wittmer \& Miller, 2011; Wei et al., 2012; Schindler, 2012). Segundo
Wittmer \& Miller (2011), no início do Devoniano as três ordens estavam presentes em proporções praticamente iguais. Os Dacryoconarida atingem o máximo de sua diversidade durante o Devoniano Médio (Schindler, 2012), enquanto os Homoctenida têm seu ápice no Frasniano (Bond, 2006; Schindler, 2012).

Entre os trabalhos que relatam a distribuição geográfica dos tentaculitoideos durante o Ordoviciano, Siluriano e Devoniano, apenas o de Wittmer \& Miller (2011) registra sua presença na América do Sul, com ocorrências somente a partir do Devoniano, porém sem maiores detalhes quanto à localização das ocorrências e andares estratigráficos. No entanto, trabalhos de Clarke (1899b) já citam a ocorrência de tentaculitoideos para o Siluriano da

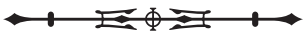


Bacia do Amazonas. Wei et al. (2012) afirmam ainda que não existem evidências convincentes quanto à presença de tentaculitoideos além dos trópicos.

O hábito de vida dos tentaculitoideos é assunto controverso. Fisher (1962) afirma que os tentaculitoideos eram animais tolerantes a diversos tipos de ambientes. Hoje em dia, sabe-se que os tentaculitoideos possuíam sua fase larval planctônica.

Nota-se que, no mesmo período (Devoniano), a diversidade de espécies da América do Sul é inferior a da Europa e da América do Norte. Como citado anteriormente, alguns autores acreditam que o grupo dos tentaculitoideos tivesse preferência por ambientes tropicais. Analisando os mapas de reconstrução paleogeográfica apresentado por Wittmer \& Miller (2011), verifica-se maior concentração dos registros do grupo em regiões mais tropicais, tais como Laurentia, Báltica e Avalonia, desde o Ordoviciano até o Devoniano.

Na América do Sul, os tentaculitoideos mais antigos que se têm registro são do Siluriano, com ocorrências no Brasil, Bolívia, Paraguai e Peru (Clarke, 1899b; Isaacson et al., 1976; Grahn, 1992; Ciguel, 1989; Heredia et al., 2007; Malanca et al., 2010). Até o momento, só existe registro do gênero Tentaculites para as camadas silurianas brasileiras.

Na América do Sul, durante o Devoniano, os tentaculitoideos ocorriam na Argentina, Bolívia, Brasil, Peru e Uruguai (Hartt \& Rathbun, 1875; Ulrich, 1893; Derby, 1890; Von Ammon, 1893; Katzer, 1897; Kayser, 1897, 1900; Siemiradzki, 1898; Clarke, 1899a; Schuchert, 1906;
Knod, 1908; Katzer, 1903, 1933; Clarke, 1913; Boucot et al., 1980). O registro pioneiro quanto ao surgimento dos primeiros dacryoconarida ocorre com o trabalho de Hartt (1897), com o gênero Styliolina. Ciguel \& Rosler (1985) fazem a primeira citação da ocorrência de Homoctenus e Volynites para as camadas do Devoniano da Bacia do Paraná.

Apesar do grande número de registro de tentaculitoideos para o Devoniano da América do Sul, verificou-se a necessidade de um refinamento sistemático, pois a citação da ocorrência, na maioria das vezes, não vem acompanhada por figuras ou fotos dos exemplares citados. Se o material apresenta-se mal preservado e sem classificação mais refinada, torna-se difícil obter estimativas quanto às prováveis rotas migratórias para o grupo.

Após as análises, foi verificada a ocorrência das espécies Tentaculites trombetensis, Tentaculites eldredgianus, Tentaculites stubeli, Tentaculites oseryi e Styliolina clavulus (Tabela 1) nas bacias do Amazonas e do Parnaíba. Na Tabela 1, é mostrada em qual formação cada espécie foi encontrada, assim como a idade atualizada das formações.

As quatro espécies de Tentaculites encontradas nas bacias do Amazonas e do Parnaíba foram citadas para o Devoniano da Bolívia e do Uruguai. Na Argentina, foi verificado o relato da ocorrência apenas da espécie T. crotalinus, e no Peru da espécie Tentaculites jaculus (sendo que esta espécie, no Brasil, só foi encontrada na Bacia do Paraná).

Clarke (1899a) e Katzer (1903) descrevem de forma pioneira a espécie Tentaculites crotalinus para as bacias do Amazonas e Parnaíba. Tal espécie tem seu holótipo descrito

Tabela 1. Distribuição das espécies de tentaculitoideos nas bacias do Amazonas (formações Maecuru e Ererê) e do Parnaíba (Formação Cabeças).

\begin{tabular}{c|c|c|c}
\hline \multirow{2}{*}{} & \multicolumn{2}{|c|}{ Bacia do Amazonas } & Bacia do Parnaíba \\
\cline { 2 - 4 } & $\begin{array}{c}\text { Formação Maecuru } \\
\text { (Eifeliano) }\end{array}$ & $\begin{array}{c}\text { Formação Ererê } \\
\text { (Neoeifeliano - Eogivetiano) }\end{array}$ & Formação Cabeças (Givetiano) \\
\hline Tentaculites eldredgianus & $\times$ & & $\times$ \\
\hline Tentaculites trombetensis & $x$ & $\times$ & $\times$ \\
\hline Tentaculites oseryi & & & $\times$ \\
\hline Tentaculites stubeli & $x$ & & \\
\hline Styliolina clavulus & & & $\times$ \\
\hline
\end{tabular}

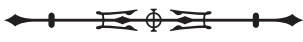


no Grupo Bokkeveld, na África (Salter, 1856). A presença desse táxon em camadas devonianas brasileiras indicaria uma provável comunicação remota entre essas bacias com o Grupo Bokkeveld. Após análises da diagnose original da espécie, observação de espécimes de T. crotalinus encontrados no Devoniano da Bacia do Paraná e examinar as figuras-tipo, constataram-se que os espécimes descritos por Katzer $(1897,1903)$ não se referem a T. crotalinus. As descrições e as figuras apresentadas nos trabalhos de Katzer (1897, 1903) não apresentam as mesmas características morfológicas, do espécime proposto por Salter (1856) como T. crotalinus. O mesmo fato ocorre com a espécie Tentaculites tenellus Katzer (1897), pois o autor apresenta uma diagnose pobre e figuras de baixa qualidade. $\bigcirc$ espécime não possui características morfológicas distintas o suficiente para a criação de uma nova espécie. Com base na descrição da espécie e na figura apresentada em seu trabalho, os presentes autores não reconheceram esta espécie em nenhuma das amostras analisadas. Schuchert (1906) apresenta uma tabela com os espécimes encontrados na Bacia do Amazonas, e nela o autor cita a ocorrência de $T$. tenellus, porém não apresenta uma descrição ou figura da espécie.

Um resultado importante foi que as cinco espécies encontradas nas bacias do Amazonas e do Parnaíba são diferentes daquelas encontradas na Bacia do Paraná. Verificou-se também que as espécies de tentaculitoideos encontrados na Bacia do Paraná ocorrem desde o Neopraguiano até o Neogivetiano, enquanto as espécies das bacias do Amazonas e do Parnaíba ocorrem em afloramentos datados do Eifeliano ao Givetiano. As espécies encontradas na Bacia do Paraná foram também localizadas em camadas do Devoniano da Bolívia. Esses dados nos levam a supor que, com base na ocorrência dessas espécies, não houve conexão e, portanto, migração entre as bacias intracratônicas brasileiras nessa época. Outra consideração importante seria o fato de que provavelmente esta fauna provenha da Bolívia, visto que a ocorrência do gênero Tentaculites tem seus primeiros registros durante o Siluriano da Bolívia, surgindo apenas no Neopraguiano da Bacia do Paraná e durante o Siluriano Inferior da Bacia do Amazonas.

Como citado em alguns trabalhos (Bond, 2006; Wittmer \& Miller, 2011; Schindler, 2012; Wei et al., 2012), a extinção dos tentaculitoideos ainda é motivo de discussões, sabendo-se que a extinção total do grupo ocorre no final do Devoniano. Bond (2006) afirma que os homoctenídeos apresentam seu ápice no Devoniano Médio e durante - limite Frasniano-Fameniano ocorre sua extinção, juntamente com a extinção total do grupo. Segundo Bond (2006), Wittmer \& Miller (2011) e Schindler (2012), a extinção do grupo ocorre concomitantemente a um evento de extinção conhecido como "crise de Kellwaser". Esta crise tem sido constantemente citada como a possível causa do desaparecimento dos tentaculitoideos do Hemisfério Norte, embora eles estivessem em competição com gastrópodes planctônicos, que estavam no auge de seu desenvolvimento. Ela é reconhecida como gradual, afetando primeiramente comunidades bentônicas por meio da anoxia. Eventuais pulsos anóxicos subsequentes reduziriam a extensão das áreas de ocorrência dos organismos pelágicos (Wittmer \& Miller, 2011).

Para Berkyová et al. (2007), o período Devoniano é considerado de grandes mudanças nas biosferas terrestre e marinha, o que resultou em perturbações no reino dos planctônicos (incluindo a extinção dos graptólitos, aparecimento dos dacryoconarídeos, declínio de acritarcas e extinção do tentaculitoideos no final do Devoniano).

Niko (2000) cita a ocorrência de homoctenídeos no limite Carbonífero/Permiano, porém a falta de dados sedimentológicos consistentes tornou esta ocorrência questionável (Schindler, 2012).

\section{CONCLUSÃO}

Das 39 amostras analisadas nas quatro instituições de ensino e pesquisa visitadas, foram reconhecidas as seguintes espécies de tentaculitoideos no Devoniano Médio da Bacia do Amazonas: Tentaculites trombetensis, T. stubeli, 
T. eldredgianus e S. clavulus. Na Bacia do Parnaíba, foram reconhecidas: T. trombetensis, T. oseryi, T. eldredgianus e $S$. clavulus. Diferentemente do que alguns autores haviam citado anteriormente, não foi reconhecida a espécie Tentaculites crotalinus nas bacias do Amazonas e do Parnaíba. Na América do Sul, o registro dos primeiros tentaculitoideos ocorreu durante o início do Siluriano, com o gênero Tentaculites. Representantes das ordens Dacryoconarida e Homoctenida foram encontrados a partir do Devoniano Inferior. Nas bacias do Amazonas e do Parnaíba só existe registro das ordens Tentaculitida e Dacryoconarida.

\section{AGRADECIMENTOS}

Comniskey agradece à Fundação de Amparo à Pesquisa do Estado de São Paulo (FAPESP) pela bolsa de doutorado concedida (2013/04884-0). Bosetti agradece ao Conselho Nacional Desenvolvimento Científico e Tecnológico (CNPq PQ 311483/2014-3). Os autores agradecem às instituições de ensino e pesquisa brasileiras que permitiram a análise do material estudado. Ao Prof. Dr. Antonio Carlos Sequeira Fernandes, pelas informações sobre o material de Clarke.

\section{REFERÊNCIAS}

ALBERTI, G. K. B., 1993. Dacryoconariden und homocteniden Tentaculiten des Unter-und Mittel-Devons I. Courier Forschungsinstitut Senckenberg 158: 1-230.

AZEVEDO-SOARES, H. L. C., 1999. Classe Tentaculita na Formação Ponta Grossa: uma proposta de sistematização: 1-117. Dissertação (Mestrado em Análise de Bacias e Faixas Móveis) Universidade do Estado do Rio de Janeiro, Rio de Janeiro.

BARRANDE, J., F. POČTA, J. PERNER, W. H. WAAGEN \& J. JAHN, 1852. Systéme Silurien du centre de la Bohéme. Chez l'Auteur, Prague.

BERKYOVÁ, S., J. FRYDA \& P. LUKES, 2007. Unsuccessful predation on Middle Paleozoic plankton: shell injury and anomalies in Devonian dacryoconarid tentaculites. Acta Palaeontologica Polonica 52(2): 407.

BLIND, W., 1969. Die systematische Stellung der Tentakuliten. Palaeontographica Abteilung A 133: 101-145.

BOND, D., 2006. The fate of the homoctenids (Tentaculitoidea) during the Frasnian-Famennian mass extinction (Late Devonian). Geobiology 4(3): 167-177.
BOUČEK, B., 1964. The Tentaculites of Bohemia: their morphology, taxonomy, ecology, phylogeny and biostratigraphy: 1-215. Publishing House of the Czechoslovak Academy of Sciences, Prague.

BOUCOT, A. J., P. E. ISAACSON \& G. LAUBACHER, 1980. An early Devonian, eastern Americas realm faunule from the coast of southern Peru. Journal of Paleontology 54(2): 359-365.

CIGUEL, J. H. G, 1989. Bioestratigrafia dos Tentaculitoidea no flanco oriental da Bacia do Paraná e sua ocorrência na América do Sul: 2 v. Dissertação (Mestrado em Geociências) - Universidade de São Paulo, São Paulo.

CIGUEL, J. H. G., O. ROSLER \& D. CAMINEIRO, 1984. Tentaculitoidea da formação Ponta Grossa no estado do Paraná. Anais do Congresso Brasileiro de Geologia 33: 655-669.

CIGUEL, J. H. G. \& O. ROSLER, 1985. Caracterização das formas brasileiras de Tentaculites crotalinus Salter, 1856. Anais da Academia Brasileira de Ciências 57(1): 116.

CIGUEL, J. H. G., O. ROSLER \& R. M. HOFMEISTER, 1987. Preservação parcial da concha de Tentaculites crotalinus, da Formação Ponta Grossa (Devoniano). Boletim IG-USP. Série Científica 18: 17-26.

CLARKE, J. M., 1899a. Moluscos devonianos do Estado do Pará, Brasil. Archivos do Museu Nacional 10(3-8): 49-174.

CLARKE, J. M., 1899b. A fauna siluriana superior do Rio Trombetas. Archivos do Museu Nacional 10: 1-48

CLARKE, J. M., 1913. Fósseis Devonianos do Paraná: 1-353. Monographias do Serviço Geológico e Mineralógico do Brasil, Rio de Janeiro.

COMNISKEY, J. C. \& R. P. GHILARDI, 2013. Levantamento histórico da Classe Tentaculitoidea no Devoniano brasileiro: principais características e padrões de preservação. Terr@ Plural 7(2): 115-126.

DERBY, O. A., 1890. Nota sobre a geologia e paleontologia de Matto Grosso. Imprensa Nacional, Rio de Janeiro.

FARSAN, N. M., 1994. Tentaculiten: Ontogenese, Systematik, Phylogenese, Bioestratonomie und Morphologie. Abhandlungen Der Senckenbergischen Naturforschenden Gesellschaft 547(1): 128.

FISHER, D. W., 1962. Small conoidal shells of uncertain affinities. In: R. C. MOORE (Ed.): Treatise on invertebrate paleontology: 98-143. Geological Society of America/University of Kansas Press, Boulder/Lawrence.

FISHER, D. W. \& R. S. YOUNG, 1955. The oldest known tentaculitid: from the Chepultepec Limestone (Canadian) of Virginia. Journal of Paleontology 29(5): 871-875.

FONSECA, V. M. M., 2004. Chonetoidea (Brachiopoda) do Devoniano Médio das Bacias do Amazonas e Parnaíba, Brasil. Arquivos do Museu Nacional 62(2): 193-215. 
GRAHN, Y., 1992. Revision of Silurian and Devonian strata of Brazil. Palynology 16(1): 35-61.

HARTT, C. F., 1897. A fauna devonica do rio Maecuru. Boletim do Museu Paraense de História Natural e Ethnographia 204-246.

HARTT, C. F. \& R. RATHBUN, 1875. Morgan expedition, 18701871: on the Devonian trilobites and mollusks of Ererê, Province of Para, Brazil. Annals of the Lyceum of Natural History of New York 11(13): 110-127.

HEREDIA, S., A. MESTRE \& J. P. MILANA, 2007. Reappraisal of the Silurian stratigraphy at Cerro del Fuerte section (San Juan, Argentina). Anais do Congresso de Paleontología y Bioestratigrafía de Latinoamérica 4: 195-200.

ISAACSON, P. E., B. ANTELO \& A. J. BOUCOT, 1976. Implications of a Llandovery (early Silurian) brachiopod fauna from Salta Province, Argentina. Journal of Paleontology 50(6): 1103-1112.

KATZER, F., 1897. Das Amazonas-Devon und seine Beziehungen zu den anderen Devongebieten der Erde. Sitzungsberichte der Königlichen B'hmischen Gesellschaft der Wissenschaften, Mathematisch-Naturwissenschaftliche Classe 46: 1-50.

KATZER, F., 1903. Grundzuge der Geologie des unteren Amazonasgebietes (dês Staates Pará in Brasilien): 1-298. Max Weg, Leipzig.

KATZER, F., 1933. Geologia do Pará (Brasil). Boletim do Museu Paraense Emílio Goeldi 9: 270.

KAYSER, E., 1897. Beiträge zur Kenntniss einiger paläozoischer Faunen Sud-Amerikas. Zeitschrift der Deutschen Geologischen Gesellschaft 49: 274-311.

KAYSER, E., 1900. Alguns fósseis paleozóicos do Estado do Paraná. Revista do Museo Paulista 4: 301-311.

KNOD, R., 1908. Devonische faunen boliviens. Neues Jahrbuch für Geologie und Paläontologie Beilage 25: 493-601.

LARDEUX, H., 1969. Nouvelles données sur la morphologie des Tentaculitoidea. Éditions du Centre National de la Recherche Scientifique 258(24): 5939-5942.

LARSSON, K., 1979. Silurian tentaculitids from Gotland and Scania. Fossil and Strata 11: 1-180.

LINDEMANN, R. H. \& E. L. YOCHELSON, 1992. Viriatellina (Dacryoconarida) from the Middle Devonian Ludlowville Formation at Alden, New York. Journal of Paleontology 66(2): 193-199.

LINDEMANN, R. H. \& D. A. MELYCHER, 1997. Tentaculites (Tentaculitoidea) from the Manlius Limestone (Lower Devonian) at Schoharie, New York. Journal of Paleontology 71(3): 360-368.
LJASHENKO, G. P., 1955. Novye dannye o sistimatike tentakulitov, novakiyi I stiliolii. Biulleten Moskovskogo Obschestva Ispytatelei Prirody, Otdel Geologichskii, Novaia Seriia 30: 94-95.

LJASHENKO, G. P., 1957. Systematics of the tentaculitoids, nowakiids, and styliolinids. Ezhegodnik Vsesoyuznogo Paleontologicheskogo Obshchestva 16: 82-99.

LJASHENKO, G. P., 1959. Devonian Conoconchia of the central and eastern parts of the Russian Platform:1-220. The All-Russian Research Institute of Oil, Moscow.

MALANCA, S., M. J. ARIS, M. A. BOSO, E. GALLARDO, E. M. BRANDÁN \& J. C. FERNÁNDEZ, 2010. Invertebrados fósiles de la formación Lipeón (Silúrico superior) del área Bermejo-los Toldos, noroeste argentino. Revista de La Asociacíon Geológica Argentina 66(1): 171-177.

MELO, J. H. G., 1985. A Província Malvinocáfrica no Devoniano do Brasil. Dissertação (Mestrado em Geociências) - Universidade Federal do Rio de Janeiro, Rio de Janeiro.

NIKO, S., 2000. Youngest record of tentaculitoids: Hidagaienites new genus from near the Carboniferous-Permian boundary in central Japan. Journal of Paleontology 74(3): 381-385.

PONCIANO, L. C. M. O., 2011. Fósseis devonianos da Bacia do Amazonas: Bookess, Florianópolis 1-143.

PONCIANO, L. C. M. D. O. \& D. M. D. C. MACHADO, 2007. Hábitos de vida da associação "Schuchertella" agassizi - Pthychopteria eschwegei, formação Maecuru, Devoniano, Bacia do Amazonas, Brasil. Anuário do Instituto de Geociências 30(1): 135-144.

PONCIANO, L. C. M. D. O., A. R. D. S. F. D. CASTRO, V. M. M. D. FONSECA \& D. M. D. C. MACHADO, 2012. Tafocenoses da Formação Pimenteira, devoniano da Bacia do Parnaíba, Piauí: mapeamento, inventário e relevância patrimonial. Anuário do Instituto de Geociências 35(1): 5-27.

SALTER, J. W., 1856. Description of Palaeozoic Crustacea and Radiata from South Africa. Geological Society of London Transactions 7(2): 215-224.

SCHEFFLER, S. M., 2010. Crinoides e Blastoides do Devoniano brasileiro. Tese (Doutorado em Geologia, - Universidade Federal do Rio de Janeiro, Rio de Janeiro.

SCHINDLER, E., 1990. The late Frasnian (Upper Devonian) Kellwasser Crisis. Lecture Notes in Earth Sciences 30: 151-159.

SCHINDLER, E., 2012. Tentaculitoids - an enigmatic group of palaeozoic fossils. In: J. A. TALENT (Ed.): Earth and life: global biodiversity, extinction intervals and biogeographic perturbations through time: 479-490. Springer, Netherlands.

SCHUCHERT, C., 1906. Geology of the Lower Amazon region. The Journal of Geology 14(8): 722-746. 
SIEMIRADZKI, J., 1898. Geologische reisebeobachtungen in Südbrasilien. Aus Der Kaiserlich-Königlichen Hof-Und Staatsdruckerei 107(1): 23-40.

ULRICH, A., 1893. Palaeozoische Versteinerungen aus Bolivien. Neues Jahrbuch, Beil. Band 8: 60-64.

VINN, O., 2010. Adaptive strategies in the evolution of encrusting tentaculitoid tubeworms. Palaeogeography, Palaeoclimatology, Palaeoecology 292(1-2): 211-221.

VINN, O., 2013. Cornulitid tubeworms from the Ordovician of eastern Baltic. Carnets de Geologie [Notebooks on Geology] 2013(3): 131-138.

VINN, O. \& P. D. TAYLOR, 2007. Microconchid tubeworms from the Jurassic of England and France. Acta Palaeontologica Polonica 52(2): 391-399.

VINN, O. \& M. ZATON', 2012. Phenetic phylogenetics of tentaculitoids - extinct, problematic calcareous tube-forming organisms. Geologiska Föreningen i Stockholm Förhandlingar (GFF) 134(2): 145-156.
VON AMMON, L., 1893. Devonische Versteinerungen von Lagoinha in Matto Grosso (Brasilien). Zeitschrift der Gesellschaft für Erdkunde zu Berlin 28: 352-366.

WEEDON, M. J., 1991. Microstructure and affinity of the enigmatic Devonian tubular fossil Trypanopora. Lethaia 24(2): 227-234.

WEI, F., Y. GONG \& H. YANG, 2012. Biogeography, ecology and extinction of Silurian and Devonian tentaculitoids. Palaeogeography, Palaeoclimatology, Palaeoecology 358-360: 40-50.

WITTMER, J. M. \& A. MILER, 2011. Dissecting the global diversity trajectory of an enigmatic group: the paleogeographic history of tentaculitoids. Paleogeography, Paleoeclimatology, Paleoecology 312(1-2): 54-65.

ZATON', M. \& P. D. TAYLOR, 2009. Microconchids (Tentaculita) from the Middle Jurassic of Poland. Bulletin of Geosciences 84(4): 653-660.

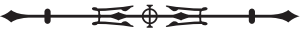


